\title{
Fire Resilience of a Steel-Concrete Composite Floor System: Full-Scale Experimental Evaluation for U.S. Prescriptive Approach with a 2-Hour Fire-Resistance Rating (Test \#1)
}

Lisa Choe Selvarajah Ramesh Xu Dai

Matthew Hoehler Matthew Bundy Rodney Bryant Brian Story Anthony Chakalis Artur Chernovsky 
NIST Technical Note 2165

\section{Fire Resilience of a Steel-Concrete Composite Floor System: Full-Scale Experimental Evaluation for U.S. Prescriptive Approach with a 2-Hour Fire-Resistance Rating (Test \#1)}

Lisa Choe, Selvarajah Ramesh, Xu Dai, Matthew Hoehler, Matthew Bundy, Rodney Bryant, Brian Story, Anthony Chakalis, Artur Chernovsky Fire Research Division Engineering Laboratory

This publication is available free of charge from: https://doi.org/10.6028/NIST.TN.2165

October 2021

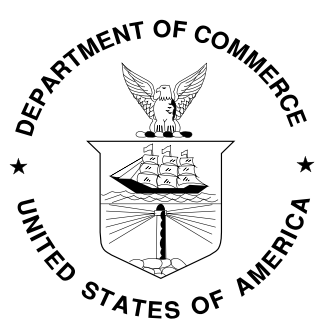

U.S. Department of Commerce Gina M. Raimondo, Secretary

National Institute of Standards and Technology James K. Olthoff, Performing the Non-Exclusive Functions and Duties of the Under Secretary of Commerce for Standards and Technology \& Director, National Institute of Standards and Technology 
The policy of the National Institute of Standards and Technology is to use metric units in all its published materials. Because this report is intended for the U.S. building construction industry, in some cases U.S.

customary units are used.

Certain commercial entities, equipment, or materials may be identified in this document in order to describe an experimental procedure or concept adequately. Such identification is not intended to imply recommendation or endorsement by the National Institute of Standards and Technology, nor is it intended to imply that the entities, materials, or equipment are necessarily the best available for the purpose.

The policy of the National Institute of Standards and Technology is to include statements of uncertainty with all NIST measurements. In this document, some measurements made by authors outside of NIST are presented, for which uncertainties are not reported and are unknown.

National Institute of Standards and Technology Technical Note 2165 Natl. Inst. Stand. Technol. Tech. Note 2165, 176 pages (October 2021) CODEN: NTNOEF

This publication is available free of charge from: https://doi.org/10.6028/NIST.TN.2165 


\begin{abstract}
The National Institute of Standards and Technology is currently conducting a series of large compartment fire tests to investigate the behavior and fire-induced failure mechanisms of the full-scale composite floor assemblies with the two-story steel gravity frame, two bays by three bays in plan. This report presents the research goal, background, details of experimental design, and the results from the first fire experiment (Test \#1) conducted at the National Fire Research Laboratory.

The Test \#1 was aimed to quantify the fire resistance and behavior of the $9.1 \mathrm{~m} \times 6.1 \mathrm{~m}$ steelconcrete composite floor assembly constructed in accordance with the 2-hour fire-resistance rating requirements for steel buildings in the United States. The fire test compartment, measuring $10 \mathrm{~m} \times 6.9 \mathrm{~m}$ in plan, was situated on the ground floor of the two-story test building to heat the composite floor above. The fire condition was created using natural gas burners to mimic a standard fire environment in a large compartment. During fire exposure, the test floor assembly was subjected to a mechanical load of $2.7 \mathrm{kPa}$, determined from the gravity load combination for extraordinary events as permitted by the applicable building code. This experimental study showed that the protected steel beams and girders within the fire test bay achieved matching or superior fire resistance based on the acceptance criteria of standard furnace testing. However, the heated floor slab developed large concrete cracks (integrity failure) prior to reaching the specified fire rating period, posing a potential fire hazard above the test floor. Large concrete cracks occurred around the hogging moment region (next to the test-bay column gridline) less than $30 \mathrm{~min}$ into heating, and the hot glowing steel deck was exposed through mid-panel concrete cracks along the longitudinal centerline of the fire test bay at $70 \mathrm{~min}$. The steel wire reinforcement $\left(60 \mathrm{~mm}^{2} / \mathrm{m}\right)$ within enlarged concrete cracks completely ruptured in tension. This first experiment suggests that the minimum steel reinforcement $\left(60 \mathrm{~mm}^{2} / \mathrm{m}\right)$ used for crack control of the composite slab, which is permitted by the applicable building code, may not be sufficient to maintain the integrity of a full-scale composite floor under the 2-hour standard fire exposure.
\end{abstract}

\title{
Key words
}

Composite floors; steel buildings; fire resistance; compartment fire experiments. 


\section{Preface}

This work was conducted as part of the project "Measurement of Structural Performance in Fire" under the National Institute of Standards and Technology (NIST) Engineering Laboratory's Fire Risk Reduction in Buildings Program. We thank William Baker (Skidmore, Owings \& Merrill), Craig Beyler (Jensen Hughes), Luke Bisby (University of Edinburgh), Ian Burgess (University of Sheffield), Charles Carter (AISC), Charles Clifton (University of Auckland), Michael Engelhardt (University of Texas), Graeme Flint (Arup), Nestor Iwankiw (Jensen Hughes), Kevin LaMalva (Warrington Fire), Roberto Leon (Virginia Tech.), and Amit Varma (Purdue University) for their expert consultation. We also thank the NIST colleagues including William Grosshandler, Laurean DeLauter, Philip Deardorff, Marco Fernandez, Michael Selepak, Fahim Sadek, Joseph Main, Jonathan Weigand, Chao Zhang, and Mina Seif for their significant contributions to design, construction, and execution of this test series. 


\section{Table of Contents}

1. Introduction ............................................................................................................................... 1

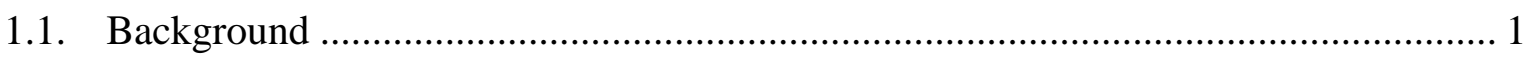

1.2. Previous Fire Experiments ........................................................................ 3

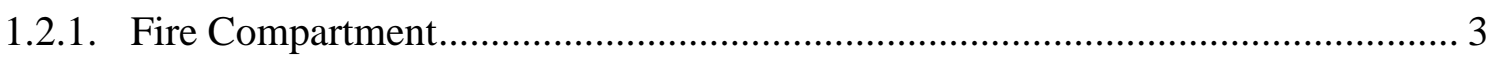

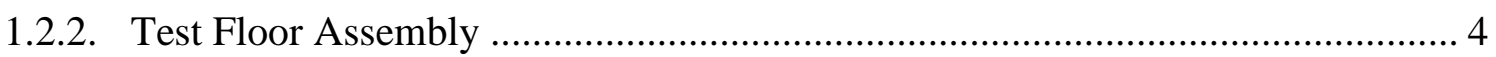

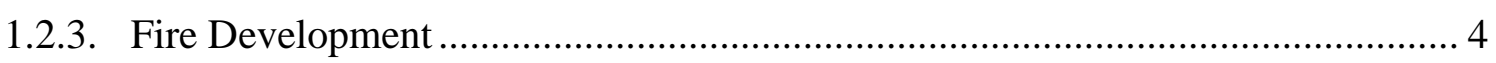

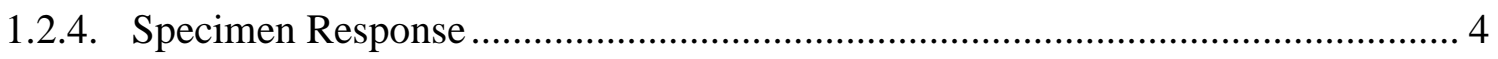

1.2.5. Conclusions from Previous Studies.................................................................... 5

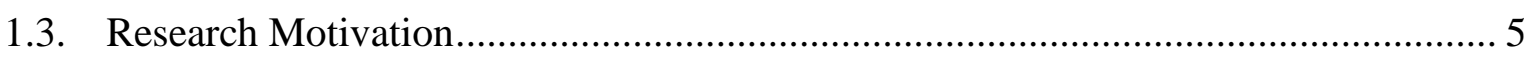

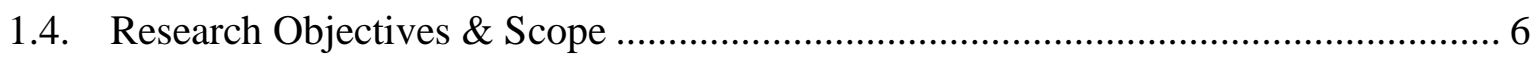

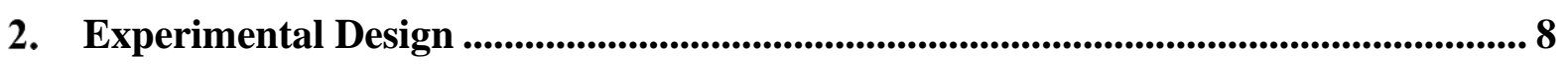

2.1. NFRL Two-Story Test Frame …………………..................................... 8

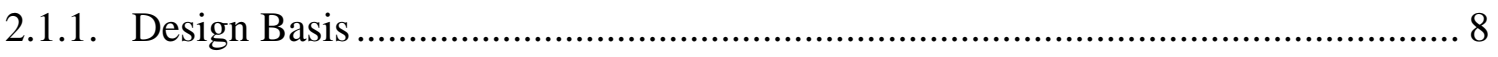

2.1.2. Structural Steel Frame …….............................................................................. 10

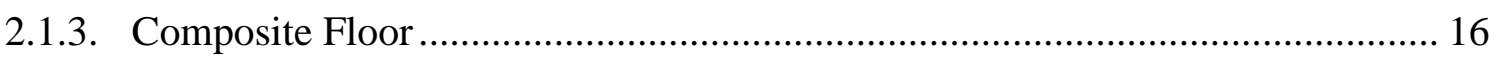

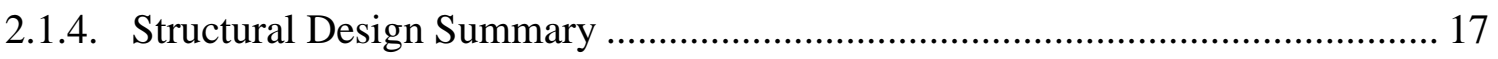

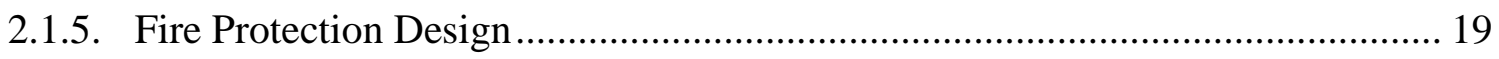

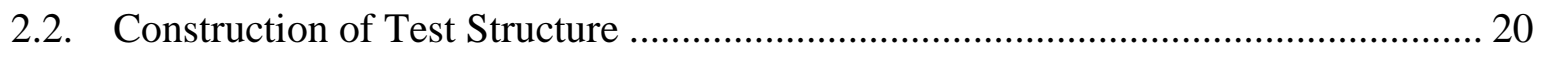

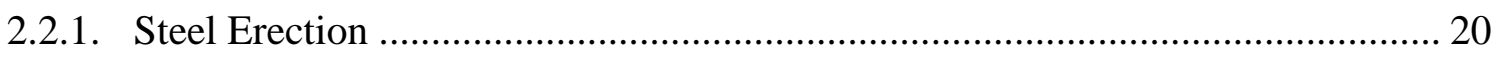

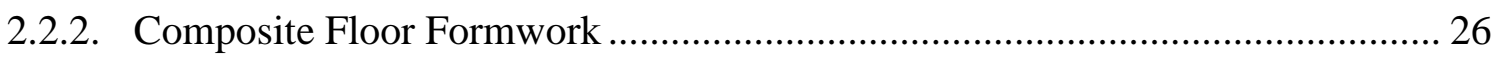

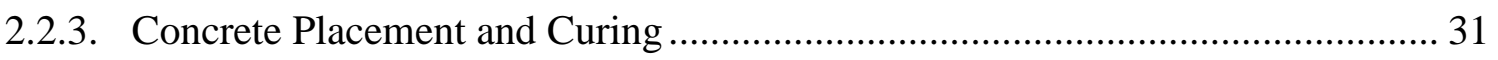

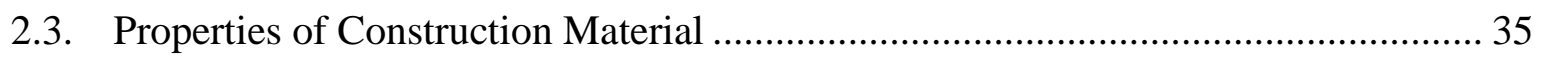

2.3.1. Mechanical Properties of Steel..................................................................... 35

2.3.2. Hardened Concrete Properties .......................................................................... 38

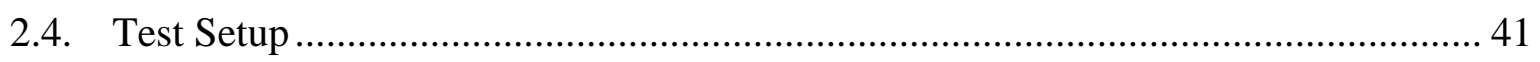

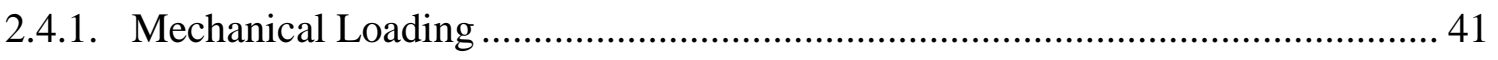

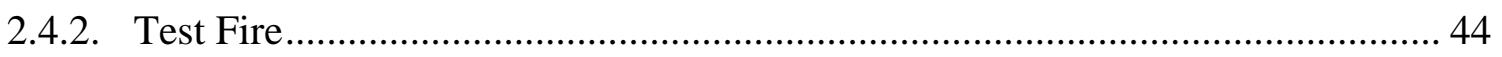

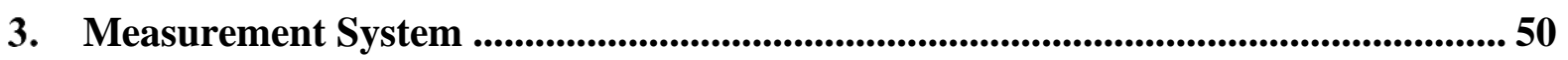

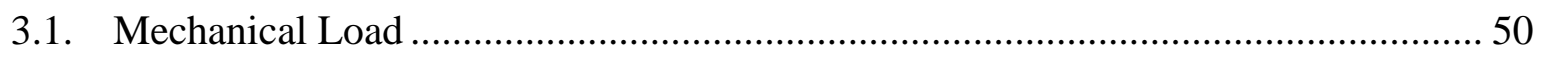

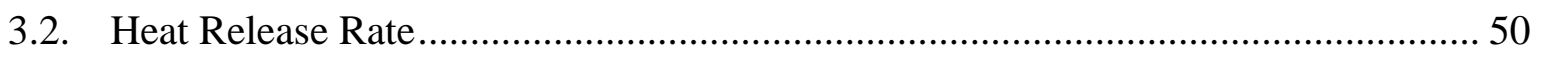

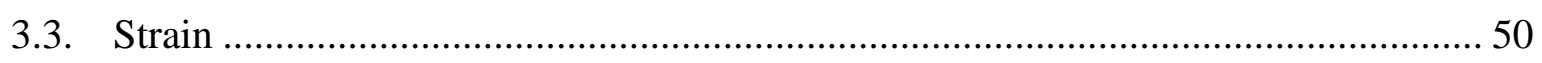

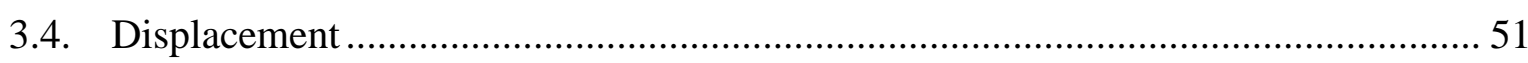

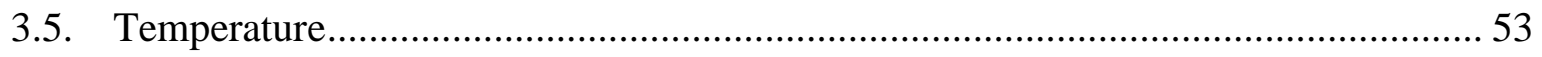




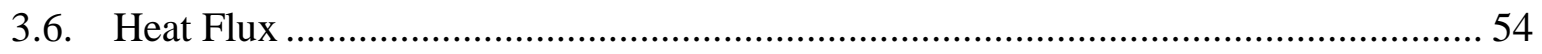

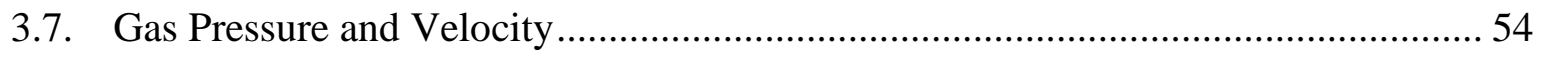

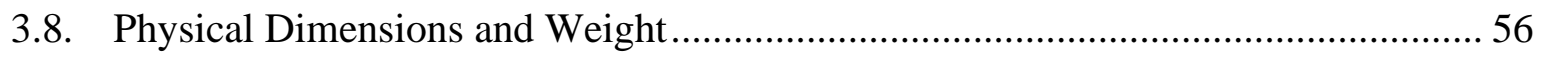

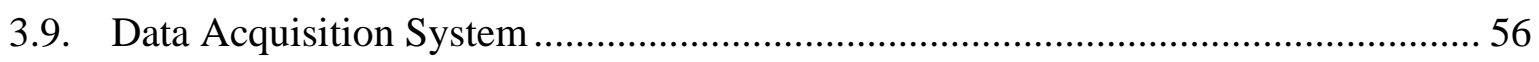

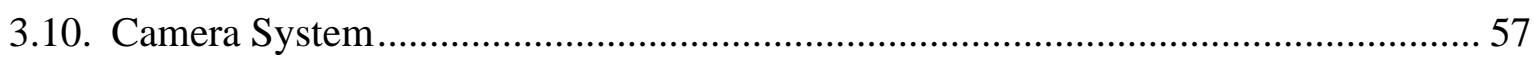

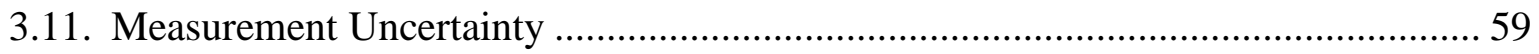

4. Test Results ................................................................................................................................ 61

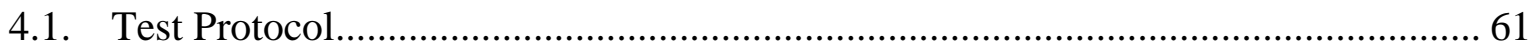

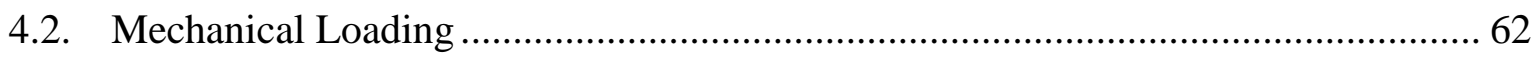

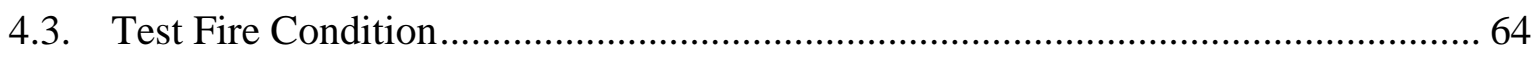

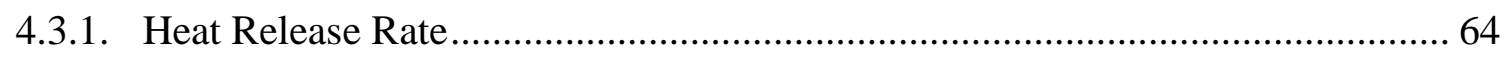

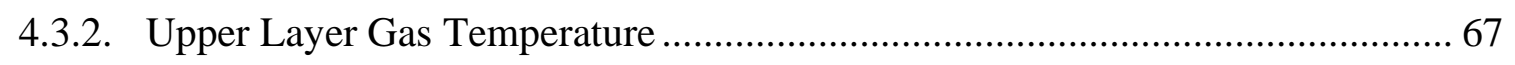

4.3.3. Compartment Opening Velocities and Temperatures ........................................ 69

4.3.4. Convective Heat Loss through Compartment Vent Opening.............................. 72

4.4. Thermal Response ........................................................................................... 74

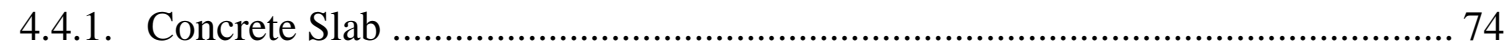

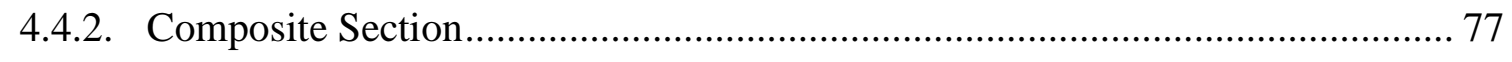

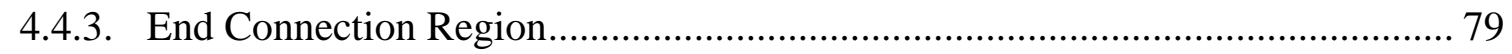

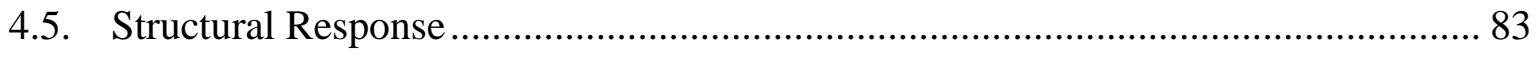

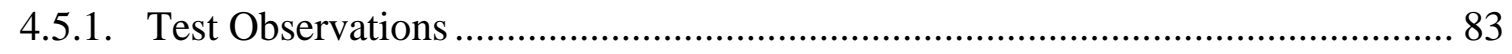

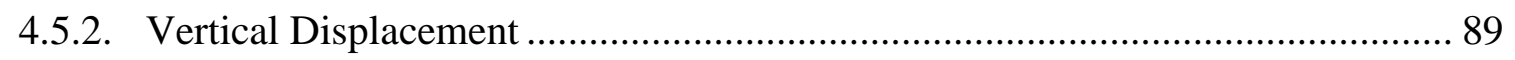

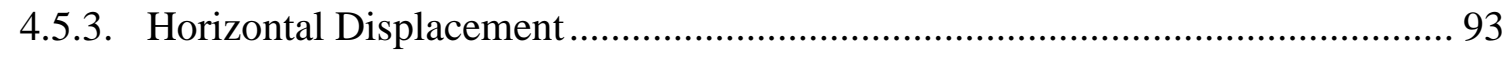

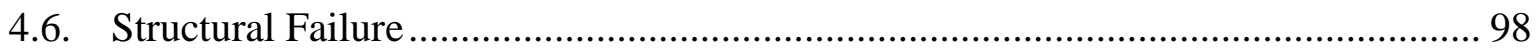

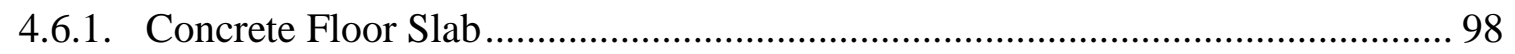

4.6.2. Headed Stud Anchor .................................................................................... 102

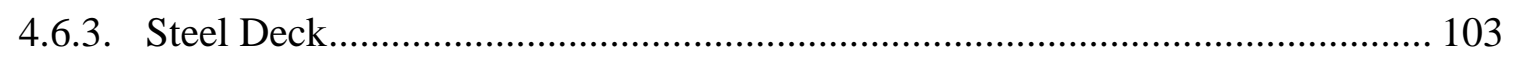

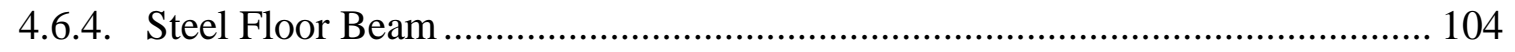

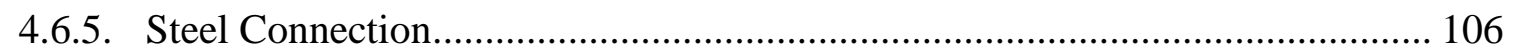

4.7. Comparison with ASTM E119 Criteria............................................................. 108

5. Summary and Conclusions ..................................................................................................... 110

References.......................................................................................................................................... 113

Appendix A Experimental Design - Supplemental Materials.......................................... 118

A.1. Structural Steel Frame …………………………….................................... 118

A.2. Slab Reinforcement ....................................................................................... 124 
A.3. Gravity Loading System................................................................................ 126

A.4. Fire Test Compartment.................................................................................. 127

Appendix B Instrumentation and Raw Data .................................................................... 129

B.1. Mechanical Loading ...................................................................................... 129

B.2. Test-Bay Beam Strains Prior to Fire Exposure ……………………………….... 130

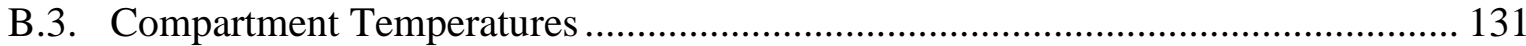

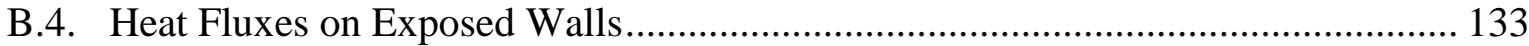

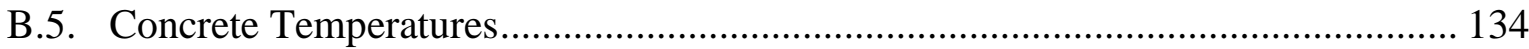

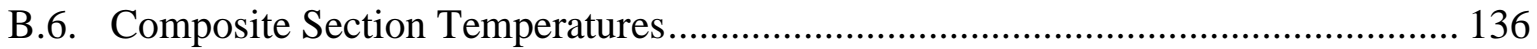

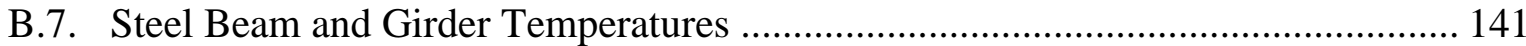

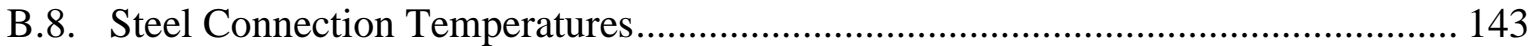

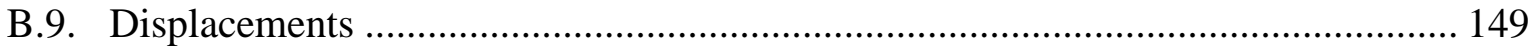

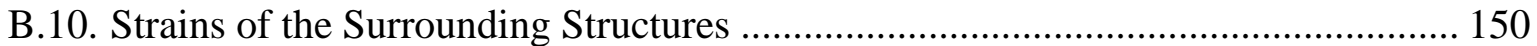

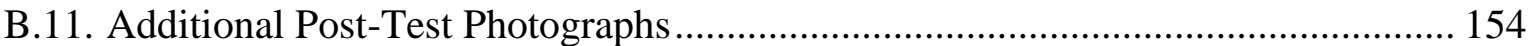

Appendix C Post-Processed Data ..................................................................159

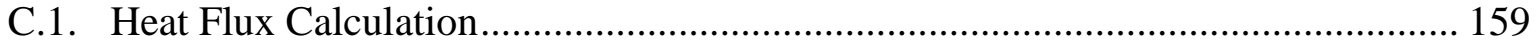

\section{List of Tables}

Table 1-1. Summary of experimental features used in previous fire experiments on composite floor systems 3 Table 2-1. Survey results of common U.S. design values for a $6.1 \mathrm{~m}$ (20 ft.) by $9.1 \mathrm{~m}$ (30 ft.) composite floor and the values considered in present study............................................... 10 Table 2-2. Structural design summary with composite beams or girders in Fig. 2-3............. 18

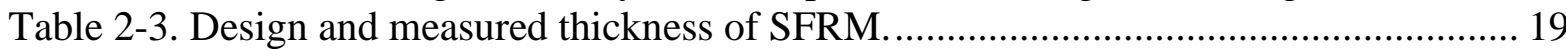
Table 2-4. Concrete design mixture proportions. .................................................................... 31 Table 2-5. Mechanical properties of steel components. All values are rounded to the nearest

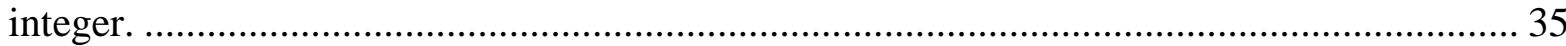

Table 2-6. Matrix of measured concrete properties............................................................. 38

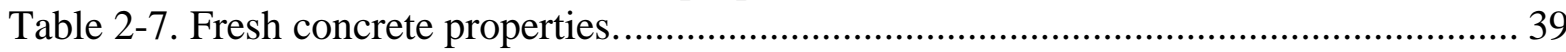

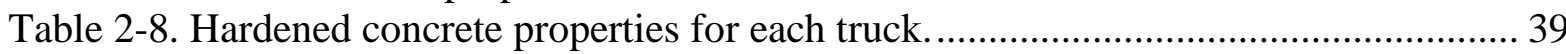

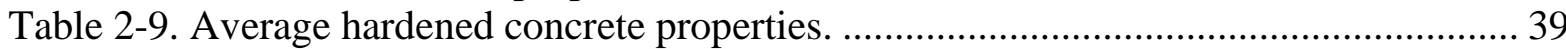

Table 3-1. Thermal imaging camera preset parameters....................................................... 58

Table 3-2. Estimated measurement uncertainty. $\mathrm{FSO}_{\mathrm{E}}=$ maximum measured values; $\mathrm{N}=$

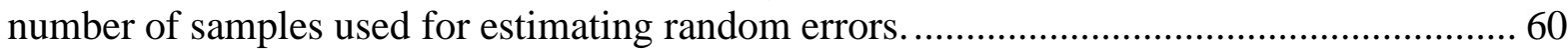

Table 4-1 Measured total heat release and fuel load density. The values after \pm symbols

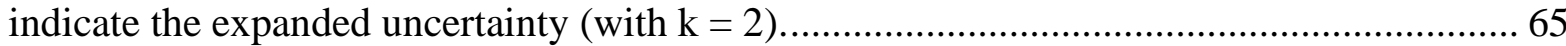

Table 4-2. Test observations following the burner ignition.................................................... 83 
Table 4-3 Maximum and final values of the vertical displacements of the fire exposed steel members at midspan, where the final values were recorded at 17 hours after the fire was extinguished at $107 \mathrm{~min}$. 91

Table A-1. Floor framing connections. 118

Table B-1 The coordinates of thermocouple locations where the $\mathrm{Z}$ datum is at the top flange surface of steel members.

Table B-2. Coordinates of thermocouples mounted in member connection regions, where the origin of the $\mathrm{x}$ and $\mathrm{y}$ coordinates is shown in Fig. B-17 and the $\mathrm{z}$ datum is located at the top flange of steel members. 146

Table B-3. List of thermocouples used in steel connection regions and peak values of average temperatures during fire loading. The value after \pm symbol is the standard deviation of temperatures from grouped thermocouples. 148

\section{List of Figures}

Fig. 2-1. Plan view of NFRL structural fire test bay including the test frame with fire compartment and footprint of exhaust hood; dimensions in $\mathrm{cm}$............................................ 9

Fig. 2-2. NFRL two-story test frame prior to fire experiment. ............................................ 9

Fig. 2-3. Plan view of the test frame on the first floor.......................................................... 11

Fig. 2-4. Connection detail of column B2. Units are in inches.............................................. 13

Fig. 2-5. Details of beam-to-girder connection in the test bay. Units are in inches. .............. 13

Fig. 2-6. Connection detail of column C2. Units are in inches.......................................... 14

Fig. 2-7. Connection detail of column C1. Units are in inches............................................. 15

Fig. 2-8. Beam-to-girder connection in the surrounding bay. Units are in inches.................. 15

Fig. 2-9. Composite girder and beam sections. Units are in inches....................................... 17

Fig. 2-10. Steel framing (a) test bay (b) north surrounding bay (c) west surrounding bay. Note that red post shoring was removed prior to fire test. Top of the specimen catch system was 10

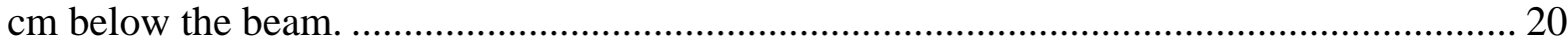

Fig. 2-11. Steel frame connections in the fire test bay: (a) beam-to-girder connection (b)

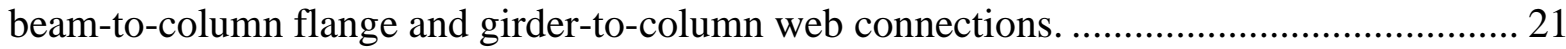

Fig. 2-12. Column splice (a) front view (b) side view (unit $=$ inch)................................... 23

Fig. 2-13. Column splice - Northeast column of test bay (unit $=$ inch). .............................. 23

Fig. 2-14. Column support conditions: (a) typical; (b) modified at the southeast column of

test bay. $($ unit = inch). ................................................................................................. 24

Fig. 2-15. Beam splice in the surrounding bay - side view $($ unit $=$ inch)............................ 25

Fig. 2-16. Beam splice in the surrounding bay $($ unit $=$ inch) . .............................................. 25

Fig. 2-17. Concrete slab formwork above the fire test compartment. ................................... 26

Fig. 2-18. Concrete slab formwork in the surrounding bays ................................................ 27

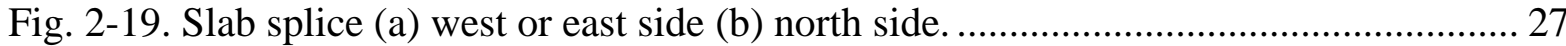

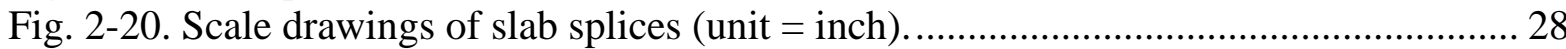

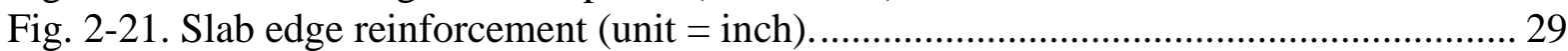

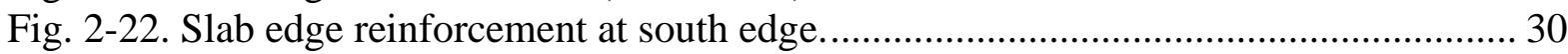

Fig. 2-23. Reinforcement details around slab penetration holes............................................. 30

Fig. 2-24. Casting of the concrete: (a) Pump truck in National Fire Research Laboratory test hall; (b) concrete placement in test specimen; (c) concrete placement in surrounding bays; (d)

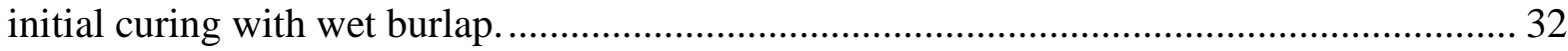


Fig. 2-25. Air temperature and relative humidity in test hall......................................... 33

Fig. 2-26. Temperature in the test specimen and surrounding bays. ................................... 34

Fig. 2-27. Relative humidity in the test specimen and surrounding bays........................... 34

Fig. 2-28. Engineering stress-strain relationship for (a) W16×31 beam (b) W18×35 girder. 36

Fig. 2-29. Engineering stress-strain relationship for (a) shear tab connection plate (b) steel

deck and welded wire reinforcement.

Fig. 2-30. Mechanical loading arrangement on the first floor of the test building; Dimensions in $\mathrm{cm}$.

Fig. 2-31. Photographs of (a) the gravity loading system on the test floor slab and (b) the actuator mounted in the NFRL basement.

Fig. 2-32. Floor plan with the fire test compartment and distribution of burners. (Unit in $\mathrm{cm}$ ).

Fig. 2-33. Photographs of the outside of the fire test compartment: (a) the south wall with a main vent opening and (b) the north wall with a slit.

Fig. 2-34. Photographs of (a) inside of the test compartment and (b) south edge of the test

floor assembly. 46

Fig. 2-35. Photographs of (a) enclosure around the beam-to-girder connection region; (b) enclosure around column (outside of the compartment).

Fig. 2-36. Photographs of (a) burners placed inside of the fire test compartment, (b) NFRL's natural gas fuel delivery system; (c) balancing values at upstream of the burners.... 48 Fig. 2-37. Proposed heat release rate versus time relationship and predicted gas temperatures compared with ASTM E119 temperature-time curve.

Fig. 3-1. Photographs of strain gauges attached to (a) secondary steel beam $(\mathrm{W} 16 \times 31)$ prior to installation of SFRM and (b) No.4 reinforcing bar inside the concrete formwork. ........... 51 Fig. 3-2. String potentiometers used for the vertical displacement measurements. Measuring strings were directly attached to the eye bars partially embedded in the concrete slab......... 52 Fig. 3-3 String potentiometers installed at (a) the interior (B3) column and (b) the exterior (C4) column.

Fig. 3-4. Photographs of temperature sensors installed at (a) $305 \mathrm{~mm}$ below exposed steel deck; (b) ends of the west girder and the north beam prior to fireproofing; (c) top of the steel deck prior to concrete casting; (d) midspan of secondary beam....................................... 54 Fig. 3-5. Schematic of a bi-directional probe used for gas velocity measurements. ............. 55 Fig. 3-6. Photographs of bi-directional probes at (a) southeast vent and (b) northwest vent of the test compartment. 56 Fig. 3-7. Water-cooled cameras used to capture the test assembly during and after fire

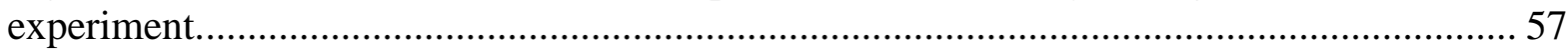
Fig. 3-8. Infrared camera mounted on the strong wall.................................................. 58 Fig. 4-1 Timeline of Test \#1 conducted on Thursday, November 14, 2020........................ 62 Fig. 4-2. Locations of loading points tied to four hydraulic actuators (NE, NW, SE, and SW).

Fig. 4-3. (a) Average mechanical load applied by four actuators and (b) average stroke displacement of the north actuators (NE and NW) and the south actuators (SE and SW).... 63 Fig. 4-4. Measured heat release rates at the natural gas fuel delivery system (HRRburner) and at the $20 \mathrm{MW}$ exhaust hood (HRR). 65 Fig. 4-5. Snapshots of the video showing the inside the test compartment at $1.5 \mathrm{~min}, 10.9$ $\min$, and $104 \mathrm{~min}$. 
Fig. 4-6. Average measured upper layer temperature within the test compartment. Error bars $=$ standard deviation of temperatures measure using twelve thermocouple probes mounted $30.5 \mathrm{~cm}$ below the steel deck.

Fig. 4-7. Comparisons of average measured upper layer gas temperatures of the test compartment with prescribed standard furnace temperatures.

Fig. 4-8. Temperature distribution through the height of the test compartment at various fire exposure times. The bottom surface of the test compartment is at $0 \mathrm{~cm}$........................... 68 Fig. 4-9. Locations of opening velocity probes and thermocouples; (a) south opening and (b) north opening, unit in $\mathrm{cm}$.

Fig. 4-10. Measured gas velocities along with the average upper gas temperature. The plotted data are the moving average values of the raw data over $25 \mathrm{~s}$. 70 Fig. 4-11. Thermocouple temperatures in the south and north window openings. The plotted

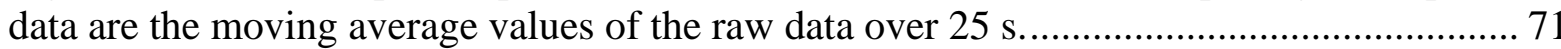
Fig. 4-12. Temperature profile development on the south opening................................... 71 Fig. 4-13. Gas velocity distribution at the south opening, assumed with (a) maximum velocity at the window top edge and (b) no-slip boundary condition as suggested by Bryant (2009). 72 Fig. 4-14. Estimated convective heat loss........................................................................ 73

Fig. 4-15. Estimated mass flow rate at compartment openings. ..................................... 73 Fig. 4-16. Average temperatures measured at various locations within (a) $15.9 \mathrm{~cm}$ deep sections and (b) $8.3 \mathrm{~cm}$ deep sections of the concrete slab. Error bars indicate the maximum standard deviation of temperatures during fire or cooling after extinguishment................. 75 Fig. 4-17. Locations of thermocouple probes $3 \mathrm{~mm}$ below the top (unexposed) surface of the

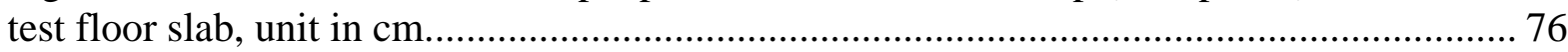
Fig. 4-18. Concrete temperatures measured $3 \mathrm{~mm}$ below the top (unexposed) surface of the

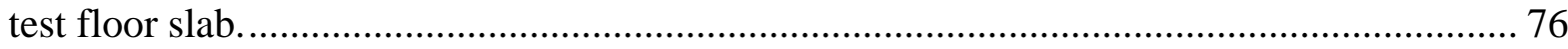
Fig. 4-19. Average temperatures of (a) $9.1 \mathrm{~m}$ long composite beams at midspan and (b) $6.1 \mathrm{~m}$ long composite girders at midspan. Error bars indicate the maximum variation in temperatures recorded using thermocouples mounted at the same height during fire loading.

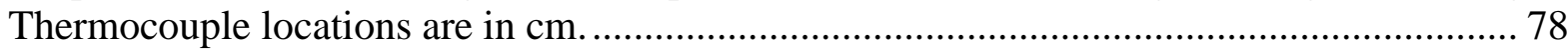
Fig. 4-20. Typical locations of temperature measurements in beam end regions of (a) the secondary beam and (b) the girder inside the fire test compartment. ................................ 79 Fig. 4-21. Temperatures of shear tab connections used in the middle (secondary) W16 $\times 31$ beam.

Fig. 4-22. Temperatures of shear tab connections used in (a) north and (b) south primary beams $(\mathrm{W} 16 \times 31)$.

Fig. 4-23. Temperatures of extended shear tab connections used in (a) east and (b) west girders $(\mathrm{W} 18 \times 35)$.

Fig. 4-24. Snapshots from the test video viewing inside the test compartment at about (a) 5 min, (b) 9 min, and (c) 107 min after the burner ignition. 84 Fig. 4-25. A snapshot of the test video showing local buckling of the north steel deck at about 12 min. 85

Fig. 4-26. Snapshots of the test video looking down on the top of the test floor assembly at about (a) $18 \mathrm{~min}$ and (b) $24 \mathrm{~min}$.

Fig. 4-27. Snapshots of the test video looking down on the top of the test floor assembly at about (a) $41 \mathrm{~min}$, (b) $69 \mathrm{~min}$, and (c) $100 \mathrm{~min}$. 
Fig. 4-28. Snapshots of the test video displaying the view from the east surrounding bay at (a) $87 \mathrm{~min}$, (b) $106 \mathrm{~min}$, and (c) $130 \mathrm{~min}$ (cooling).................................................... 87 Fig. 4-29. Thermal images displaying top of the slab at (a) $69 \mathrm{~min}$, (b) $82 \mathrm{~min}$, and (c) 106 $\min$.

Fig. 4-30. Locations of vertical displacement measurement, unit in $\mathrm{cm}$. Measuring strings were attached to the eye bars embedded in the test floor slab.

Fig. 4-31. Measured vertical displacements of the exposed steel members at midspan (a) up to $40 \mathrm{~min}$ and (b) up to $240 \mathrm{~min}$ including cooling (beginning at $107 \mathrm{~min}$ ).

Fig. 4-32. Measured vertical displacements of the exposed steel members at midspan as a function of the bottom flange temperatures from $0 \mathrm{~min}$ to $107 \mathrm{~min}$.

Fig. 4-33. Vertical displacement profile of the test floor assembly at (a) the north-south centerline and (b) the east-west centerline. The upper horizontal axes indicate the corresponding position of each vertical displacement sensors.

Fig. 4-34. Locations of horizontal displacement measurements, unit in $\mathrm{cm}$. The XY origin is defined at the center of the southwest column of the test bay; The $\mathrm{Z}$ datum is defined at the laboratory strong floor.

Fig. 4-35. Time history of lateral displacements measured (a) the east side and (b) the north side of the prototype building at the first-story level, compared with horizontal (axial) displacements measured along the edges of the test column grid (HD4 and HD6). Fig. 4-36. Lateral displacements of the prototype building at the first-story level as a function of bottom flange temperatures in the test bay; (a) the east or west side during heating, (b) the north or south side during heating, (c) the east or west side during cooling, and (d) the north or south side during cooling....

Fig. 4-37. Lateral displacements of the northeast column of the test column grid during (a) fire and (b) cooling; lateral displacements of the southeast column during (c) fire and (d) cooling......

Fig. 4-38. Post-test photographs of (a) final deflected shape and (b) crack pattern of the test floor slab.

Fig. 4-39. Post-test photographs of the test floor slab; locations 1 through 8 are closeups of concrete fractures. 101

Fig. 4-40. Post-test photographs: (a) slab through-hole used for running a water-cooled loading tube; (b-c) deck delamination from concrete. Localized spalling is indicated by arrows.

Fig. 4-41. Saw cut concrete over (a) east and (b) west ends of the secondary beam; three stud anchors at (c) east and (d) west ends of the secondary beam. 102 Fig. 4-42. Post-test photographs: (a) overall deflected shape and color of the exposed decking; (b) closeup of the steel decking south of the secondary beam; (c) southeast corner of the steel decking. 103

Fig. 4-43. Post-test photographs: (a) north primary beam; (b) secondary beam; (c) south primary beam.

Fig. 4-44. Post-test photographs: (a) W16×31 beams; (b) W18×35 girders 104 Fig. 4-45. Post-test photographs: (a-b) west end of secondary beam; (c-d) west end of north beam.

Fig. 4-46. Post-test photographs: (a) east and (b) west ends of south primary beam. 105 Fig. 4-47. Post-test photographs of the end connections of the secondary beam: (a) east beam web; (b) west beam web; (c) east shear tab connection; (d) west shear tab connection....... 106 
Fig. 4-48. Post-test photographs of extended shear tab (girder-to-column) connections: (a) north end of the east girder; (b) south end of the east girder; (c) north end of the west girder; (d) south end of the west girder.

Fig. 4-49. Comparisons of the test results with (a) limiting temperatures and (b) limiting displacements and displacement rates, where Dmax = maximum displacement and $\mathrm{Rmax}=$ maximum displacement rate.

Fig. A-1. Scale drawing of building floor plan. Units in inch.

Fig. A-2. Scale drawing of the two-story steel frame along line B in Fig. A-1. Dimensions in inch.

Fig. A-3. Scale drawing of the two-story steel frame along (a) line 1 and (b) line 2 shown in

Fig. A-1. Dimensions in inch.

Fig. A-4. Scale drawings of typical frame connections in the surrounding bay: (a) angle connection (b) extended shear tab connection. Dimensions in inch.

Fig. A-5. Plan view of beam and girder connections to exterior columns: (a) column A1 and

(b) column B1. Units in inch.

Fig. A-6. Scale drawing of the beam-to-girder connection in the surrounding bay: (a) plan and (b) front view. Units in inch.

Fig. A-7. Scale drawing of the steel reinforcement layout (U.S. customary units)............ 125

Fig. A-8. Scale drawings of gravity loading system. Dimensions in cm.......................... 126

Fig. A-9. Scale drawings of (a) compartment floor plan and (b) south wall. Dimensions in

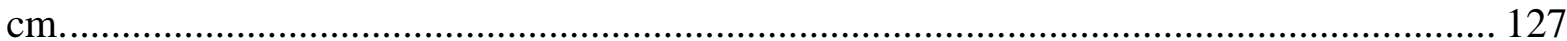

Fig. A-10. Scale drawings of (a) north wall and (b) east wall. Dimensions in cm............. 128 Fig. B-1. Hydraulic actuator data: (a) mechanical load and (b) stroke displacement of four actuators named each as NE, SE, NW, and SW.

Fig. B-2. Measured beam strains during mechanical loading at ambient temperature: (a) secondary $(\mathrm{W} 16 \times 31)$ beam; east and west $(\mathrm{W} 18 \times 35)$ girders at midspan.

Fig. B-3. Distribution of thermocouple probes for measurements of upper layer gas temperatures within the test bay. The distance between a thermocouple probe and the steel deck flute is $30.5 \mathrm{~cm}$.

Fig. B-4. Compartment temperatures measured at $30.5 \mathrm{~cm}$ below the composite floor soffit.

Fig. B-5. Locations of natural gas burners and thermocouple trees in the test bay. The $\mathrm{x}$ and $\mathrm{y}$ coordinates of the burners indicate the center of each burner. The floor of the test compartment was at $\mathrm{Z}=0 \mathrm{~cm}$. 132

Fig. B-6. Gas temperature measured using South TC and North TC trees........................ 132

Fig. B-7. Locations of heat flux gauges (HG1 through HG3)........................................ 133

Fig. B-8. Measured heat fluxes on exposed wall surfaces.

Fig. B-9. Locations of thermocouples embedded into the test floor slab where $\mathrm{i}=$ an assigned number of each cylinder (1 through 8). The bottom rib of the steel decking is at $\mathrm{Z}=0 \mathrm{~cm} .134$ Fig. B-10. Slab temperatures measured at various locations (TST1 through TST 8). The upper layer temperature is the average value of compartment temperatures measured using TCC channels.

Fig. B-11. Locations of thermocouples mounted at the midspan composite sections, where $\mathrm{i}$ is the section number. 136

Fig. B-12. Composite section temperature at midspan of south primary beam (section 2); secondary beam (section 6); north primary beam (section 11 ). 
Fig. B-13. Composite section temperature at midspan of west girder (section 13) and east girder (section 16).

Fig. B-14. Change in thermal gradients through the depth of the midspan composite sections of (a) south primary beam, (b) secondary beam, (c) north primary beam, (d) west girder, and (e) east girder during heating.

Fig. B-15. Locations of (a) steel temperature measurements where the $\mathrm{Z}$ datum is located at top of the steel members and thermocouples mounted to (b) W16 $\times 31$ beams (TB1, TB5, TB7, and TB10 sections) and (c) W18 $\times 35$ girders (TB12 and TB17 sections). $\mathrm{i}=$ section number shown in (a).

Fig. B-16. Protected steel beam and girder temperatures: W16 $\times 31$ primary beams (sections 1 and 10); W16 $\times 31$ secondary beam (sections 5 and 7) and W18×35 girders (sections 12 and 17).

Fig. B-17. Locations of thermocouples mounted at the ends of composite beams and girders in the test bay.

Fig. B-18. Temperatures of the beam-end connection regions.

Fig. B-19. (a) Vertical displacement, (b) horizontal displacement measured at the first story level, and (c) horizontal displacement measured at the second story level.

Fig. B-20. Locations of strain measurement. Note that strain gauges of SSWB and SSEB sections are lettered in red.

Fig. B-21. Column strain data............................................................................ 152

Fig. B-22. Measured strains of the west-bay beams. ................................................... 153

Fig. B-23. Post-test photographs of headed stud anchors in the test bay.......................... 155

Fig. B-24. Post-test photographs of W16×31 beams in the test bay; (a) east end and (b) west

end.

Fig. B-25. Post-test photographs of W18 $\times 35$ girders in the test bay; (a) north end and (b) south end.

Fig. B-26. Beam-end connections of north primary beam; (a, b, c) east end and (d, e, f) west end.

Fig. B-27. Beam-end connections of south primary beam; (a, b, c) east end and (d, e, f) west end

Fig. C-1. Locations of plate thermometers.

Fig. C-2. Temperatures measured using (a) plater thermometers (PT) and (b) bare-bead thermocouples close to the plate thermometers (PT_gas). 160

Fig. C-3. Incident radiant fluxes estimated using the plate thermometer data 161 


\section{List of Acronyms and Abbreviations}

AISC

ASTM

ASCE

ANSI

EC

IBC

ICC

UL

ISO

NFPA

NFRL

NIST

WTC

SCI

SCNZ

SFRM

WWR
American Institute of Steel Construction

American Society for Testing and Materials

American Society of Civil Engineers

American National Standards Institute

Eurocode

International Building Code

International Code Council

Underwriters Laboratories Inc.

International Organization for Standardization

National Fire Protection Association

National Fire Research Laboratory

National Institute of Standards and Technology

World Trade Center

Steel Construction Institute, United Kingdom

Steel Construction New Zealand

Sprayed Fire Resistive Material

Welded Wire Reinforcement 


\section{Introduction}

The multi-year experimental research project is being conducted at the NIST National Fire Research Laboratory to study the behavior of full-scale composite floor systems exposed to large enclosure fires. The present test program is aimed to generate technical information and data essential for the development and validation of predictive tools that can be used for performance-based design and assessment for steel-framed buildings in structurally significant fires.

\subsection{Background}

Structural steel framing constitutes over 40 percent of the United States construction market for multi-story buildings, creating roughly 44000 new projects (valued at nearly $\$ 680$ billion) between 2014 and 2019 (AISC 2020). The majority of steel-framed buildings typically require passive fire protection to meet the code-prescribed fire-resistance rating in the range of 1 hour to 3 hours. Given that an approximate cost of installing passive fire protection typically ranges from $12 \%$ to $15 \%$ of the overall construction cost (NFPA 2017), annual expenditure on passive fire protection for steel-framed buildings is estimated up to $\$ 20$ billion. In particular, the steel composite floor construction, which is commonly used for spanning large open spaces, can incur high costs of passive fire protection because of a significant use of structural steel requiring fireproofing insulation (e.g., SFRM or intumescent paint).

For composite floor systems, the prescriptive compliance of passive fire protection is aimed to minimize the possibility of a fire that spreads beyond its compartment of origin and to provide means of occupant egress routes and safe paths for first responders. The process of prescriptive design is straightforward. The mandatory fire-resistance rating of a building is determined based on combination of several factors, such as occupancy and use, construction materials, building configurations (area and height), and the presence of active fire protection systems (smoke detectors, sprinklers, etc.), as specified in building codes, e.g., IBC (ICC 2018) or NFPA 5000 (NFPA 2021). In most cases, architects then choose an appropriate fireproofing scheme that has been qualified by the fire testing methods in accordance with ASTM E119 (2020) or standard calculation methods, e.g., ASCE 29 (2005).

The intent of standard fire testing is to provide a consensus-based method for evaluating the duration for which a single floor assembly maintains its structural integrity under prescribed furnace heating conditions. This testing method usually requires a test assembly that is representative of the structural details used in construction, however, the size and support conditions of a test assembly are limited by available furnaces in testing facilities. According to the ASTM E119 standard, the minimum required area of a test floor assembly placed on top of a furnace chamber is $16.7 \mathrm{~m}^{2}$ with a minimum length of $3.7 \mathrm{~m}$ on each side. While subjected to furnace heating with a prescribed time-temperature relationship, a test assembly is required to resist its maximum load condition permitted in the national structural design standard. The fire-resistance rating of a test floor assembly, typically expressed in hours of the thermal endurance time, can be determined using the following criteria (AISC 2003):

- A test assembly fails to resist a maximum load as specified,

- A cotton waste on the unexposed (top) surface of a test floor is ignited, 
- An average temperature of the unexposed surface of a test floor exceeds $139{ }^{\circ} \mathrm{C}$ above its initial temperature, or

- For test specimens employing steel structural members spaced more than $1.2 \mathrm{~m}$ on center, the temperature of the steel structural members shall not have exceeded 704 ${ }^{\circ} \mathrm{C}$ at any location during the classification period nor shall the average temperature recorded by four thermocouples at any section have exceeded $593{ }^{\circ} \mathrm{C}$ for a specified duration. The duration during which this average temperature shall not be exceeded varies depending on whether a restrained or unrestrained approval is sought. For specimens employing steel structural members spaced $1.2 \mathrm{~m}$ or less on centers, the single location temperature limit does not apply.

Fire-resistance rating values of various test assemblies detailed with commercial fireproofing materials are available through public databases (e.g., https://iq.ulprospector.com/) and manufacturer's websites. These values vary with concrete slab properties (including compressive strength, unit weight, and thickness of concrete), steel deck properties (including deck profile, thickness and finish coating of sheet steel, and attachment to steel beams), and the thickness of fireproofing materials applied to floor beams. However, the actual test results, such as thermal gradients developed within tested assemblies, temperaturedependent thermal properties of fireproofing materials, structural responses (forces, displacements, and failure modes) of tested assemblies, and the governing criterion used for termination of testing, are not required to be reported and mostly remain proprietary. More importantly, the fire-resistance rating itself seldom provides useful insight into the overall fire resilience of a building (as a whole system) exposed to uncontrolled fires which may be vastly different from prescribed furnace heating conditions.

With inherent limitations in prescriptive approaches, there has been renewed interest in development of performance-based approaches which can improve both fire resilience and cost effectiveness of building construction in the United States. Alternative engineering approaches have been established along with guidance and design references, e.g., Appendix 4 Structural Design for Fire Conditions of AISC 360 (AISC 2016) and the ASCE Structural Fire Engineering manual of practice (ASCE 2018). However, most of the suggested methods rely heavily on numerical models of assemblies or members limited in sizes or tested under idealized support conditions. Large knowledge gaps still exist including (1) temperature dependence of composite interactions between a concrete slab and steel floor beams used in long-span floor systems under realistic fire exposure and (2) the effects of thermal restraints from the surrounding structures and steel framing connections. This knowledge cannot be readily achieved by standard furnace testing of a single floor assembly limited by its small size and support conditions. Research-quality data from large-scale testing of structural systems (including connections) will be needed to quantify the complex structure-fire interaction and vulnerabilities (limit states) from realistic fires and to benchmark or validate computational models used for performance-based fire protection design of buildings. 


\subsection{Previous Fire Experiments}

Over the last few decades, there have been active research efforts in Europe to better understand the fire resilience of steel-concrete composite floors (Bisby et al. 2013). Of particular interest for the present study are the experimental investigations on the full-scale composite floor assemblies with steel framing connections, especially those spanning in excess of $6 \mathrm{~m}$.

The Cardington test program (British Steel 1999; Wald et al 2006) utilizing the eight-story steel framed building demonstrated membrane action of composite floors as the secondary load-carrying mechanism in fire and the possibility of eliminating fire protection of the secondary (filler) beams. These findings led to the development of simplified desktop design methods (Bailey 2000; 2001; 2003) accounting for tensile membrane action of composite floor assemblies at elevated temperatures. Both FRACOF (Zhao et al. 2008) and COSSFIRE projects (Zhao et al. 2011) further examined the benefit from Bailey's method by conducting standard fire tests on large-scale composite floor assemblies. Table 1-1 presents a summary of key features of the test floor assemblies used in those studies. A comparison of experimental features as well as important observations and conclusions from these studies are presented in the following subsections.

Table 1-1. Summary of experimental features used in previous fire experiments on composite floor systems

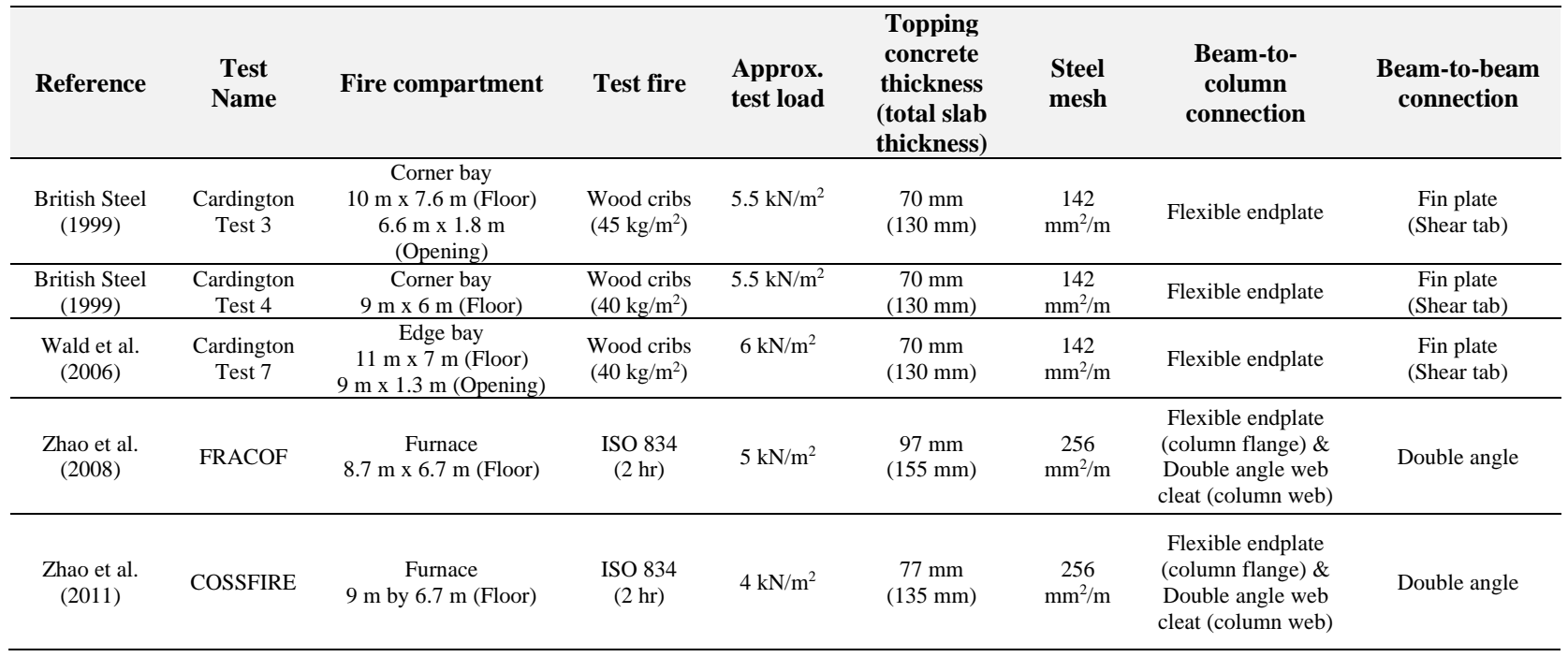

\subsubsection{Fire Compartment}

The floor area of the fire compartments used in the Cardington tests varied from $54 \mathrm{~m}^{2}$ to 77 $\mathrm{m}^{2}$. Both Test 3 and Test 4 were conducted in the $9 \mathrm{~m} \times 6 \mathrm{~m}$ corner bay of the test building on different floors, whereas Test 7 was situated in the edge bay enclosing the same size column grid. In Test 3, the compartment walls were constructed with non-load bearing CMU (Concrete Masonry Unit). In Test 4 and Test 7, the interior walls were replaced with steel stud partitions with fire-rated plasterboards. All three Cardington tests used a single opening (with an approximate area of $12 \mathrm{~m}^{2}$ ) on the exterior wall. On the other hand, both FRACOF and COSSFIRE tests were conducted using a $9 \mathrm{~m} \times 6.7 \mathrm{~m}$ furnace chamber that simulated standard fire conditions. 


\subsubsection{Test Floor Assembly}

All tested floor specimens in Table 1 consisted of concrete slabs cast in-situ on light gauge steel decking with a trapezoidal profile, acting compositely with steel beams (weighing 40 $\mathrm{kg} / \mathrm{m}$ to $51 \mathrm{~kg} / \mathrm{m}$ ) via headed stud anchors. The deck flute used in those studies was approximately $60 \mathrm{~mm}$ deep, whereas the depth of concrete topping (above the deck flute) varied from $70 \mathrm{~mm}$ to $97 \mathrm{~mm}$. In the Cardington tests, anti-crack steel mesh with an area of $142 \mathrm{~mm}^{2} / \mathrm{m}$ was used based on the British construction practice in 1990s. However, the area of steel mesh used in FRACOF and COSSFIRE was $256 \mathrm{~mm}^{2} / \mathrm{m}$, designed based on Bailey's method.

The primary beams were supported by steel columns using either flexible endplate or all bolted double angle connections. The ends of the secondary beam(s) had fin-plate connections to the primary beams. Among these five experiments, fire protection scheme (e.g., insulation type and thickness) of the primary beams and member connections varied. However, all columns were protected with SFRM, whereas the secondary beams left unprotected.

A number of sandbags were used to load the test assemblies during test fires. The total gravity load (including the self-weight of a test floor assembly) ranged from $4 \mathrm{kPa}$ to $6 \mathrm{kPa}$. This load level provided the demand-to-capacity ratio of the secondary composite beam approximately equal to 0.5 .

\subsubsection{Fire Development}

The Cardington test series employed wood cribs $\left(40 \mathrm{~kg} / \mathrm{m}^{2}\right.$ to $\left.45 \mathrm{~kg} / \mathrm{m}^{2}\right)$ as fuel to simulate a real compartment fire in typical office buildings. On the other hand, both FRACOF and COSSFIRE tests incorporated the furnace fire conditions simulating the ISO 834 temperature-time curve up to $2 \mathrm{hr}$.

The test fires used in these studies created the upper layer gas temperatures reaching near or beyond $1000{ }^{\circ} \mathrm{C}$ within the compartment enclosure or a furnace chamber. In the Cardington tests, however, the fire development was highly influenced by thermal boundary conditions of the compartment walls and opening schemes, resulting in dissimilar gas temperature-time relations among tests. The fire growth was much slower than that predicted using the EC parametric curve as outlined in the Annex of EC1-1-2 (2004). In Test 3 and Test 7, a peak value of the gas temperature reached to $900{ }^{\circ} \mathrm{C}$ and $1100{ }^{\circ} \mathrm{C}$, respectively, at about $1 \mathrm{hr}$ after ignition, followed by the decay stage that took another $1 \mathrm{hr}$. However, in Test 4 , a flashover was not developed until 100 min due to the lack of oxygen within the compartment, thereby a window glazing system was manually removed for air intake. A peak value of the recorded gas temperature was $1050{ }^{\circ} \mathrm{C}$ at $102 \mathrm{~min}$, but it sharply decreased afterward.

\subsubsection{Specimen Response}

The actual response of the heated floor assemblies varied by fire intensity and duration as well as the fire protection scheme of exposed steel. In all five experiments, temperatures of unprotected steel beams reached nearly $1000{ }^{\circ} \mathrm{C}$. The maximum vertical displacement measured at the center of the floor assemblies was in the range of $27 \mathrm{~cm}$ (Test 4) to $120 \mathrm{~cm}$ (Test 7), equivalent to the ratio of $L / 30$ to $L / 8$ where $L$ is the length of the secondary beam(s). Bare steel beams also exhibited local buckling toward the ends due to the restraint to thermal elongation. The beam-end connections exhibited minor damage except for the flexible 
endplates used in Test 7. Temperatures of these connections were in excess of $700{ }^{\circ} \mathrm{C}$ during fire.

Despite these high-temperature effects, the test assemblies in Table 1-1 did not reach the collapse mechanism. However, both the Cardington Test 7 and FRACOF test reported concrete cracks resulted from inadequate splice detailing of steel mesh mat. Temperatures of the top (unexposed) surface of the concrete slab, measured using discrete thermocouples away from locations of concrete cracks, did not exceed $140{ }^{\circ} \mathrm{C}$ during the heating phase. None of the tests reported the extent of damage in steel deck exposed to fire.

\subsubsection{Conclusions from Previous Studies}

The Cardington test series demonstrated that the fire performance of composite floor systems was markedly superior compared to that observed in standard fire tests on isolated composite beams with the simply supported boundary conditions. The aforementioned experiments showed that temperatures of exposed steel and deflections of floors exceeded the conventional limiting criteria specified in standard testing methods. Also, both FRACOF and COSSFIRE projects proved that the increased amount of steel reinforcement in composite slabs can significantly enhance their fire resistance for a longer duration of a fire. Adequate details of the steel reinforcement in concrete slabs in combination with robust end supports would be required for activating tensile membrane action in the composite floor assemblies enduring extremely high compartment temperatures $\left(>1000{ }^{\circ} \mathrm{C}\right)$.

These large-scale experiments led to the development of simplified design tools that can be used for the optimized fire-resistance design of composite floor systems, e.g., TSLAB by SCI P288 (Newman et al. 2006), Slab Panel Method (SPM) by SCNZ (Clifton et al. 2010) and MACS+ (Vassart et al. 2014).

\subsection{Research Motivation}

To date, there is lack of data describing the actual fire performance of full-scale steelconcrete composite systems designed and constructed in compliance with the United States building codes and standards. The large-scale experiments discussed in Sect. 1.2 have provided useful insights into realistic fire performance of composite floor systems; however, the data and findings from those studies are more applicable to structures constructed following the European standard practice. In addition, none of these experimental studies accurately characterized fire loading in terms of measured heat energy (heat release rate) that would be essential for developing design-basis fires used for performance-based fire protection design. Furthermore, simple design tools exclude the influence of thermal restraints from the adjacent structures and connections as well as thermally induced buckling of steel members in estimating the load bearing capacity of composite floor systems in fire. Although computational modeling techniques have evolved, they still need to be validated against comprehensive test data with quantified uncertainty in measurements and qualitative evidence describing a full course of fire-induced structural damage during and after fire exposure.

Motivated by such research needs, NIST has proposed the experimental research project on full-scale structural steel frames with composite floor assemblies to measure fire behavior and structural failure modes under structurally significant fire conditions. The goal of this project is aligned with several recommendations from NIST's WTC Disaster Study 
(https://www.nist.gov/topics/disaster-failure-studies/world-trade-center-disasterstudy/recommendations), such as

- to improve the technical basis for the century-old standard for fire resistance testing by establishing a capability to measure the thermal and structural responses of realscale structural systems mechanically loaded to simulate service (or incipient collapse) conditions and exposed to real fire

- to produce the experimental data and technical information essential for both benchmarking and validation of computational models and design tools used for performance-based design of structures in fire

This research project involves a series of large enclosure fire experiments conducted at the NFRL (Bundy et al. 2016), including

- Phase I: 12.8 m (42 ft.) span composite floor beams with simple shear connections

- Phase II: $9.1 \mathrm{~m}$ by $6.1 \mathrm{~m}$ (30 ft. by $20 \mathrm{ft}$.) composite floor assemblies in a two-story gravity frame and two bays by three bays in plan

The Phase I study was completed in 2018 (Ramesh et al. 2019; Choe et al. 2019; Choe et al. 2020), and the Phase II study is currently in progress.

\subsection{Research Objectives \& Scope}

The objective of the Phase II study is to provide the technical basis and guidance needed to improve performance-based design for steel-framed buildings through large-scale structural fire experiments. A total of four compartment fire experiments are planned on a $9.1 \mathrm{~m}$ by 6.1 $\mathrm{m}$ composite floor assembly situated in the two-story steel framed building. Test variables will likely include: the amount of slab reinforcement, passive fire protection of the secondary beam, and structural layout including but not limited to steel frame connections, slab continuity and floor plate geometry. To compare the results from a series of fire tests on a consistent basis, the fire exposure and structural loading applied to the test floor assemblies remain unchanged throughout the Phase II study. Natural gas burners are used to create a compartment fire simulating the standard time-temperature relationship until substantial structural failures occur. For structural loading, the ASCE 7 (2017) load combination for extraordinary events $(1.2 \times$ dead load $+0.5 \times$ live load $)$ is used to define the imposed gravity load on the test floor assemblies while exposed to fire.

This report presents the first experiment of the Phase II program (Test \#1) conducted on November 14, 2019. This fire test is aimed to investigate the system-level fire resistance and structural performance of the full-scale composite test floor assembly constructed following the current U.S. construction practice, including prescriptive fireproofing insulation details and the minimum code-prescribed shrinkage reinforcement in the composite slab. The results from Test \#1 will serve as the baseline data to compare the results from other subsequent experiments conducted throughout the Phase II study.

The specific objectives of Test \#1 are the following:

1) to develop and verify a standard fire condition in the test compartment controlled by the heat release rate of natural gas fueled burners and ventilation schemes, 
2) to characterize the thermal and structural responses of the full-scale composite floor assembly heated to its incipient collapse or substantial integrity failure during and after standard fire exposure, and

3) to evaluate the embedded safety factor or vulnerability posed by prescriptive design approaches.

The experimental measurements include:

- fire characteristics including heat release rates, gas temperatures, velocity flow of the openings, and heat fluxes from a natural gas fueled compartment fire,

- thermal (temperatures) and structural responses (displacements, forces, and strains) of the test building, and

- any noteworthy observations during the fire test and post-test inspections critical to understand the overall fire performance and failure modes of the test floor assembly.

This report offers the unique experimental results that provide insight into the effects of standard fire exposure in a real building structure and potential failure mechanisms of fullscale steel-concrete composite floor systems including steel frame connections and slab continuity. This technical information can be used to guide the development and validation of physics-based computational models of composite floor assemblies in fully developed fires as well as after fire is extinguished. This research effort also provides important steps toward the improvement of the current fire testing methods and performance-based design provisions for steel-framed buildings in fire. 


\section{Experimental Design}

This chapter describes the design and construction of the two-story structural steel frame with composite floors, the fire test compartment, and mechanical loading setup.

\subsection{NFRL Two-Story Test Frame}

The two-story steel test frame was designed and constructed at the NFRL to provide a framework for conducting a series of large compartment fire experiments on full-scale composite floor systems. This test frame is representative of a steel gravity frame commonly used in modern office buildings. This section presents the design basis and structural design of the test frame and composite floor assemblies.

\subsubsection{Design Basis}

For design of the test frame, there were several constraints related to laboratory space as follows. The footprint of the test frame was limited by the NFRL's strong floor, nominally $2680 \mathrm{~cm} \times$ $1830 \mathrm{~cm}(88 \mathrm{ft} . \times 60 \mathrm{ft}$.). The height of the test frame was controlled by the clearance under the overhead cranes (hook height above floor) of $914 \mathrm{~cm} \mathrm{(30} \mathrm{ft.).} \mathrm{For} \mathrm{accurate} \mathrm{measurements} \mathrm{of} \mathrm{the}$ heat release rate of a test fire, the fire test compartment was also needed to be situated beneath the $1524 \mathrm{~cm} \times 1372 \mathrm{~cm}(50 \mathrm{ft}$. $\times 45 \mathrm{ft}$.) exhaust hood suspended from the ceiling of the NFRL's structural fire test bay. The required "stand-off" distance between the vented wall (wall from which flames extend) and the hood curtain was estimated to be approximately $400 \mathrm{~cm}$ (13 ft.). Another major consideration in selecting the plan framing was the ability to uniformly load the test floor using hydraulic actuators mounted beneath the strong floor through $74 \mathrm{~mm}(2.9 \mathrm{in}$.) diameter anchor holes on $61 \mathrm{~cm} \times 61 \mathrm{~cm}$ grid.

Taking the above limitations into account, the test frame suggested for this study was a two-story gravity frame with $366 \mathrm{~cm}$ (12 ft.) story heights. A plan showing the extent of the strong floor and strong wall, the footprint of the hood, and the plan view of the test structure is shown in Fig. 2-1. It was proposed to be two bays by three bays in plan with a total footprint of $1036 \mathrm{~cm} \times$ $1768 \mathrm{~cm}(34 \mathrm{ft} . \times 58 \mathrm{ft}$.). The steel frame had symmetrical bays in the east-west direction, i.e., three bays spaced $427 \mathrm{~cm}, 914 \mathrm{~cm}$, and $427 \mathrm{~cm}$. Composite floor assemblies were constructed on the first floor of the test frame. The test bay was the south-central bay, $610 \mathrm{~cm}$ wide and $914 \mathrm{~cm}$ long. The fire test compartment was built on the ground floor to enclose the test bay and heat the composite floor assembly above. The main vent of the test bay was on the south side, allowing the maximum horizontal flame extension (distance to hood curtains) of $396 \mathrm{~cm}$ (13 ft.).

A photograph of the test frame is shown in Fig. 2-2. For this study, the support columns were protected from fire so that they could provide a reliable load path during the experiment. Further, the same steel beam framing was assembled at the second story level without concrete slabs, providing support conditions of the steel columns continuous over two stories. This design decision was based on pre-test analyses in which the presence of a second-floor slab had negligible effect on the fire behavior of the test floor assembly on the first-floor level. In addition, this configuration (i.e., no concrete slabs on the second floor) allowed to expedite replacement of the test floor assembly (on the first-floor level) for subsequent fire tests. Details of the test frame design are presented in the following subsections. 


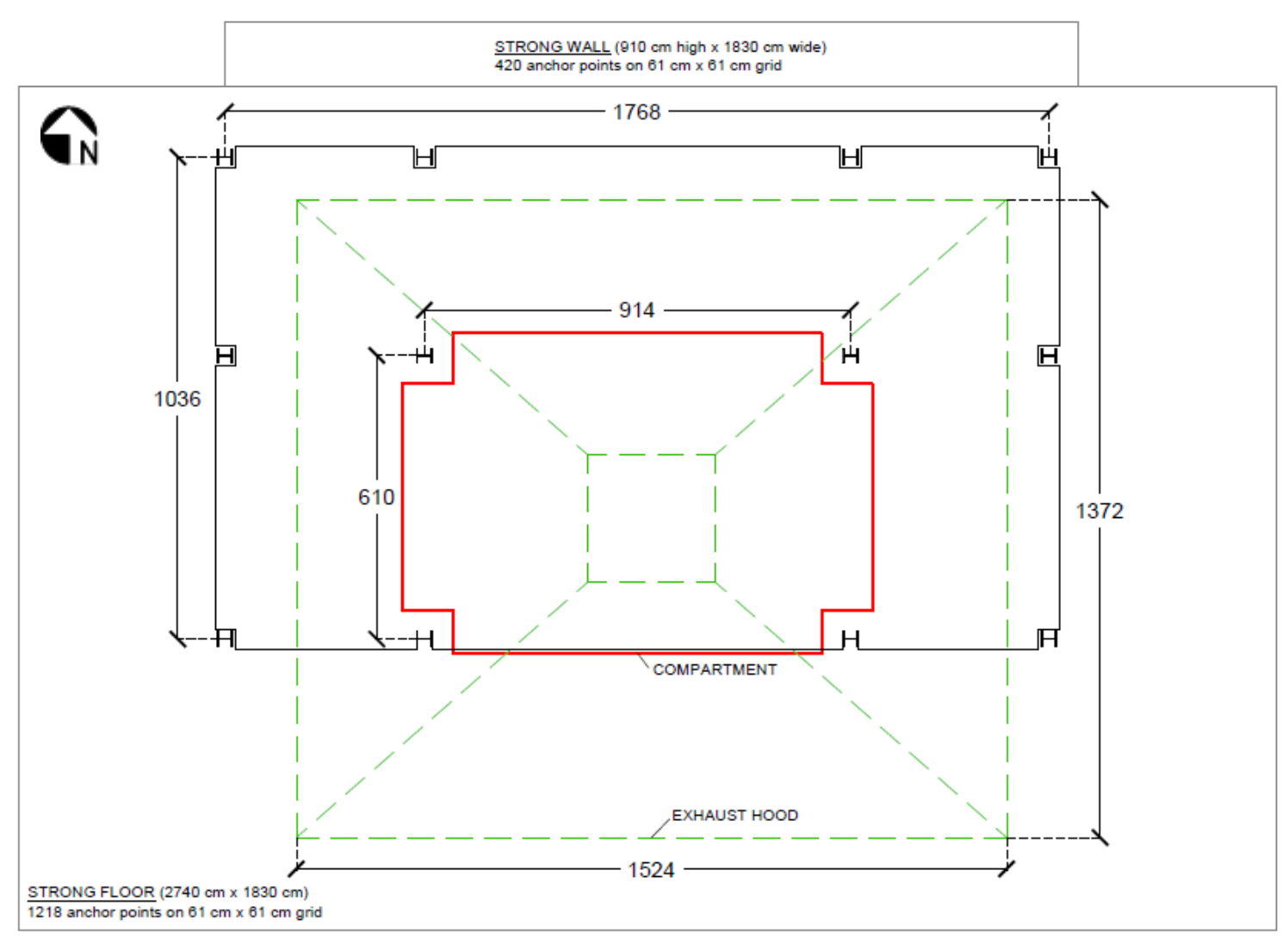

Fig. 2-1. Plan view of NFRL structural fire test bay including the test frame with fire compartment and footprint of exhaust hood; dimensions in $\mathrm{cm}$.

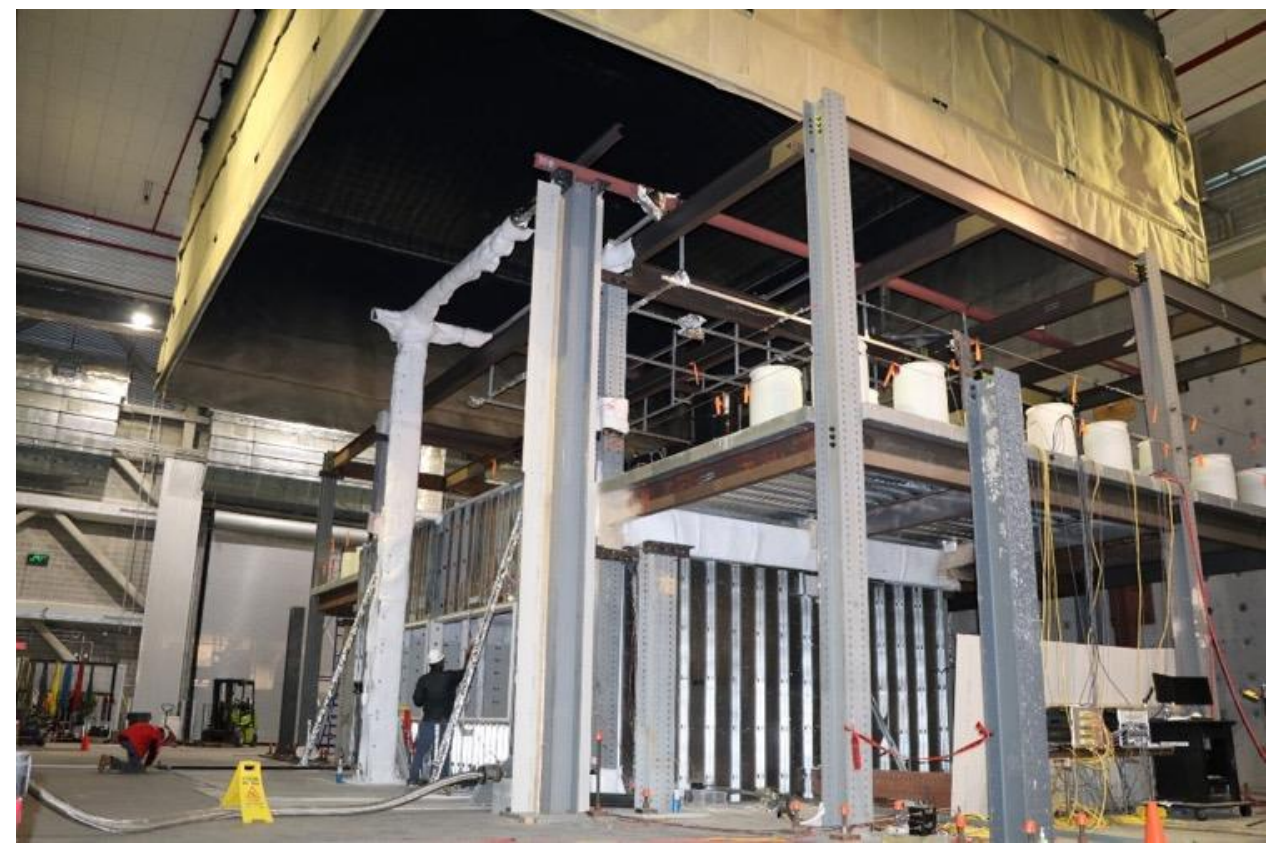

Fig. 2-2. NFRL two-story test frame prior to fire experiment. 
Prior to the structural design of the test structure, a survey of U.S. design firms was conducted to gather information on the common design practices. The test structure was then further detailed in accordance with the U.S. building codes and design specifications, including IBC (ICC, 2018), ASCE 7 (ASCE, 2016), AISC 360 (AISC, 2016) and SDI C-2011 (SDI, 2011). In addition, floor vibration of the composite floor assembly was checked against serviceability criteria specified in AISC Design Guide 11 (Murray et al., 2016).

Table 2-1 shows a summary of the selected survey result presented in Ramesh et al. (2019) and the actual design values adopted in this study. The values of design gravity loads conform to the ASCE 7 provisions on dead and live loads. According to this survey, the most common floor construction uses a lightweight concrete slab with $7.6 \mathrm{~cm}$ (3 in.) deep trapezoidal steel decking supported by steel beams protected for a $2 \mathrm{hr}$ fire-resistance rating. However, the required amount of shrinkage reinforcement in concrete slabs appears to be less consistent among state jurisdictions, varying from $60 \mathrm{~mm}^{2} / \mathrm{m}$ to $90 \mathrm{~mm}^{2} / \mathrm{m}$. Hence, the present study considers the minimum shrinkage reinforcement of $60 \mathrm{~mm}^{2} / \mathrm{m}$ calculated following the SDI provisions.

Table 2-1. Survey results of common U.S. design values for a $6.1 \mathrm{~m} \mathrm{(20} \mathrm{ft.)} \mathrm{by} 9.1 \mathrm{~m}(30 \mathrm{ft}$.) composite floor and the values considered in present study.

\begin{tabular}{|c|c|c|}
\hline Parameter & Range of Survey Result & $\begin{array}{l}\text { Selected Design } \\
\text { Value }\end{array}$ \\
\hline Construction live load & $0.96 \mathrm{kPa}$ to $1.92 \mathrm{kPa}$ (20 psf to $40 \mathrm{psf})$ & $0.96 \mathrm{kPa}(20 \mathrm{psf})$ \\
\hline Live load (office) & $2.40 \mathrm{kPa}$ to $4.80 \mathrm{kPa}(50 \mathrm{psf}$ to $100 \mathrm{psf})$ & $2.40 \mathrm{kPa}(50 \mathrm{psf})$ \\
\hline Live load (partitions) & $0.72 \mathrm{kPa}$ to $1.44 \mathrm{kPa}$ ( $15 \mathrm{psf}$ to $30 \mathrm{psf}$ ) & $0.96 \mathrm{kPa}(20 \mathrm{psf})$ \\
\hline Superimposed dead load & $0.48 \mathrm{kPa}$ to $1.44 \mathrm{kPa}$ (10 psf to $30 \mathrm{psf})$ & $0.48 \mathrm{kPa}(10 \mathrm{psf})$ \\
\hline $\begin{array}{l}\text { Minimum specified concrete } \\
\text { strength (lightweight concrete) }\end{array}$ & $\begin{array}{l}21 \mathrm{MPa} \text { to } 34 \mathrm{MPa} \text { ( } 3000 \text { psi to } 5000 \\
\text { psi) }\end{array}$ & $28 \mathrm{MPa}$ (4000 psi) \\
\hline Steel deck properties & $\begin{array}{l}5.1 \mathrm{~cm} \text { or } 7.6 \mathrm{~cm} \text { ( } 2 \text { to } 3 \text { in.) deep } \\
\text { trapezoidal profile; sheet metal } \\
\text { thickness } 16 \text { ga. to } 20 \text { ga. }\end{array}$ & $\begin{array}{l}7.6 \mathrm{~cm}(3 \mathrm{in} .) \text { deep } \\
\text { trapezoidal profile; } \\
\text { sheet metal thickness } \\
20 \text { ga. }\end{array}$ \\
\hline $\begin{array}{l}\text { Shrinkage Reinforcement } \\
\text { (welded wire reinforcement) }\end{array}$ & $\begin{array}{l}60 \mathrm{~mm}^{2} / \mathrm{m} \text { to } 90 \mathrm{~mm}^{2} / \mathrm{m} \\
\left(0.028 \mathrm{in}^{2} / \mathrm{ft} \text { to } 0.042 \mathrm{in}^{2} / \mathrm{ft}\right)\end{array}$ & $60 \mathrm{~mm}^{2} / \mathrm{m}$ \\
\hline $\begin{array}{l}\text { Fire-resistance rating of floor } \\
\text { assembly }\end{array}$ & $2 \mathrm{hr}$ & $2 \mathrm{hr}$ \\
\hline
\end{tabular}

\subsubsection{Structural Steel Frame}

The steel framing at each floor level consisted of structural steel beams (members carrying prescribed floor loads), structural steel girders (members supporting reaction forces from the beams), and simple shear connections of structural steel members. The plan view of the test frame is shown in Fig. 2-3. The W14×22 and W16×31 shapes were selected for the floor beams spanning $427 \mathrm{~cm}$ (14 ft.) and $914 \mathrm{~cm}(30 \mathrm{ft}$.), respectively. The W18×35 and W16×26 shapes were used for the internal and edge girders, respectively. All W-shapes were rolled with ASTM A992 (ASTM, 2020) steel, with the minimum specified yield strength of $345 \mathrm{MPa}$ (50 ksi). For this study, the $732 \mathrm{~cm}$ ( $24 \mathrm{ft}$.) long W12×106 columns were assumed not to play a role in the floor failure. Each column had a $91 \mathrm{~cm}$ wide and $5 \mathrm{~cm}(2 \mathrm{in}$.) thick base plate and was anchored to the strong floor using four $3.5 \mathrm{~cm}$ (1-3/8 in.) diameter steel rods post-tensioned to $690 \mathrm{MPa}$ (100 ksi) each. 
A portion of the two-story test frame will be reused throughout this test program. The surrounding steel members framing into the test bay were spliced to allow replacement of the fire-exposed beam frame for each test. The two secondary beams in the southeast and southwest surrounding bays were spliced (i.e., Beam-4 in Fig. 2-3). Also, the four W12×106 columns supporting the test floor assembly, i.e., B2, B3, C2, and C3 columns in Fig. 2-3, were spliced at $92 \mathrm{~cm}$ above top of the floor slab. In addition, the concrete slab and steel decking was spliced 82 $\mathrm{cm}$ and $99 \mathrm{~cm}$ away from the test-bay column grid in the east/west and north sides of the test bay, respectively. Details of the slab splice design are described in Sect. 2.2.2.2. The same splices will be used for the remaining tests.

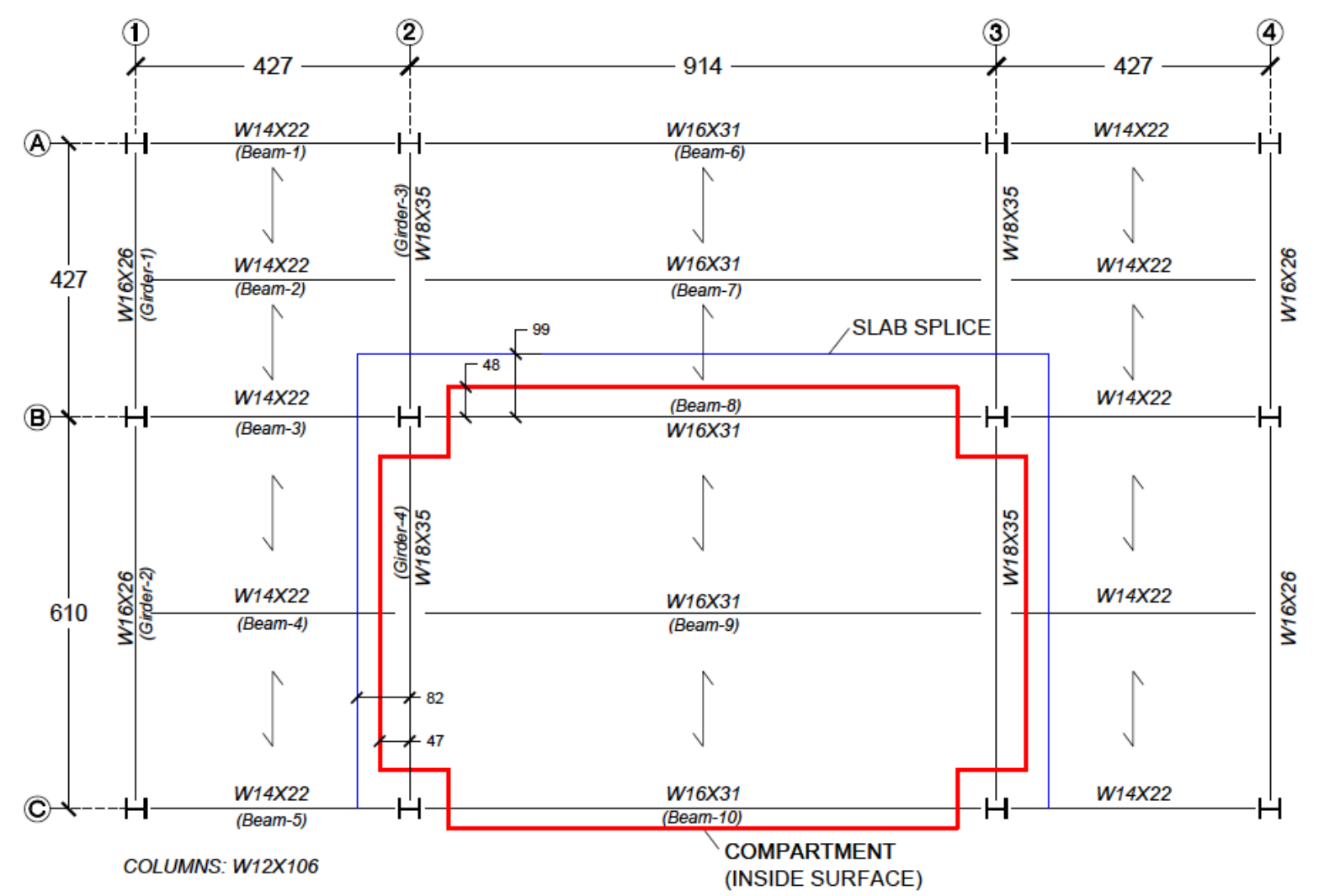

Fig. 2-3. Plan view of the test frame on the first floor. 
A variety of the simple shear connections were used for the first-floor framing of the test building. As shown in Fig. 2-4 and Fig. 2-5, the standard shear tabs (PL81/2×6×3/8) were used at the ends of the W16 $\times 31$ beams in the test bay on the first floor (i.e., Beam-8, Beam-9, Beam-10 in Fig. 2-3). For the end connections of the north and south primary beams in the test bay (i.e., Beam-8 and Beam-10), two stacked plates, including a $19 \mathrm{~mm}(3 / 4 \mathrm{in}$.) thick sacrificial plate and a $44 \mathrm{~mm}$ (13/4 in.) bearing plate, were bolted together to the flanges of the columns (Fig. 2-4). They were intended to minimize any local damage of columns during fire exposure. The bolted connections of these plates were designed to exceed the ambient strength of the shear-tab connections.

For the girder-to-column web connections, the extended shear-tab connections were used so that

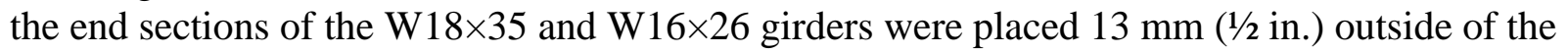
column flange. The details of these connections are presented in Fig. 2-6 and Fig. 2-7. The extended shear tabs used for the W16×26 girders were welded to the $13 \mathrm{~mm}$ thick plates which were bolted to the column web. The extended shear tabs of the $\mathrm{W} 18 \times 35$ girders were directly welded to the column web, and the size of fillet weld is $6.3 \mathrm{~mm}(1 / 4 \mathrm{in}$.).

As shown in Fig. $2-8$, the single angle (L5 $\times 5 \times 3 / 8$ or $\mathrm{L} 5 \times 3 \times 3 / 8)$ bolted connections were used at the ends of the W14×22 and W16×31 beams in the surrounding bays. The same angle connections were used for all members on the second floor except for the south edge beams (Beam-5 and Beam-10) which were connected using the bolted double angles $(2 \mathrm{~L} 5 \times 5 \times 3 / 8)$. The shear tab connection (Fig. 2-5) was used at the ends of the east and west-bay secondary beams (Beam-4) connecting to the test-bay girder (Girder-4). More details of connections are presented in Appendix A.

All structural bolts were rolled with A325 steel as specified in ASTM F3125 (ASTM, 2019). The diameter of bolts connected to the beam web was $19 \mathrm{~mm}(0.75 \mathrm{in}$.) and that connected to the columns was $25 \mathrm{~mm}$ (1 in.). All other connecting elements (rolled steel angles or steel plates) were ASTM A36 (ASTM, 2019) steel. Short-slotted holes, $21 \mathrm{~mm}$ (13/16 in.) wide and $25 \mathrm{~mm}$ ( 1 in.) long, were drilled on the connecting elements, whereas the standard holes with the diameter of $21 \mathrm{~mm}$ were drilled in the webs of beams and girders.

All the girders were initially fabricated with the same end connections as shown in Fig. 2-7. However, the girder-to-column web connection with a two by three bolt hole pattern was found to be less common based on the consultation with practitioners. Hence, the end connections of the W18 $\times 35$ girders framing into the fire test bay columns (Girder-3 and Girder-4 in Fig. 2-3) were modified to use five bolts in a single line (Fig. 2-6), whereas those connecting the W16×26 girders in the surrounding bays were unchanged. 


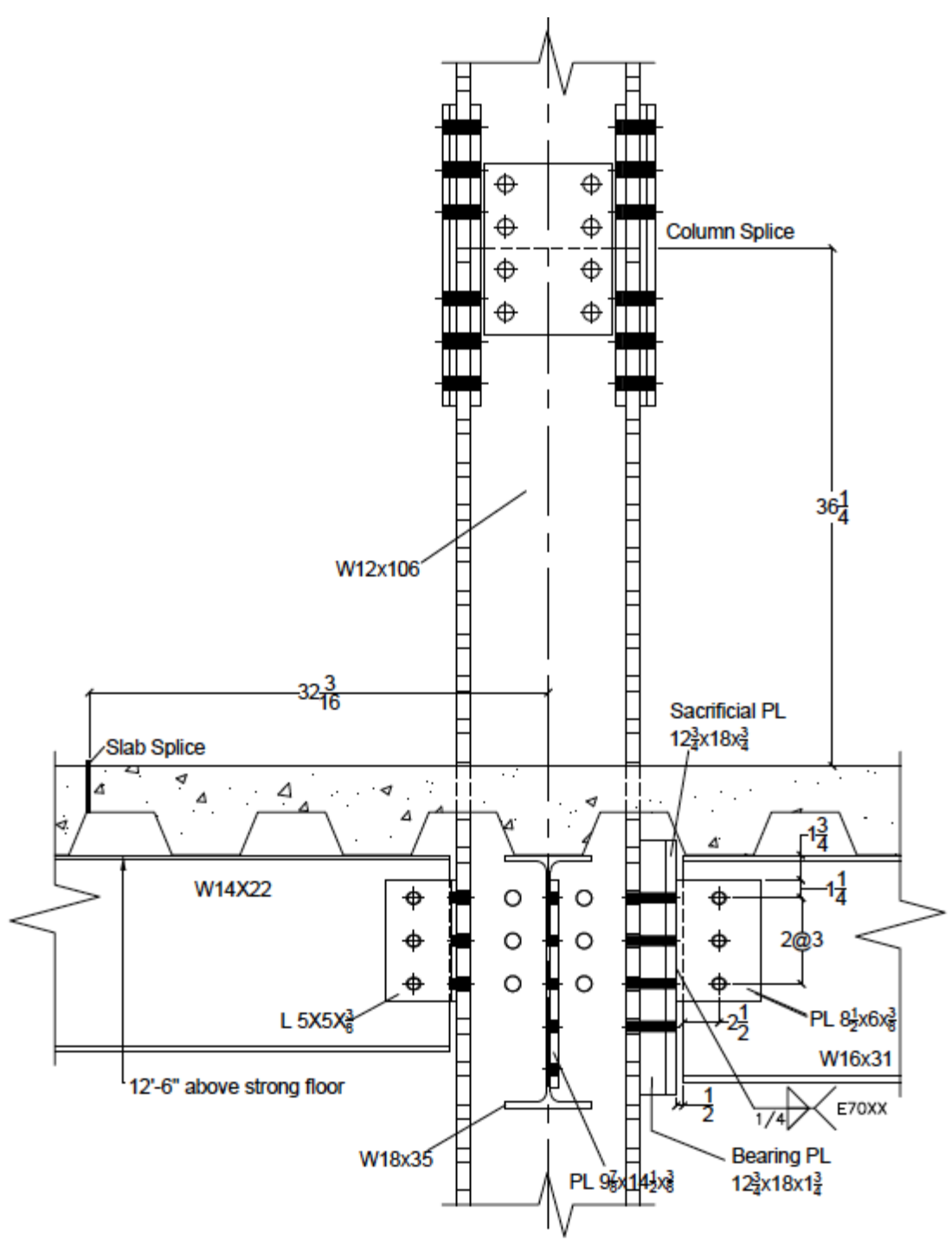

Fig. 2-4. Connection detail of column B2. Units are in inches.

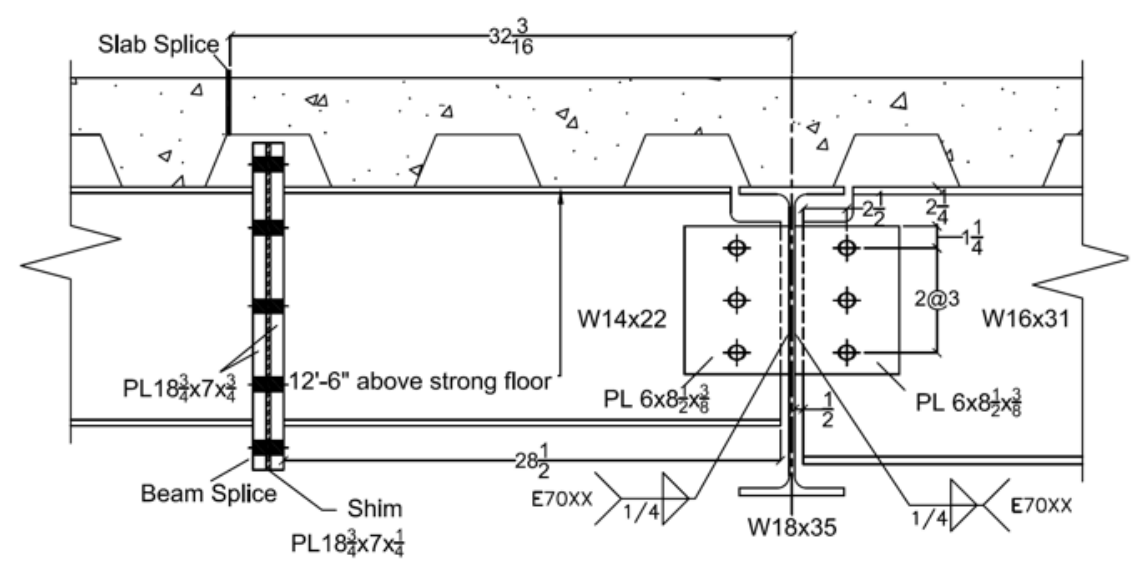

Fig. 2-5. Details of beam-to-girder connection in the test bay. Units are in inches. 

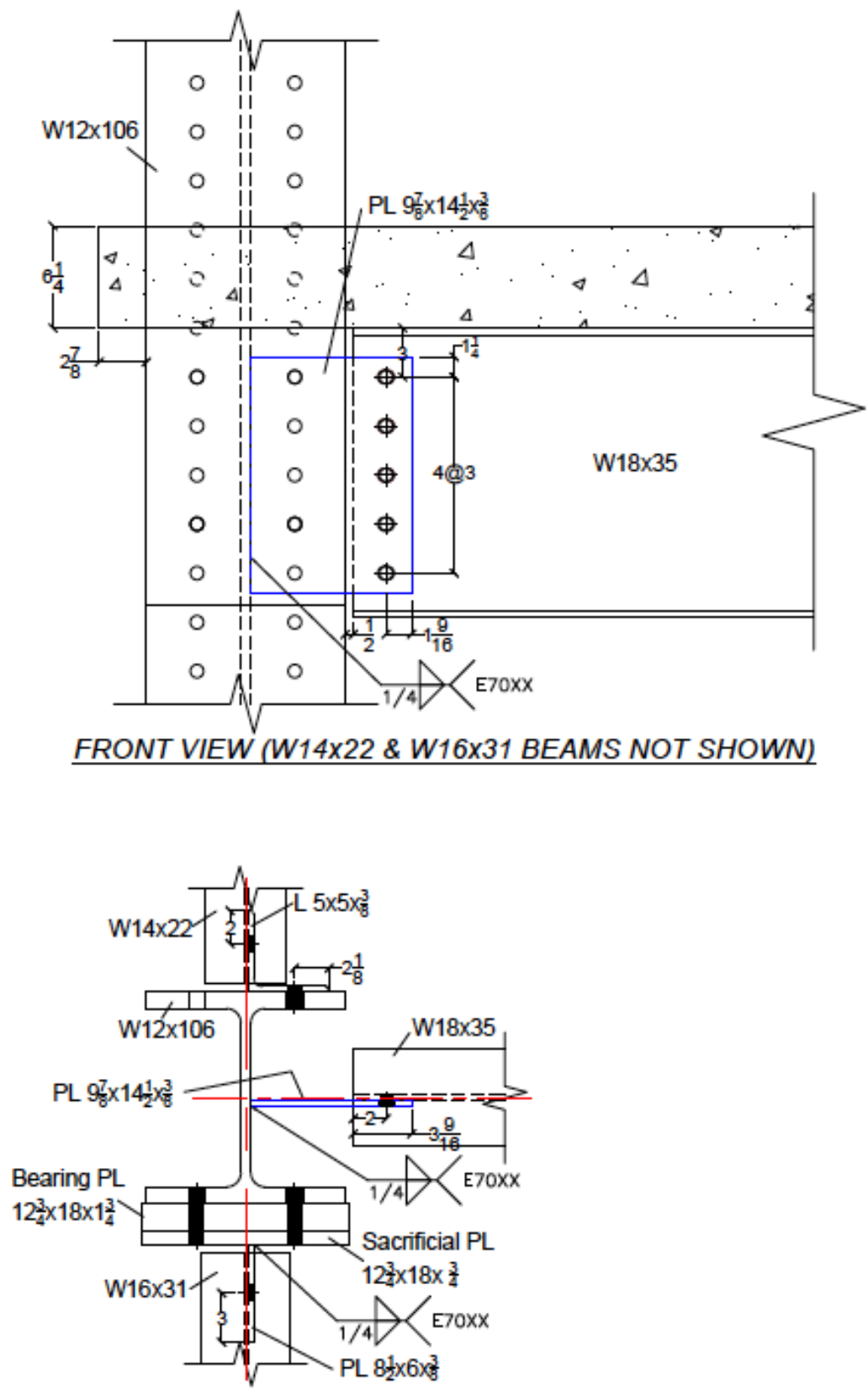

TOP VIEW (CONCRETE SLAB NOT SHOWN)

Fig. 2-6. Connection detail of column C2. Units are in inches. 

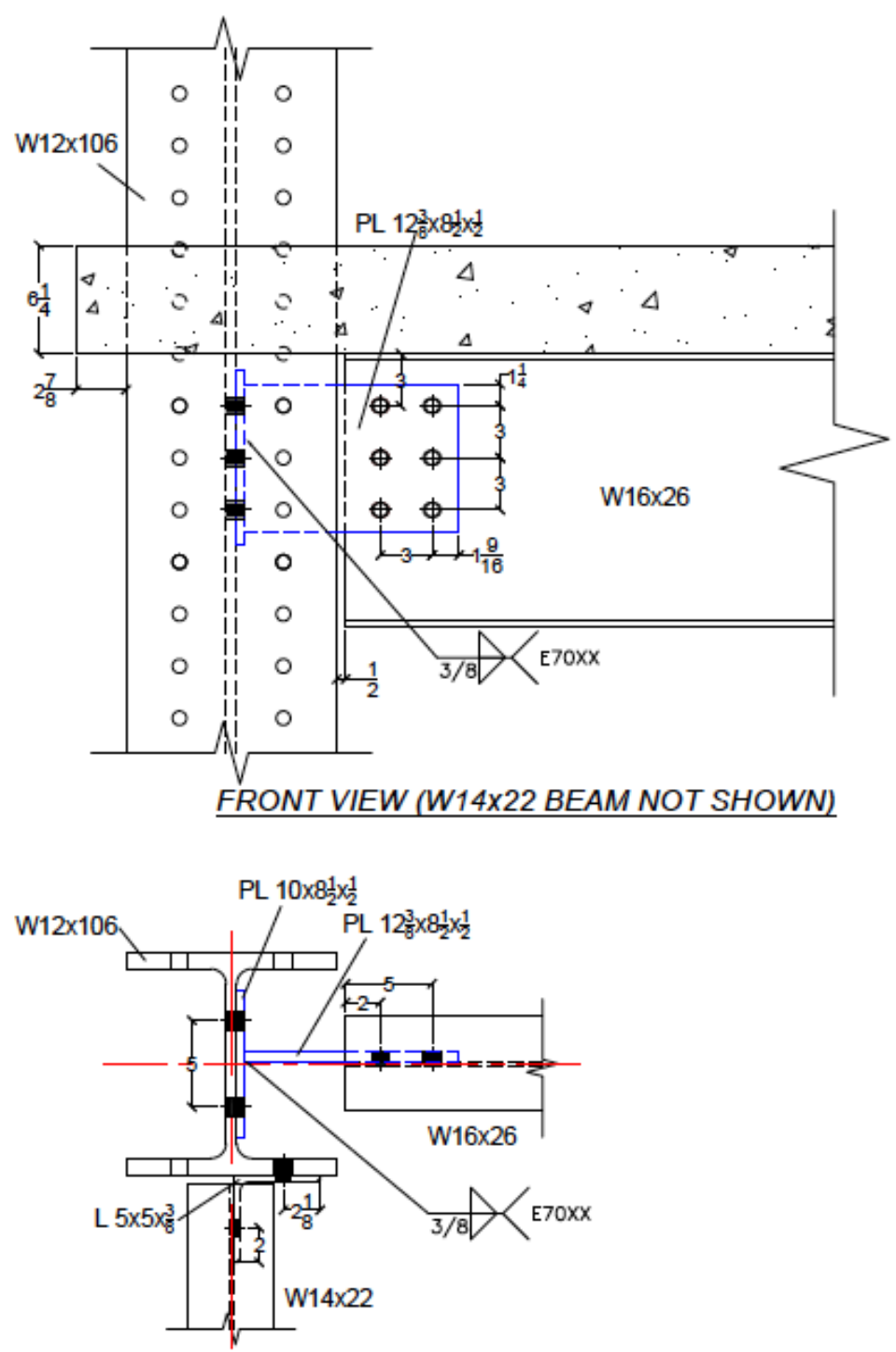

TOP VIEW (CONCRETE SLAB NOT SHOWN)

Fig. 2-7. Connection detail of column $\mathrm{C} 1$. Units are in inches.

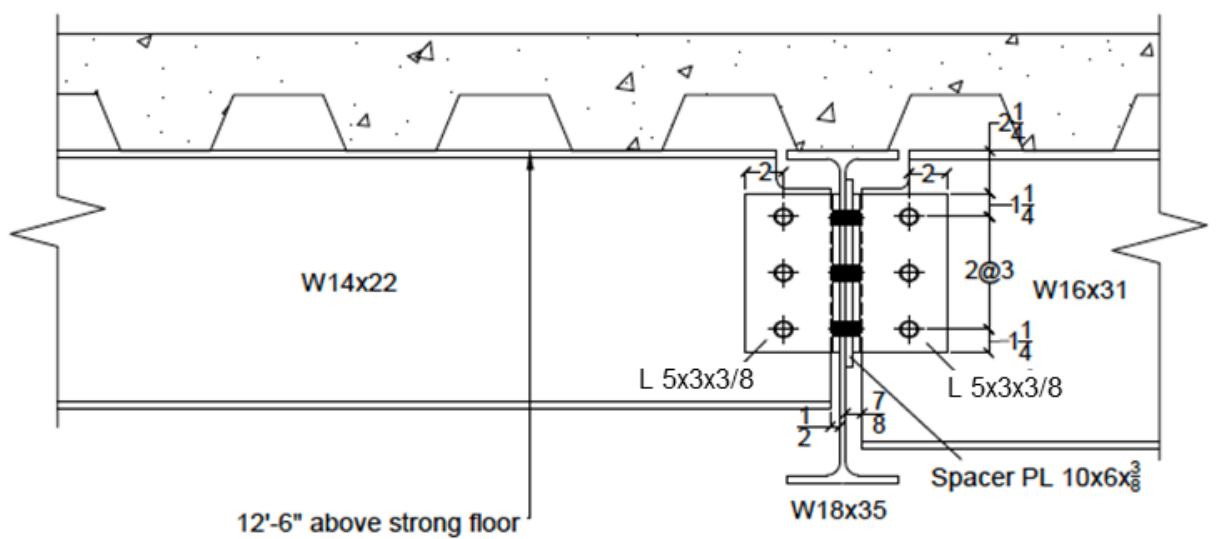

Fig. 2-8. Beam-to-girder connection in the surrounding bay. Units are in inches. 


\subsubsection{Composite Floor}

The cross sections of the composite floor beams and girders are shown in Fig. 2-9. These members were designed as a simply supported composite beam consisting of a steel beam acting compositely with concrete slabs through $19 \mathrm{~mm}$ (3/4 in.) shaft diameter steel headed stud anchors rolled with ASTM A29 (ASTM, 2020) steel.

Degree of composite action ${ }^{1}$ varied by the total number of stud anchors welded on the top flange of each steel beam. The composite beams with W14×22 and W16×31 shapes had headed studs welded at every flute of the steel decking with spacing of $30 \mathrm{~cm}$. This detail provided the design composite action ranging from $40 \%$ to $65 \%$. For the composite girders with $\mathrm{W} 18 \times 35$ and W16×26 shapes, two stud anchors were spaced at $33 \mathrm{~cm}, 35 \mathrm{~cm}$, or $46 \mathrm{~cm}$ (13 in., 14 in., or 18 in.) with the composite action equivalent to $66 \%$. According to the Chapter I Commentary of AISC 360, this design satisfies the condition that headed studs would not reach ductility failure until the designed composite action is achieved at ambient temperature.

The $0.9 \mathrm{~mm}$ (20 ga.) thick galvanized steel decking was selected based on construction loads and

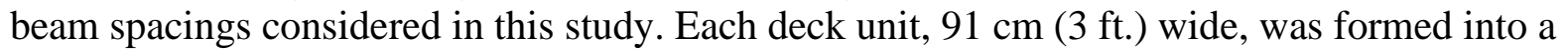
trapezoidal shape with the depth of $7.6 \mathrm{~cm}$ (3 in.). It was placed such that the deck flute was continuous in the north-south direction.

The floor slab was lightweight concrete with the minimum specified compressive concrete strength of $28 \mathrm{MPa}$ (4000 psi). The topping concrete (above top ribs) was $83 \mathrm{~mm}$ (3.25 in.) thick. This was required to achieve the 2-hr fire-resistance rating of a floor assembly with exposed deck according to the latest edition of manufacturer's catalog (www.vulcraft.com).

The welded wire reinforcement, 6×6 W1.4×W1.4 (rolled with ASTM A1064 (ASTM, 2018)); $3.4 \mathrm{~mm}$ diameter plain steel wires in $15 \mathrm{~cm}$ grid) was placed at mid-height of the topping concrete (i.e., $41 \mathrm{~mm}$ from the top surface of concrete) as the minimum required shrinkage reinforcement according to the SDI manual.

\footnotetext{
${ }^{1}$ In structural engineering, composite construction exists when two different materials are bound together so that they act together as a single unit from a structural point of view. When this occurs, it is called composite action. The composite action can be determined by the total shear strength of stud anchors normalized by the lesser of the concrete compressive strength or the yield strength of a steel beam at normal temperature.
} 

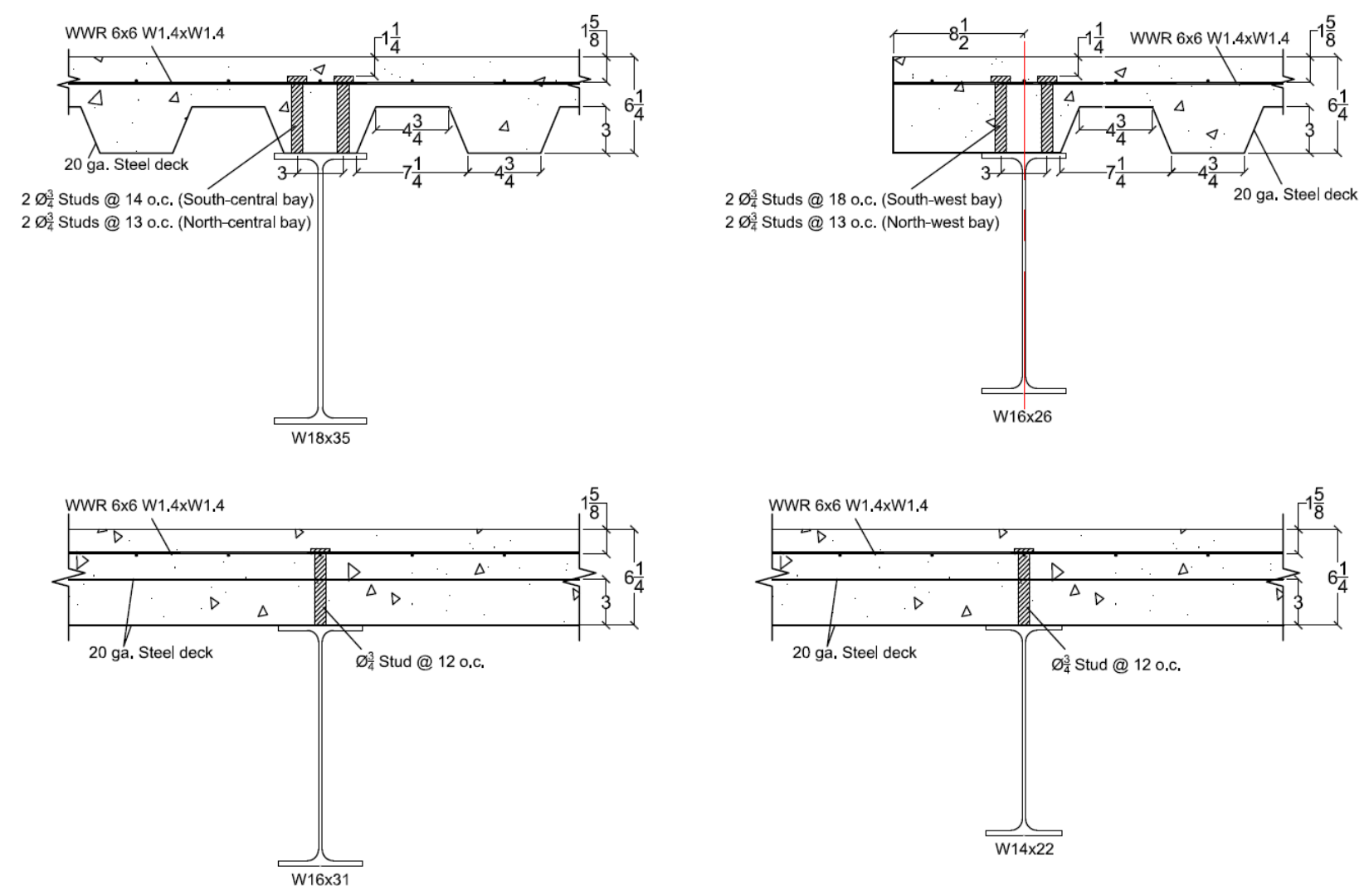

Fig. 2-9. Composite girder and beam sections. Units are in inches.

\subsubsection{Structural Design Summary}

Table 2-2 presents a summary of the calculated demand-to-capacity ratios (DCR) of the composite members, $\mathrm{DCR}_{\text {member, }}$ and connections, $\mathrm{DCR}_{\text {conn, }}$, at ambient temperature. Refer to Fig. 2-3 for labels of the composite members. Required member strengths (demands) were determined from the ASCE 7 load combination of $1.2 \times$ dead load $+1.6 \times$ live load at ambient temperature. Available strengths (capacities) were calculated using appropriate AISC 360 provisions. However, the design calculation indicated that the floor vibration criteria governed the final selection of the steel beams of the composite floor assemblies, subsequently increasing the sizes of steel shapes and decreasing DCR values. For the connections of steel floor framing, the ambient-temperature design was controlled by bolt rupture due to eccentricity of vertical shear forces. As shown in Table 2-2, the value of DCR is approximately 0.5 for the secondary composite beam in the test bay and 0.4 for its shear-tab connections. For the composite members and connections in the surrounding bays, the DCR values range from 0.1 to 0.3 depending upon their tributary area of floor loads.

In the same table, the applied load ratios (LR) used in the fire experiment are listed, denoted as $\mathrm{LR}_{\text {member }}$ for composite members and $\mathrm{LR}_{\text {conn }}$ for their end connections. These values are defined as the ratio of the applied load to the nominal capacity at ambient temperature computed using AISC 360 provisions. A total vertical load, including self-weight of specimen, applied to the test floor assembly was $5.2 \mathrm{kPa}$ (109 psf) based on the ASCE 7 load combination for extraordinary events, i.e., $1.2 \times$ dead load $+0.5 \times$ live load. The mechanical load imposed on the surrounding 
floor slab was $1.2 \mathrm{kPa}$ (26 psf), approximately equivalent to $0.5 \times$ office live load. The steel frame at the second-story level was not loaded. In the test bay, the applied load ratio is approximately 0.3 for the secondary composite beam and 0.2 for the shear-tab connections of the same beam. The applied load ratios are less than 0.2 for the members and connections of the surrounding bays.

Table 2-2. Structural design summary with composite beams or girders in Fig. 2-3.

\begin{tabular}{|c|c|c|c|c|c|}
\hline \multirow{2}{*}{ Composite Member } & \multirow{2}{*}{ End Connection Type } & \multicolumn{2}{|c|}{ Moment } & \multicolumn{2}{|c|}{ Shear } \\
\hline & & DCRmember & LR $R_{\text {member }}$ & DCR conn & $\mathbf{L R}_{\text {conn }}$ \\
\hline Beam-1 (with W14×22) & Single angle & 0.08 & 0.03 & 0.10 & 0.04 \\
\hline Beam-2 (with W14×22) & Single angle & 0.13 & 0.05 & 0.13 & 0.06 \\
\hline Beam-3 (with W14×22) & Single angle & 0.16 & 0.06 & 0.21 & 0.08 \\
\hline Beam-4 (with W14×22) & Single angle & 0.18 & 0.08 & 0.19 & 0.08 \\
\hline Beam-5 (with W14×22) & Single angle & 0.11 & 0.04 & 0.14 & 0.06 \\
\hline Beam-6 (with W16×31) & Single angle & 0.21 & 0.08 & 0.23 & 0.09 \\
\hline Beam-7 (with W16×31) & Single angle & 0.33 & 0.14 & 0.29 & 0.12 \\
\hline Beam-8 (with W16×31)a & Standard shear tab & 0.40 & 0.20 & 0.32 & 0.16 \\
\hline Beam-9 (with W16×31) ${ }^{\mathrm{a}}$ & Standard shear tab & 0.46 & 0.27 & 0.38 & 0.22 \\
\hline Beam-10 (with W16×31) & Standard shear tab & 0.27 & 0.15 & 0.22 & 0.12 \\
\hline Girder-1 (with W16×26) & Extended shear tab & 0.09 & 0.04 & 0.11 & 0.05 \\
\hline Girder-2 (with W16×26) & Extended shear tab & 0.18 & 0.08 & 0.16 & 0.07 \\
\hline Girder-3 (with W18×35) & Extended shear tab & 0.21 & 0.09 & 0.24 & 0.10 \\
\hline Girder-4 (with W18×35) & Extended shear tab & 0.38 & 0.20 & 0.34 & 0.18 \\
\hline
\end{tabular}

a composite members and connections exposed to fire 


\subsubsection{Fire Protection Design}

Fire-exposed steel members and connections were protected with SFRM. The thickness of SFRM was designed to meet the 2-hr fire-resistance rating requirement for Type IB building construction as specified in the IBC. For this study, the selected SFRM product was Southwest Type 5MD, a cementitious gypsum-based material manufactured by Carboline. This material has the minimum density ranging from $240 \mathrm{~kg} / \mathrm{m}^{3}$ to $350 \mathrm{~kg} / \mathrm{m}^{3}$ according to the manufacture's specification. The SFRM application was performed by the manufacturer-approved contractor about 4 months prior to the fire test.

The required SFRM thickness for the 2-hr fire-resistance rating was calculated in accordance with appropriate UL directories, including N791 for the primary beams and girders and D949 for the secondary composite beam. The required thickness and measured thickness of the SFRM are summarized in Table 2-3. The deck flute atop the steel beams or girders was filled with SFRM as specified in the UL directories. The remaining area of the steel deck was left unprotected since the concrete slab had a minimum thickness of $83 \mathrm{~mm}$ to meet the 2-hr fire-resistance rating with exposed deck. The IBC does not specify a fire-resistance rating required for the connection regions. For this study, hence, the SFRM thickness of the connection regions was at least $25 \mathrm{~mm}$, assuming that this region could be over-sprayed due to the SFRM installation of columns. Prior to the fire experiment, the SFRM thickness was measured at more points than those required in the ASTM E605 standard (ASTM, 2019). The results of the SFRM thickness measurements are summarized in Table 2-3. The dry density of the applied SFRM was not measured.

Table 2-3. Design and measured thickness of SFRM.

\begin{tabular}{llll}
\hline Steel Component & UL Design No. & Design Thickness & $\begin{array}{l}\text { Average Measured } \\
\text { Thickness }\end{array}$ \\
\hline W16×31 (north primary beam) & $\mathrm{N} 791$ & $18 \mathrm{~mm}(11 / 16 \mathrm{in})$. & $18 \mathrm{~mm} \pm 15 \%{ }^{*}$ \\
W16×31 (south primary beam) & $\mathrm{N} 791$ & $18 \mathrm{~mm}(11 / 16 \mathrm{in})$. & $19 \mathrm{~mm} \pm 16 \%$ \\
W16×31 (secondary beam) & $\mathrm{D} 949$ & $11 \mathrm{~mm}(7 / 16 \mathrm{in})$. & $13 \mathrm{~mm} \pm 13 \%$ \\
W18×35 (east girder) & $\mathrm{N} 791$ & $18 \mathrm{~mm}(11 / 16 \mathrm{in})$. & $19 \mathrm{~mm} \pm 15 \%$ \\
W18×35 (west girder) & $\mathrm{N} 791$ & $18 \mathrm{~mm}(11 / 16 \mathrm{in})$. & $18 \mathrm{~mm} \pm 15 \%$ \\
$\begin{array}{l}\text { Standard shear tab } \\
\text { (beam connections) }\end{array}$ & - & $25 \mathrm{~mm}(1 \mathrm{in})$. & $28 \mathrm{~mm} \pm 15 \%$ \\
$\begin{array}{l}\text { Extended shear tab } \\
\text { (girder connections) }\end{array}$ & - & $25 \mathrm{~mm}(1 \mathrm{in})$. & $25 \mathrm{~mm} \pm 10 \%$ \\
\hline
\end{tabular}

*The values after \pm symbol are one standard deviation of the thickness measured at 162 discrete points of each member or up to 15 discrete points of each connection region. 


\subsection{Construction of Test Structure}

\subsubsection{Steel Erection}

Fig. 2-10 shows photographs of the first story steel framing and the composite floor soffits at various locations. The 1 st floor steel framing was erected at $380 \mathrm{~cm}(150 \mathrm{in}$.) above the strong floor. The flutes of metal deck units were continuous in the north-south direction, perpendicular to the secondary beams.

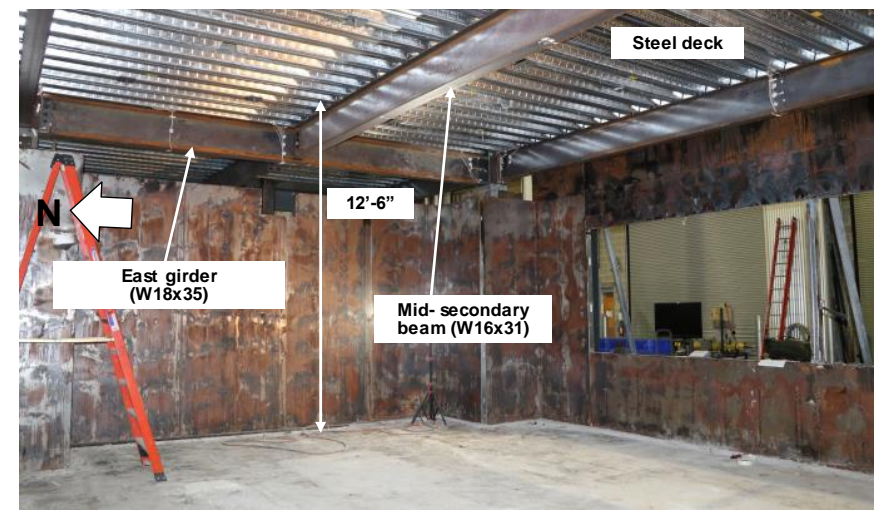

(a)

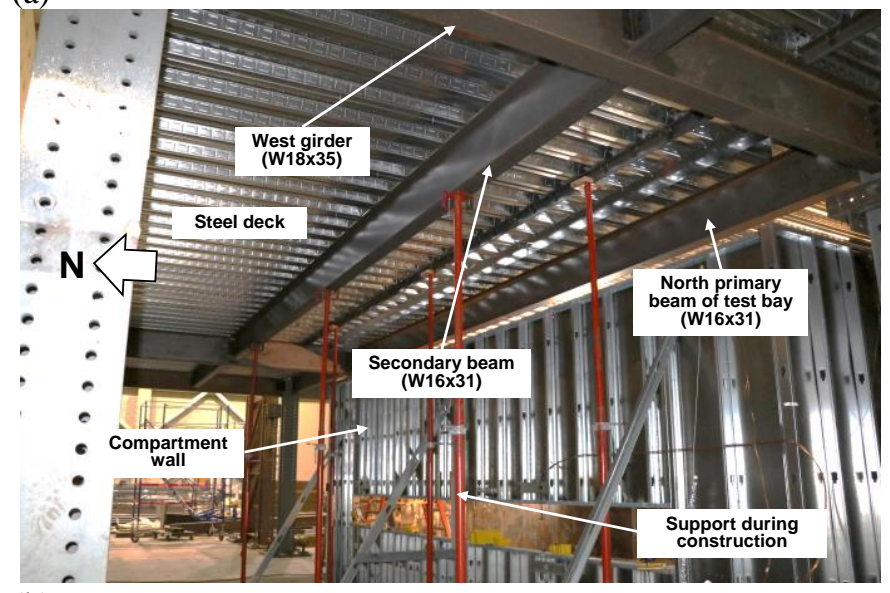

(b)

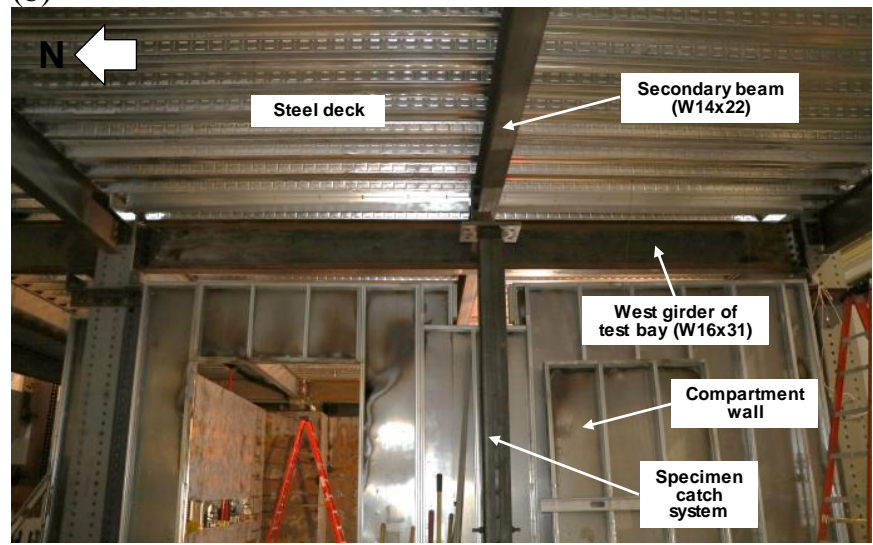

(c)

Fig. 2-10. Steel framing (a) test bay (b) north surrounding bay (c) west surrounding bay. Note that red post shoring was removed prior to fire test. Top of the specimen catch system was $10 \mathrm{~cm}$ below the beam. 
Fig. 2-11 shows photographs of the steel frame connections in the test bay. The shear tab and extended shear tab connections were attached using $6.4 \mathrm{~mm}(0.25 \mathrm{in}$.) size fillet weld with E70 electrodes ( $480 \mathrm{MPa}$ ) and $19.1 \mathrm{~mm}(0.75 \mathrm{in}$.) diameter A325 bolts. The bolts were snug tightened using a wrench to represent a typical bearing-type connection. Refer to Appendix A for assembly drawings.
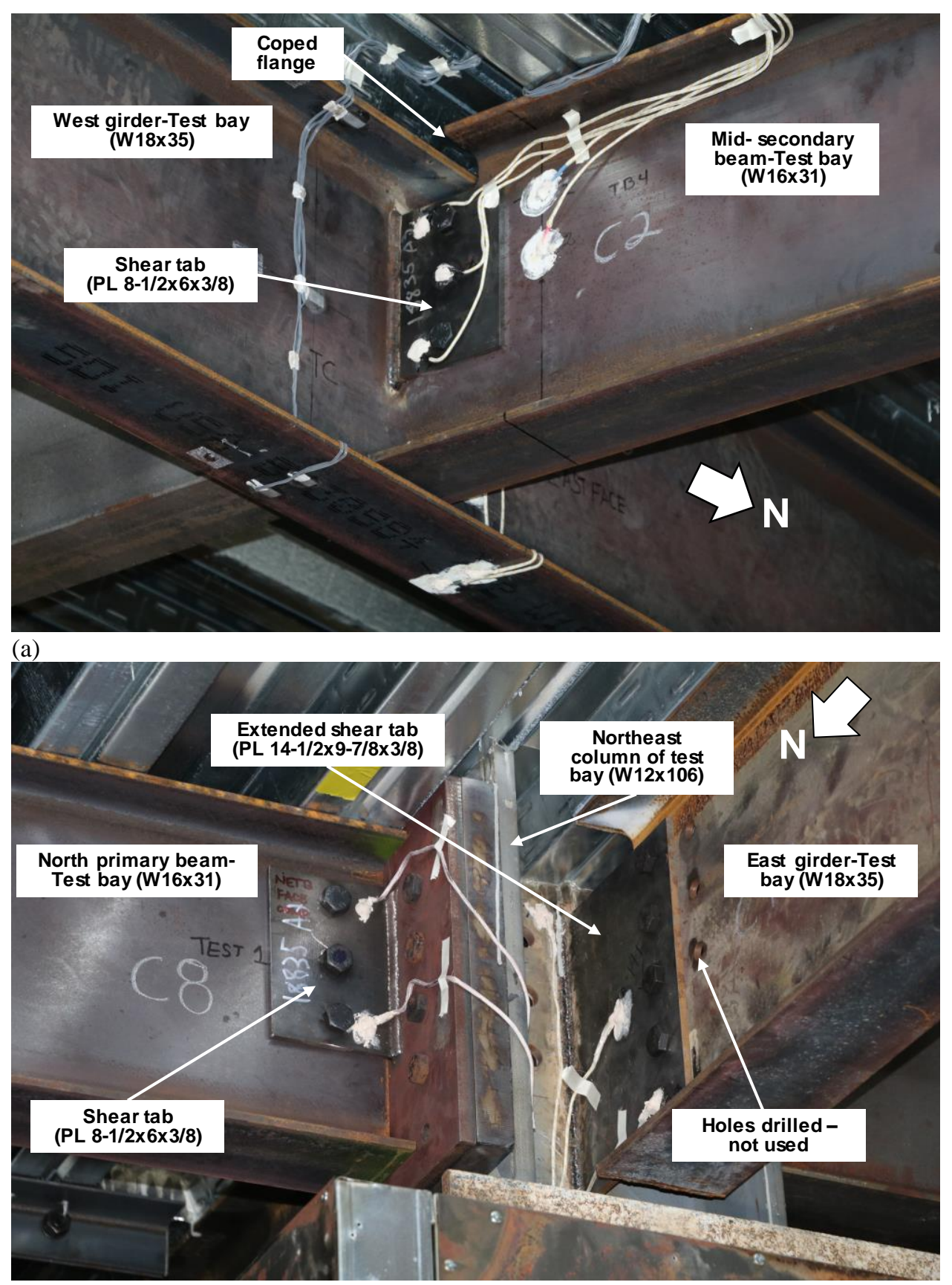

(b)

Fig. 2-11. Steel frame connections in the fire test bay: (a) beam-to-girder connection (b) beam-to-column flange and girder-to-column web connections. 


\subsubsection{Column Splice}

The test bay columns were spliced at $92 \mathrm{~cm}$ ( $3 \mathrm{ft}$.) above the concrete slab to facilitate construction and removal of the composite floor specimen. Fig. 2-12 and Fig. 2-13 show the drawings and photograph of the column splices used in the test structure, respectively. It should be noted that these column splices are not standard splices used for gravity columns as specified in AISC 360. Rather, they were intended to transfer the moment and shear introduced by fire effects. Since the moment and shear demands due to fire effects were unknown prior to the test, the column splice was designed conservatively compared to the typical column splices under normal conditions. The strong-axis and weak-axis moment capacity of the column splice was estimated at $84 \%$ and $94 \%$ of the nominal plastic moment capacity of the column, respectively. Similarly, its strong-axis and weak-axis shear capacity was equals to $68 \%$ and $66 \%$ of the nominal shear capacity of the column, respectively.

The nominal plastic moment capacity was equal to $F_{y} \times Z_{x}$ or $F_{y} \times Z_{y}$, where $F_{y}=$ specified minimum yield stress, $Z_{x}=$ plastic section modulus about the strong axis, and $Z_{y}=$ plastic section modulus about the weak axis. The nominal shear capacity was equal to $0.6 \times F_{y} \times A_{w}$, where, $A_{w}=d \times t_{w}$ in the strong axis or $A_{w}=2 \times b_{f} \times t_{f}$ in the weak axis, $d=$ depth of section, $t_{w}$ $=$ thickness of web, $b_{f}=$ flange width, and $t_{f}=$ thickness of flange.

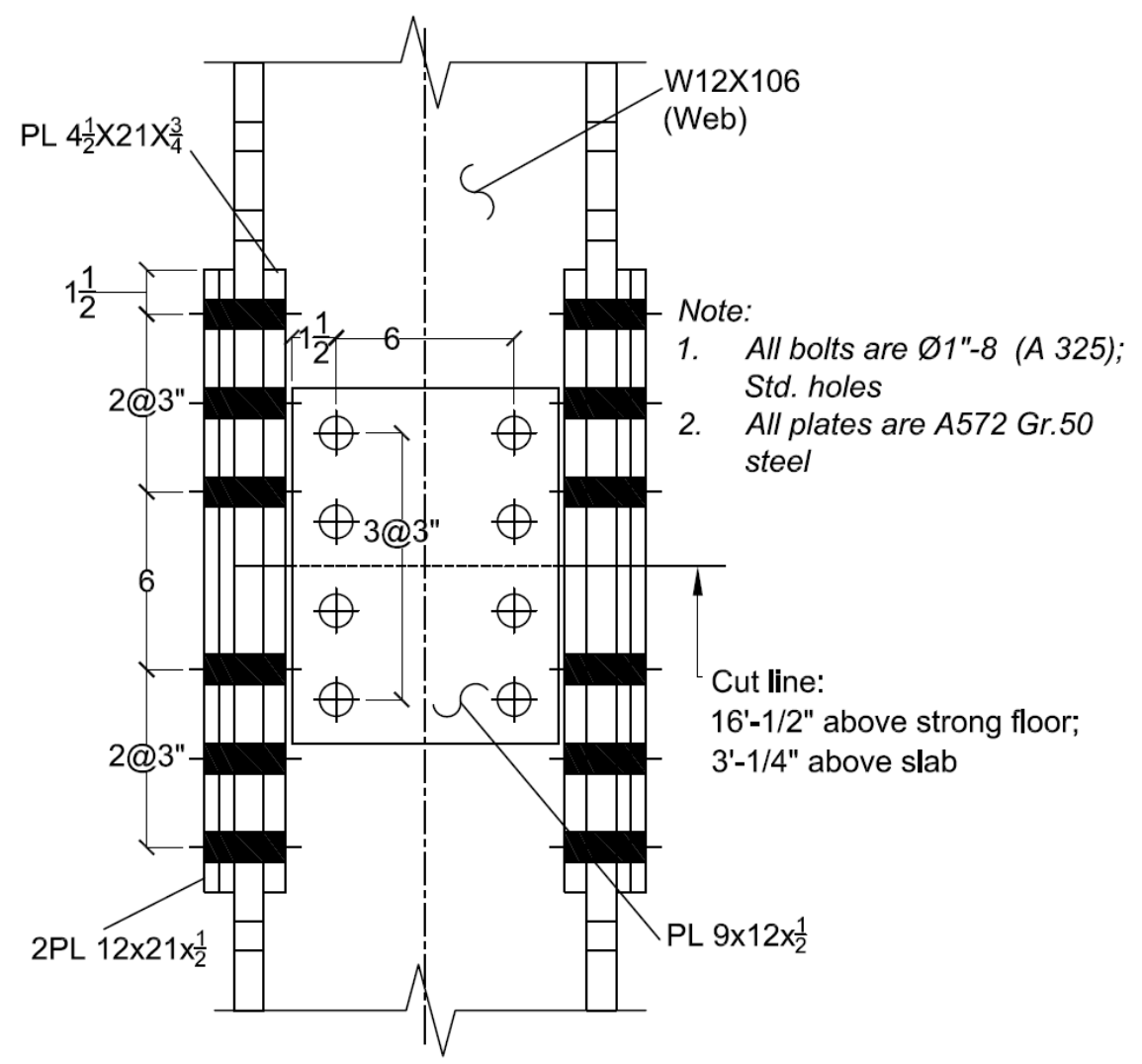

(a) 


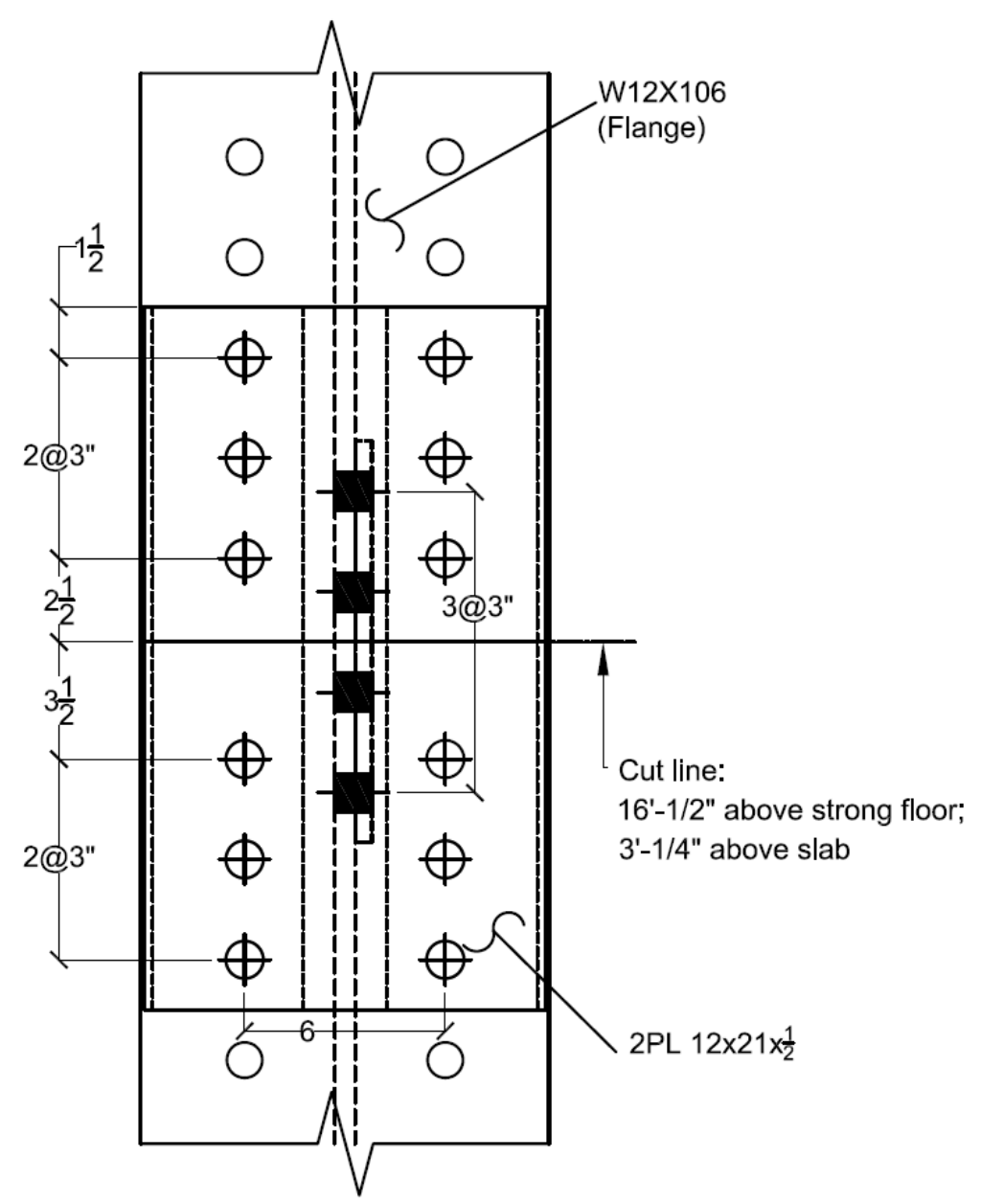

(b)

Fig. 2-12. Column splice (a) front view (b) side view (unit = inch).

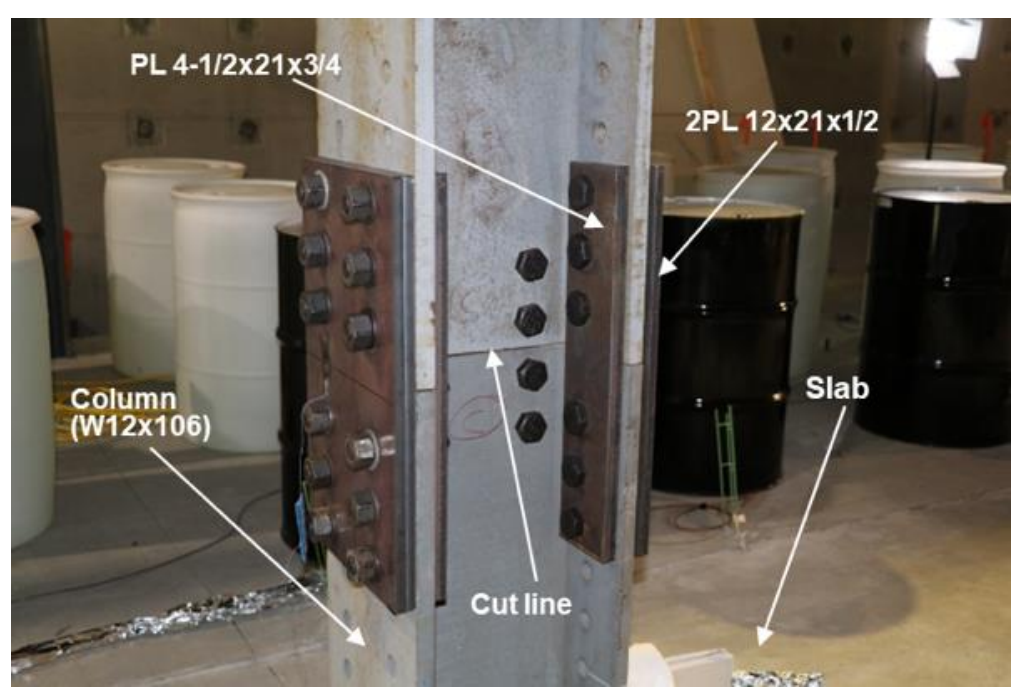

Fig. 2-13. Column splice - Northeast column of test bay (unit = inch). 


\subsubsection{Column Support Conditions}

The support column was fabricated with a W12×106 shape and a $5 \mathrm{~cm} \mathrm{(2} \mathrm{in.)} \mathrm{thick} \mathrm{plate} \mathrm{welded}$ at its base, as shown in Fig. 2-14. The base of the column was anchored to the strong floor by tensioning $35 \mathrm{~mm}$ (1-3/8 in.) diameter high strength steel bars, with a total tension force of $445 \mathrm{kN}$ (100 kip). The anchor points on the strong floor were situated in a $61 \mathrm{~cm} \times 61 \mathrm{~cm}(24 \mathrm{in}$. $\times 24$ in.) grid. It should be noted that the southeast column of the test bay was anchored differently due to damage in one of the anchor holes. As shown in Fig. 2-14b, a hollow structural section (HSS) $6 \times 6 \times 1 / 2$ shape was bolted to top of the base plate over its southeast corner. The ends of this HSS shape were then anchored to the strong floor using the same bars tensioned to $222 \mathrm{kN}$ (50 kip) force each.
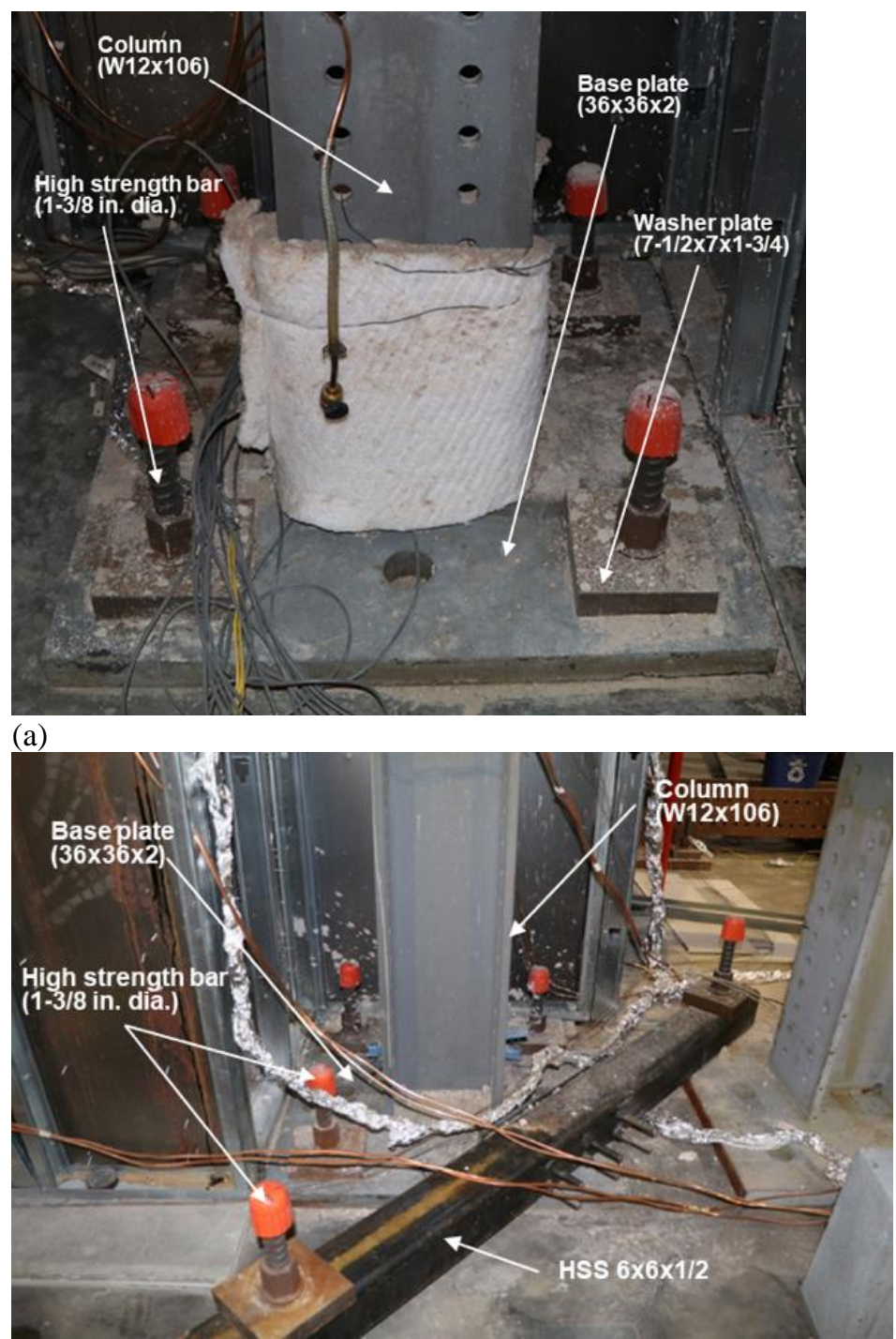

(b)

Fig. 2-14. Column support conditions: (a) typical; (b) modified at the southeast column of test bay. (unit = inch). 


\subsubsection{Beam Splice}

Some portion of the $\mathrm{W} 14 \times 22$ secondary beams framing into the test-bay girders were spliced in order to reuse the surrounding bays for the subsequent tests (Fig. 2-5). A detailed drawing and photograph of the beam splice are shown in Fig. 2-15 and Fig. 2-16, respectively. The slip critical bolted connection was used between the connected steel surfaces as all bolts were tightened by following a turn-of-nut method to achieve the minimum bolt pretension specified in AISC 360. The moment and shear capacities of the beam splice were designed to be equal to 100 $\%$ and $93 \%$ of the plastic moment capacity $\left(F_{y} \times Z_{x}\right)$ and shear capacity $\left(0.6 \times F_{y} \times d \times t_{w}\right)$ of the $\mathrm{W} 14 \times 22$ beam, respectively.

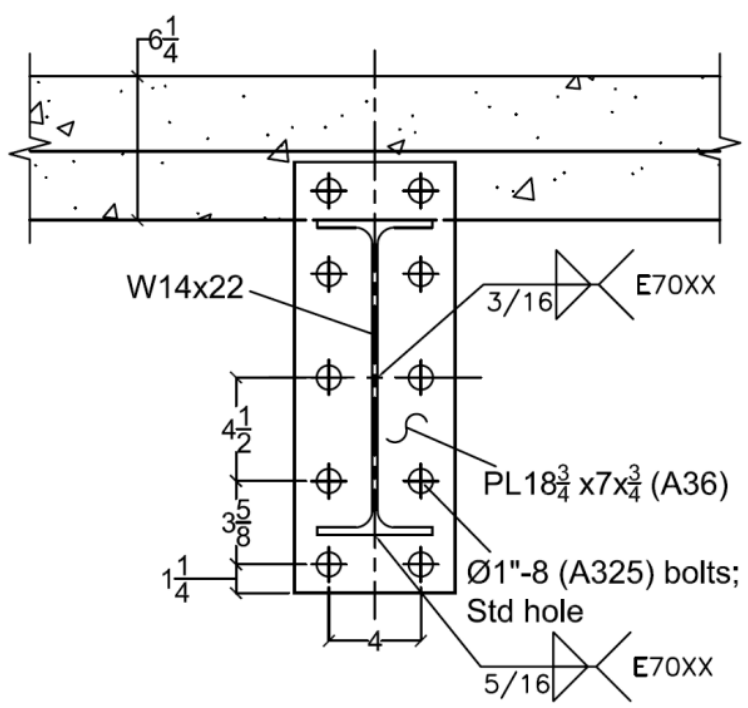

Fig. 2-15. Beam splice in the surrounding bay - side view (unit $=$ inch).

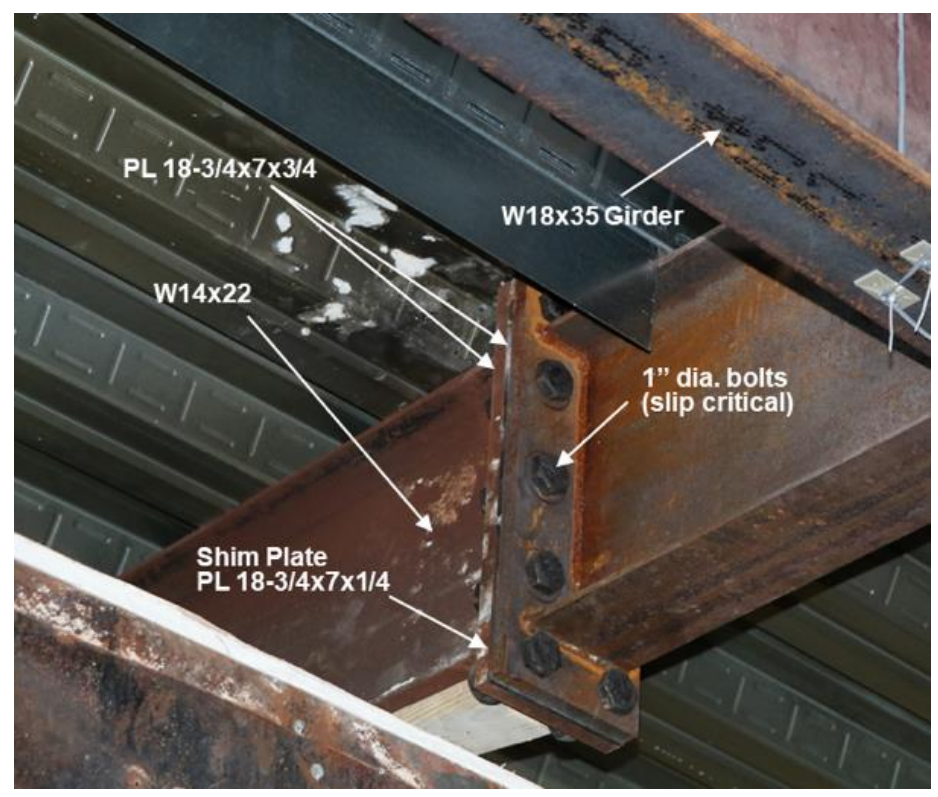

Fig. 2-16. Beam splice in the surrounding bay $($ unit $=$ inch $)$. 


\subsubsection{Composite Floor Formwork}

The formwork of the test bay slab with the steel reinforcement is shown in Fig. 2-17. Details of the installation of steel deck units, headed studs, slab splices, and steel reinforcement in the concrete slab are described in the following subsections.

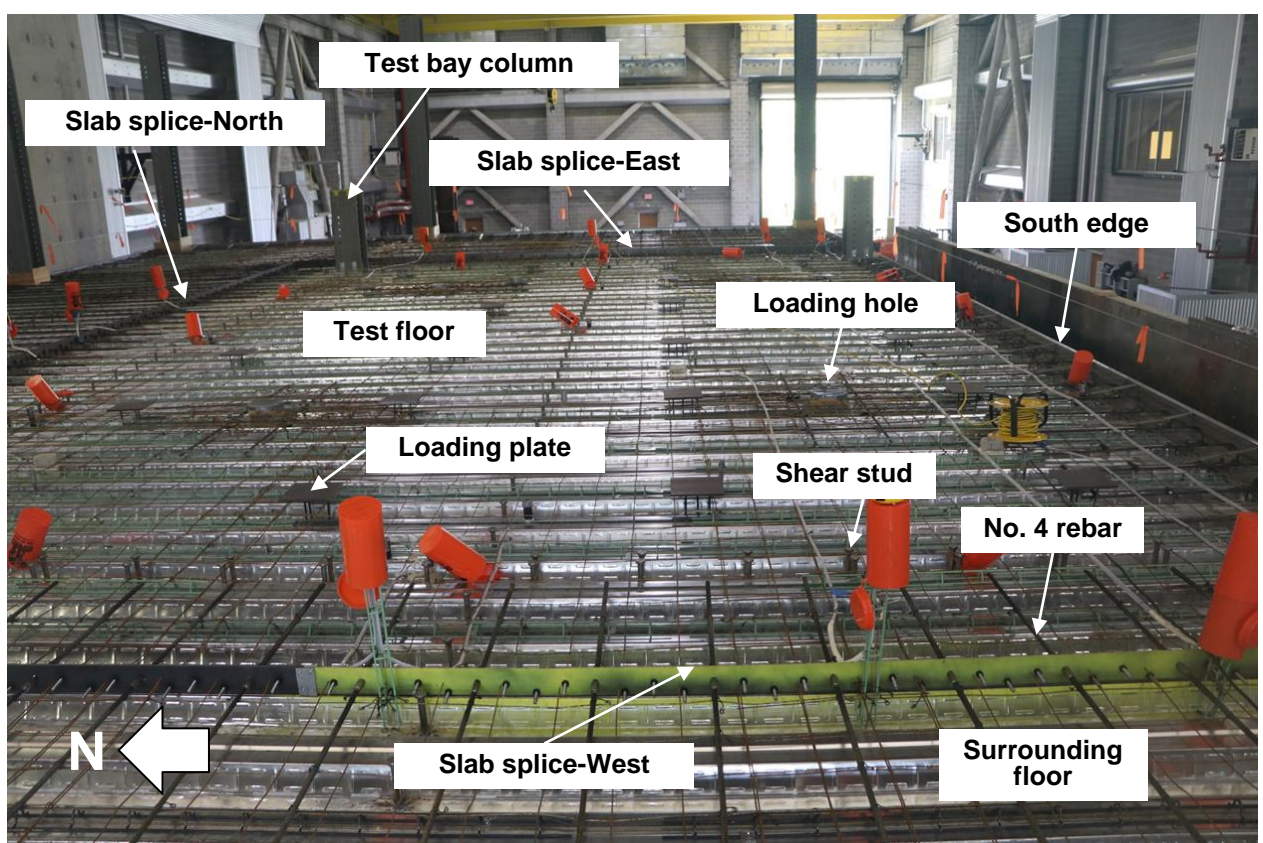

Fig. 2-17. Concrete slab formwork above the fire test compartment.

\subsubsection{Steel Deck Attachment}

The $91 \mathrm{~cm}(3 \mathrm{ft})$ wide steel deck units were attached to the top of the steel beams and girders using \#10 (5 mm) diameter fasteners. These fasteners were spaced $30.5 \mathrm{~cm}(1 \mathrm{ft}$.) along the perimeter beams and spaced $61 \mathrm{~cm}(2 \mathrm{ft}$.) along the interior beams. In most places, steel deck units were joined side by side using $6.4 \mathrm{~mm}(0.25 \mathrm{in}$.) diameter fasteners spaced $61 \mathrm{~cm}$ along the deck seams. The steel deck unit placed in the center of the test bay was $61 \mathrm{~cm}$ wide and joined to the adjacent deck units using $6.4 \mathrm{~mm}$ diameter fasteners spaced $15.3 \mathrm{~cm}$ (6 in.). Pour stops (Fig. 2-18) were attached to the exterior beams and girders using \#10 fasteners at a spacing of 30.5 $\mathrm{cm}$.

After the steel decking was installed, $1.9 \mathrm{~cm}(0.75 \mathrm{in}$.) headed stud anchors were welded to the top flanges of the steel beams and girders, directly burnt through the steel decking. The installed studs were $12.7 \mathrm{~cm}(5 \mathrm{in}$.) tall. The spacing of studs varied with the beam sizes as described in Sect. 2.1.3. Studs used for the composite beams were installed in so-called "strong" positions as specified in AISC 360 . They were welded $2.5 \mathrm{~cm}$ (1 in.) away from the center of the deck valley placed on top of the beams. For the interior primary beams in the east and west surrounding bays (Beam-3 in Fig. 2-3) where the ends of deck pans were placed, studs were welded on alternating sides of the deck butt joint in a staggered pattern as shown in Fig. 2-18. 


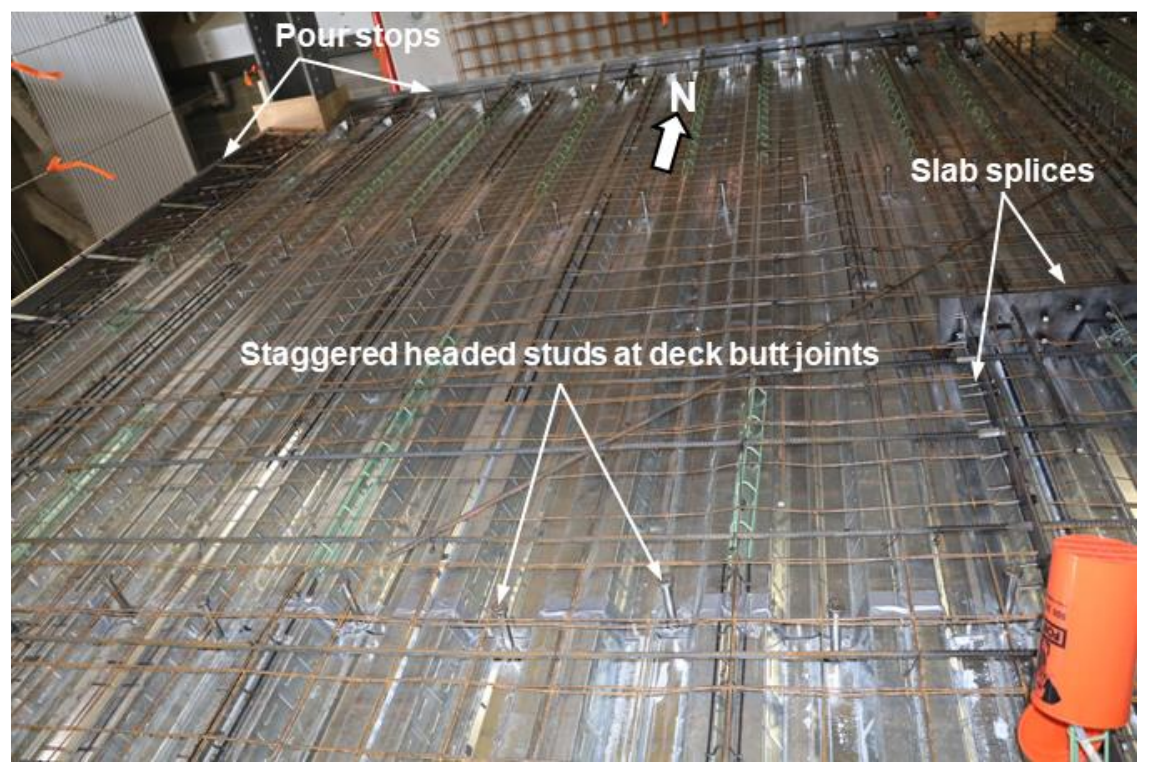

Fig. 2-18. Concrete slab formwork in the surrounding bays

\subsubsection{Slab Splice}

Photographs and scale drawings of the slab splices are shown in Fig. 2-19 and Fig. 2-20, respectively. The $63.5 \mathrm{~cm}$ (25 in.) long No. 4 steel reinforcing bars (12.7 $\mathrm{mm}$ in diameter) were spaced every $30.5 \mathrm{~cm}$ on top of the welded wire reinforcement as non-contact splices where a single bar was placed between two $3.4 \mathrm{~mm}$ diameter steel wires. The bars were continuous through the surrounding bays. Steel bolts $(9.5 \mathrm{~mm}$ in diameter and $76 \mathrm{~mm}$ in length) were mounted on the splice plate to increase the friction between the plate and the concrete. The splices were designed to carry a bending moment equivalent to the moment capacity of the full wire reinforced concrete sections per ACI 318. However, this detail only permits $21 \%$ of the vertical shear capacity of the full concrete section along the north edge and $31 \%$ along the east or west edge. The calculated shear capacity was approximately 1.5 times greater than the shear demand from the ambient gravity load combination $(1.2 \times$ dead load $+1.6 \times$ live load $)$.

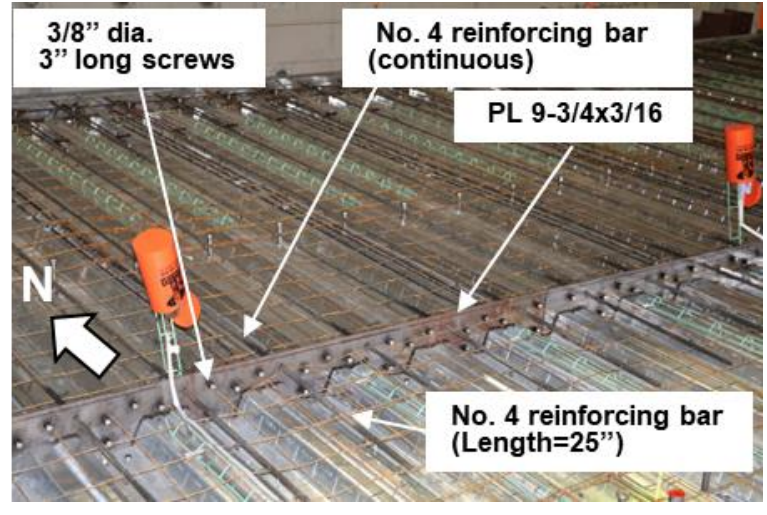

(a)

Fig. 2-19. Slab splice (a) west or east side (b) north side.

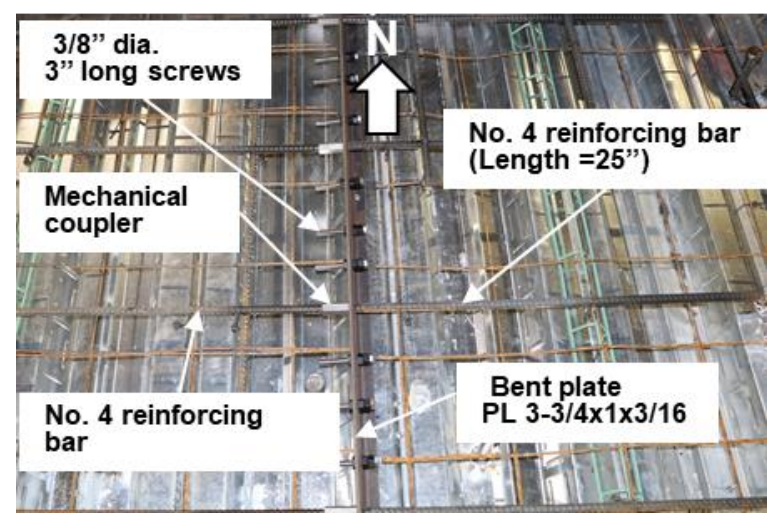

(b) 

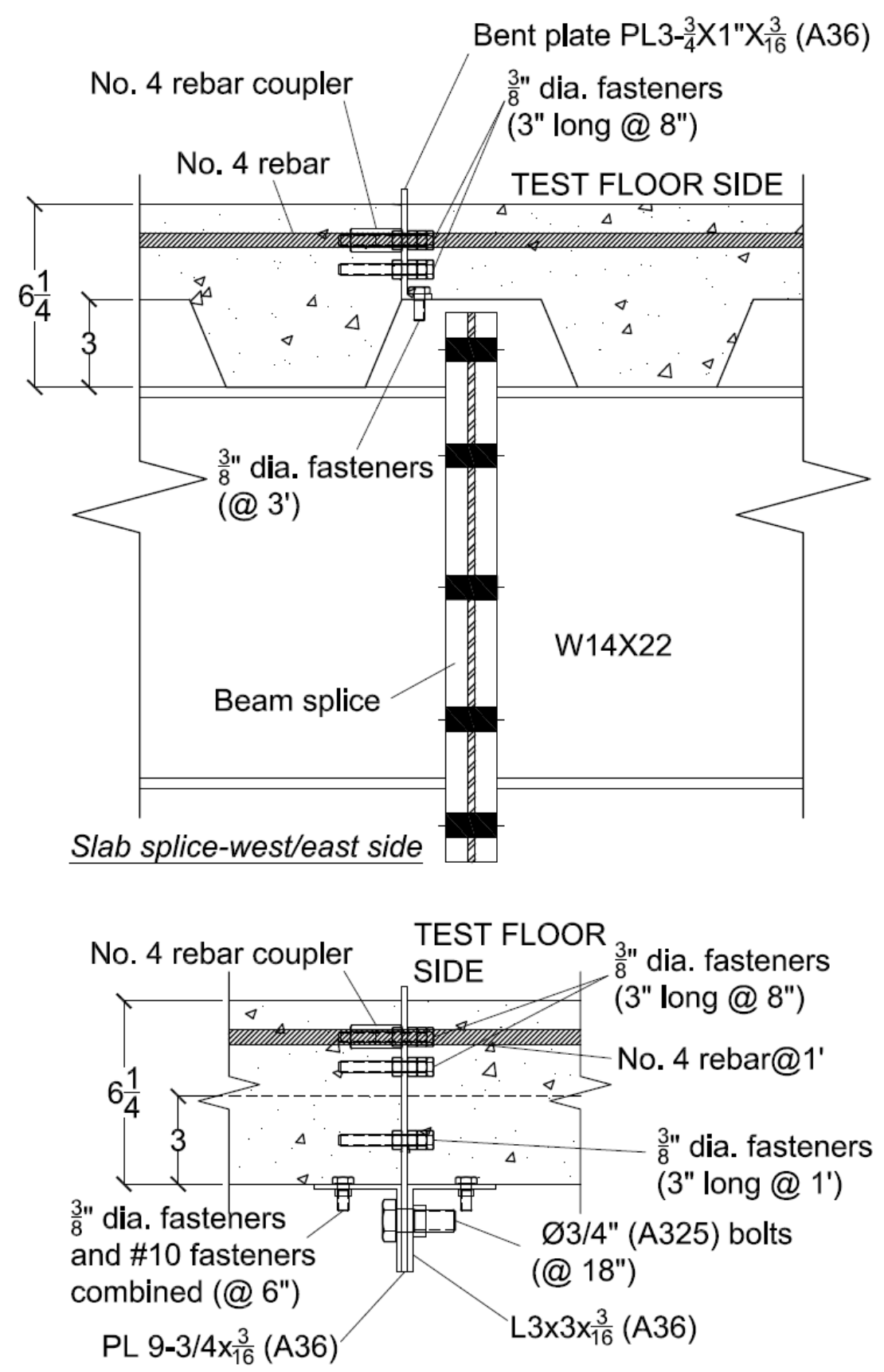

Slab splice-north side

Fig. 2-20. Scale drawings of slab splices (unit = inch). 


\subsubsection{Slab Reinforcement}

The welded wire reinforcement (WWR) was chosen as the primary steel reinforcement to control shrinkage and temperature induced cracks during curing of the cast-in-place concrete slab. The selected type was $6 \times 6 \mathrm{~W} 1.4 \times \mathrm{W} 1.4$ mesh mats, $6.1 \mathrm{~m}(20 \mathrm{ft})$ long and $2.4 \mathrm{~m}(8 \mathrm{ft})$ wide each. They were placed on $38 \mathrm{~mm}$ (1.5 in.) tall slab bolsters (chairs) attached to top of the steel deck in the north-south direction. The bottom wire was continuous in the east-west direction, and the top wire was in the north-south direction. The edges of each WWR mat had an overlap of $0.46 \mathrm{~m}$ (18 in.) with the adjacent mats. This overlap met the minimum required splice length of $0.34 \mathrm{~m}$ (13 in.) in accordance with ACI 318-14 (ACI, 2014).

Additional No. 4 steel reinforcing bars, with 180-degree hooks at one of the ends, were placed in the slab formwork above the edge beams or girders on the first floor of the test building, as shown in Fig. 2-21 and Fig. 2-22. These bars were positioned perpendicular to the edge beams or girder. The bar length was approximately $77 \mathrm{~cm}$ and $67 \mathrm{~cm}$ from the longitudinal centerlines of the steel beams or girders in the south side and in the remaining three sides, respectively. The 180-degree hooks were slanted such that the bars were positioned below the head of stud anchors welded on top of the edge beams or girders. It should be noted that this slab edge detail is not necessarily a representative of that commonly used in construction practice in the United States. Rather, these bars were intended to delay or prevent the separation of the concrete slab from the south edge beam in the test bay when exposed to fire.

Fig. 2-23 shows the steel reinforcement around the slab penetration holes (19.4 $\mathrm{cm}$ in diameter) used for the water-cooled loading tubes connected between the loading frame above the slab and the actuators at the basement. As shown, the two WWR mats, $91 \mathrm{~cm}$ by $91 \mathrm{~cm}(3 \mathrm{ft}$. by $3 \mathrm{ft}$.) were placed on top of each other, together with two $1.5 \mathrm{~m}$ long No. 4 bars in each orthogonal direction.

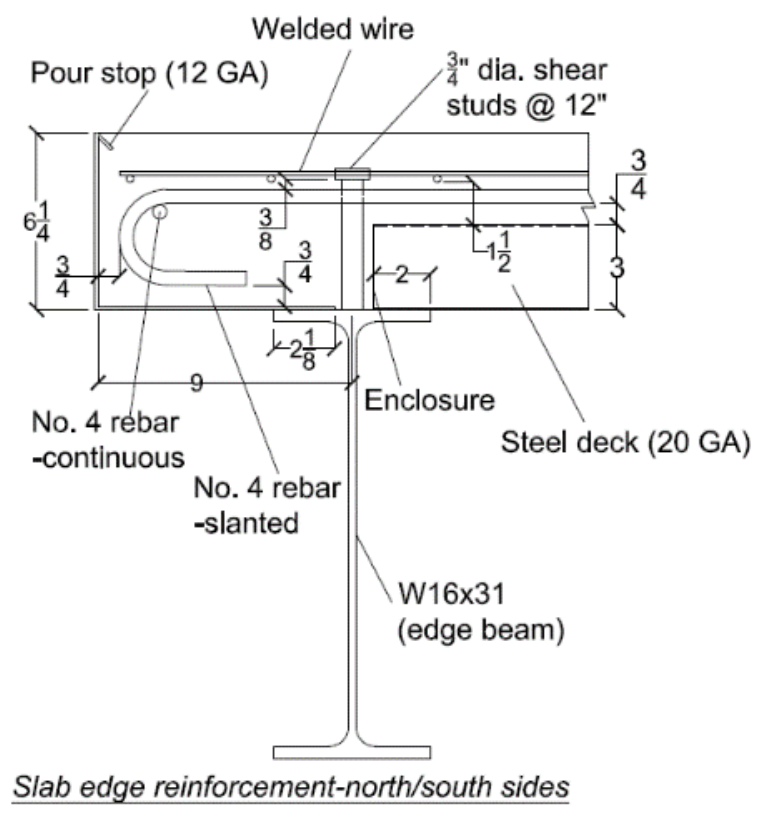

Fig. 2-21. Slab edge reinforcement $($ unit $=$ inch $)$.

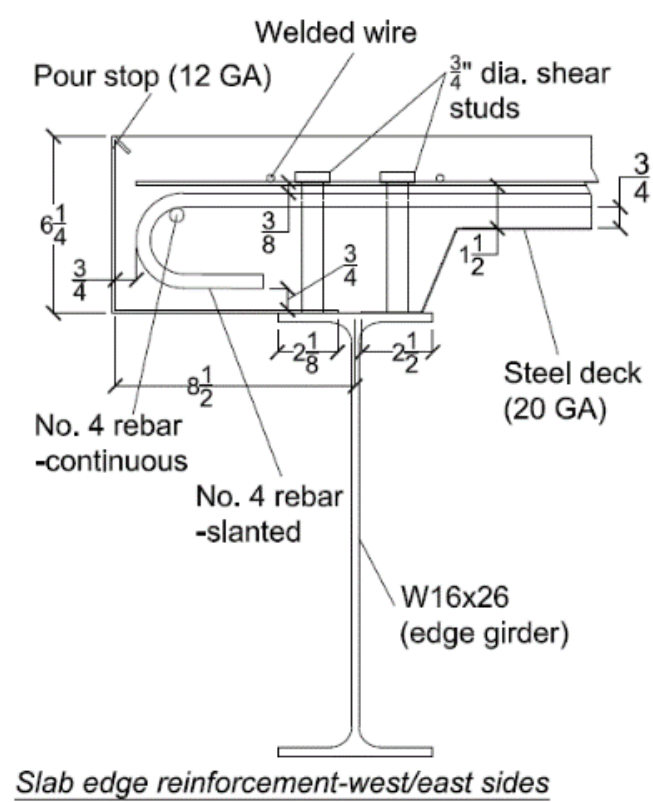




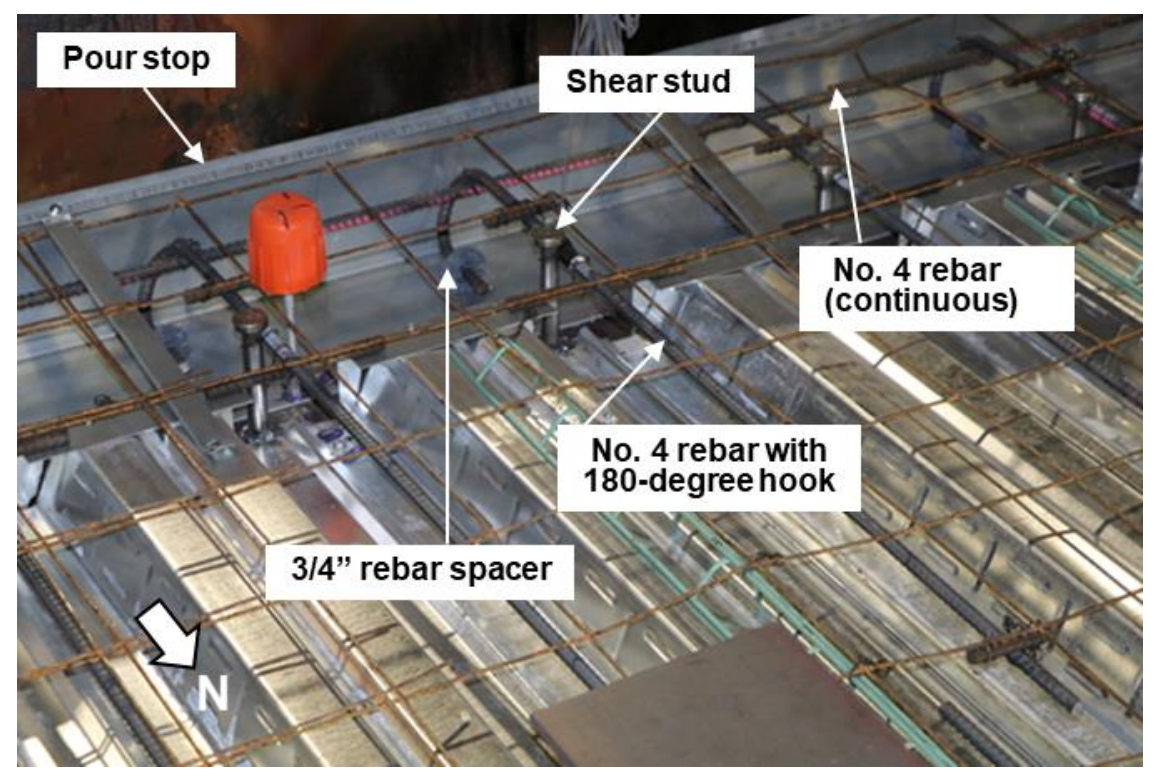

Fig. 2-22. Slab edge reinforcement at south edge.

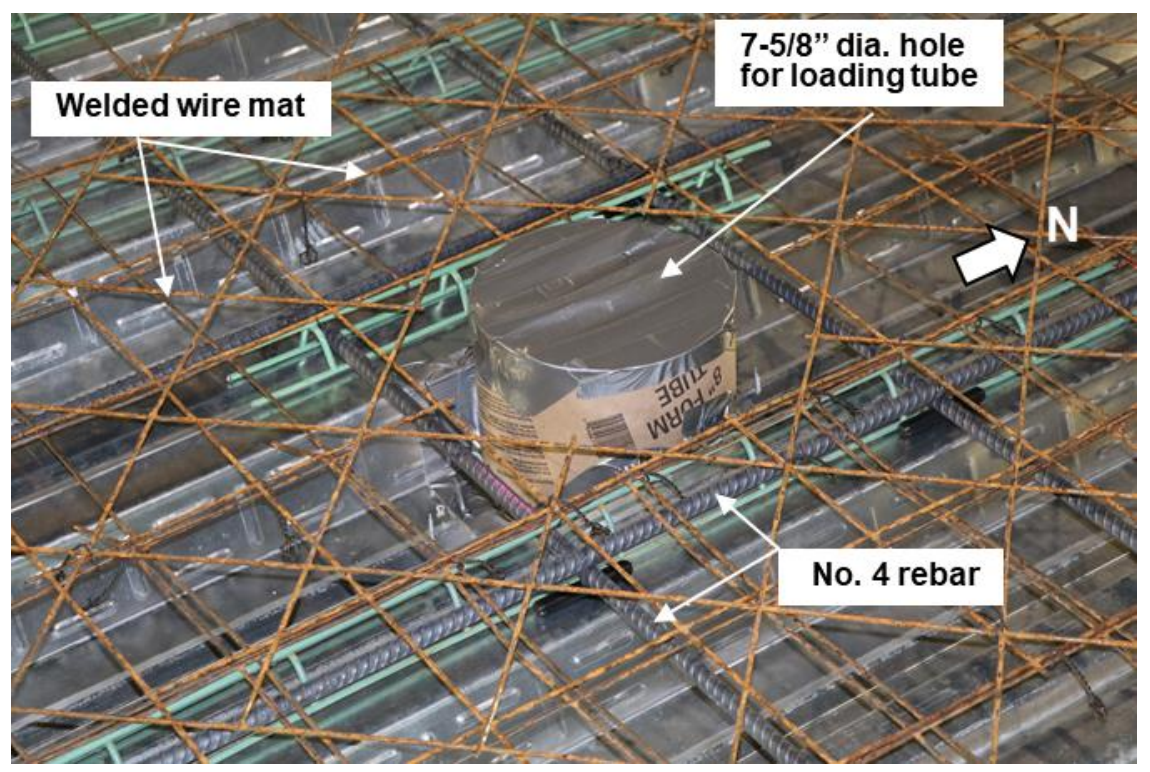

Fig. 2-23. Reinforcement details around slab penetration holes. 


\subsubsection{Concrete Placement and Curing}

\subsubsection{Mixture Design}

The concrete mixture was designed to provide a lightweight aggregate concrete with hardened mechanical properties typical of those used in current construction practice, but with a low propensity for fire-induced spalling. To reduce the likelihood of spalling, $2.37 \mathrm{~kg} / \mathrm{m}^{3}\left(4 \mathrm{lb} / \mathrm{yd}^{3}\right)$ of monofilament polypropylene microfibers were used in the mix (Maluk et al., 2017). To further reduce the chance of fire-induced spalling, expanded slate lightweight aggregate with low waterretention characteristics and high desorption was selected as suggested in Pour-Ghaz et al (2012), to expedite the reduction of moisture in the concrete during curing. The concrete design mixture proportion are provided in Table 2-4.

Table 2-4. Concrete design mixture proportions.

\begin{tabular}{|c|c|c|c|}
\hline & $\begin{array}{l}\text { water/cement: } \\
0.41 \\
\end{array}$ & $\begin{array}{l}\text { Slump: } 14.0 \pm 2.5 \mathrm{~cm} \\
(5.5 \pm 1.0 \text { in. })\end{array}$ \\
\hline \multicolumn{2}{|r|}{ Material } & $\begin{array}{l}\text { Surface Saturated } \\
\text { Dry, kg (lb) }\end{array}$ & Volume, $\mathrm{m}^{3}\left(\mathrm{ft}^{3}\right)$ \\
\hline Cement: & ASTM C-150: Type I/II Lehigh & $254(560)$ & $0.081(2.85)$ \\
\hline Fly Ash: & $\begin{array}{l}\text { ASTM C-618: Separation Technologies } \\
\text { Class F }\end{array}$ & $64(140)$ & $0.025(0.89)$ \\
\hline Aggregate: & ASTM C-33: Carolina Stalite LTWT & $404(890)$ & $0.269(9.51)$ \\
\hline Sand: & ASTM C-33: Chaney Sand & $622(1372)$ & $0.240(8.46)$ \\
\hline Air: & $2.5 \%$ & - & $0.019(0.67)$ \\
\hline Water: & ASTM C-1602; ASTM C-1603 & $129(284)$ & $0.129(4.55)$ \\
\hline \multirow[t]{4}{*}{ Admixture: } & See details below & $5(10)$ & $0.002(0.07)$ \\
\hline & Total & $1477(3256)$ & $0.765(27.00)$ \\
\hline & Unit Weight $\mathrm{kg} / \mathrm{m}^{3}$ (pcf) & $1932(120.6)$ & \\
\hline & $\begin{array}{l}\text { Calculated Equilibrium Dry Density } \\
\mathrm{kg} / \mathrm{m}^{3} \text { (pcf) }\end{array}$ & $1853(115.7)$ & \\
\hline \multicolumn{4}{|l|}{$\underline{\text { Admixtures }}$} \\
\hline \multicolumn{4}{|c|}{ FRC MONO-150 - $2.37 \mathrm{~kg} / \mathrm{m}^{3}\left(4 \mathrm{lb} / \mathrm{yd}^{3}\right)$} \\
\hline \multicolumn{4}{|c|}{ Sika Visocrete $2100-1.75 \pm 1.75 \mathrm{ml} / \mathrm{kg}(3 \pm 3 \mathrm{oz} / \mathrm{cwt})$} \\
\hline \multicolumn{4}{|c|}{ Sika Plastocrete $161-2.91 \pm 1.16 \mathrm{ml} / \mathrm{kg}(5 \pm 2 \mathrm{oz} / \mathrm{cwt})$} \\
\hline \multicolumn{4}{|c|}{ SikaTard $440-1.16 \pm 1.16 \mathrm{ml} / \mathrm{kg}(2 \pm 2 \mathrm{oz} / \mathrm{cwt})$} \\
\hline \multicolumn{4}{|c|}{ Sika ViscoFlow $2020-2.33 \pm 1.16 \mathrm{ml} / \mathrm{kg}(4 \pm 2 \mathrm{oz} / \mathrm{cwt})$} \\
\hline
\end{tabular}




\subsubsection{Concrete placement}

The concrete was batched at a local ready-mix concrete plant and trucked to NIST for casting. A total of four trucks were used. Although the design mixture proportions were the same for all batches (trucks), small adjustments were made by adding superplasticizer (for low moisture and pumpability) prior to the concrete placement. The concrete was cast indoors (Fig. 2-24a) in the test hall. Trucks 1 and 2 provided the concrete for the test slab (Fig. 2-24b) and Trucks 3 and 4 provided the concrete for the surrounding bays (Fig. 2-24c). Immediately after casting, the concrete was covered with wet burlap to maintain a wet surface condition (Fig. 2-24d). The burlap was re-wet, as necessary, for the first 7 days of curing, after which the burlap was removed.

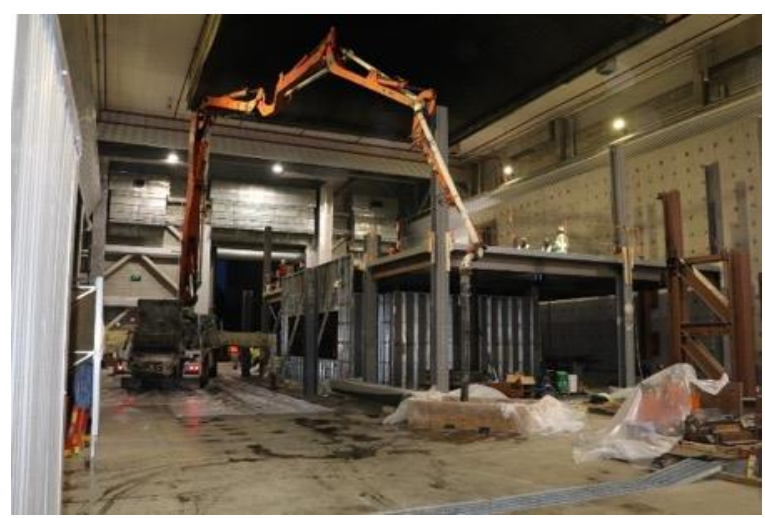

(a)

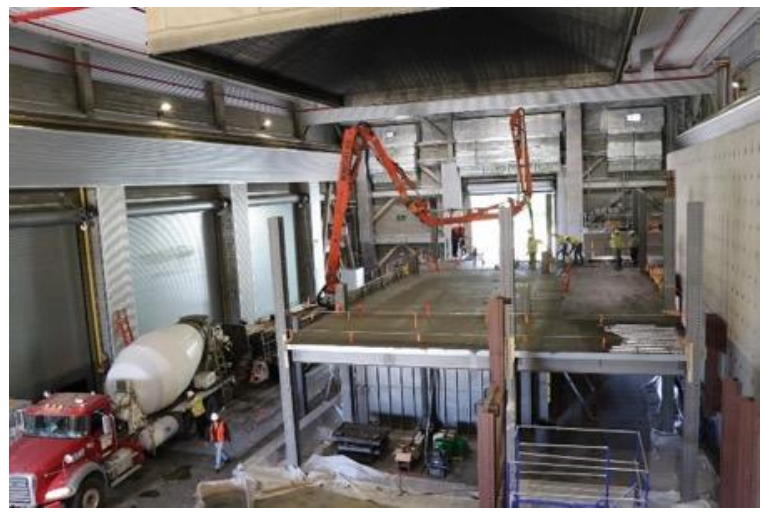

(c)

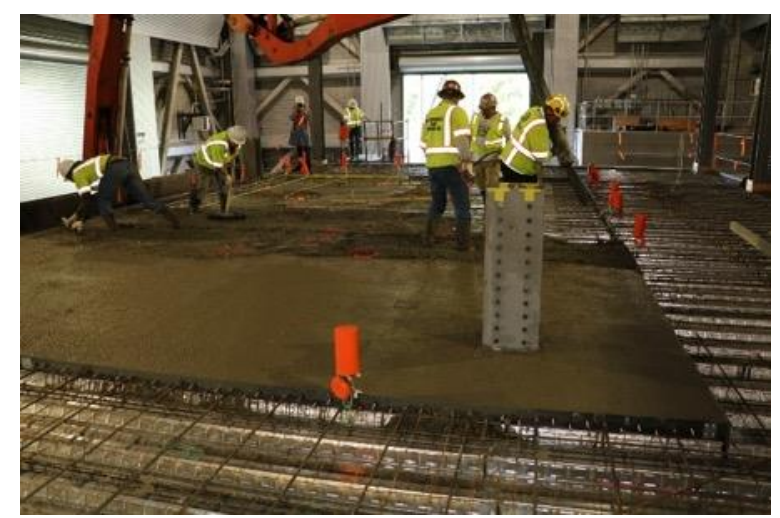

(b)

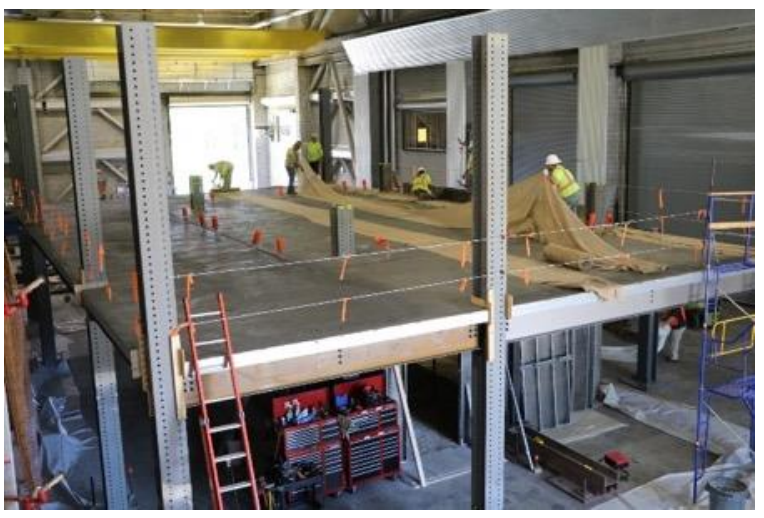

(d)

Fig. 2-24. Casting of the concrete: (a) Pump truck in National Fire Research Laboratory test hall; (b) concrete placement in test specimen; (c) concrete placement in surrounding bays; (d) initial curing with wet burlap. 


\subsubsection{Curing Conditions}

The measured relative humidity and air temperature in the test hall where the specimens were cured from the date of casting until fire testing are plotted in Fig. 2-25. There are gaps in the data because the building monitoring systems went offline and were subsequently replaced.

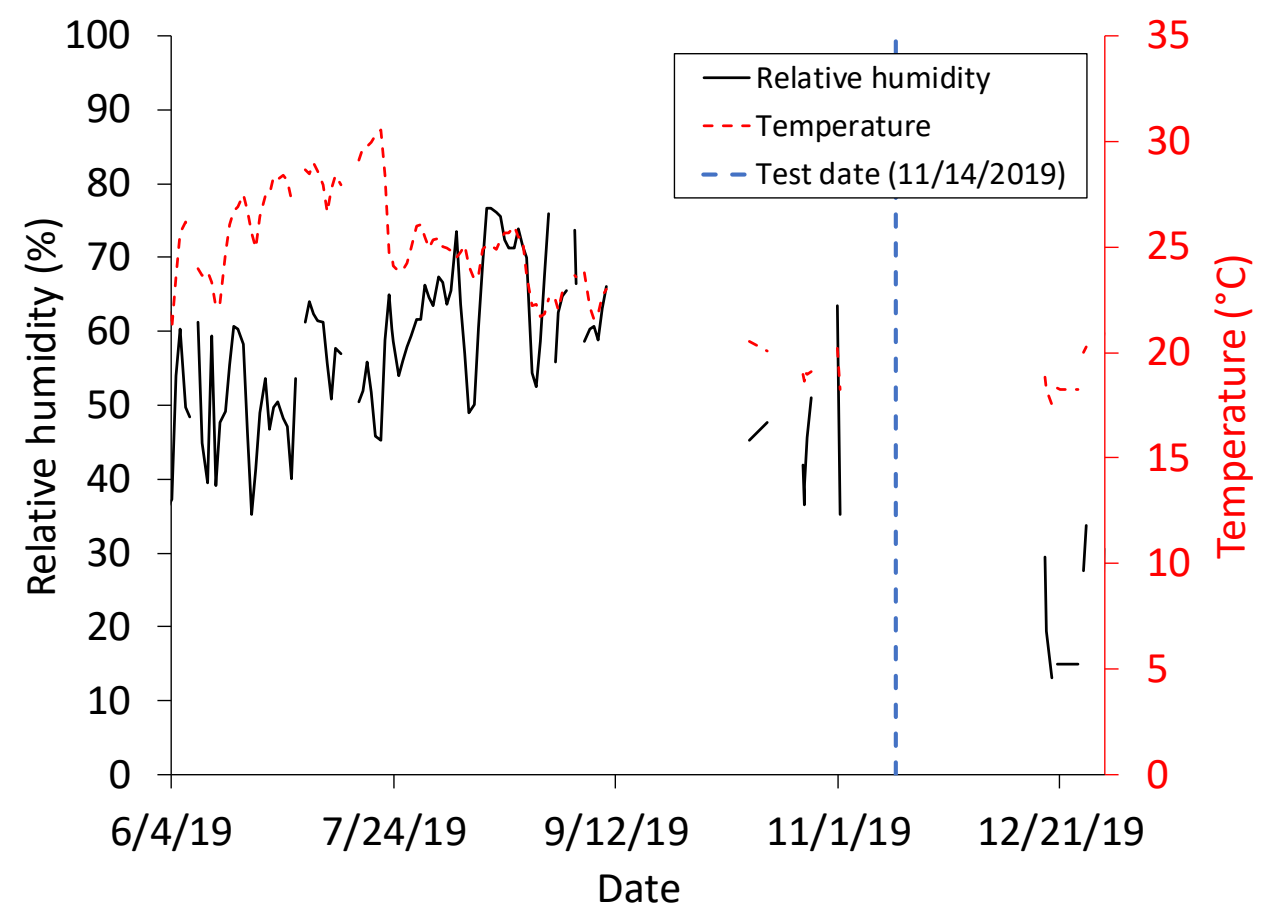

Fig. 2-25. Air temperature and relative humidity in test hall.

The relative humidity and temperature in the concrete during curing were measured using wired probes placed into perforated sleeves embedded in the concrete during casting. The manufacturer specified accuracy of the temperature and relative humidity in the applied temperature range are $\pm 0.2{ }^{\circ} \mathrm{C}$ and less than $\pm 2.5 \%$, respectively. The temperatures measured in the concrete are shown in Fig. 2-26 and the relative humidity measurements in Fig. 2-27. Measurement locations in the test specimen were in the southwest and northeast quadrants of the specimen to provide an indication of variation across the specimen. The measurement location for the surrounding bays was in the middle of the center north bay. The moisture content of the specimens, which is related to the relative humidity, was measured separately on concrete cylinders cured under the same conditions as the slabs (See Sect 2.3.2). 


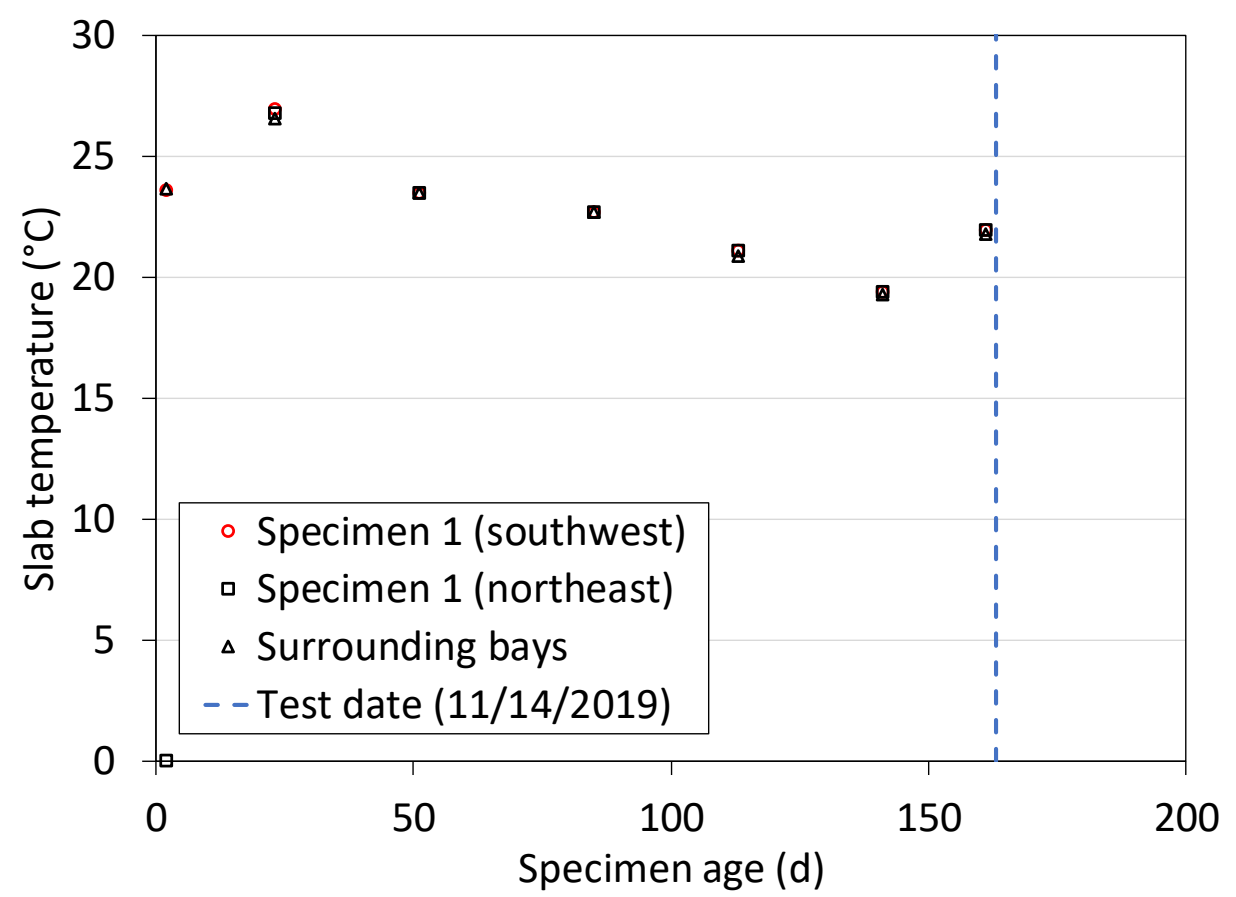

Fig. 2-26. Temperature in the test specimen and surrounding bays.

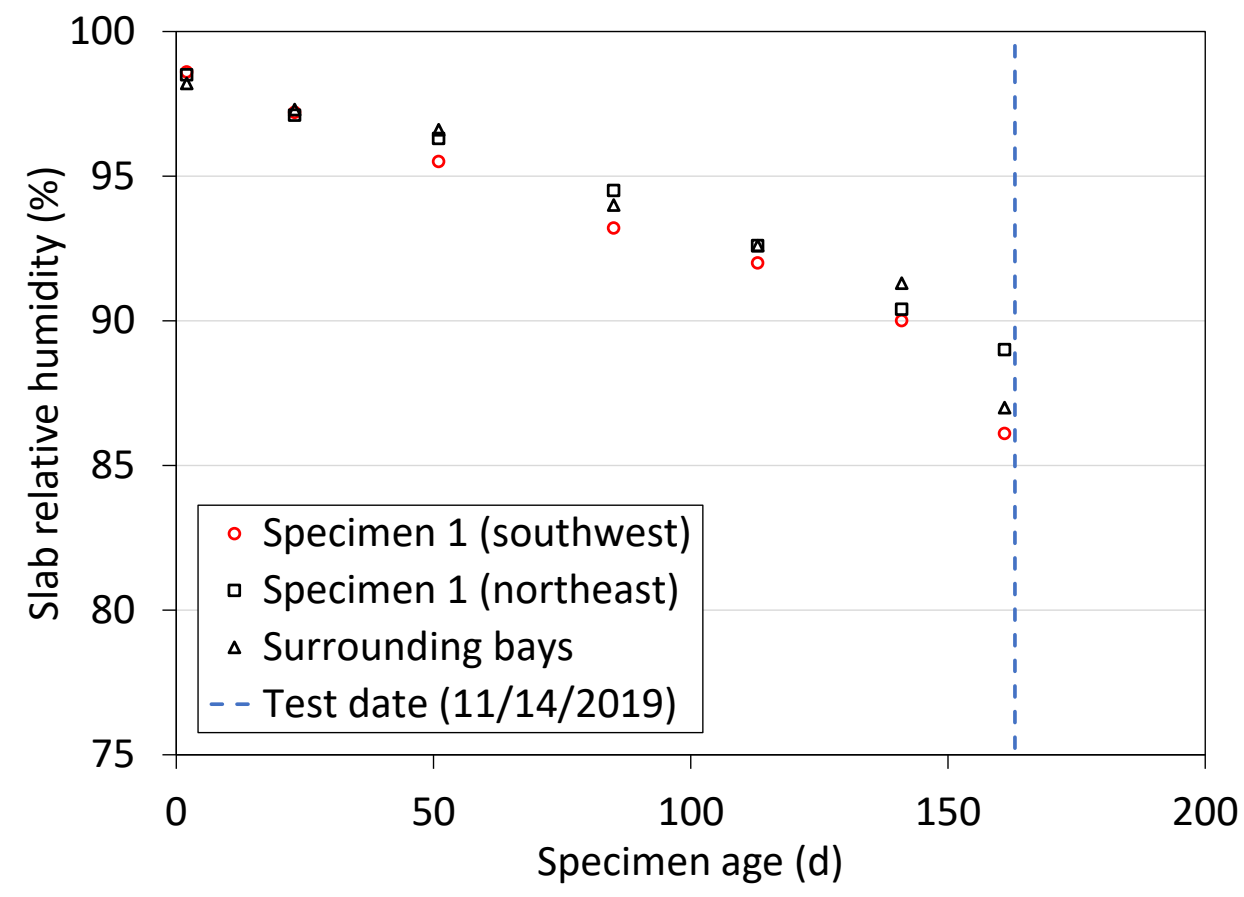

Fig. 2-27. Relative humidity in the test specimen and surrounding bays. 


\subsection{Properties of Construction Material}

\subsubsection{Mechanical Properties of Steel}

A variety of steel components constituting the test floor assembly were sent to a commercial testing facility to measure the mechanical properties at ambient temperatures. The fabrication of specimens (coupons) and testing procedures conformed to ASTM E8/E8M (2016) standard. All flat steel samples were saw cut from their original shapes and machined to make the standard coupons for tensile testing. Note that the test-bay secondary beam $(\mathrm{W} 16 \times 31)$ had a manufacturer's heat number different from that of the north and south primary beams. All beamend connection plates (shear tabs) had the same heat number.

The connection bolts were machined to make round-shaped coupons, whereas the $3.4 \mathrm{~mm}$ diameter wires from the WWR mat were not machined, but grit blasting was applied to remove rust before testing. No tensile coupon testing was performed on the $19 \mathrm{~mm}$ diameter headed stud anchors since their heat number was the same as those used in the Phase 1 composite beam tests. Refer to Ramesh et al. (2019) for their room-temperature mechanical properties.

Fig. 2-28 and Fig. 2-29 show the measured engineering stress-strain diagrams. Where the data end, the operator removed the extensometer. Table 2-5 provides the average values of the $0.2 \%$ offset yield strength $\left(S y_{002}\right)$, the ultimate tensile strength $\left(S_{u}\right)$, and percent elongation at fracture $(\delta)$. The values after \pm symbols indicate one standard deviation estimated using a uniform distribution of the two measured values. A gauge length of $51 \mathrm{~mm}$ was used to measure the strains in the flat coupons. The gauge length of the round coupons (bolts and wires) was four times the diameter of the specimen. The elongation $(\delta)$ was equal to a ratio of the final elongation after testing to the initial gauge length. The $0.2 \%$ offset yield strength and tensile strength of the shear stud steel were $410 \mathrm{MPa}$ and $510 \mathrm{MPa}$, respectively, as reported in Ramesh et al. (2019).

Table 2-5. Mechanical properties of steel components. All values are rounded to the nearest integer.

\begin{tabular}{lllll}
\hline Specimen Name & $\begin{array}{l}\text { ASTM } \\
\text { Designation }\end{array}$ & $\begin{array}{l}S y_{002} \\
(\mathrm{MPa})\end{array}$ & $S_{u}(\mathrm{MPa})$ & $\delta(\%)$ \\
\hline W16x31-Beam-Flange & A992 & $376 \pm 0$ & $507 \pm 0$ & $35 \pm 0$ \\
W16x31- Beam-Web & A992 & $438 \pm 16$ & $533 \pm 9$ & $28 \pm 2$ \\
W16x31-Secondary-Beam-Flange & A992 & $332 \pm 0$ & $474 \pm 1$ & $37 \pm 1$ \\
W16x31-Secondary-Beam-Web & A992 & $381 \pm 5$ & $493 \pm 0$ & $33 \pm 0$ \\
W18x35-Girder-Flange & A992 & $341 \pm 3$ & $509 \pm 1$ & $32 \pm 1$ \\
W18x35-Girder-Web & A992 & $346 \pm 1$ & $510 \pm 0$ & $32 \pm 1$ \\
A36-Connection Plates & A36 & $290 \pm 1$ & $436 \pm 1$ & $37 \pm 1$ \\
20-gauge steel deck & A653 & $403 \pm 4$ & $473 \pm 2$ & $26 \pm 1$ \\
A325 Bolt, 2inch (for standard shear tabs) & A325 (F3125) & $876 \pm 4$ & $958 \pm 4$ & $18 \pm 1$ \\
A325 Bolt, 2.25 inch (for extended shear tabs) & A325 (F3125) & $903 \pm 4$ & $972 \pm 4$ & $20 \pm 0$ \\
Welded wire mesh & A185 & $755 \pm 2$ & $790 \pm 2$ & $15 \pm 0$ \\
\hline
\end{tabular}




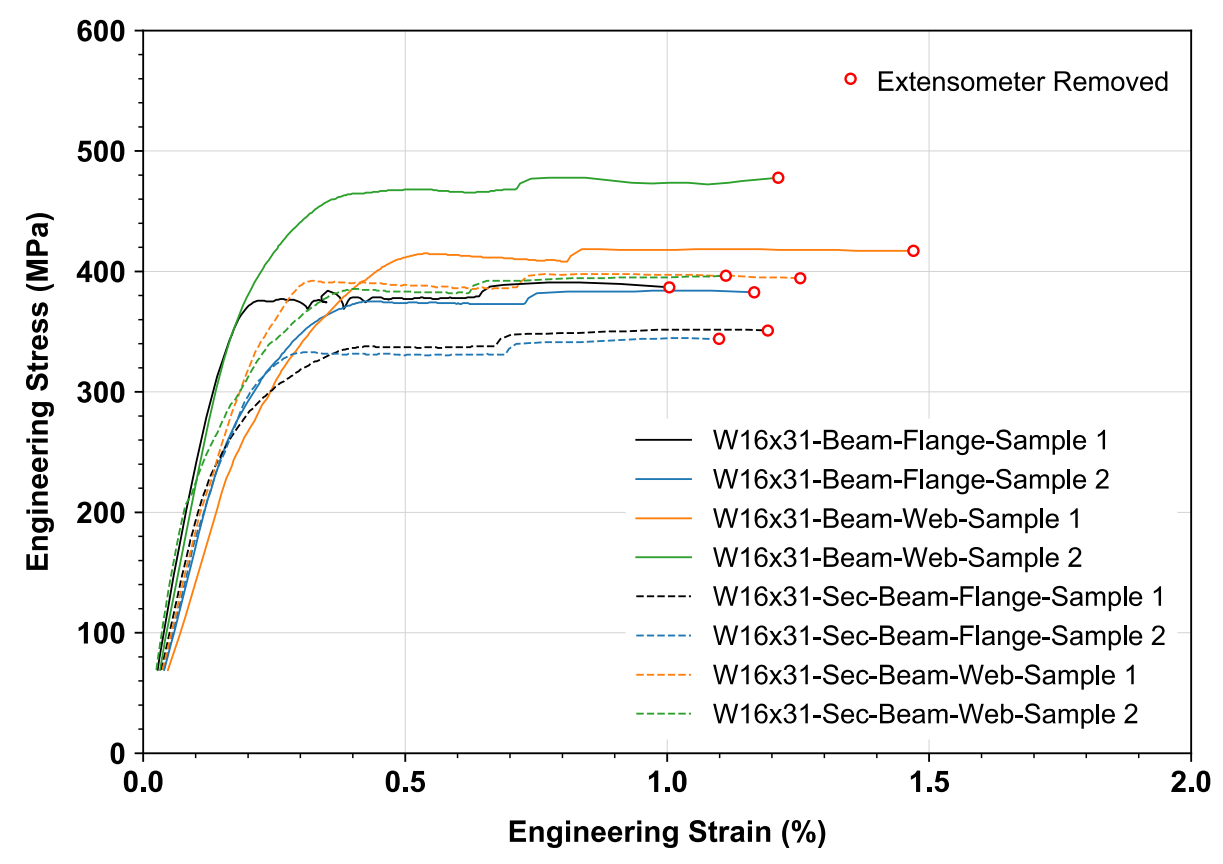

(a)

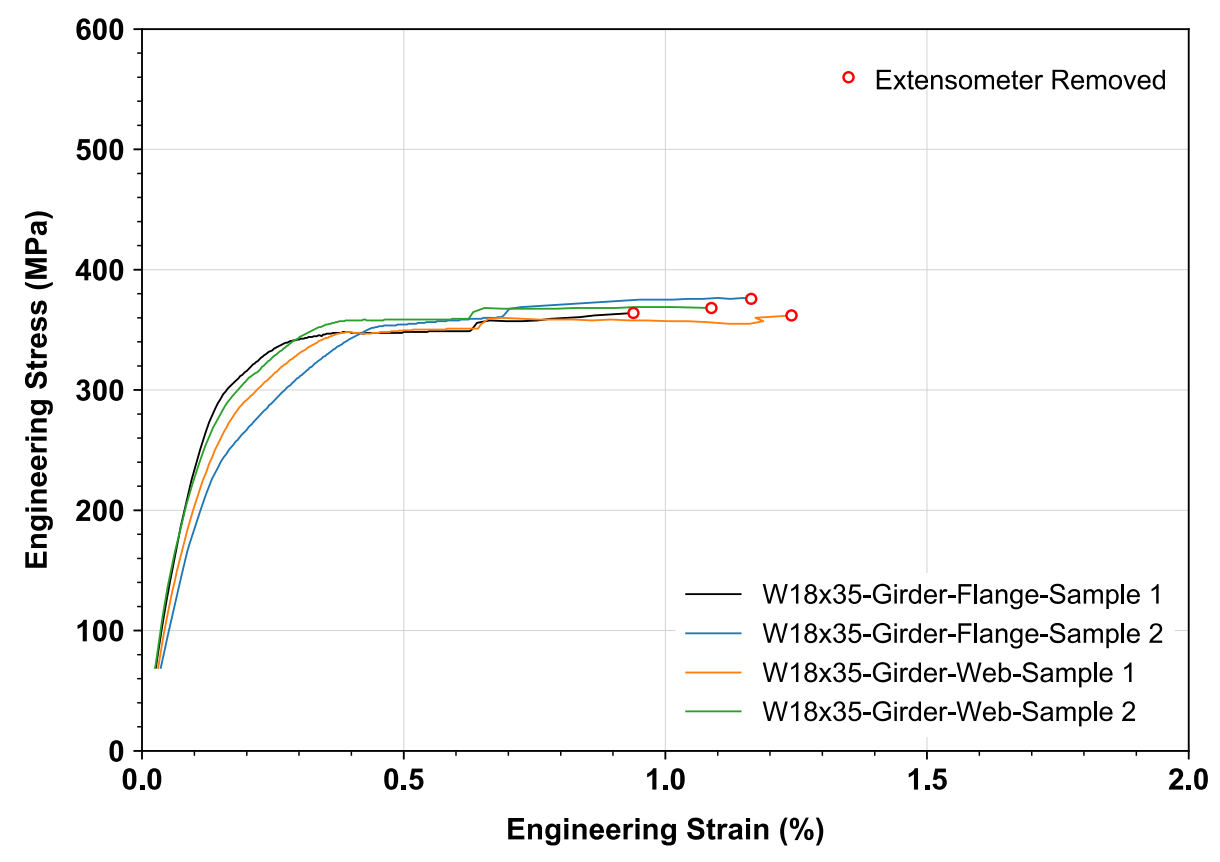

(b)

Fig. 2-28. Engineering stress-strain relationship for (a) W16 $\times 31$ beam (b) W18 $\times 35$ girder. 


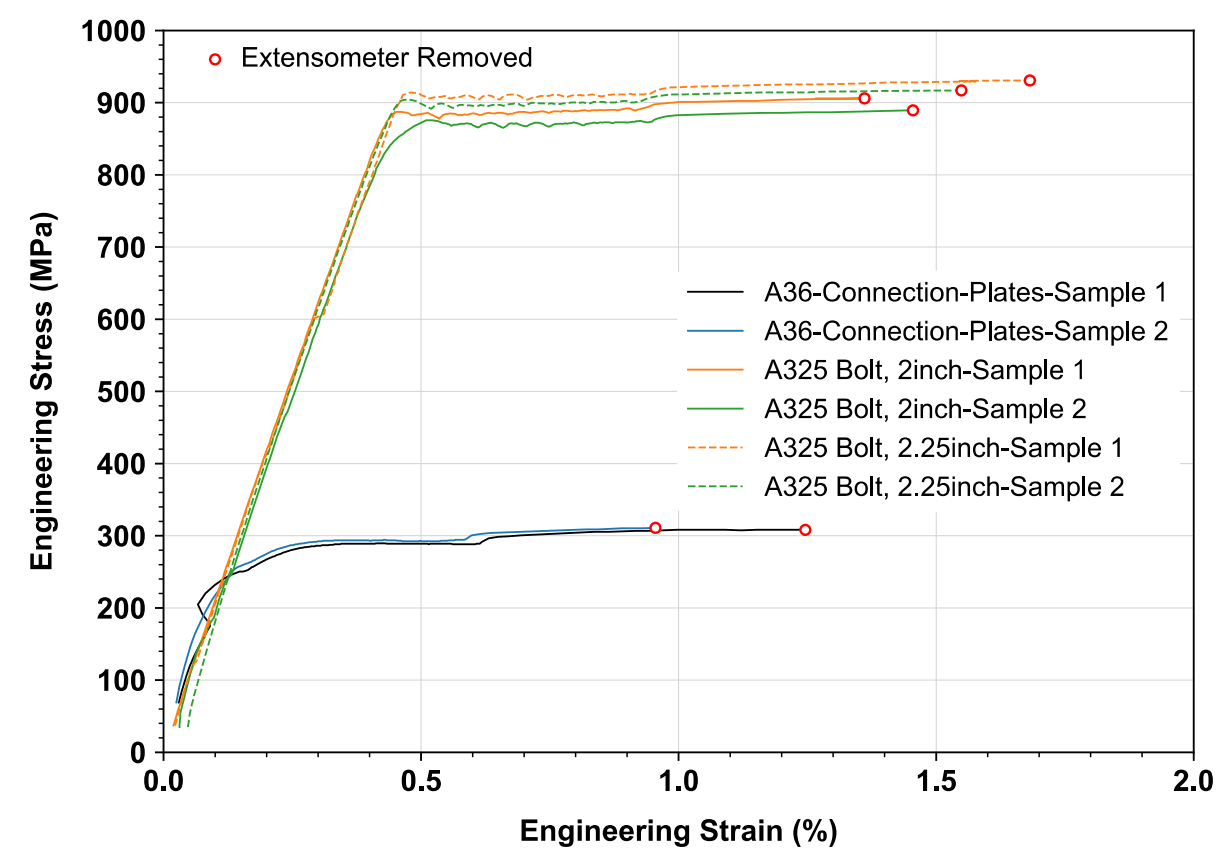

(a)

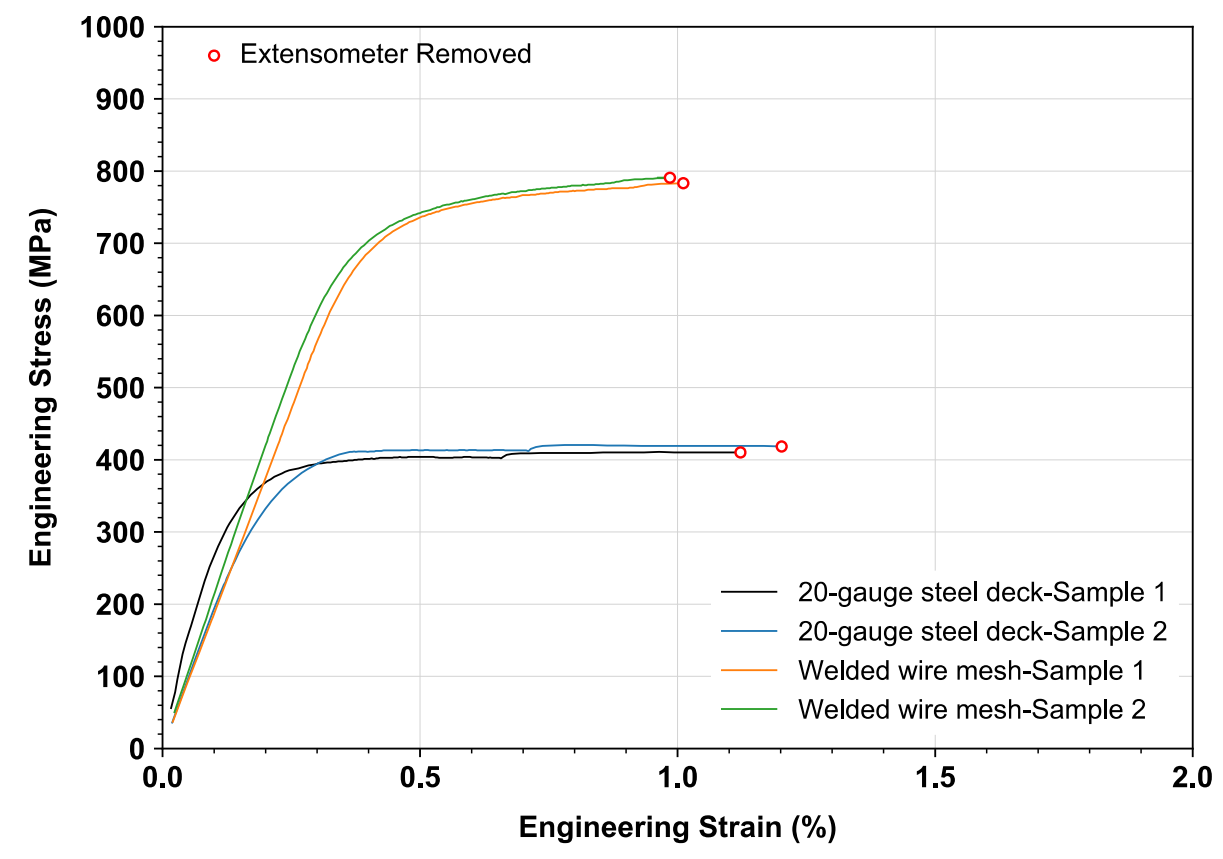

(b)

Fig. 2-29. Engineering stress-strain relationship for (a) shear tab connection plate (b) steel deck and welded wire reinforcement. 


\subsubsection{Hardened Concrete Properties}

Table 2-6 summarizes the measured concrete properties. Where applicable, the relevant ASTM test standard used is provided in the table. The reader is directed to the current edition of these standards for details on those test methods. Relevant details about the tests used to determine the thermal conductivity and specific heat of the concrete are provided below. The 28-day compressive strength tests were performed by a third-party testing laboratory, and the 'day of test' measurements were performed at NIST within one week after the large specimen fire test with the exception of the tension splitting strength tests which were conducted by a third-party party at a later date. Except for the measurements made at the time of casting of the concrete, all measurements were made from $102 \mathrm{~mm} \times 204 \mathrm{~mm}$ concrete cylinders prepared according to ASTM C192 (2019) and cured alongside the concrete slab in the test hall. All measurements were made at ambient laboratory temperatures; nominally $23{ }^{\circ} \mathrm{C}$. No measurements of the concrete properties at elevated temperatures were made.

The slump and plastic unit weight of the concrete are reported in Table 2-7. No replicate measurements of the fresh concrete were made so standard deviation is not reported. Table 2-8 summarizes the measured properties (mean and one standard deviation) of the hardened concrete for each individual delivery truck (batch). Each value is from two or more replicates. Average values for all four trucks as well as grouped for the concrete in the test specimen and surrounding bays are provided in Table 2-9.

Table 2-6. Matrix of measured concrete properties.

\begin{tabular}{lllll}
\hline & \multicolumn{2}{l}{ Number of cylinders } & \\
\cline { 2 - 4 } Property & Casting & 28 -day & Total \\
& $6 / 4 / 2019$ & $7 / 2 / 2019$ & - & - \\
\hline Slump (ASTM C143) & $\checkmark$ & - & - & - \\
Plastic unit weight (ASTM C138) & $\checkmark$ & - & 12 & 24 \\
Compressive strength (ASTM C39) & - & 12 & a & - \\
Density (ASTM C642) & - & - & b & - \\
Static modulus (ASTM C469) & - & - & 12 & 12 \\
Splitting strength (ASTM C496) & - & - & 12 & 12 \\
Moisture content (ASTM C642) & - & - & 4 & 4 \\
Thermal conductivity & - & - & c & - \\
Specific heat & - & - & Total & 52 \\
\hline a Used moisture content cylinders. & & & & \\
${ }^{b}$ Used compressive strength cylinders. & & & &
\end{tabular}


Table 2-7. Fresh concrete properties.

\begin{tabular}{lllll}
\hline & \multicolumn{2}{l}{ Truck number } & \\
Property & $\mathrm{T} 1$ & $\mathrm{~T} 2$ & $\mathrm{~T} 3$ & $\mathrm{~T} 4$ \\
\hline Water-to-binder (cement + fly ash), - & 0.39 & 0.40 & $\mathrm{n} / \mathrm{a}$ & 0.39 \\
Slump, cm & 20.3 & 20.3 & 21.0 & 19.1 \\
Tare ==> Empty measure, kg & 6.41 & 6.44 & 6.42 & 6.43 \\
Mass ==> Measure + Concrete, $\mathrm{kg}$ & 34.62 & 34.06 & 33.7 & 33.6 \\
Unit weight $\mathrm{kg} / \mathrm{m}^{3}$ & 1988 & 1947 & 1923 & 1915 \\
\hline
\end{tabular}

Table 2-8. Hardened concrete properties for each truck.

\begin{tabular}{llllll}
\hline Category & Description & Truck T1 & Truck T2 & Truck T3 & Truck T4 \\
\hline Structural & Compressive strength, MPa & $64.4 \pm 1.6$ & $69.5 \pm 1.2$ & $63.2 \pm 1.4$ & $62.7 \pm 0.3$ \\
& Splitting tensile strength, MPa & $5.8 \pm 0.1$ & $5.6 \pm 0.5$ & not available & not available \\
& Static modulus, GPa & $26.0 \pm 0.6$ & $27.2 \pm 0.6$ & $25.0 \pm 0.2$ & $24.8 \pm 0.1$ \\
\hline \multirow{2}{*}{ Thermal } & Bulk density, $\mathrm{kg} / \mathrm{m}^{3}$ & $1923 \pm 3.4$ & $1937 \pm 2.2$ & $1916 \pm 12.0$ & $1906 \pm 4.2$ \\
& Moisture content, \% mass & $8.0 \pm 0.2$ & $7.0 \pm 0.2$ & $7.6 \pm 0.1$ & $7.9 \pm 0.05$ \\
& Thermal conductivity, $\mathrm{W} / \mathrm{m} \cdot \mathrm{K}$ & $2.117 \pm 0.188$ & $2.232 \pm 0.170$ & $2.084 \pm 0.029$ & $2.276 \pm 0.134$ \\
& Specific heat, $\mathrm{J} / \mathrm{kg} \cdot \mathrm{K}$ & $1020 \pm 26$ & $906 \pm 25$ & $901 \pm 56$ & $873 \pm 28$ \\
\hline
\end{tabular}

Table 2-9. Average hardened concrete properties.

\begin{tabular}{lllll}
\hline Category & Description & $\begin{array}{l}\text { Test 1 average } \\
(\mathrm{T} 1+\mathrm{T} 2+\mathrm{T} 3+\mathrm{T} 4)\end{array}$ & $\begin{array}{l}\text { Specimen 1 } \\
(\mathrm{T} 1+\mathrm{T} 2)\end{array}$ & $\begin{array}{l}\text { Surrounding bays } \\
(\mathrm{T} 3+\mathrm{T} 4)\end{array}$ \\
\hline Structural & Compressive strength, $\mathrm{MPa}$ & $64.9 \pm 3.0$ & $66.9 \pm 2.9$ & $63.0 \pm 1.1$ \\
& Splitting tensile strength, $\mathrm{MPa}$ & not available & $5.7 \pm 0.4$ & not available \\
& Static modulus, $\mathrm{GPa}$ & $25.7 \pm 1.1$ & $26.6 \pm 0.8$ & $24.9 \pm 0.2$ \\
\hline \multirow{2}{*}{ Thermal } & Bulk density, $\mathrm{kg} / \mathrm{m}^{3}$ & $1920 \pm 13$ & $1930 \pm 7$ & $1911 \pm 10$ \\
& Moisture content, \% mass & $7.6 \pm 0.4$ & $7.5 \pm 0.5$ & $7.7 \pm 0.2$ \\
& Thermal conductivity, $\mathrm{W} / \mathrm{m} \cdot \mathrm{K}$ & $2.177 \pm 0.164$ & $2.174 \pm 0.188$ & $2.180 \pm 0.136$ \\
& Specific heat, $\mathrm{J} / \mathrm{kg} \cdot \mathrm{K}$ & $925 \pm 67$ & $963 \pm 62$ & $887 \pm 47$ \\
\hline
\end{tabular}

The thermal conductivities of the concretes at ambient temperature were determined using the transient plane source (TPS) method (Gustafsson 1991; Log and Gustafsson 1995). Additionally, the heat capacities (specific heat) of the concretes at ambient temperature were measured using a gold pan heat capacity cell connected to the TPS measurement system. The procedure reported here was previously described by Bentz (Bentz et al. 2011).

For thermal conductivity measurements, a $14.67 \mathrm{~mm}$ radius probe (Ni foil encased in Kapton) was sandwiched between two $45 \mathrm{~mm}$ thick slices of a $102 \mathrm{~mm}$ diameter hardened concrete cylinder. After an equilibration time of at least $45 \mathrm{~min}$, measurements were obtained using a power of $0.3 \mathrm{~W}$ applied for a measurement time of $10 \mathrm{~s}$. The measured response of points 100 to 
200 of those sampled during the $10 \mathrm{~s}$ was analyzed using the built-in software to estimate the thermal conductivity of the specimens. To account for heterogeneity of the concrete, the cylinder slices were rotated 90-degrees after each measurement to capture a representative average response from the cement paste and aggregates. Four measurements were made for each batch of concrete. According to the manufacturer's specifications, thermal conductivity measurements made in this way are reproducible within $\pm 2 \%$ standard uncertainty.

For the heat capacity measurements, approximately $1.0 \mathrm{~g}$ of material from the cylinders was ground to a powder using a mortar and pestle and placed in the heat capacity unit, which consisted of a Kapton probe attached to the base of a gold pan/lid. The gold pan with its lid was surrounded by polystyrene insulation to minimize energy loss. First, a reference measurement was made with an empty pan, followed by the measurement with the specimen placed in the pan. A power of $0.1 \mathrm{~W}$ was applied for a measurement time of $80 \mathrm{~s}$ and points 100 to 200 of those sampled in the $80 \mathrm{~s}$ were used in the analysis. Knowing the mass of the specimen, its heat capacity in units of $\mathrm{J} /(\mathrm{kg} \cdot \mathrm{K})$ could be determined. Three measurements were made for each batch of concrete. According to the manufacturer, heat capacity measurements made in this way are reproducible within $\pm 2 \%$ standard uncertainty. 


\subsection{Test Setup}

\subsubsection{Mechanical Loading}

The test building was imposed by mechanically applied gravity loads on the first floor during the fire experiment, as shown Fig. 2-30. In the test bay, a total actuator load of $125 \mathrm{kN}$ was applied by four servo-hydraulic actuators mounted at the basement via purpose-built loading frames above the test floor slab; see Sect. 2.4.1.1. This load was distributed at twenty-four points across the $9.1 \mathrm{~m} \times 6.1 \mathrm{~m}$ floor slab, providing a total gravity load of $5.2 \mathrm{kPa}$, including total self-weight of the loading systems $(25 \mathrm{kN}$, equivalent to $0.45 \mathrm{kPa})$ and specimen $(2.5 \mathrm{kPa})$, determined from the ASCE 7 load combination for extraordinary events (1.2xdead load $+0.5 \times$ live load). The surrounding floors were loaded by a total of seventy-six water-filled drums with a diameter of 59 $\mathrm{cm}$ each, providing a uniform load of $3.7 \mathrm{kPa}$ (dead load $+0.5 \times$ live load). The weight of a single water-filled drum was approximately $2.1 \mathrm{kN}$.

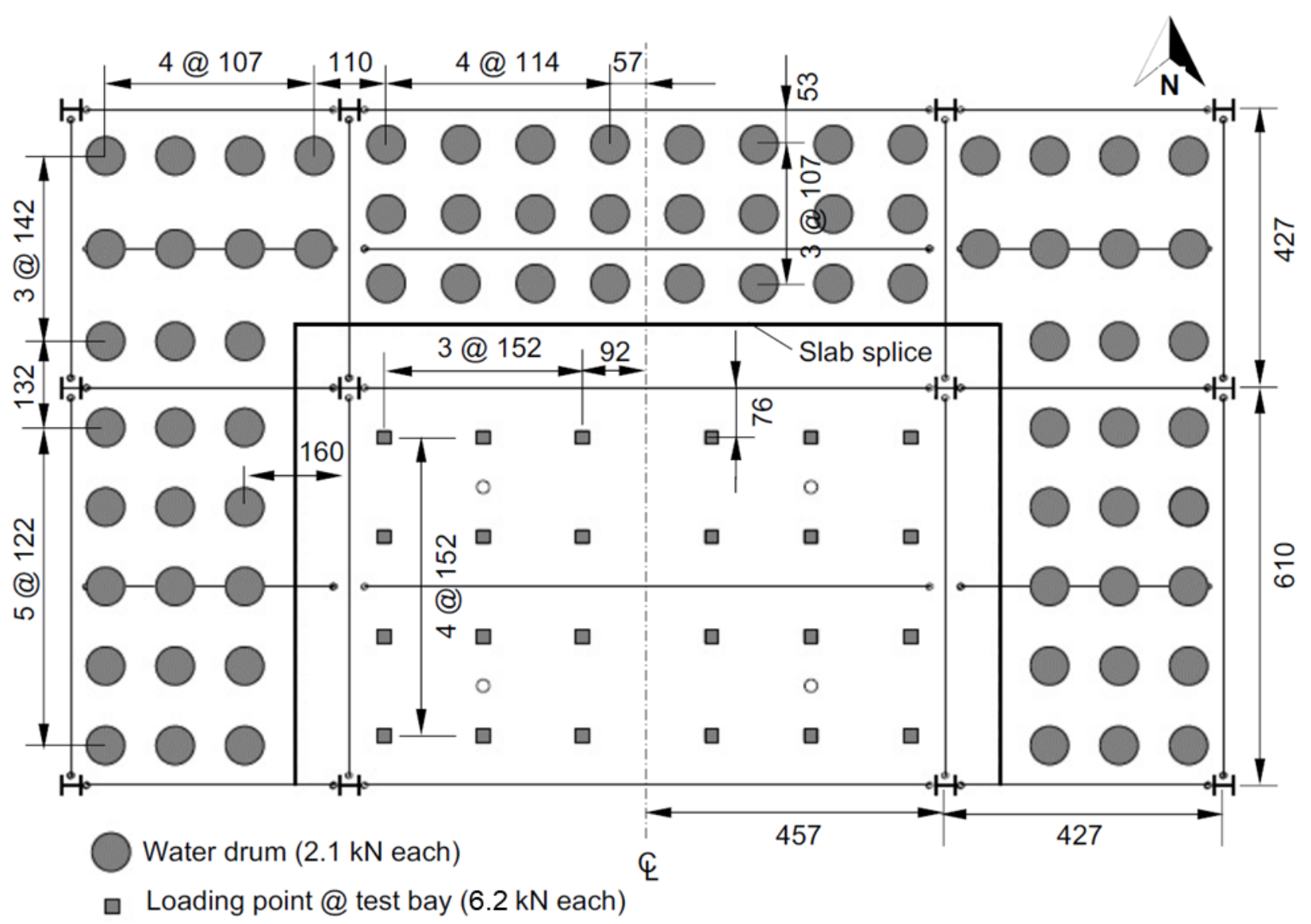

Fig. 2-30. Mechanical loading arrangement on the first floor of the test building; Dimensions in $\mathrm{cm}$. 


\subsubsection{Gravity Loading System}

In the test bay, the purpose-built gravity loading system was used to distribute the mechanical loads applied using hydraulic actuators; See Fig. 2-31. Each gravity loading system comprised a pair of triangular spreader frames, a loading beam, and a water-cooled round tube. All loadbearing components were built with Hollow Structural Section (HSS) shapes made of ASTM A500 (2021) steel. The ends of each loading beam were supported at the centroid of the triangular frame that were placed horizontally on the slab. The water-cooled steel tube (HSS $2 \times$ 0.281) was attached at midspan of the loading beam using a coupler, and its far end was connected to a hydraulic actuator mounted in the laboratory basement. Hence, the mechanical load applied by a single actuator was equally transferred at six corners (vertices) of triangular frames, spaced $1.5 \mathrm{~m}$ apart. This water-cooled tube was $550 \mathrm{~cm}$ long, running through the 19.4 $\mathrm{cm}$ diameter hole in the test slab, the fire test compartment $(381 \mathrm{~cm}$ in height) and the $137 \mathrm{~cm}$ deep strong floor. MTS 249 series swivels were utilized to join each load-carrying part of the system to allow flexible rotations as the slab deformed into a dish-shaped profile under fire conditions. Refer to Appendix A for the physical dimensions of the gravity loading system.

A total of four servo-hydraulic actuators (Model: MTS 201.35TS) were utilized in this test. As shown in Fig. 2-31b, these actuators were mounted to the ceiling of the strong floor basement using a purpose-built yoke (Choe et al. 2018). The actuator piston was aligned with the center of a through hole of the strong floor. A steel plate coupler was used to connect the water-cooled steel tube (attached to the loading frame on the test floor level) to the actuator piston. MTS Series 793 control software was used to regulate hydraulic servo valves and monitor and store real-time values of hydraulic forces and displacements applied by actuators. 


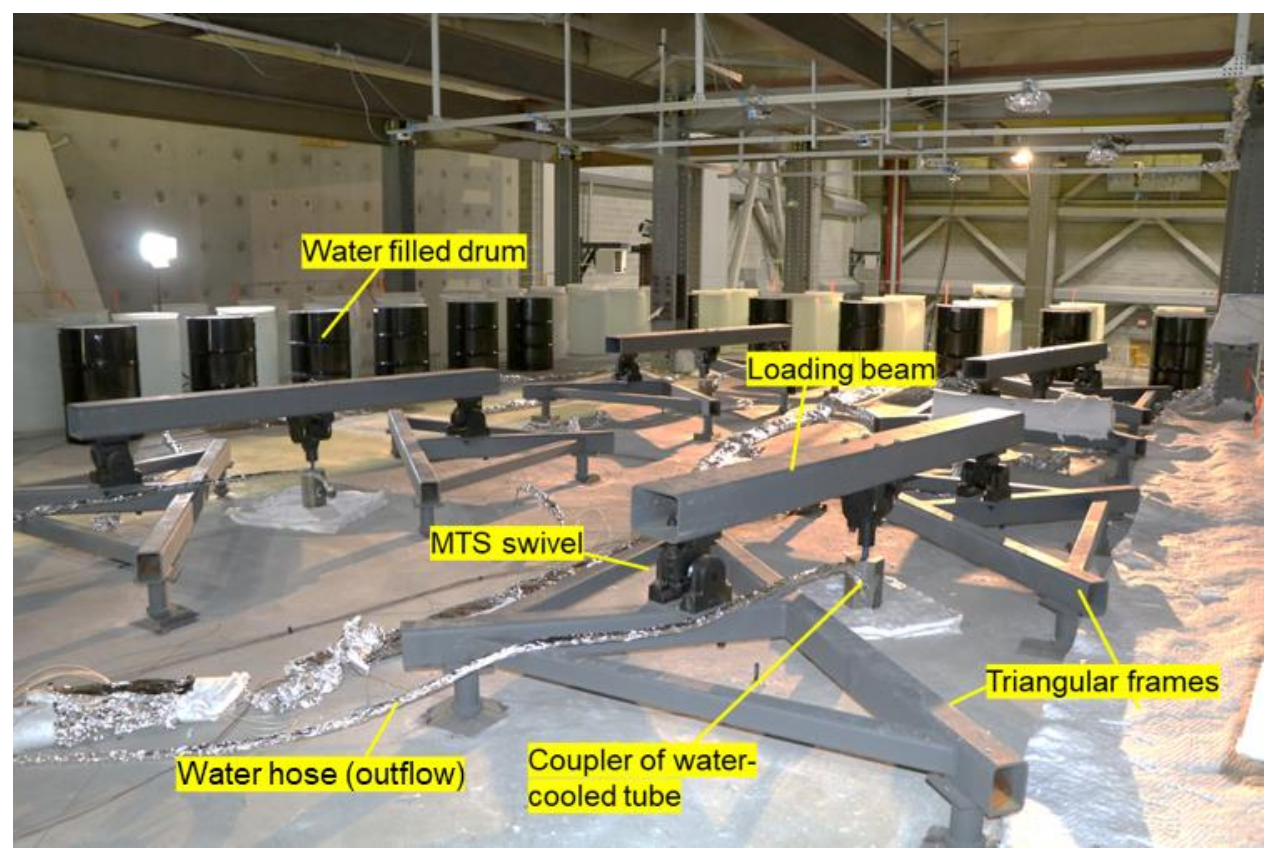

(a)

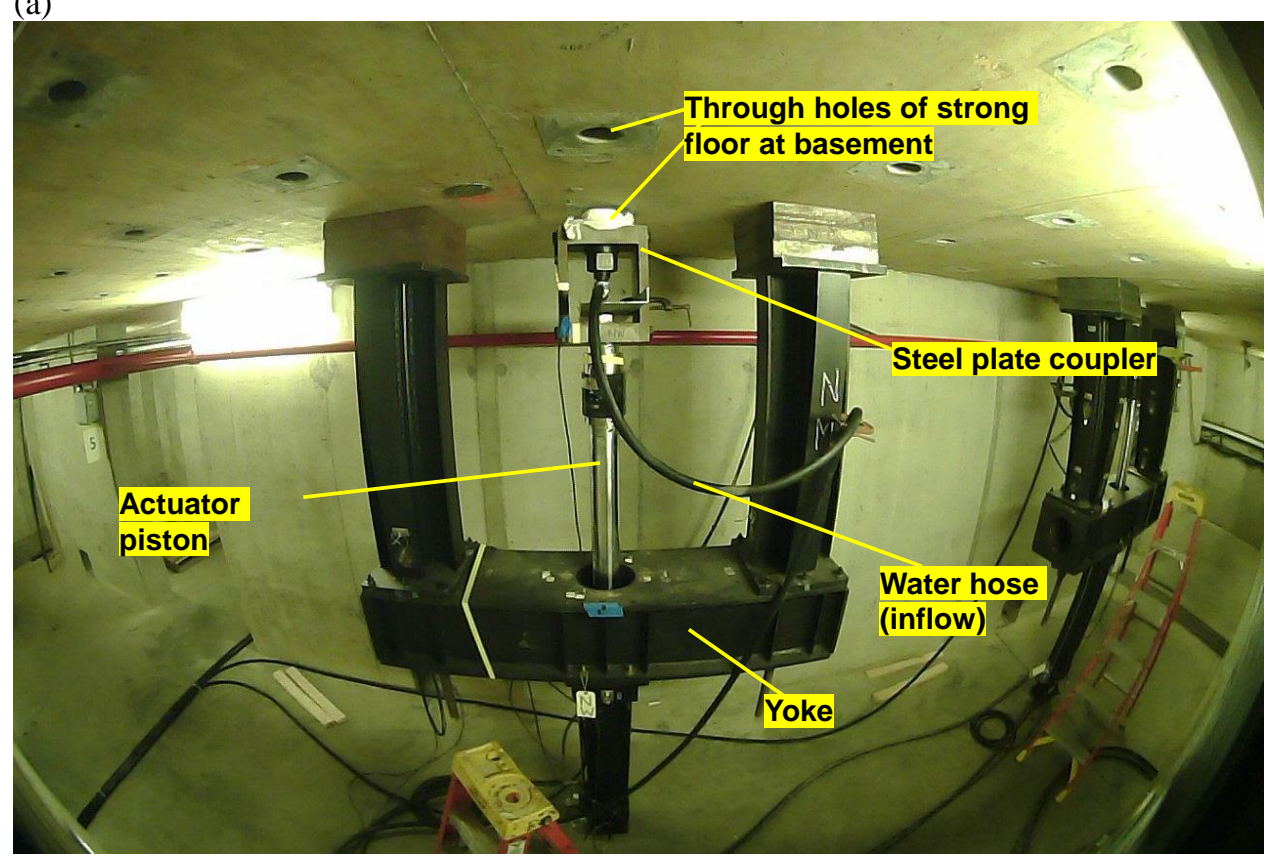

(b)

Fig. 2-31. Photographs of (a) the gravity loading system on the test floor slab and (b) the actuator mounted in the NFRL basement. 


\subsubsection{Test Fire}

The test floor assembly was exposed to a compartment fire simulating the standard temperaturetime curve (ASTM E119 or ISO834). Similar to the Phase I composite beam study, natural gas was used as a fuel because it allowed independent and near-instantaneous control of heat release rate during the experiment (Choe et al. 2020).

The key elements necessary to create a standard fire exposure without using a furnace include the design of a fire room, ventilation conditions, and fuel loads. The design objectives were to:

1) safely confine a fire within the test compartment, allowing flame leakage through a single vent only and minimize overheating of the surrounding bays,

2) create uniform gas temperatures, increased following the standard time-temperature relationship, in the upper layer of the compartment, and

3) produce a repeatable compartment fire controlled by the heat release rate of burners.

The following subsections describe the features of the fire test enclosure, burners, the proposed heat release rate of a fire used in this experiment.

\subsubsection{Fire Confinement}

The floor plan with the location of the fire test compartment and burners is shown in Fig. 2-32. The test compartment, measuring $1008 \mathrm{~cm} \times 687 \mathrm{~cm}$ in plan, was built on the ground floor of the two-story test building to heat the composite floor assembly above. The floor of the test compartment was slightly larger than the test-bay column grid $(914 \mathrm{~cm} \times 610 \mathrm{~cm})$; therefore, all primary beams, girders, and their end connections were exposed to fire. Columns were not directly exposed to fire except for the upper region where the floor beams or girders of the test bay were joined.

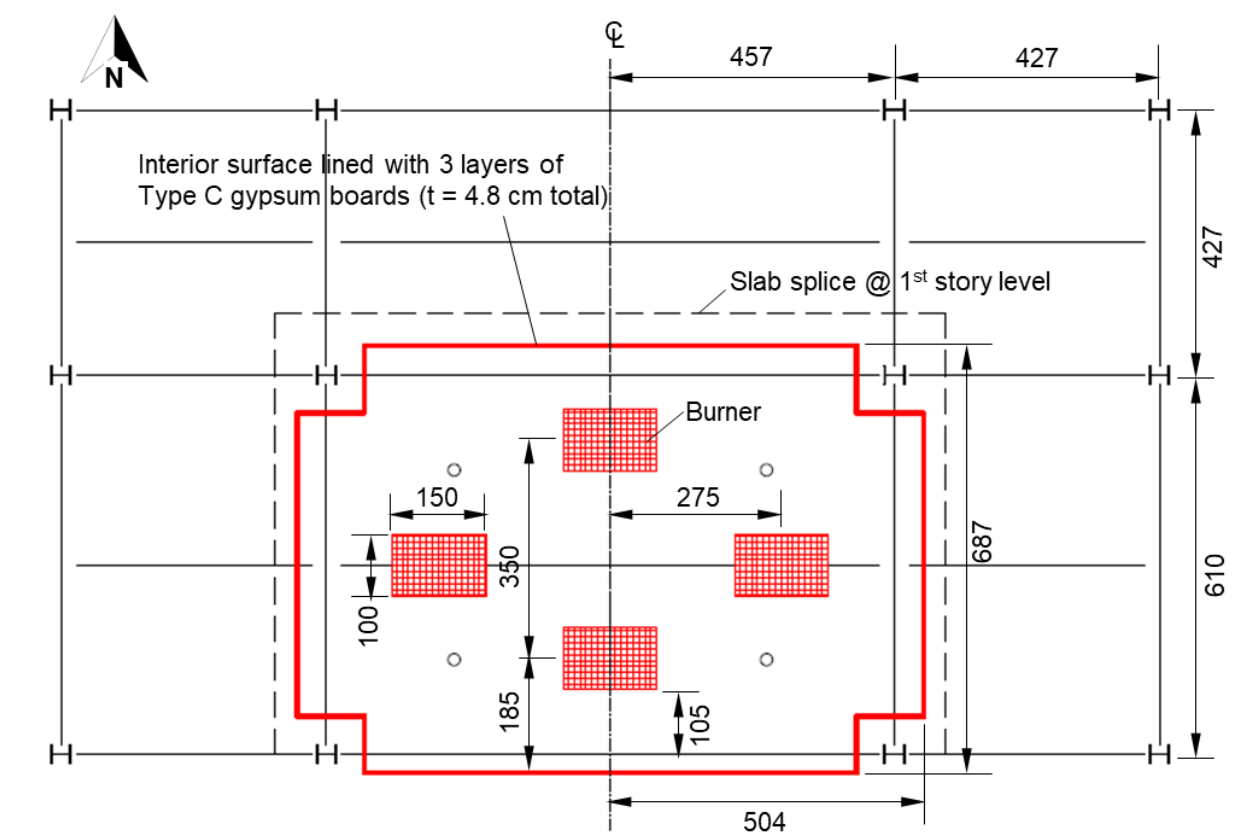

Fig. 2-32. Floor plan with the fire test compartment and distribution of burners. (Unit in cm). 
The compartment walls were considered as non-load bearing walls so that the heated floor assembly above could move freely downward during a test fire. All enclosing walls were constructed using cold-formed steel framing with wall sheathing made of $0.8 \mathrm{~mm}$ ( 22 gauge) sheet steel. As shown in Fig. 2-33, the main ventilation opening was on the south wall, approximately $150 \mathrm{~cm}$ tall $\times 582 \mathrm{~cm}$ wide. There was a $30 \mathrm{~cm}$ tall $\times 582 \mathrm{~cm}$ wide slit on the north wall. This silt was designed for air intake only. The height of the windowsill was $100 \mathrm{~cm}$ from the strong floor. The scaled drawings of the fire test enclosure are presented in Appendix A.

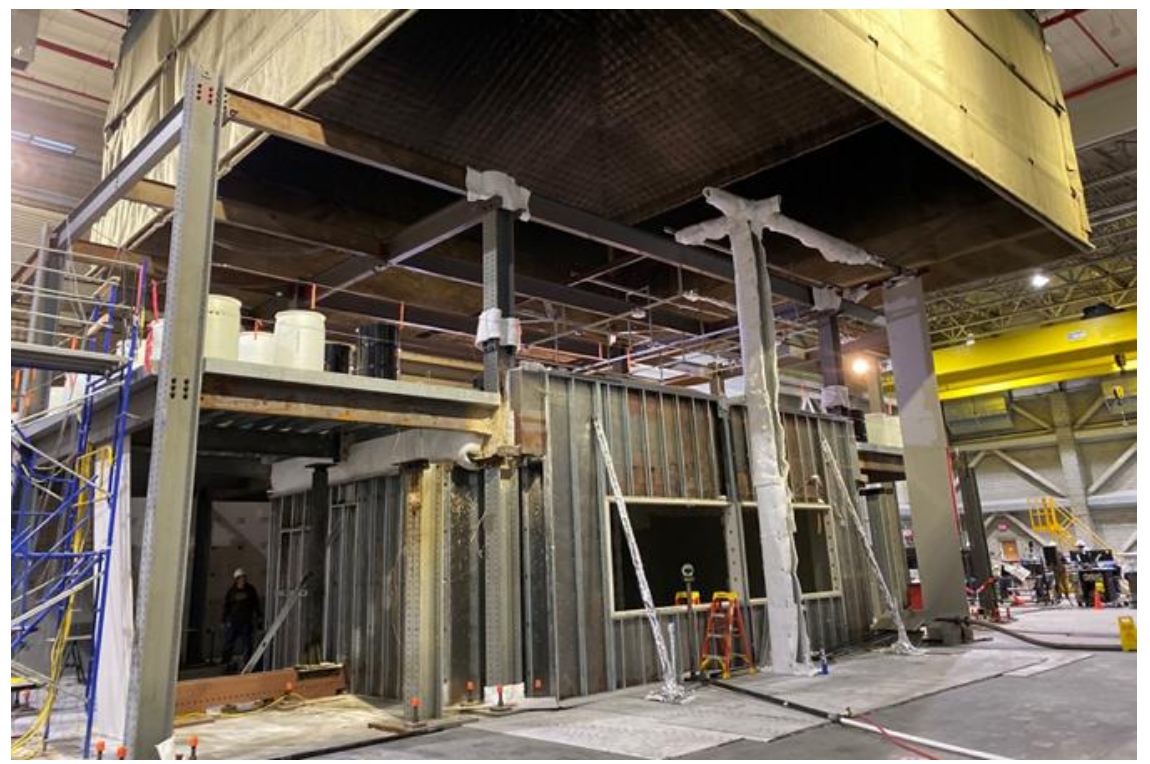

(a)

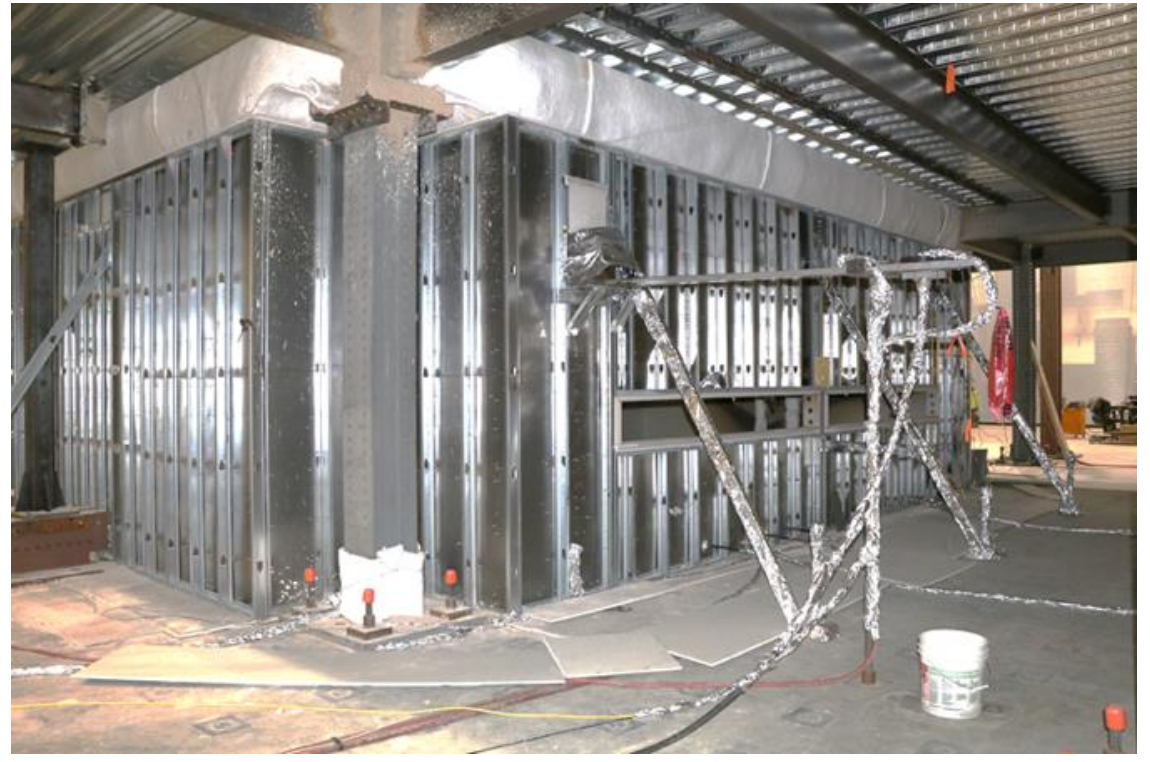

(b)

Fig. 2-33. Photographs of the outside of the fire test compartment: (a) the south wall with a main vent opening and (b) the north wall with a slit. 
The strong floor inside the test compartment was protected with two $16 \mathrm{~mm}$ thick layers of Type$\mathrm{X}$ gypsum boards and a $13 \mathrm{~mm}$ thick concrete board, Fig. 2-34a. The height of the ceiling (the composite floor soffit), measured from the top surface of the compartment floor, was $377 \mathrm{~cm}$. Refer to Appendix A for detailed 2D drawings of the test compartment. The exposed surfaces of the walls were lined with three layers of Type-C gypsum boards (16 $\mathrm{mm}$ thick each), as shown Fig. 2-34a. The south wall was extended beyond the top surface of the slab but its exposed surface was kept $7.6 \mathrm{~cm}$ away from the slab edge (Fig. 2-33a and Fig. 2-34a). A strip of ceramic fiber blanket was used to block the gap between the south slab edge and the wall lining (Fig. 2-34b).
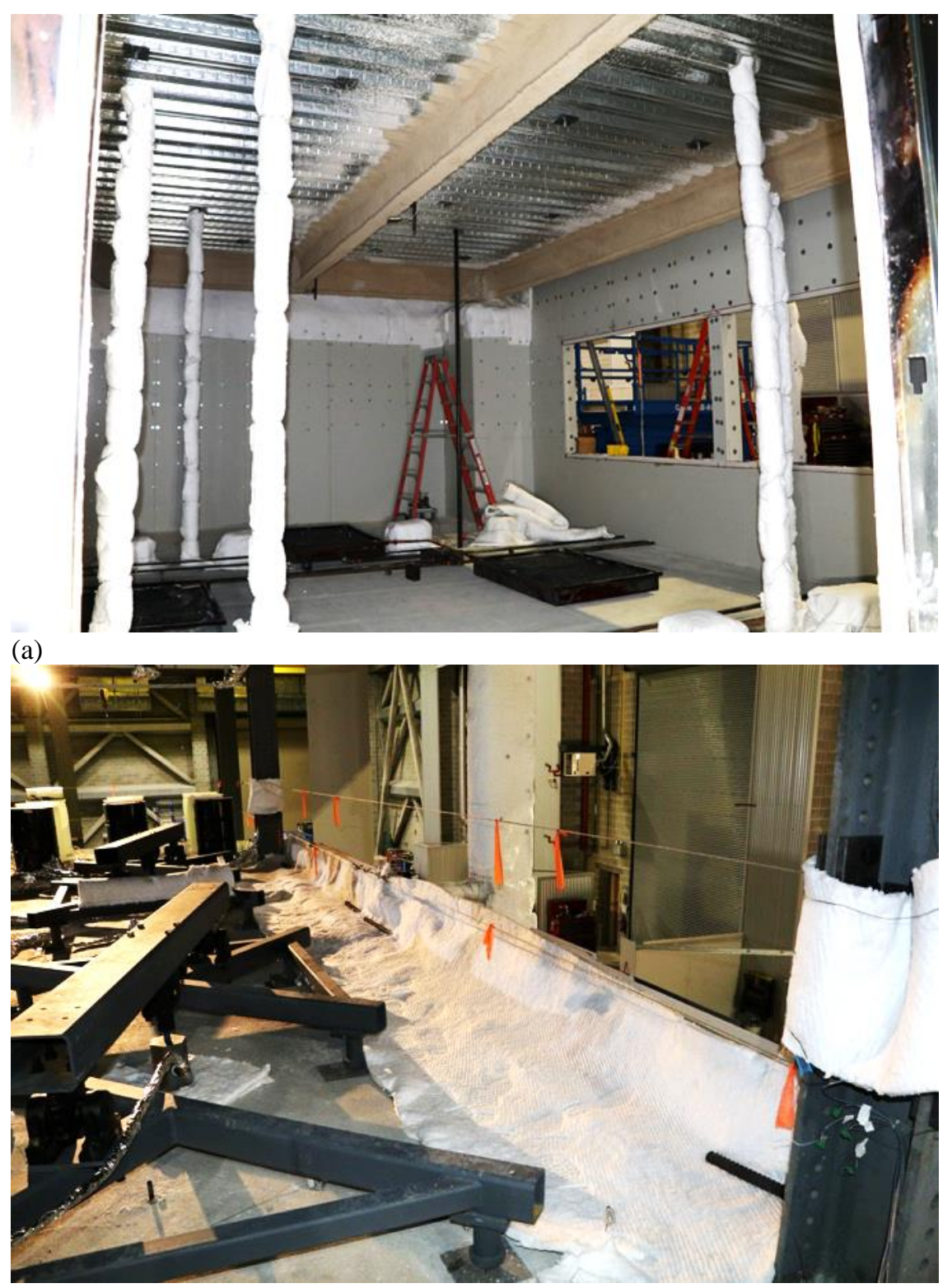

(b)

Fig. 2-34. Photographs of (a) inside of the test compartment and (b) south edge of the test floor assembly. 
In contrast, the other three (north, east, and west) walls were $77 \mathrm{~cm}$ shorter than the height of the composite floor soffit, as shown in Fig. 2-33b. The gap between the ceiling and the top edges of the walls was enclosed by two layers of Kaowool blanket (25 mm thick each), Fig. 2-35.
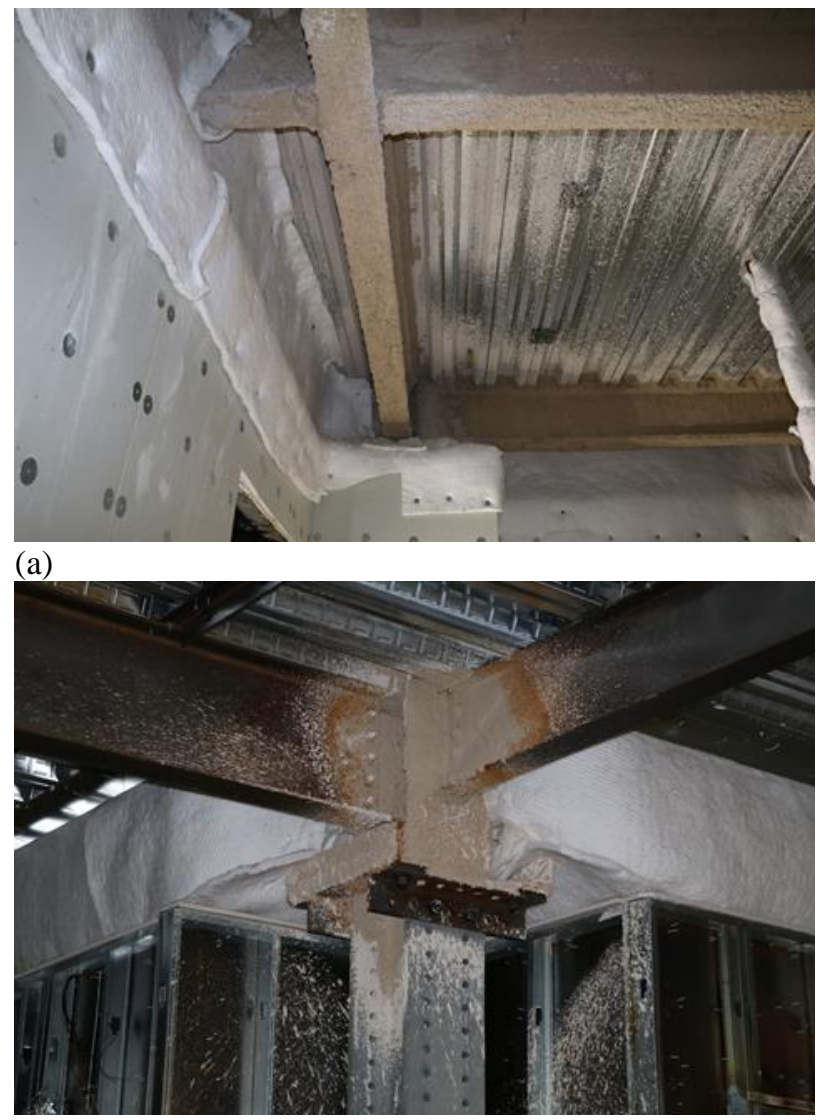

(b)

Fig. 2-35. Photographs of (a) enclosure around the beam-to-girder connection region; (b) enclosure around column (outside of the compartment). 


\subsubsection{Natural Gas Burners}

Fig. 2-36 shows photographs of the natural gas burners, NFRL fuel delivery system, and valves for the burners. The test fire was created using four natural gas fueled burners $(150 \mathrm{~cm}$ long and $100 \mathrm{~cm}$ wide each) distributed across the floor of the test compartment. The four burners were made from steel sheet metal boxes and had the fuel inlet tube at the bottom of each burner box. Steel mesh screens were placed to keep the ceramic fiber blanket inside the burner box. A copper pilot flame tube was placed on the top of each burner to aid the burner ignition. The pilot flame was fed by a small propane bottle outside of the test compartment. The NFRL's natural gas fuel delivery system (Bryant and Bundy, 2019) supplied the burners. The flow of natural gas was regulated using a computer controlled pneumatic valve. A balancing valve manifold at upstream of each of the four burners was used to distribute the fire inside the compartment.

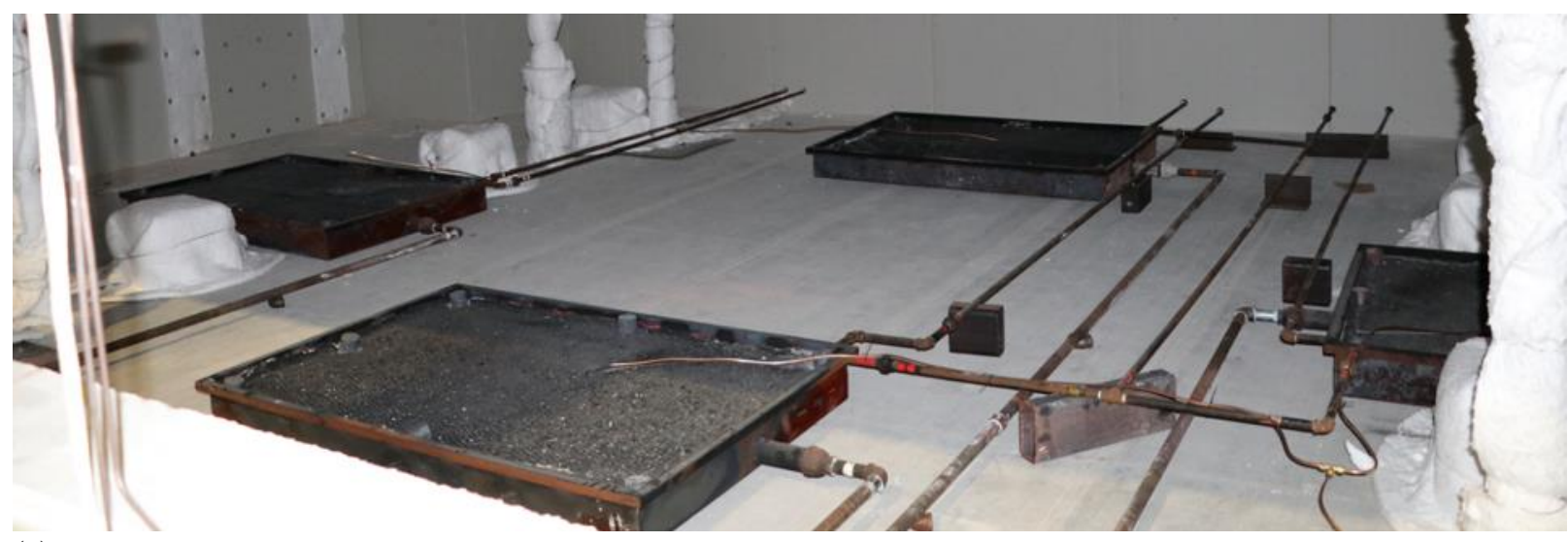

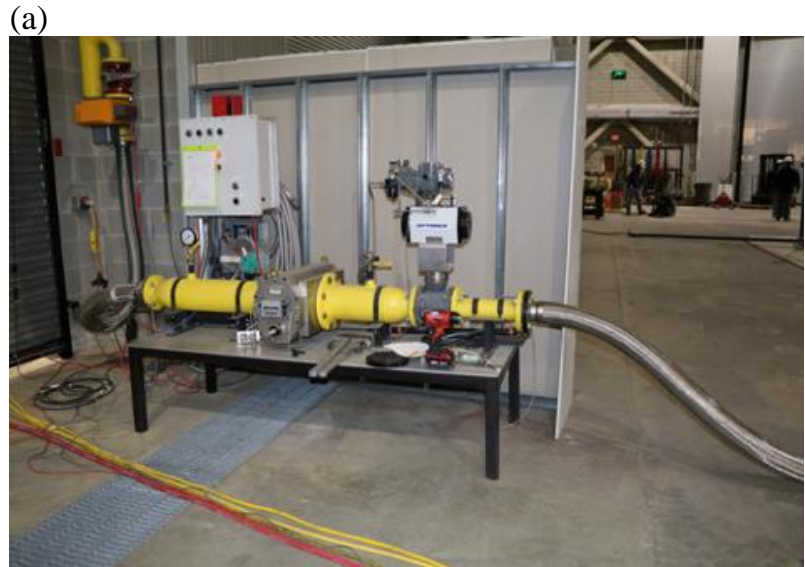

(b)

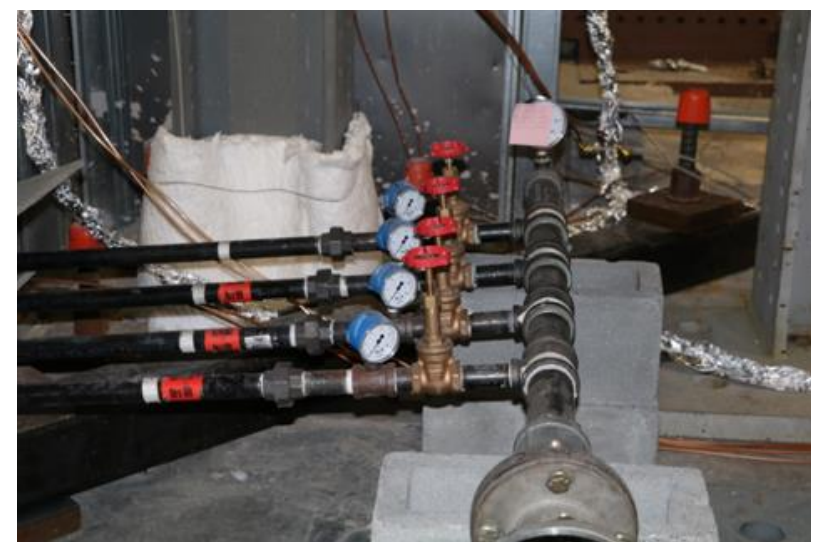

(c)

Fig. 2-36. Photographs of (a) burners placed inside of the fire test compartment, (b) NFRL's natural gas fuel delivery system; (c) balancing values at upstream of the burners. 


\subsubsection{Fire Curve}

The test fire was controlled by the total Heat Release Rate (HRR) of the natural gas burners. In order to replicate the standard time-temperature curve (ASTM E119 or ISO834), the timedependent values of the burner HRR as proposed by Zhang et al. (2019) were used. This proposed relationship was determined by the NIST's Fire Dynamics Simulator (FDS) (McGrattan et al. 2018), accounting for thermal boundary conditions of the test compartment, distribution of the burners, and vent scheme as described in previous sections. A series of mockup fire tests (Sauca et al. 2019) were conducted in a similar room to verify the applicability of the proposed HRR versus time curve, shakedown the burner control and check uniformity of the upper layer gas temperatures within the compartment. Fig. 2-37 shows the proposed burner HRR versus time curve considered in this study and the predicted gas phase temperatures $(\mathrm{Tg})$ at $30.5 \mathrm{~cm}$ below the ceiling of the compartment.

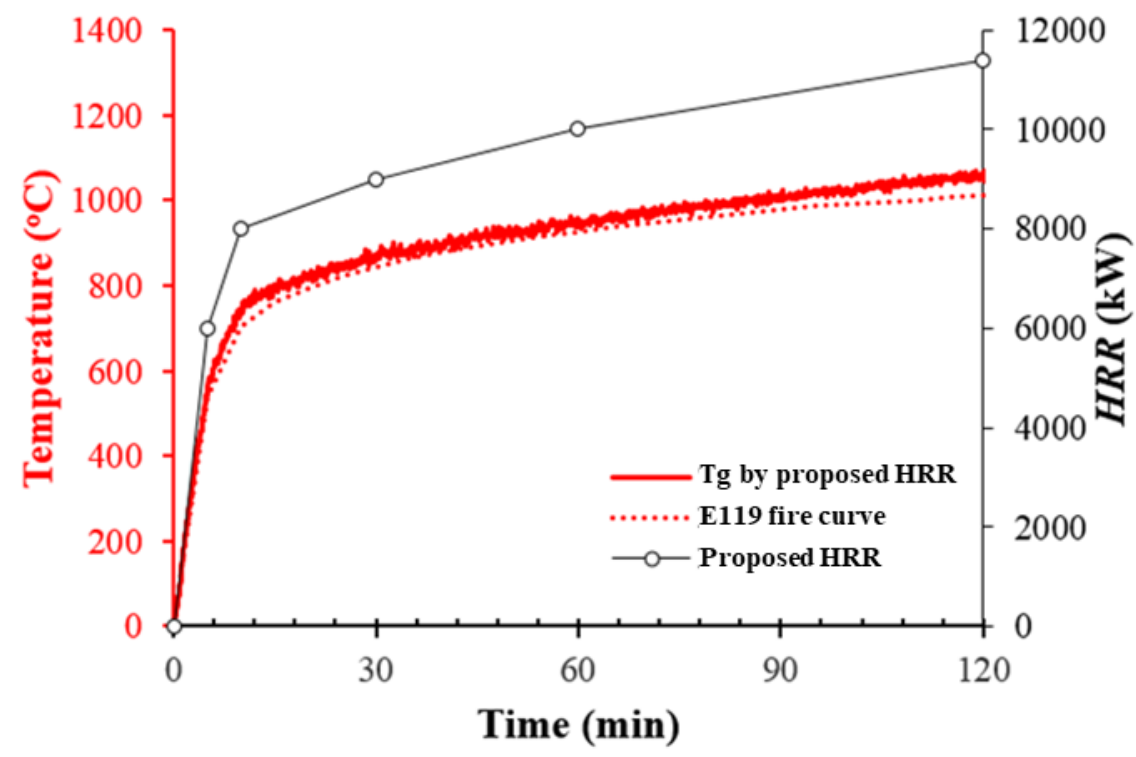

Fig. 2-37. Proposed heat release rate versus time relationship and predicted gas temperatures compared with ASTM E119 temperature-time curve. 


\section{Measurement System}

A variety of sensors were used to measure (1) mechanical loads applied by hydraulic actuators, (2) fire conditions (heat release rates, heat fluxes, gas velocity, and gas-phase temperatures), (3) temperatures of the test floor assembly, and (4) structural responses of the test floor assembly and the surrounding structure (displacements and strains). Details of each measurement system are provided in the following subsections. The estimated measurement uncertainties are reported in Sect. 3.11. Appendix B provides the physical locations of the sensors and raw data.

\subsection{Mechanical Load}

A total of four double-acting servo-hydraulic actuators (Model: MTS 201.35TS) were utilized to apply mechanical loads on the test assembly. Each actuator can generate a hydraulic force up to $250 \mathrm{kN}$ in tension with a full stroke length of $760 \mathrm{~mm}$. The total expanded relative uncertainty (k $=2$ ) was approximately $1 \%$ at $125 \mathrm{kN}$.

\subsection{Heat Release Rate}

The heat release rate of combustion of the natural gas was calculated using the measured mass flow rate and composition of the natural gas (Bryant and Bundy, 2019). The gas mass flow rate was measured using a positive displacement rotary flow meter, pressure gauge, and thermistor. The composition of natural gas was measured using a gas chromatograph with a sampling period of 3 min. The Ideal Gross Heating Value was calculated using the method described in ASTM D3588-98 (2017). The total expanded relative uncertainty $(\mathrm{k}=2)$ of the heat release rate measured by the NFRL's system of natural gas burners was approximately $1.4 \%$ at $10 \mathrm{MW}$ (Bryant and Bundy, 2019).

During the experiment, the fire effluents were captured by the NFRL's 20 MW canopy-style exhaust hood and then transported via the $2.4 \mathrm{~m}$ diameter duct for quantification of the heat release rate using the oxygen consumption calorimetry. In this experiment, exhaust flow was adjusted to approximately $83 \mathrm{~kg} / \mathrm{s}$. The total expanded relative uncertainty $(\mathrm{k}=2)$ of the heat release rate measured by the oxygen consumption calorimeter was approximately $8 \%$ at $10 \mathrm{MW}$ (Bryant and Bundy, 2019).

\subsection{Strain}

Strains of load-bearing steel elements were measured using linear strain gauges (with a nominal resistance of $120 \mathrm{ohm}$ ) manufactured by Tokyo Measuring Instruments Laboratory Co, Ltd. (www.tml.jp). Two different types were deployed in this experiment as follows:

The F series gauges (Model: FLA-5-11) with an operating temperature up to $80^{\circ} \mathrm{C}$ were used to measure steel strains of the following locations: (1) the midspan of the secondary beam (W16×31) and girders (W18×35) of the $9.1 \mathrm{~m}$ by $6.1 \mathrm{~m}$ test floor assembly when subjected to mechanical loading at ambient temperature (Fig. 3-1a) and (2) the No. 4 hooked reinforcing bars in the test floor slab during the fire experiment until the bar temperature reached $80^{\circ} \mathrm{C}$ (Fig. 3-1b).

To eliminate the thermal effects on the strain measurements at temperatures in the range of $20^{\circ} \mathrm{C}$ and $80^{\circ} \mathrm{C}$, the raw data were post-processed using Eq. (3-1) provided by the manufacturer's data sheet. The estimated total expanded uncertainty $(\mathrm{k}=2)$ incorporating temperature compensation is approximately $1 \%$ for the strain measurements of steel elements subjected to the ambienttemperature mechanical loading or those at outside of the test compartment. 
The QF series strain gauges (Model: QFLA-6-11) with an operating temperature up to $200{ }^{\circ} \mathrm{C}$ were attached to (1) the base of steel columns $51 \mathrm{~mm}$ above the end plates anchored to the strong floor; (2) center of the column splices above the test floor assembly; and (3) midspan of the $\mathrm{W} 14 \times 22$ beams in the south-west bay. These strains were used to estimate thermally induced forces from the restraint to thermal expansion or contraction of the test floor assembly exposed to fire. The strain data reported in Appendix B incorporated temperature compensation using Eq. (3-2) provided by the manufacture's data sheet. The total expanded uncertainty $(\mathrm{k}=2)$ of reported strain data measured using QF strain gauges was approximately $1 \%$.

$$
\begin{aligned}
\varepsilon_{\text {report }} & =\varepsilon_{\text {raw }}-\left(-31.8+2.77 \times T-6.55 \times 10^{-2} \times T^{2}+3.28 \times 10^{-4} \times T^{3}\right. \\
& \left.-3.26 \times 10^{-7} \times T^{4}\right) \\
\varepsilon_{\text {report }} & =\varepsilon_{\text {raw }}-\left(-52.4+3.82 \times T-6.43 \times 10^{-2} \times T^{2}+2.36 \times 10^{-4} \times T^{3}\right. \\
& \left.-1.06 \times 10^{-7} \times T^{4}\right)
\end{aligned}
$$

where $\varepsilon_{\text {report }}$ is reported strain $(\mu \mathrm{m} / \mathrm{m})$ in Appendix B; $\varepsilon_{\text {raw }}$ is raw strain $(\mu \mathrm{m} / \mathrm{m})$; and $T$ is the temperature $\left({ }^{\circ} \mathrm{C}\right)$ of a strain gauge.

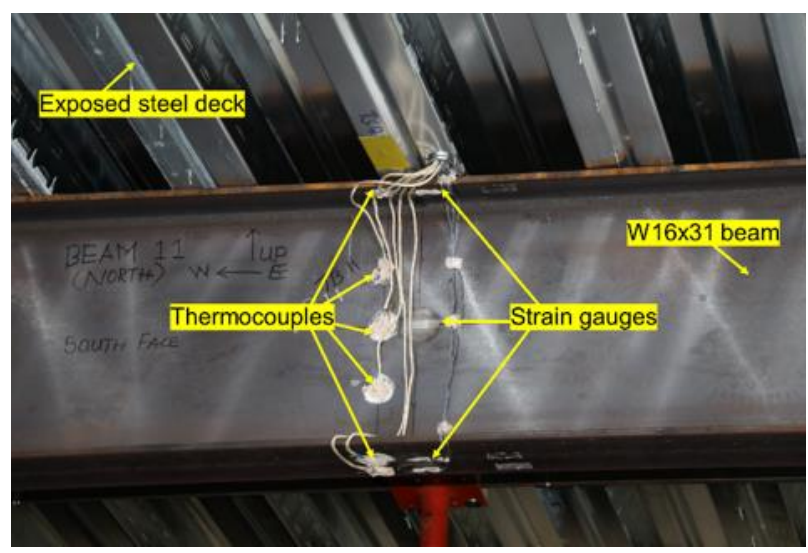

(a)

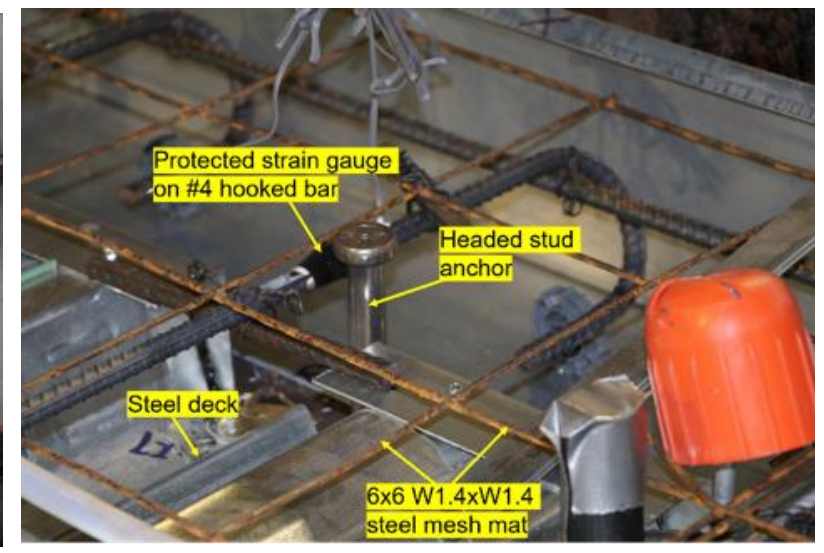

(b)

Fig. 3-1. Photographs of strain gauges attached to (a) secondary steel beam (W16 $\times 31)$ prior to installation of SFRM and (b) No.4 reinforcing bar inside the concrete formwork.

\subsection{Displacement}

Displacements of the test floor assembly and the surrounding structures were measured using string potentiometers manufactured by UniMeasure (https://unimeasure.com/). All potentiometers were installed outside of the test compartment and thermally protected not to exceed the specified operating temperature of $95^{\circ} \mathrm{C}$.

In order to measure the vertical displacement of the test floor assembly, a total of fifteen string potentiometers (Model: PA-30) were mounted to isolated aluminum frames approximately $2 \mathrm{~m}$ high from the test floor slab (Fig. 3-2). The measurement strings were directly connected to embedded steel eye bars anchored to the steel deck or the top flanges of steel beams or girders in the test bay. The total expanded uncertainty $(\mathrm{k}=2)$ of the vertical displacement measurements was estimated to be $2 \%$.

The horizontal displacements were measured at fifteen discrete locations of the two-story test frame: (1) the test bay columns at each story level (B2, B3, C2, and C3 columns in Fig. 3-2; (2) 
the exterior columns and slab edges of the two-story building. Refer to Chapter 4 for the specific locations of the displacement measurements. Some photographs of installed sensors are shown in Fig. 3-3. Most of the string potentiometers used for these measurements (Model: PA-5 and PA10) were equipped with high-tension steel wires and mounted to isolated steel frames or walls less affected by fire effects. Only the first-story drift of the southwest column of the test bay was measured using a temperature compensation technique described in Choe et al (2018). Two string potentiometers (Model: PA-10) with probes made of silicon carbide and aluminum oxide fibers were used to measure the horizontal displacement at that location. As the fibers exhibit different and approximately linear thermal expansion at the gas temperatures, the two measurements were used to correct for the influence of thermal expansion of the probes thus reducing error by more than two orders of magnitude. The total expanded uncertainty $(\mathrm{k}=2)$ of the horizontal displacement measurements was estimated to be $6 \%$.

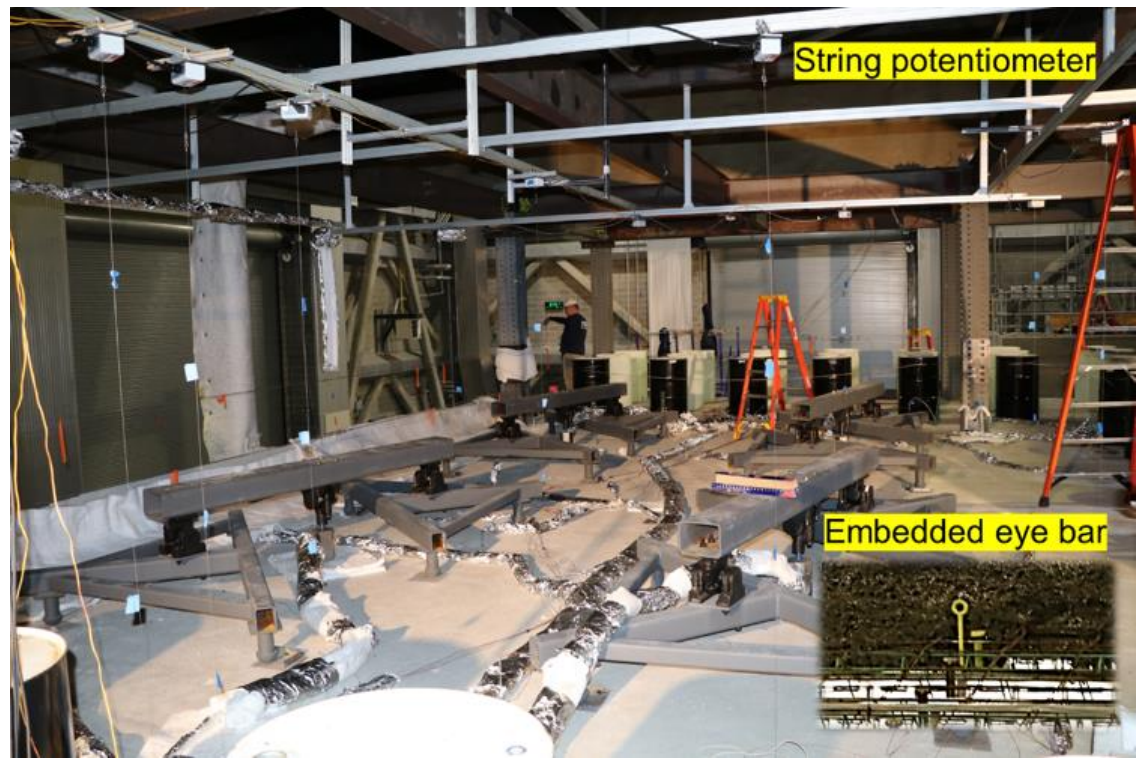

Fig. 3-2. String potentiometers used for the vertical displacement measurements. Measuring strings were directly attached to the eye bars partially embedded in the concrete slab.

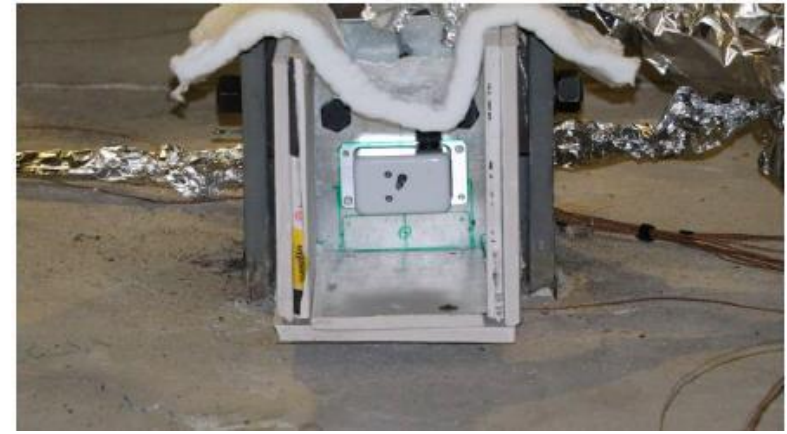

(a)

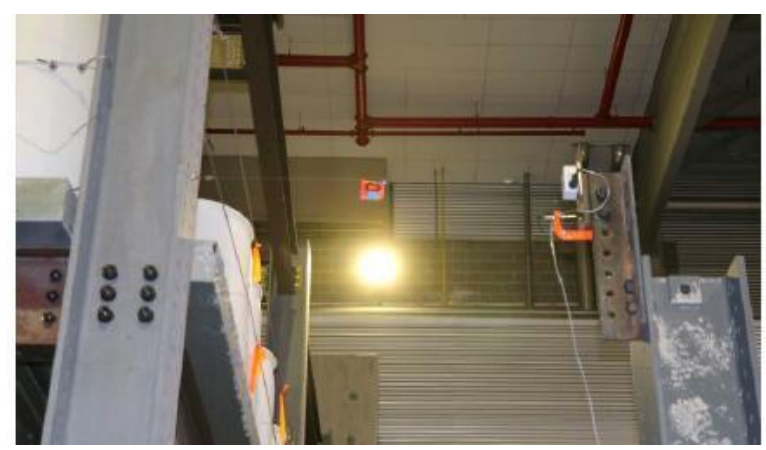

(b)

Fig. 3-3 String potentiometers installed at (a) the interior (B3) column and (b) the exterior $(\mathrm{C} 4)$ column. 


\subsection{Temperature}

Temperatures were measured using type $\mathrm{K}$ thermocouples (with the temperature range up to $1350{ }^{\circ} \mathrm{C}$ ) manufactured by Omega Engineering (https://www.omega.com/en-us/). Fig. 3-4 shows photographs of some thermocouples mounted at various locations of the test assembly. Three different types of thermocouple probes were utilized depending upon their proximity to a fire.

OMEGACLAD sheathed thermocouples (Model: TJ36-CAXL) were used to measure the gasphase temperatures within the test compartment. Twelve thermocouple probes were installed at $305 \mathrm{~mm}$ below the exposed steel deck (Fig. 3-4a) to measure the average hot layer temperatures. Two posts where four thermocouple probes were mounted each were placed to measure the temperature distribution through the height of the test compartment. The total expanded uncertainty of the gas-phase temperature measurement was approximately $8 \%$.

Ceramic fiber sheathed thermocouples (Model: XT-K-20-SLE) were mounted to the steel floor frame inside the test compartment (Fig. 3-4b). Before applying SFRM on the exposed structural steel, the bare beads of thermocouples were secured approximately $3 \mathrm{~mm}$ below the exposed surface by peening and then covered with the Omega high temperature cement (Model: CC HIGH TEMP). The lead wires were routed through the embedded pipes in the concrete slab to minimize the direct exposure to fire, and the exposed portion of wires were buried under the SFRM coating. The total expanded uncertainty $(\mathrm{k}=2)$ of the steel temperature measurement was $6 \%$.

Temperatures of the concrete slab, steel deck, and slab reinforcement were measured using glasssheathed thermocouples (Model: GG-K-24-SLE). Concrete cylinders (with the diameter of 10 $\mathrm{cm})$ were used to mount thermocouples through the depth of the concrete slab. These cylinders were either $6 \mathrm{~cm}$ or $14 \mathrm{~cm}$ tall and made of a concrete mixture similar to that cast in-situ on the steel deck. The thermocouple beads were secured about $6 \mathrm{~mm}$ outside of the concrete cylinder so that they were in contact with the cast-in-place concrete at specified locations within the slab. The same type of thermocouples was also attached to the top of the steel deck (in contact with the cast-in-situ concrete), steel reinforcement, and headed stud anchors. The lead wires of these thermocouples were protected by $8 \mathrm{~mm}$ and $12 \mathrm{~mm}$ diameter Teflon tubing embedded together in the slab. For the temperature measurement of the top (unexposed) surfaces of the concrete slab, the thermocouple probes were embedded about $3 \mathrm{~mm}$ below the top surface and secured by Omega high-temperature cement. The total expanded uncertainty $(\mathrm{k}=2)$ of the temperature measurement using glass-sheathed thermocouples was about $0.5 \%$.

In addition, four standard plate thermometers integrated with K-type thermocouples, manufactured by Pentronic (https://www.pentronic.se), were mounted about $4 \mathrm{~cm}$ off from the surface of the steel floor beams within the test compartment. The temperatures measured by the plate thermometers had a total expanded uncertainty of $8 \%(\mathrm{k}=2)$. 


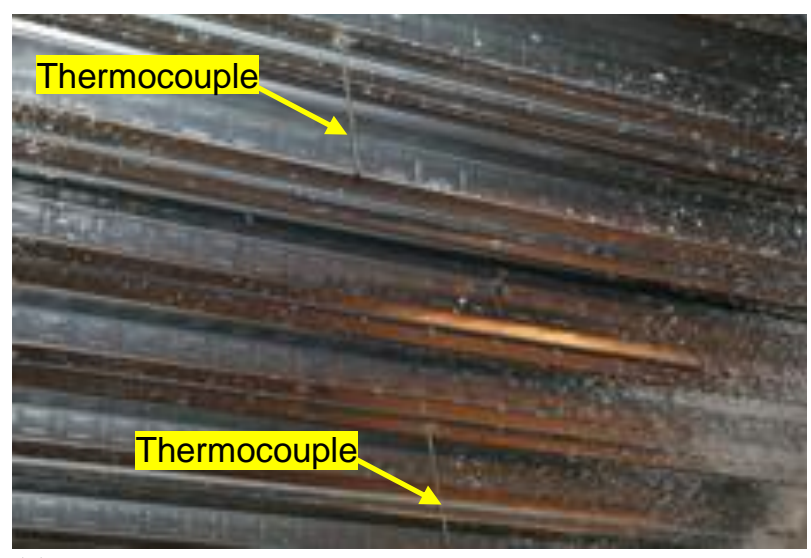

(a)

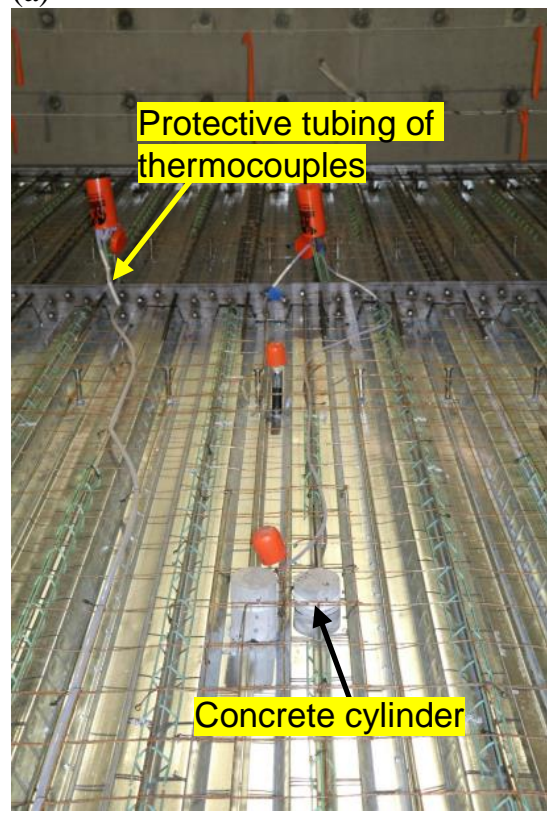

(c)

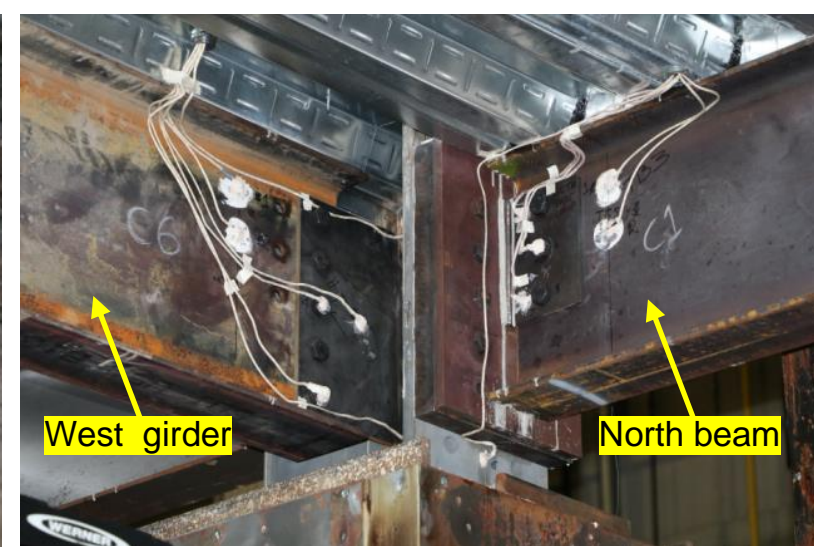

(b)

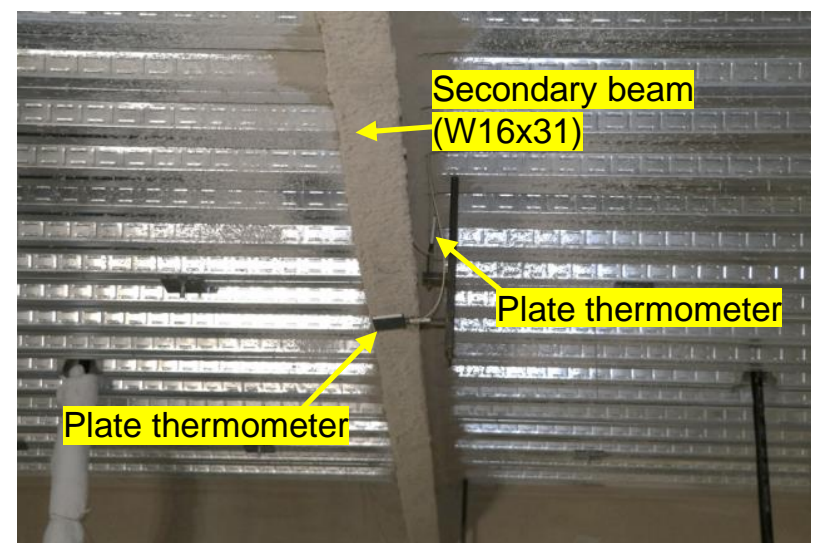

(d)

Fig. 3-4. Photographs of temperature sensors installed at (a) $305 \mathrm{~mm}$ below exposed steel deck; (b) ends of the west girder and the north beam prior to fireproofing; (c) top of the steel deck prior to concrete casting; (d) midspan of secondary beam.

\subsection{Heat Flux}

Gardon gauges (Medtherm Model GTW-15SB-6-60-40-484K) were placed to measure heat flux on the exposed surface of the compartment walls at the northwest and southeast corners of the test compartment. These sensors were placed in steel pipes of $25 \mathrm{~mm}$ inside diameter and were water cooled. The sensor temperature was monitored during the test. The measured heat flux had a total expanded uncertainty $(\mathrm{k}=2)$ of $15 \%$ (Sauca et al. 2019).

\subsection{Gas Pressure and Velocity}

Measurements of gas velocity through the vents were acquired with a few strategically placed bidirection probes. The bi-directional probe (bdp) is an impact probe similar to the pitot-static probe (McCafferey et al., 1976), Fig. 3-5. It obstructs the flow creating a pressure differential between its front and rear openings. Using Bernoulli's principle, the fluid velocity across the bi- 
directional probe, $V_{b d p}$, is inferred from measurements of differential pressure, $\Delta P_{b d p}$, and gas temperature, $T_{b d p}$, at the probe, Eq. (3-3).

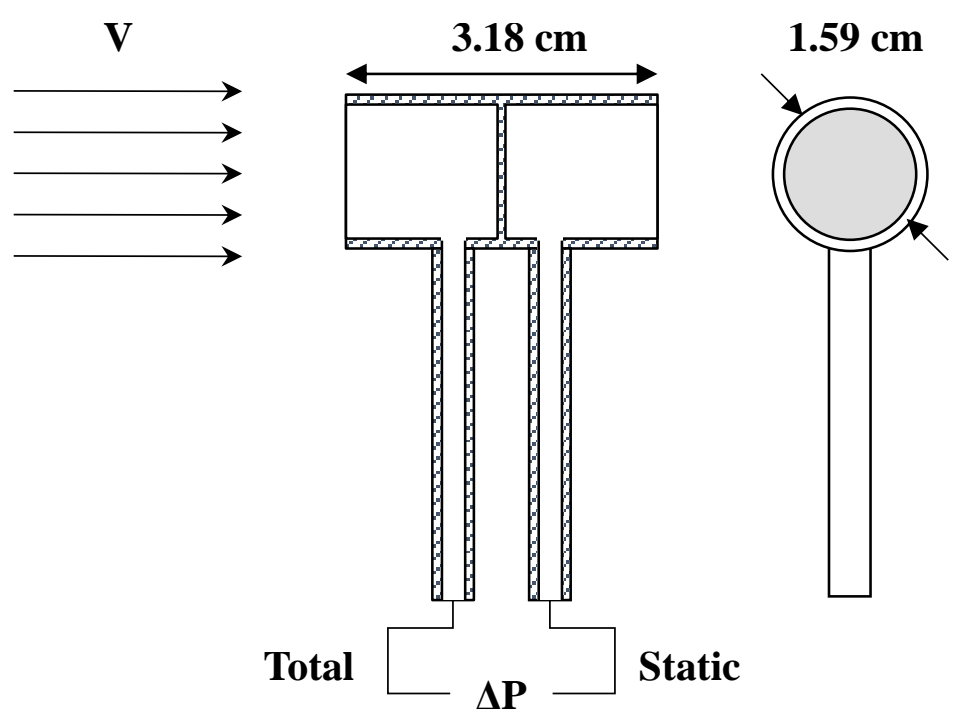

Fig. 3-5. Schematic of a bi-directional probe used for gas velocity measurements.

$$
V_{b d p}=\frac{1}{C_{b d p}} \sqrt{\frac{2 R_{u}}{P_{\text {ref }} M_{\text {gas }}} \Delta P_{b d p} T_{b d p}}
$$

High-precision capacitance manometers (MKS 220CD Baratron), with a range of $0 \mathrm{~Pa}$ to $133.32 \mathrm{~Pa}$ ( 0 torr to 1 torr) and relative expanded uncertainty of 0.01 , were used to measure differential pressure. Local gas temperature was measured using bare-bead thermocouples placed next to each probe. The thermocouples were type $\mathrm{K}$ with average bead diameter of $1.06 \pm 0.11 \mathrm{~mm}$. A probe constant, $C_{\mathrm{bdp}}=1.08 \pm 0.11$, was applied and the molecular weight of the gas, $M_{\text {gas }}$, was assumed to be equal to that of air, $28.97 \pm 0.10 \mathrm{~kg} / \mathrm{kmol}$. Standard atmospheric pressure, $P_{\text {ref }}=101325 \mathrm{~Pa}$, and the universal gas constant, $R_{\mathrm{u}}=$ $8314.46 \mathrm{~J} / \mathrm{kmol} / \mathrm{K}$ were both applied to compute gas velocity.

Two probes were placed on the centerline of the southeast vent and two on the centerline of the northwest vent (Fig. 3-6). The measured velocities had a total expanded $(\mathrm{k}=2)$ uncertainty of $22 \%$ (Bryant 2019). 


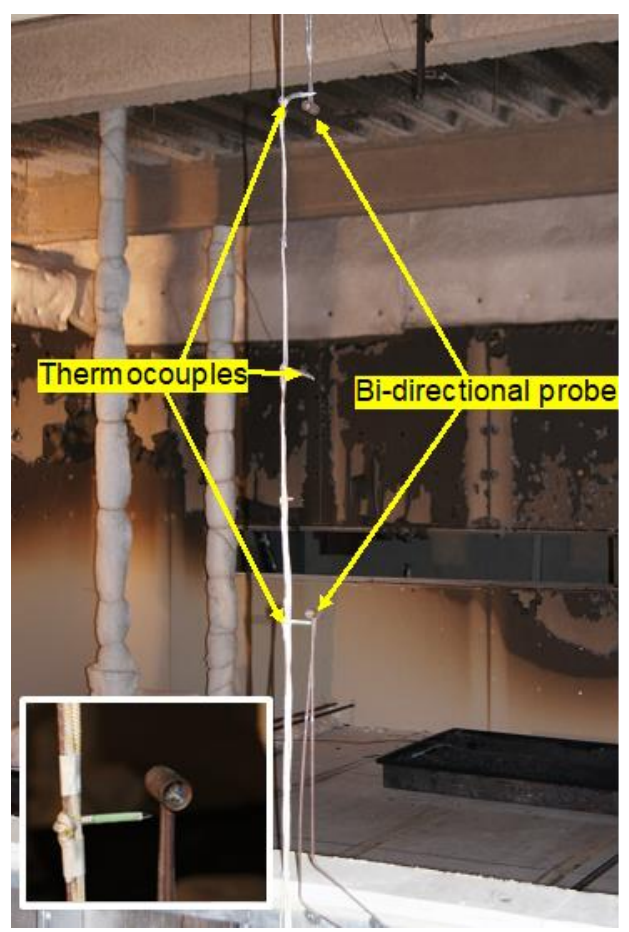

(a)

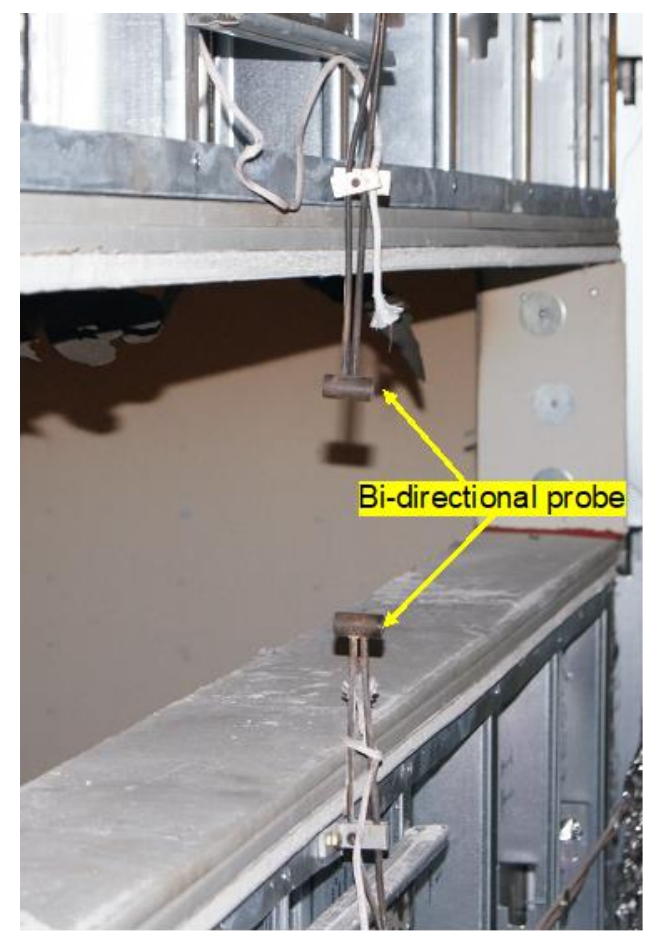

(b)

Fig. 3-6. Photographs of bi-directional probes at (a) southeast vent and (b) northwest vent of the test compartment.

\subsection{Physical Dimensions and Weight}

The reported dimensions were measured using construction tape measures with an accuracy of $1.6 \mathrm{~mm}(1 / 16 \mathrm{in}$.). The total expanded uncertainty of measured dimensions was less than $1 \%$.

The reported weights of water-filled drums and other ancillary components of gravity loading system were measured using an Intercomp CW250 Platform scale. The total expanded uncertainty in this weight measurement was approximately $2 \%$.

\subsection{Data Acquisition System}

The voltage and temperature measurements were digitized and recorded using National Instruments (NI) CompactDAQ chassis (Model: cDAQ-9181 and cDAQ-9188) populated with signal conditioned I/O Modules, including NI-9213 modules for thermocouples, NI-9205 modules for a variety of voltage-based sensors, and NI-9237 modules for strain gauges of the test assembly. In addition, strains of steel columns were acquired using NI PXIe-1082 chassis with NI PXIe-4330 I/O modules. The heat release rate measured by the NFRL's calorimeters were digitized and recorded using a separate data acquisition system described by Bryant et al (2019).

An in-house software developed in LabVIEW ${ }^{\mathrm{TM}}$ called MIDAS (Modular In-situ Data Acquisition System) was used to allocate channels and control the data acquisition. In this test, the sample rate for the cDAQ and PXIe systems was $12 \mathrm{kHz}$ and $25 \mathrm{kHz}$, respectively. The read rate was identical to the sample rate. The data were recorded at one-second intervals along with the standard deviations from the averaging process. The data acquisition hardware had 16 bit or 24 bit precision for the cDAQ and PXIe systems, respectively. The NI-9213 modules have a maximum error of $2{ }^{\circ} \mathrm{C}$ that includes offset errors, gain errors, nonlinearity, quantization errors, 
noise errors, a lead wire resistance of $50 \Omega$, and cold-junction compensation errors according to the manufacturer's specification (https:/www.ni.com). The NI-9205 modules have an absolute accuracy of $0.06 \%$ that includes a gain error of $0.05 \%$, an offset error of $0.01 \%$ and a noise uncertainty of $72 \mu \mathrm{V}$ at full output range of $10 \mathrm{~V}$. The NI-9237 modules have a typical gain error of $0.05 \%$ and an offset error of $0.05 \%$. The PXIe chassis used for the strain measurements has a typical accuracy of $0.0025 \%$.

\subsection{Camera System}

A total of thirteen high-definition cameras were deployed to record and live-stream a variety of video scenes of the test building and the fire test compartment during the heating and cooling phases of a fire. In particular, two water-cooled cameras were deployed in close proximity to test fire. One camera was placed on the floor of the test compartment at the south-east corner and another camera was placed behind a fused silica window on the northeast wall of the compartment (Fig. 3-7). Other cameras were used to capture the top of the concrete slab or the isometric view of the test building.

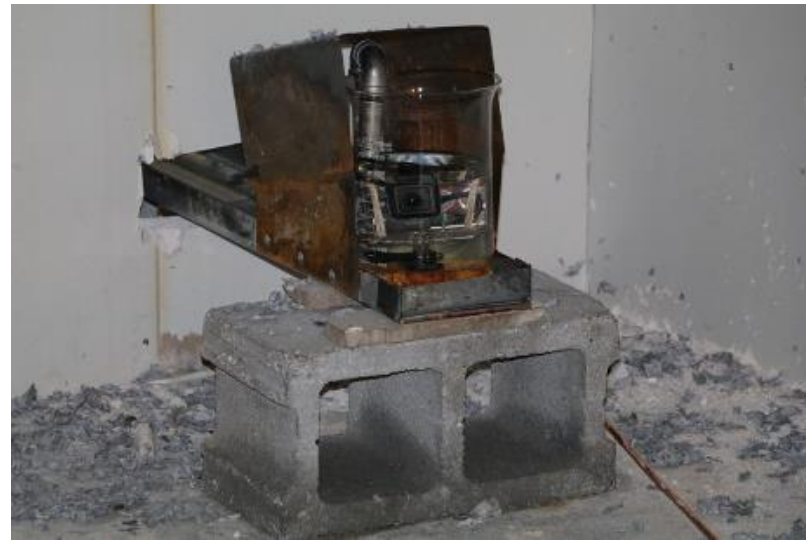

(a)

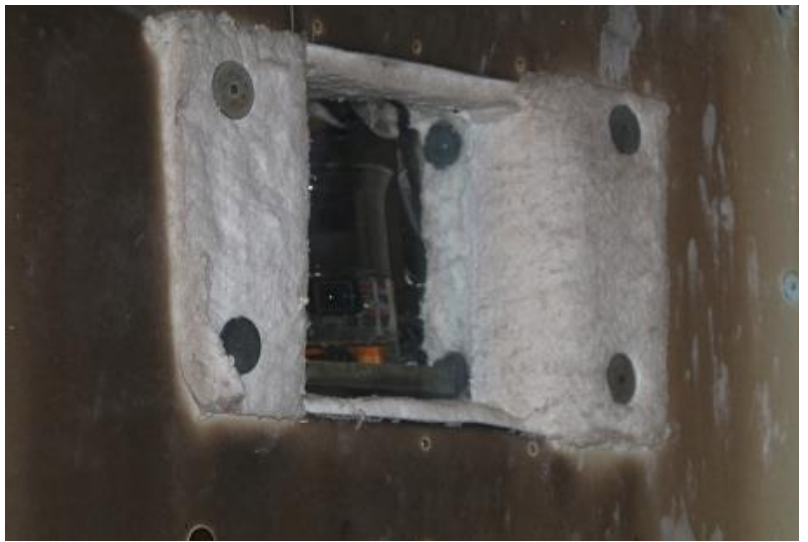

(b)

Fig. 3-7. Water-cooled cameras used to capture the test assembly during and after fire experiment.

Thermal imaging of the unexposed (top) surface of the test assembly was performed using a high-speed infrared camera (Model: FLIR SC8303). This camera was mounted on the strong wall at north of the test building, as shown in Fig. 3-8.

Temperature data were collected at 15 fps during this test. The thermal imaging camera preset parameters used in this test are summarized in Table 3-1. However, the uncertainty in temperature data from this system was not estimated since the calculated output was highly sensitive to a transient fire environment. Several images presented in Chapter 4 are intended to describe the integrity failure of the composite slab in the test bay. Future work will be performed to better understand the factors influencing the uncertainty in temperature measurements with the same camera. 


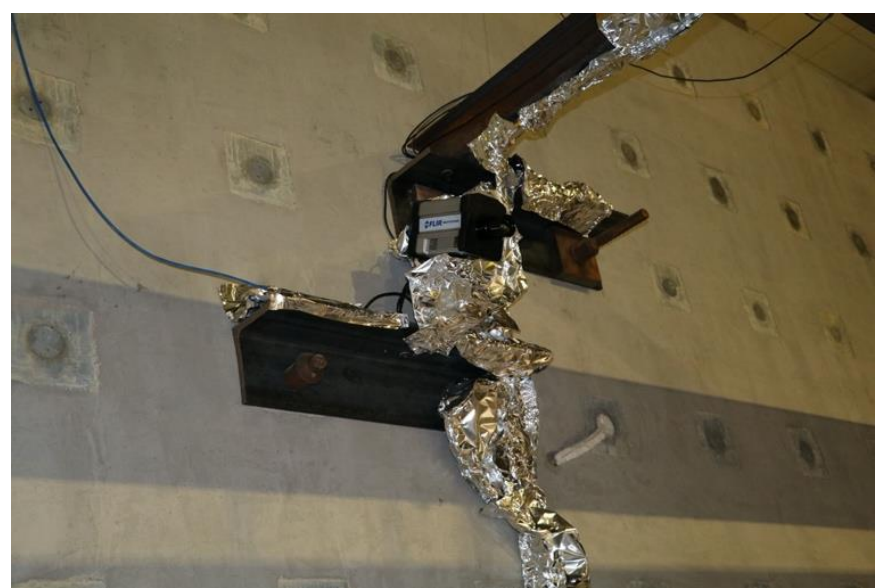

Fig. 3-8. Infrared camera mounted on the strong wall.

Table 3-1. Thermal imaging camera preset parameters.

\begin{tabular}{ll}
\hline Parameter & Selected Range or Value \\
\hline Temperature & $10{ }^{\circ} \mathrm{C}$ to $90{ }^{\circ} \mathrm{C}$ and $35{ }^{\circ} \mathrm{C}$ to $150{ }^{\circ} \mathrm{C}$ \\
Emissivity (0 to 1) & 0.92 \\
Distance to target & $1 \mathrm{~m}$ \\
Reflected temperature & $20{ }^{\circ} \mathrm{C}$ \\
Atmospheric temperature & $20{ }^{\circ} \mathrm{C}$ \\
Relative humidity & $30 \%$ \\
Transmission $(0$ to 1$)$ & 1 \\
Optics temperature & $20{ }^{\circ} \mathrm{C}$ \\
Optics Transmission $(0$ to 1$)$ & 1 \\
\hline
\end{tabular}




\subsection{Measurement Uncertainty}

The measurement uncertainty in the experiment data of the present study is summarized in Table 3-2. The estimated total expanded uncertainty values are rounded to the nearest integer, except for the construction dimensions and heat release rate of burners which are rounded to the nearest tenth. The users of this report are advised to be informed that the experimental results presented in Chapter 4 are either raw data or the statistics of raw data acquired by the aforementioned measurement systems. It is recommended incorporating the measurement uncertainty reported herein into the validation of predictive models or verification of new metrology techniques.

The standard uncertainty in measurements is estimated based on four categories in accordance with Taylor and Kuyatt (1994) as follows:

- Type A uncertainty estimated using statistical analysis of the measured data, e.g., inhouse calibration or random error caused by the test environment

- Type B uncertainty estimated by other means, such as manufacturer's data sheets (e.g., sensor resolution or factory calibration) or past experience (e.g., assumed misalignment or temperature effects)

- Combined standard uncertainty estimated using 'root-sum-of-squares' method to combine all the Type A and Type B uncertainty components

- Total expanded uncertainty computed by multiplying the combined standard uncertainty by a coverage factor $(\mathrm{k})$ of 2 for a $95 \%$ confidence level

The components considered in the component standard uncertainty include resolution, calibration, installation, and random errors. The resolution is the minimum change in the data measurement the instrument can exhibit. Calibration error includes uncertainties from calibration of the sensor. The resolution and calibration uncertainties were derived from instrument specifications (Type B). Uncertainty due to installation method was estimated based on engineering judgment (Type B) considering misalignment, quality of the mounting method of the sensors, and previous data. Random error, which resulted from random, unpredictable variations in the environment and measurement process was estimated as Type A. 
Table 3-2. Estimated measurement uncertainty. $\mathrm{FSO}_{\mathrm{E}}=$ maximum measured values; $\mathrm{N}=$ number of samples used for estimating random errors.

\begin{tabular}{|c|c|c|c|c|}
\hline Measurement / Component & $\begin{array}{l}\text { Uncertainty } \\
\text { Type }\end{array}$ & $\begin{array}{l}\text { Standard } \\
\text { Uncertainty }\end{array}$ & $\begin{array}{l}\text { Combined } \\
\text { Standard } \\
\text { Uncertainty }\end{array}$ & $\begin{array}{c}\text { Total } \\
\text { Expanded } \\
\text { Uncertainty } \\
(\mathbf{k}=2)\end{array}$ \\
\hline $\begin{array}{l}\text { Actuator Load }\left(\mathrm{FSO}_{\mathrm{E}}=125 \mathrm{kN}\right) \\
\text { Resolution } \\
\text { Calibration } \\
\text { Random }(\mathrm{N}=6390)\end{array}$ & $\begin{array}{l}\text { Type B } \\
\text { Type B } \\
\text { Type A }\end{array}$ & $\begin{array}{l} \pm 0.1 \% \\
\pm 0.5 \% \\
\pm 0.4 \%\end{array}$ & $\pm 0.6 \%$ & $\pm 1 \%$ \\
\hline $\begin{array}{l}\text { Vertical Displacement }\left(\mathrm{FSO}_{\mathrm{E}}=580 \mathrm{~mm}\right) \\
\text { Resolution } \\
\text { Calibration } \\
\text { Random }(\mathrm{N}=12000)\end{array}$ & $\begin{array}{l}\text { Type B } \\
\text { Type B } \\
\text { Type A }\end{array}$ & $\begin{array}{l} \pm 0.1 \% \\
\pm 0.2 \% \\
\pm 1.2 \%\end{array}$ & $\pm 1.2 \%$ & $\pm 2 \%$ \\
\hline $\begin{array}{l}\text { Horizontal Displacement }(\mathrm{FSO}=35 \mathrm{~mm}) \\
\text { Resolution } \\
\text { Calibration } \\
\text { Temperature compensation } \\
\text { Random }(\mathrm{N}=12000)\end{array}$ & $\begin{array}{l}\text { Type B } \\
\text { Type B } \\
\text { Type B } \\
\text { Type A }\end{array}$ & $\begin{array}{l} \pm 0.1 \% \\
\pm 1.1 \% \\
\pm 2.0 \% \\
\pm 1.8 \%\end{array}$ & $\pm 2.9 \%$ & $\pm 6 \%$ \\
\hline $\begin{array}{l}\text { Strain }(\mathrm{FSO}=4320 \mu \varepsilon) \\
\text { Resolution } \\
\text { Calibration } \\
\text { Random }(\mathrm{N}=12000)\end{array}$ & $\begin{array}{l}\text { Type B } \\
\text { Type B } \\
\text { Type A }\end{array}$ & $\begin{array}{l} \pm 0.1 \% \\
\pm 0.5 \% \\
\pm 0.1 \%\end{array}$ & $\pm 0.5 \%$ & $\pm 1 \%$ \\
\hline $\begin{array}{l}\text { Steel Temperature }\left(\mathrm{FSO}=970^{\circ} \mathrm{C}\right) \\
\text { Resolution } \\
\text { Calibration } \\
\text { Installation } \\
\text { Random }(\mathrm{N}=12000)\end{array}$ & $\begin{array}{l}\text { Type B } \\
\text { Type B } \\
\text { Type B } \\
\text { Type A }\end{array}$ & $\begin{array}{l} \pm 0.1 \% \\
\pm 0.4 \% \\
\pm 2.0 \% \\
\pm 2.4 \%\end{array}$ & $\pm 3.2 \%$ & $\pm 6 \%$ \\
\hline $\begin{array}{l}\text { Concrete Temperature }\left(\mathrm{FSO}=310^{\circ} \mathrm{C}\right) \\
\text { Resolution } \\
\text { Calibration } \\
\text { Random }(\mathrm{N}=12000)\end{array}$ & $\begin{array}{l}\text { Type B } \\
\text { Type B } \\
\text { Type A }\end{array}$ & $\begin{array}{c} \pm 0.1 \% \\
\pm 0.4 \% \\
\pm 2.8 \%\end{array}$ & $\pm 4.1 \%$ & $\pm 8 \%$ \\
\hline $\begin{array}{l}\text { Gas Temperature }\left(\mathrm{FSO} \mathrm{E}=1110^{\circ} \mathrm{C}\right) \\
\text { Resolution } \\
\text { Bias } \\
\text { Radiative cooling or heating } \\
\text { Random }(\mathrm{N}=12000)\end{array}$ & $\begin{array}{l}\text { Type B } \\
\text { Type B } \\
\text { Type B } \\
\text { Type A }\end{array}$ & $\begin{array}{l} \pm 0.1 \% \\
\pm 0.4 \% \\
\pm 4.0 \% \\
\pm 0.4 \%\end{array}$ & $\pm 4.1 \%$ & $\pm 8 \%$ \\
\hline $\begin{array}{l}\text { Construction Dimensions }\left(\mathrm{FSO}_{\mathrm{E}}=9.1 \mathrm{~m}\right) \\
\text { Resolution } \\
\text { Misalignment } \\
\text { Random }\end{array}$ & $\begin{array}{l}\text { Type B } \\
\text { Type B } \\
\text { Type B }\end{array}$ & $\begin{array}{l} \pm 0.1 \% \\
\pm 0.2 \% \\
\pm 0.1 \%\end{array}$ & $\pm 0.2 \%$ & $\pm 0.5 \%$ \\
\hline $\begin{array}{l}\text { Weight }\left(\mathrm{FSO}_{\mathrm{E}}=2.1 \mathrm{kN}\right) \\
\text { Resolution } \\
\text { Bias } \\
\text { Random }\end{array}$ & $\begin{array}{l}\text { Type B } \\
\text { Type B } \\
\text { Type A }\end{array}$ & $\begin{array}{l} \pm 0.1 \% \\
\pm 0.1 \% \\
\pm 1.2 \%\end{array}$ & $\pm 1.2 \%$ & $\pm 2 \%$ \\
\hline $\begin{array}{l}\text { Fuel Consumption Calorimetry } \\
\left(\mathrm{FSO}_{\mathrm{E}}=10 \mathrm{MW}\right)\end{array}$ & Type B & & & $\pm 1.4 \%$ \\
\hline $\begin{array}{l}\text { Oxygen Consumption Calorimetry } \\
\left(\mathrm{FSO}_{\mathrm{E}}=10 \mathrm{MW}\right)\end{array}$ & Type B & & & $\pm 8 \%$ \\
\hline
\end{tabular}




\section{Test Results}

This chapter presents the results of the first compartment fire experiment (Test \#1) conducted on the $9.1 \mathrm{~m}$ by $6.1 \mathrm{~m}$ composite floor assembly of the two-story prototype building, including:

- Testing conditions (imposed mechanical loads and heat release rates of the test fire),

- Thermal (temperatures, heat fluxes, and gas velocities) and structural (strains and displacements) responses of the test floor assembly to combined effects from the fire and mechanical loading, and

- Important observations from multimedia data as well as through the post-test inspections.

\subsection{Test Protocol}

The following test protocol was used in this experiment:

1. Apply a total actuator load of $125 \mathrm{kN}$ to the test floor assembly using four servohydraulic actuators at ambient temperature

2. Ignite pilot flames of the burners and increase natural gas flow to ignite the burners. The heat release rate of the burners (HRRburner) was then set to $1000 \mathrm{~kW}$ for approximately 2 min to verify the uniformity of natural gas flow to all four burners.

3. Increase the value of HRRburner to simulate a standard fire environment within the test compartment. The pre-programed HRRburner versus time relationship was used to heat the upper layer of the test compartment following the ASTM E119 time-temperature curve.

4. Remove the fire and mechanical loading simultaneously when any of the following criteria is met: (i) detachment of beam-to-column connection(s), (ii) breach of the fire test compartment (a test floor assembly, enclosing walls, or both), (iii) actuator displacement reaching its maximum of $690 \mathrm{~mm}$, (iv) loss of exhaust hood flow, or (v) failure of the data acquisition system network connection for a period exceeding 5 min.

The recorded timeline of the fire experiment is illustrated in Fig. 4-1. The mechanical loading was initiated at 12:45 PM. A target load value of $125 \mathrm{kN}$ was achieved at 1:20 PM. The test fire was ignited at 2:00 PM. It should be noted that there was about 2 min break in fire loading application from 3:40 PM to 3:42 PM. The burner flames went out as a network switch connecting the natural gas fuel delivery system momentarily lost power, thereby activating a safety shutoff valve. Finally, the fire and mechanical loads were manually removed at 3:47 PM due to safety concerns after a severe breach of the test floor assembly was witnessed. The exhaust flow of the hood was terminated afterwards. The recorded fire duration was approximately $107 \mathrm{~min}$ while the mechanical load was applied. 


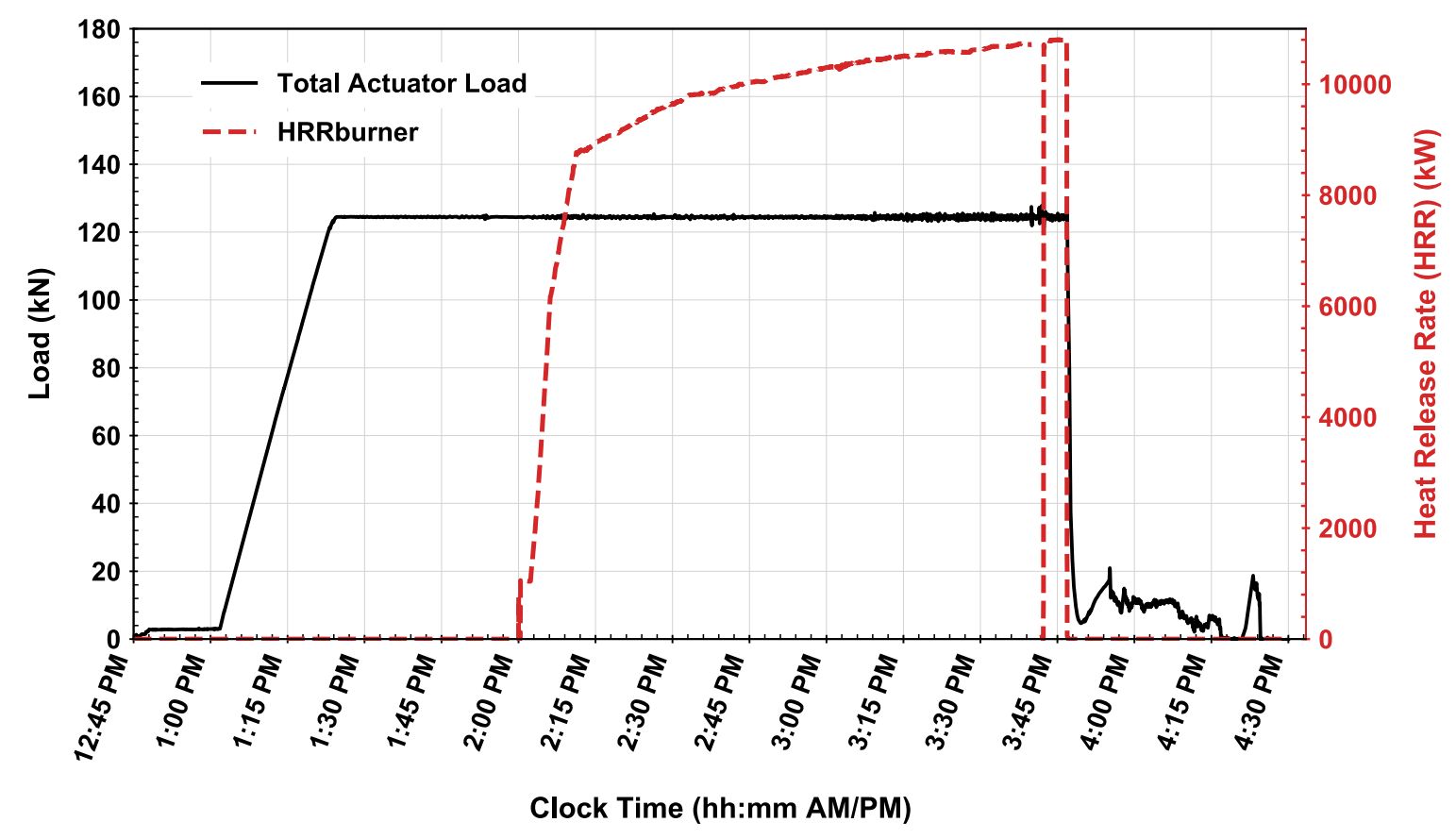

Fig. 4-1 Timeline of Test \#1 conducted on Thursday, November 14, 2020.

\subsection{Mechanical Loading}

There were four servo-hydraulic actuators (each named as NW, NE, SW, and SE) used to apply mechanical loads that were uniformly distributed at twenty-four points across the test floor slab. As shown in Fig. 4-2, each of four actuators transferred the mechanical load equally at six points spaced $152 \mathrm{~cm}$ apart during the fire exposure.

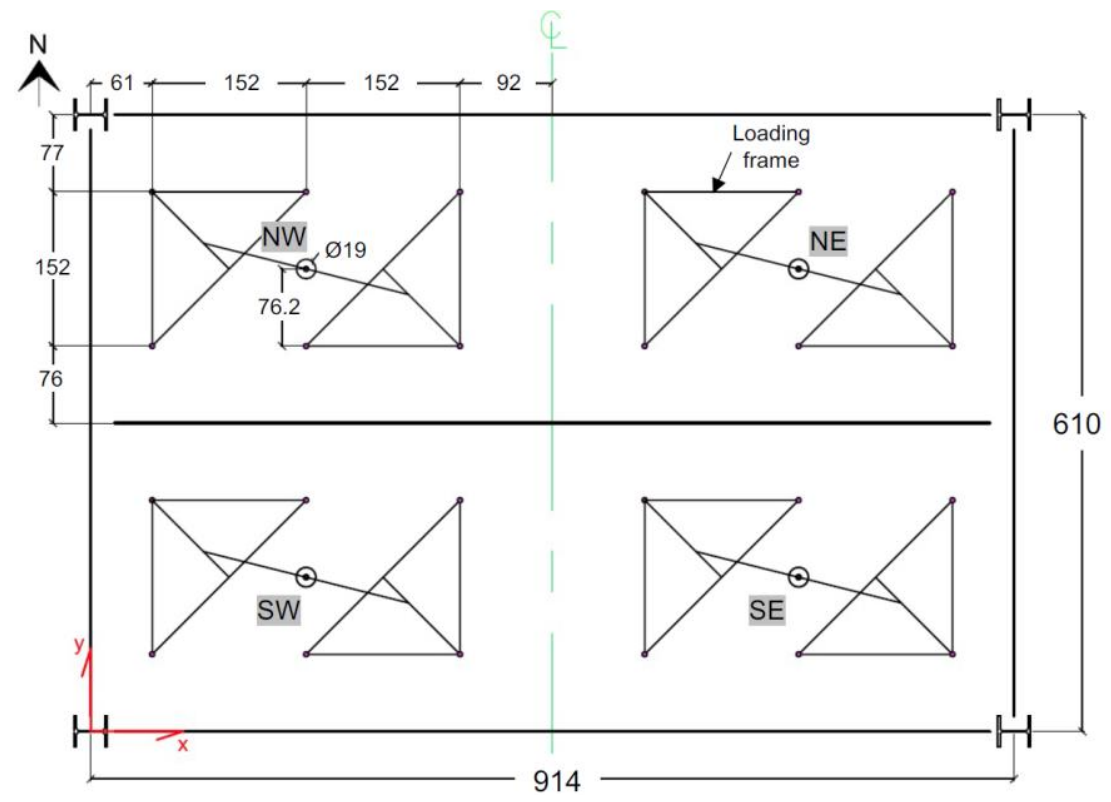

Fig. 4-2. Locations of loading points tied to four hydraulic actuators (NE, NW, SE, and SW). 
The average actuator load and stroke displacement are shown in Fig. 4-3. The data from individual actuators are presented in Appendix B. As each of four actuators increased a load to a target value of approximately $31 \mathrm{kN}$ at ambient temperature, the variation in actuator loads was about $4 \%$ due to the presence of a time lag among actuators. During the fire exposure, the actuator loads varied by less than $2 \%$. A total magnitude of the mechanical load was maintained to $124.4 \mathrm{kN}$ on average until the test fire was extinguished at $107 \mathrm{~min}$. The variation in total actuator loads over fire duration was approximately $1 \%$.

As shown in Fig. 4-3b, the actuator displacement of the north side and south side of the test slab deviated after $10 \mathrm{~min}$. Stroke displacements of the two south actuators (SE and SW) increased much quicker than the two north actuators (NE and NW). This result indicated that the south (free) edge of the test floor slab allowed more rotational flexibility than the north edge connected to the surrounding bay. The maximum stroke difference between the north and south actuators was about $40 \mathrm{~mm}$ at $107 \mathrm{~min}$. The maximum stroke difference between the east and west actuators was less than $10 \mathrm{~mm}$.

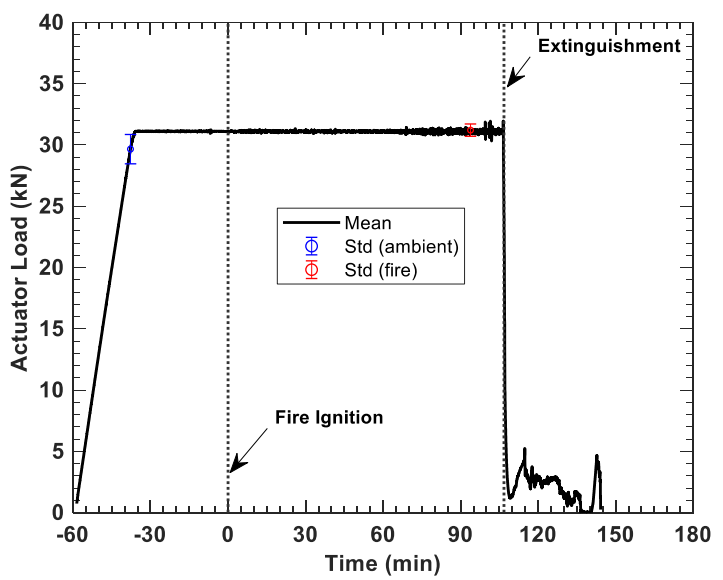

(a) north actuators (NE and NW) and the south actuators (SE and SW). 


\subsection{Test Fire Condition}

The test compartment fire was created using four natural gas burners. The test fire conditions were characterized in terms of heat release rates, gas-phase temperatures within the test compartment, and air flow through the compartment vent openings.

\subsubsection{Heat Release Rate}

There were two different measurements of the heat release rate, including the total heat release rate of the burners (HRRburner) and the heat release rate measured at the $13.7 \mathrm{~m} \times 15.2 \mathrm{~m}$ exhaust hood (HRR). Fig. 4-4 shows a comparison between the HRR and HRRburner measurements during the fire test.

After the burner ignition was confirmed at time equal to $0 \mathrm{~min}$, the initial value of HRRburner was set to $1000 \mathrm{~kW}$ to verify the uniformity of natural gas flow into all four burners. In the growth stage of a test fire, the HRR values were more closely related to the HRRburner values which were increased at about $870 \mathrm{~kW} / \mathrm{min}$ over $9 \mathrm{~min}$. From $11 \mathrm{~min}$ to $107 \mathrm{~min}$ into fire loading, the value of HRRburner was increased at approximately $22 \mathrm{~kW} / \mathrm{min}$ on average. The HRR values fluctuated $\pm 500 \mathrm{~kW}$ while the HRRburner increased more smoothly. During this phase, the moving average value of HRR (at every $1 \mathrm{~min}$ ) was approximately $400 \mathrm{~kW}$ greater than the HRRburner value. This discrepancy was within a total expanded uncertainty of oxygen calorimetry measurements. As mentioned in Sect. 4.1, there was a temporary loss of HRRburner data at $100 \mathrm{~min}$ due to the network outage, but the connection was recovered at $102 \mathrm{~min}$. In this test, a peak value of HRRburner was approximately $10.8 \mathrm{MW}$ before the fire and mechanical loads were removed at $107 \mathrm{~min}$. The value of HRR decreased to zero at $150 \mathrm{~min}$ in test time, approximately 43 min after the fire was extinguished.

Fig. 4-5 shows several video frames indicating the progress of the fire inside the test compartment when the HRRburner value hit $1 \mathrm{MW}, 8.7 \mathrm{MW}$, and 10.8 MW. This video camera was located at the southeast corner of the test compartment floor and provided a less clear view as the fire duration surpassed $80 \mathrm{~min}$.

Table 4-1 shows a summary of the measured total heat energy from the test fire and the fuel load density estimated as the total heat energy divided by the floor area of the test compartment. The total heat energy produced from the test fire up to $107 \mathrm{~min}$ was approximately equal to $60 \mathrm{GJ}$. The fuel load density was estimated to be less than $1000 \mathrm{MJ} / \mathrm{m}^{2}$ but greater than the value representing typical office settings $\left(400 \mathrm{MJ} / \mathrm{m}^{2}\right.$ to $\left.600 \mathrm{MJ} / \mathrm{m}^{2}\right)$. 
Table 4-1 Measured total heat release and fuel load density. The values after \pm symbols indicate the expanded uncertainty (with $\mathrm{k}=2$ ).

\begin{tabular}{lll}
\hline & Total heat energy $(\mathrm{GJ})$ & Fuel load density $\left(\mathrm{MJ} / \mathrm{m}^{2}\right)$ \\
\hline Based on HRR values & $63.5 \pm 8.0$ & $980 \pm 8.0$ \\
Based on HRRburner values & $61.2 \pm 1.4$ & $943 \pm 1.5$ \\
\hline
\end{tabular}

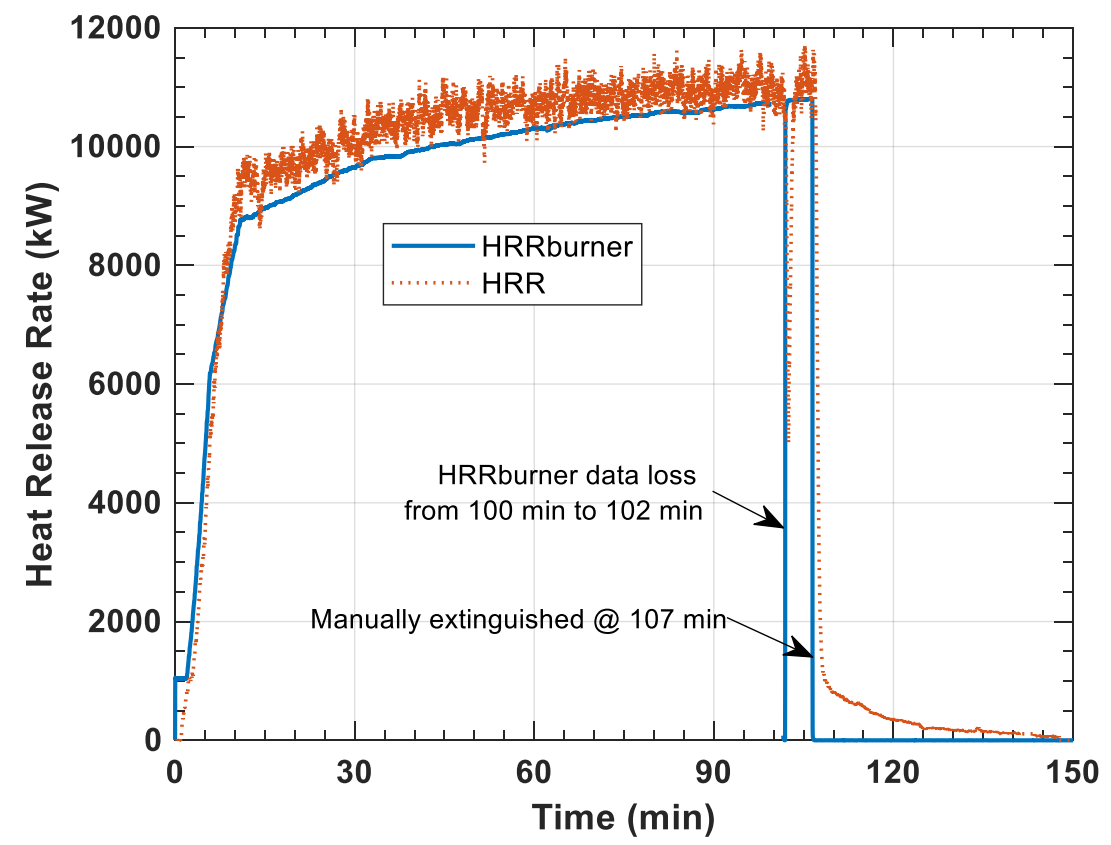

Fig. 4-4. Measured heat release rates at the natural gas fuel delivery system (HRRburner) and at the 20 MW exhaust hood (HRR). 

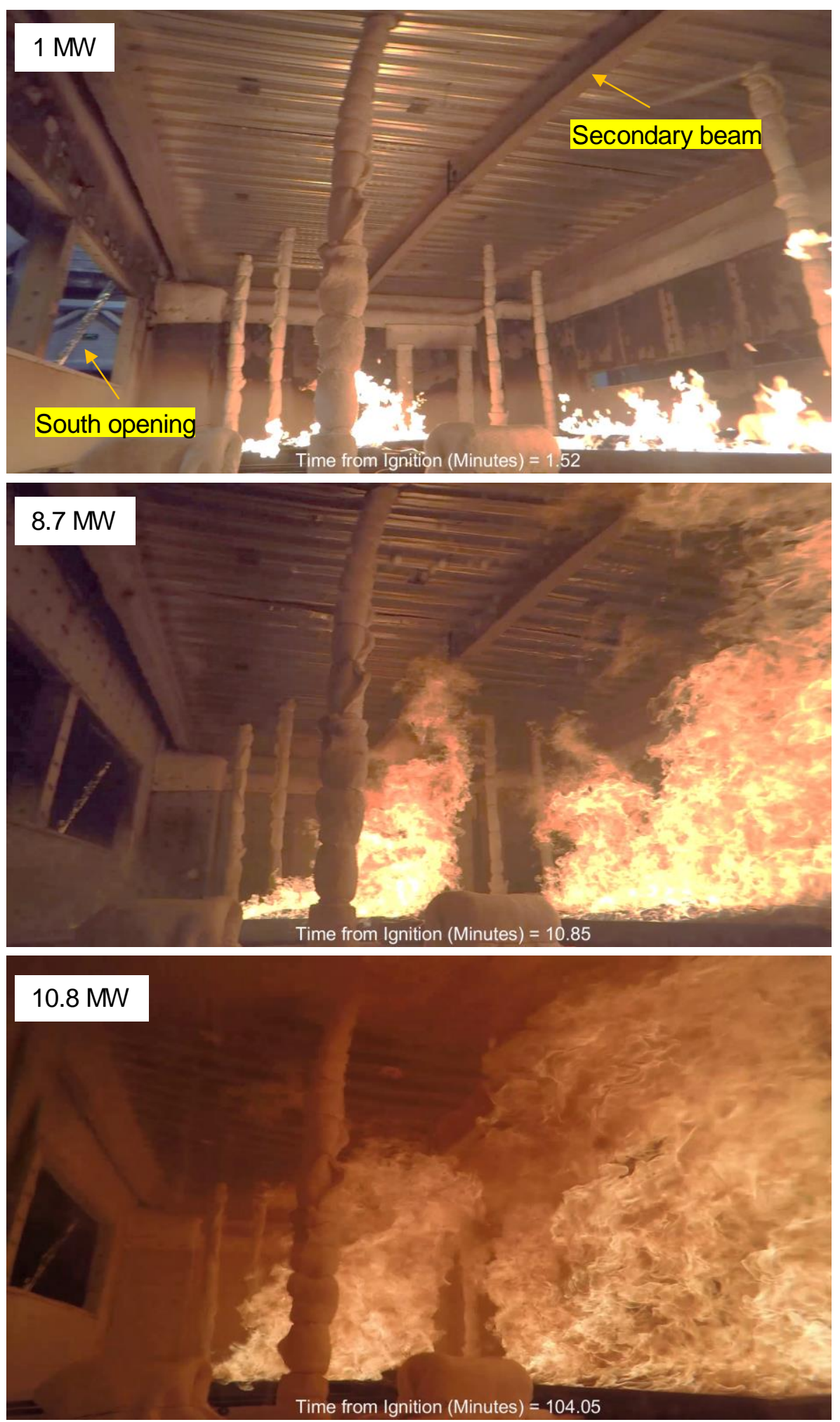

Fig. 4-5. Snapshots of the video showing the inside the test compartment at $1.5 \mathrm{~min}, 10.9 \mathrm{~min}$, and $104 \mathrm{~min}$. 


\subsubsection{Upper Layer Gas Temperature}

The test compartment fire produced hot gas temperatures trapped below the composite floor assembly within the fire test bay. Fig. 4-6 shows the average gas temperature measured using twelve thermocouple probes mounted $30.5 \mathrm{~cm}$ below the steel deck. The upper layer gas temperature exceeded $700{ }^{\circ} \mathrm{C}$ at $11 \mathrm{~min}$ and reached a peak value of $1060{ }^{\circ} \mathrm{C}$ before the fire was extinguished at $107 \mathrm{~min}$. At $20 \mathrm{~min}$ into fire loading, temperatures in the middle of the test compartment were $120{ }^{\circ} \mathrm{C}$ to $140{ }^{\circ} \mathrm{C}$ higher than those measured at the corner. However, the final standard deviation in temperatures became less than $40^{\circ} \mathrm{C}$, indicating practically uniform heating at the exposed surfaces of the test floor assembly. Note that a sudden decrease in temperatures between $100 \mathrm{~min}$ and $102 \mathrm{~min}$ was caused by temporary extinguishment of the test fire triggered by network disruption as mentioned in Sect. 4.3.1.

Fig. 4-7 shows a comparison of the average upper layer gas temperature with standard gas furnace temperature-time curves. Although the test fire was designed to simulate the ASTM E119 curve, the evolution of upper layer temperatures was much closer to the ISO 834 curve (less than $1 \%$ difference after $15 \mathrm{~min}$ ). The upper layer temperature was approximately $2 \%$ higher than the ASTM E119 standard gas temperature after 15 min.

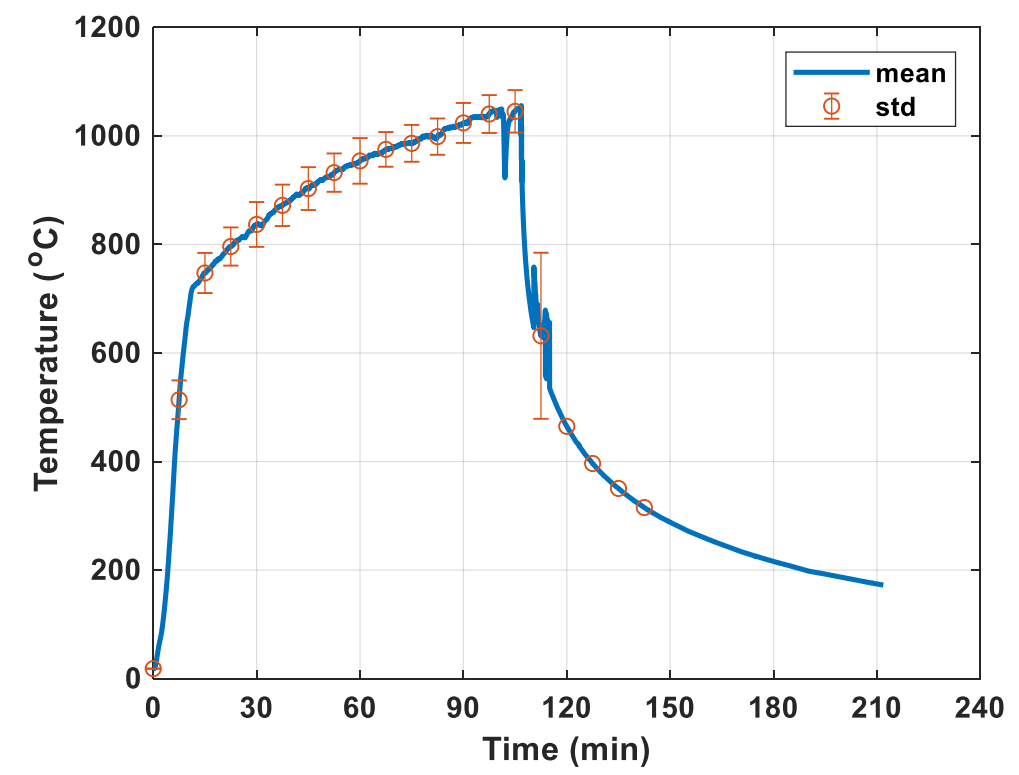

Fig. 4-6. Average measured upper layer temperature within the test compartment. Error bars = standard deviation of temperatures measure using twelve thermocouple probes mounted $30.5 \mathrm{~cm}$ below the steel deck. 


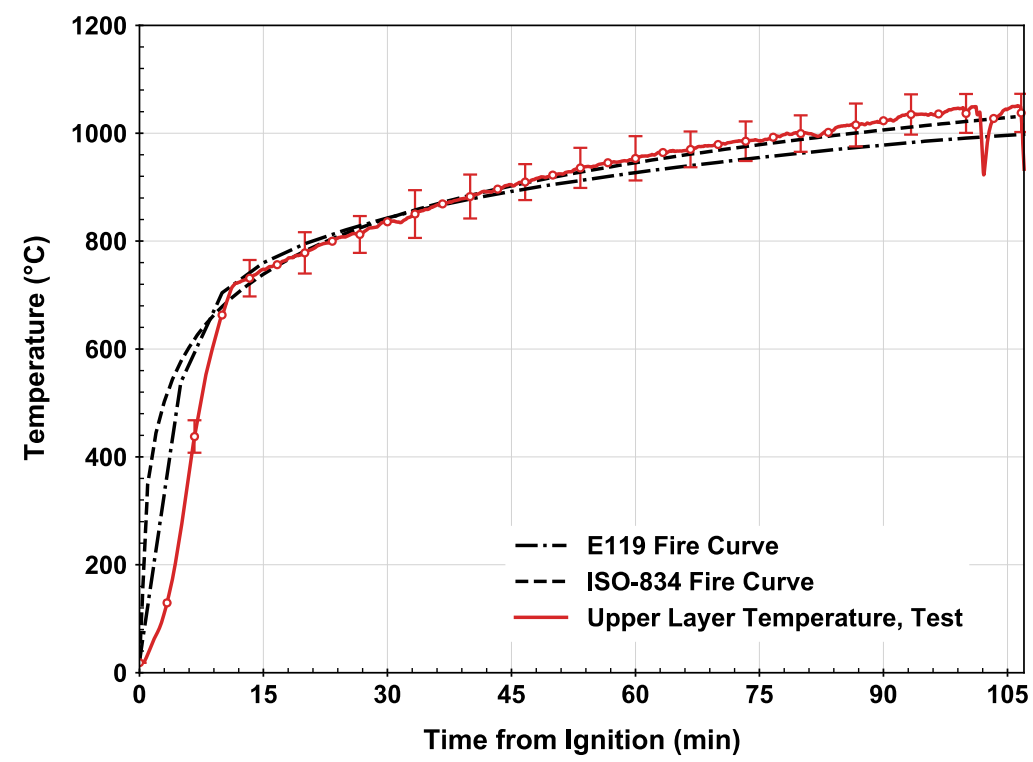

Fig. 4-7. Comparisons of average measured upper layer gas temperatures of the test compartment with prescribed standard furnace temperatures.

Fig. 4-8 shows the compartment temperatures measured at various heights. Two thermocouple trees were located inside the test compartment, including the north tree $79 \mathrm{~cm}$ from the north wall and south tree $96 \mathrm{~cm}$ from the south wall. The temperature measurement appeared to be affected by the ventilation openings at the south and north wall. Temperatures measured at the south tree were approximately $50{ }^{\circ} \mathrm{C}$ to $100{ }^{\circ} \mathrm{C}$ lower than those measured at the north tree at the same elevation. The compartment temperatures measured $201 \mathrm{~cm}$ or higher (from the floor of the test compartment) became almost uniform as the test fire continued.

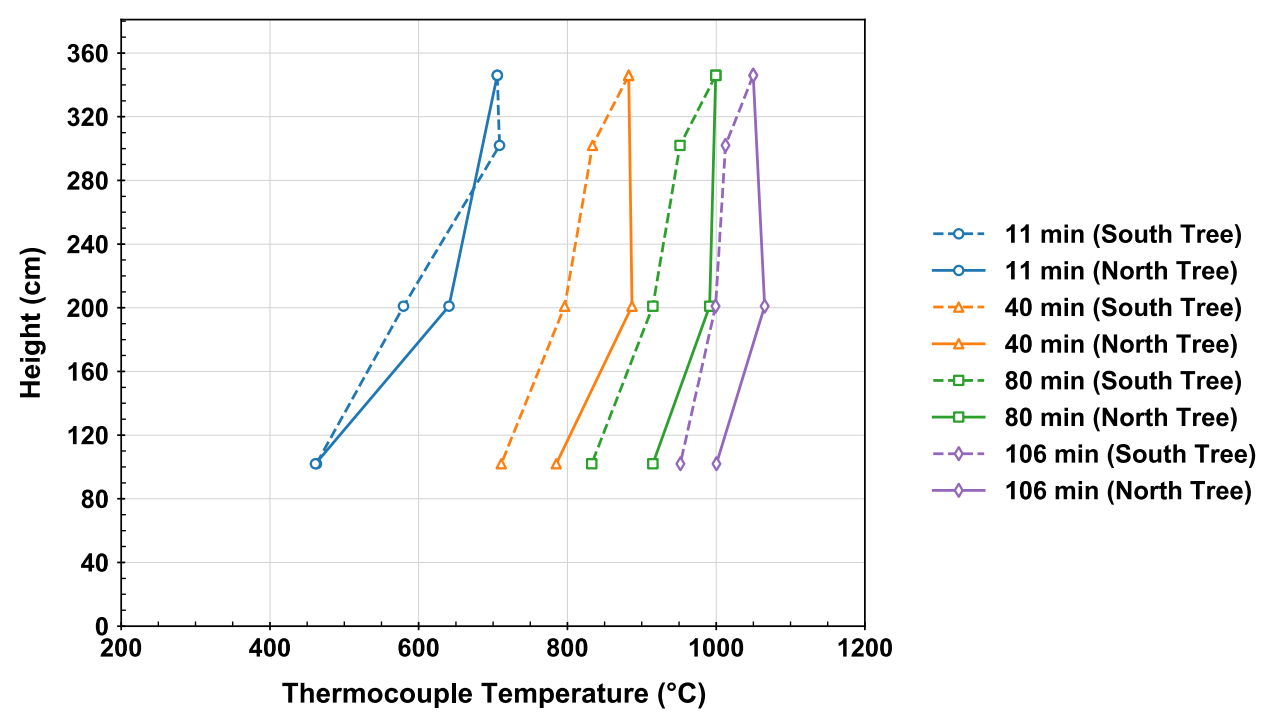

Fig. 4-8. Temperature distribution through the height of the test compartment at various fire exposure times. The bottom surface of the test compartment is at $0 \mathrm{~cm}$. 


\subsubsection{Compartment Opening Velocities and Temperatures}

Velocities at compartment openings were measured to characterize the ventilation conditions of the compartment test fire. Velocity probes were placed at two different heights in the south and north openings to monitor the air inflow and outflow. Bare bead thermocouples were placed at five different heights (SO1 through SO5) at the south opening, with two of them (SO2 and $\mathrm{SO}$ ) mounted at the vicinity of two velocity probes. Another three bare bead thermocouples (NO1 through NO3) were placed at the north opening, and two of them (NO1 and NO2) were collocated with the two velocity probes. Refer to Fig. 4-9 for distribution of the velocity probes and thermocouples at the openings.

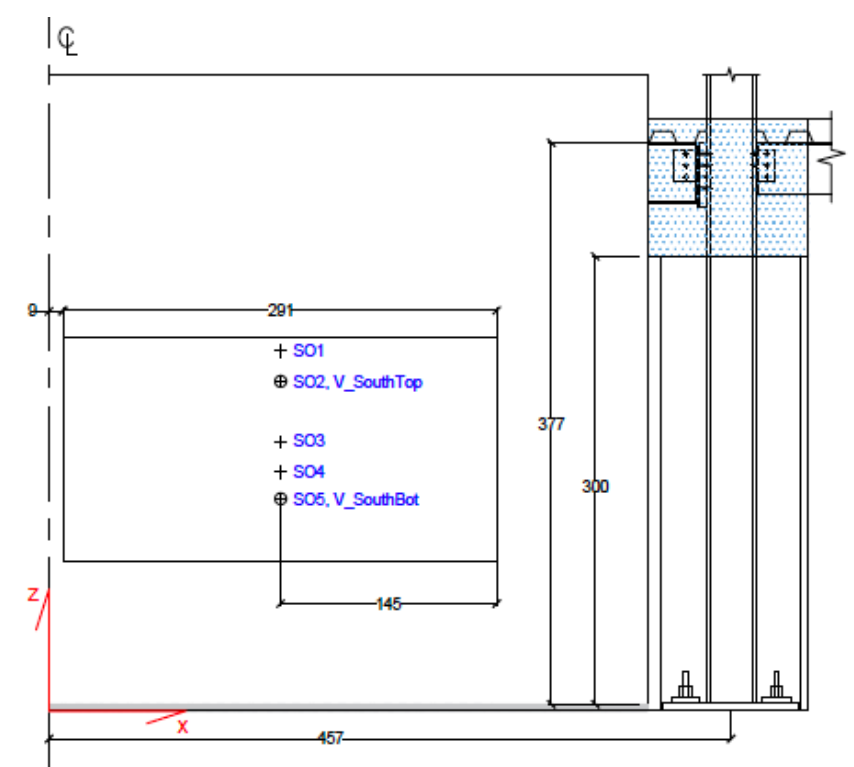

\begin{tabular}{|l|r|r|}
\hline Name/ID & X East+ & Z Up+ \\
\hline SO1 & 155 & 241 \\
\hline SO2 & 155 & 221 \\
\hline SO3 & 155 & 180 \\
\hline SO4 & 155 & 160 \\
\hline SO5 & 155 & 142 \\
\hline V_SouthTop & 155 & 221 \\
\hline V_SouthBot & 155 & 142 \\
\hline
\end{tabular}

(a)

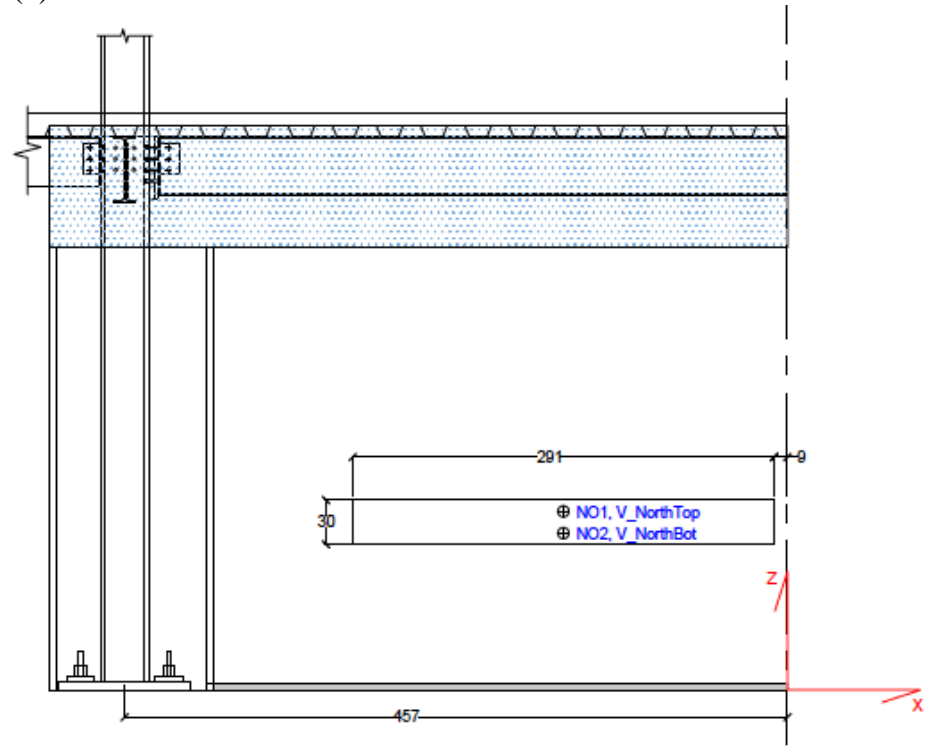

\begin{tabular}{|l|r|r|}
\hline Name/ID & X East+ & Z Up+ \\
\hline NO1 & -155 & 123 \\
\hline NO2 & -155 & 108 \\
\hline NO3 & 155 & 123 \\
\hline V_NorthTop & -155 & 123 \\
\hline V_NorthBot & -155 & 108 \\
\hline
\end{tabular}

(b)

Fig. 4-9. Locations of opening velocity probes and thermocouples; (a) south opening and (b) north opening, unit in $\mathrm{cm}$. 
Fig. 4-10 shows gas velocities measured at the south and north openings, along with the averaged upper layer gas temperature measured using twelve thermocouples (TCC) below the soffit of the test compartment. Positive velocity indicates hot gases flowing out of the compartment, while negative velocity indicates ambient air flowing into the compartment. In the first $10 \mathrm{~min}$ of the test, the velocities are all increasing with the rising upper layer gas temperature. After $15 \mathrm{~min}$ the gas velocities tend to stabilize in both directions. The north opening 'slit' only has air inflow, ranging from $-1.2 \mathrm{~m} / \mathrm{s}$ to $-2.4 \mathrm{~m} / \mathrm{s}$. The south opening has air flows in both directions, with approximately $6.4 \mathrm{~m} / \mathrm{s}$ to $7.6 \mathrm{~m} / \mathrm{s}$ for outflow (at upper part of the opening) and $-1.2 \mathrm{~m} / \mathrm{s}$ to $-1.6 \mathrm{~m} / \mathrm{s}$ for inflow (at lower part of the opening). This gas flow scenario is within the expectation from the fire design of the large compartment as suggested by Zhang et al (2019).

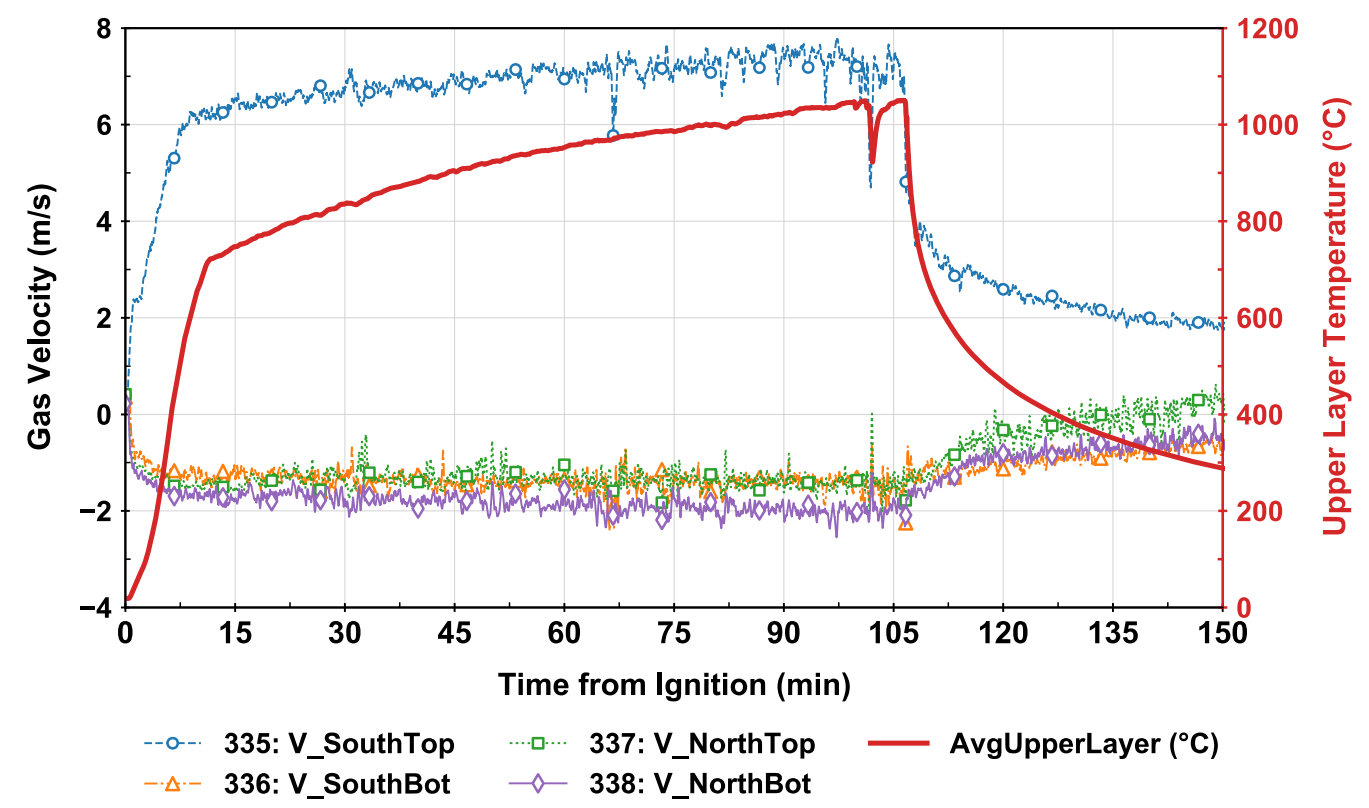

Fig. 4-10. Measured gas velocities along with the average upper gas temperature. The plotted data are the moving average values of the raw data over $25 \mathrm{~s}$.

Fig. 4-11 presents temperatures measured at the south and north openings. Fig. 4-12 shows temperature profile on the south opening at a variety of fire exposure times. The maximum value of this temperature profile tends to be at $\mathrm{SO} 2$ throughout the heating phase of a test fire. Temperatures of thermocouples SO5, NO1, NO2, and NO3 are higher than the ambient air inflow temperatures. The ambient air temperature (outside of the test compartment) was below $40{ }^{\circ} \mathrm{C}$ on average. 


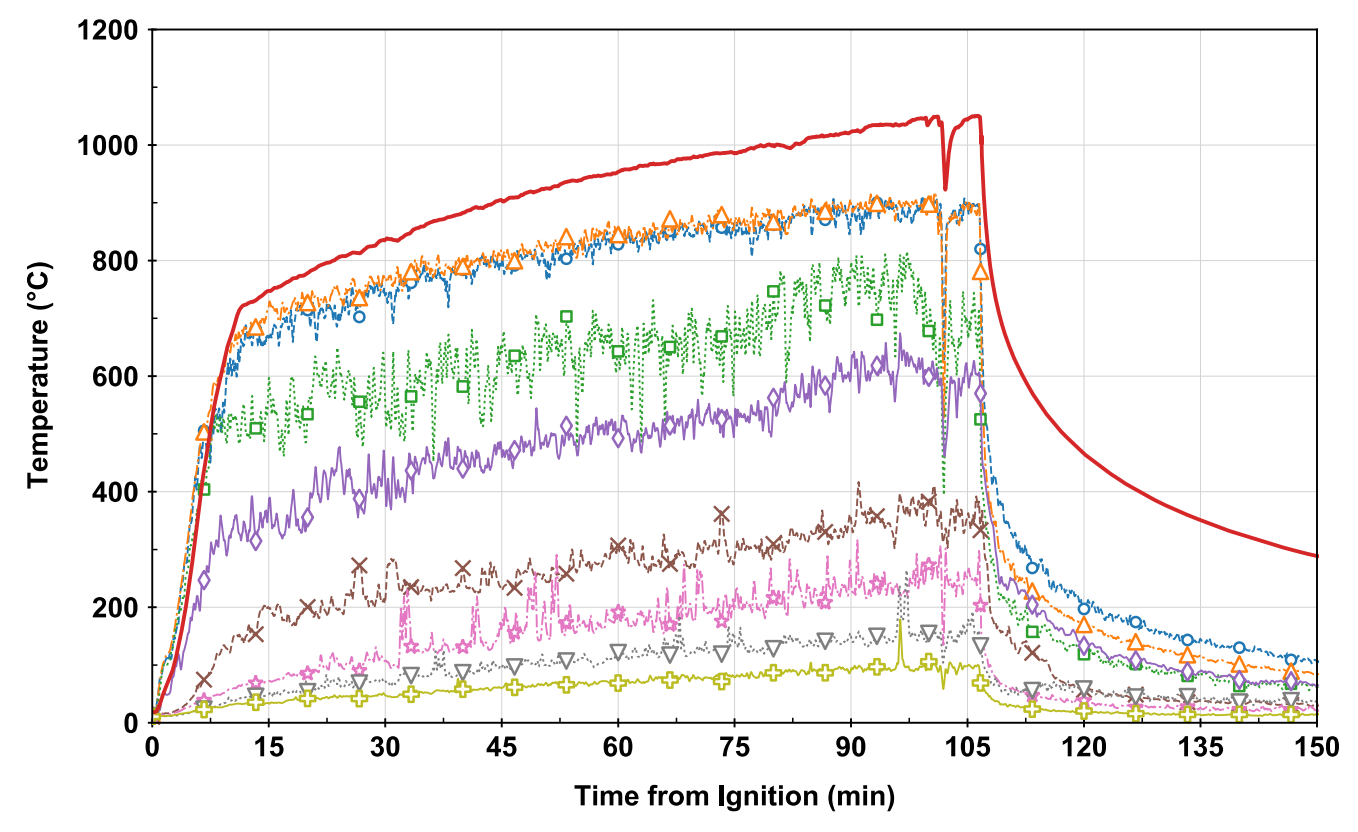

$$
\begin{aligned}
& \text {--०-. 279: SO1 } \multimap-282: \text { SO4 } \cdots \nabla \cdots \quad \text { 288: NO2 } \\
& -\triangle-\text { 280: SO2 -- - 283: SO5 - 108: NO3 } \\
& \text { …… 281: SO3 - 287: NO1 — AvgUpperLayer }
\end{aligned}
$$

Fig. 4-11. Thermocouple temperatures in the south and north window openings. The plotted data are the moving average values of the raw data over $25 \mathrm{~s}$.

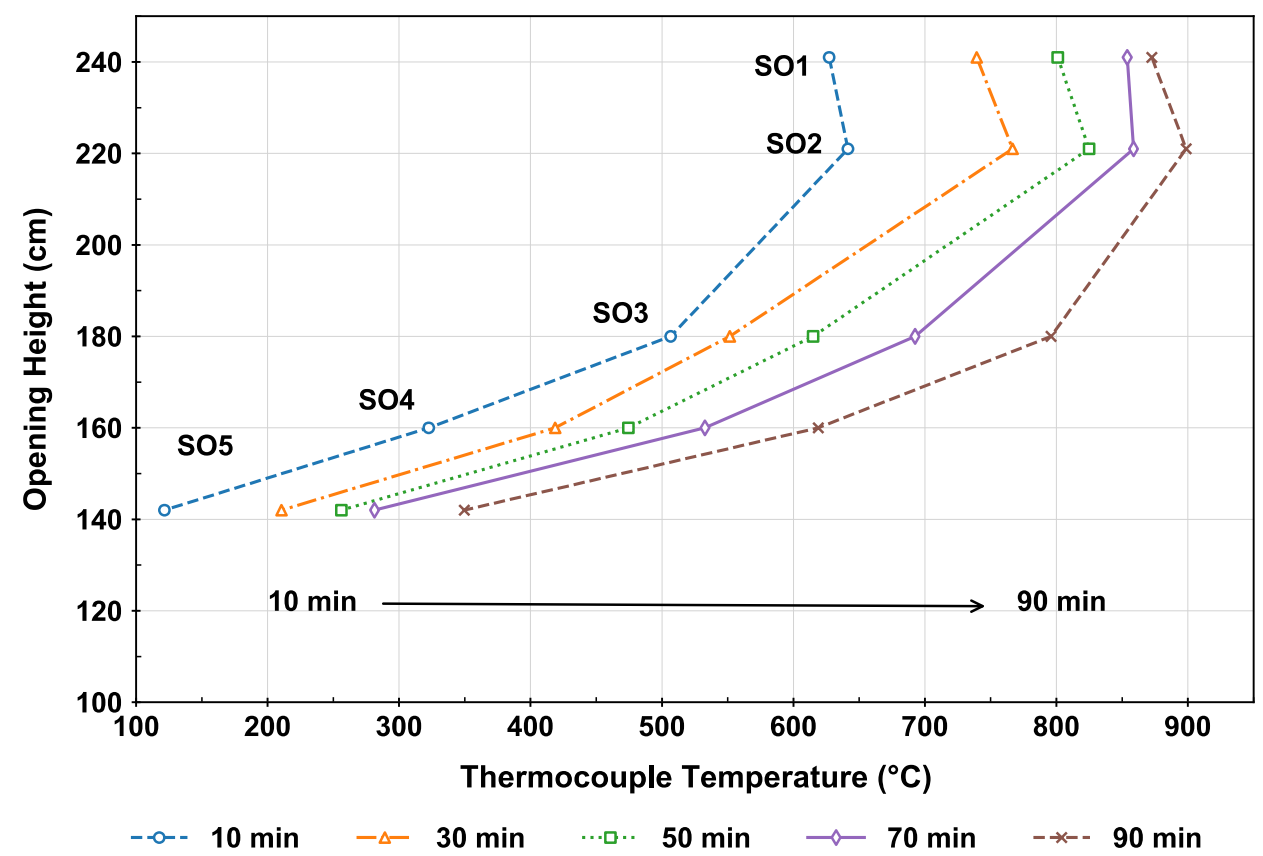

Fig. 4-12. Temperature profile development on the south opening. 


\subsubsection{Convective Heat Loss through Compartment Vent Opening}

To estimate energy balance from the test compartment fire, the convective heat loss through the vent opening, $\dot{Q}_{\text {loss,opening }}$ in MW, was estimated using Eq. (4-1) by integrating the product of mass flow, temperature, and specific heat capacity of the hot layer outflow, i.e., the enthalpy above the neutral plane at the opening:

$$
\dot{Q}_{\text {loss,opening }}=\dot{m} c_{p} \Delta T
$$

where $\dot{m}$ is the mass flow rate out of the opening $(\mathrm{kg} / \mathrm{s}), c_{p}$ is the specific heat capacity of the hot layer $(\mathrm{J} / \mathrm{kg} \cdot \mathrm{K})$, and $\Delta T(\mathrm{~K})$ is the temperature difference between the hot layer flowing out of the compartment $\left(T_{h o t}\right)$ and the ambient air temperature that was equal to the time-average value of $T_{a m b}=31{ }^{\circ} \mathrm{C}$ during a test fire. In this study, $T_{\text {hot }}$ was assumed to be a temperature of $\mathrm{SO} 2$ for the upper bound of $\dot{Q}_{\text {loss,opening }}$ and a temperature of SO4 for its lower bound.

The mass outflow rate at the south opening, $\dot{m}$, can be estimated using Eq. (4-2):

$$
\dot{m}=\rho \dot{V}=\rho \frac{v_{\max }\left(d-Z_{\text {neutral }}\right)}{2} w
$$

where $\rho$ is the density of the hot layer $\left(\mathrm{kg} / \mathrm{m}^{3}\right), \dot{V}$ is the volumetric flow rate out of the vent opening $\left(\mathrm{m}^{3} / \mathrm{s}\right), v_{\max }$ is the extrapolated maximum gas flow velocity near the top edge of the south opening, $Z_{\text {neutral }}$ is the neutral plane location from the window bottom edge, $w$ is the total window width, $582 \mathrm{~cm}$, and $d$ is the window depth, $150 \mathrm{~cm}$.

As shown in Fig. 4-13, the gas flow velocity was assumed to be linearly distributed through the window height; hence, the value of $\dot{V}$ was estimated as the product of the triangle area above the neutral plane and the total window width.
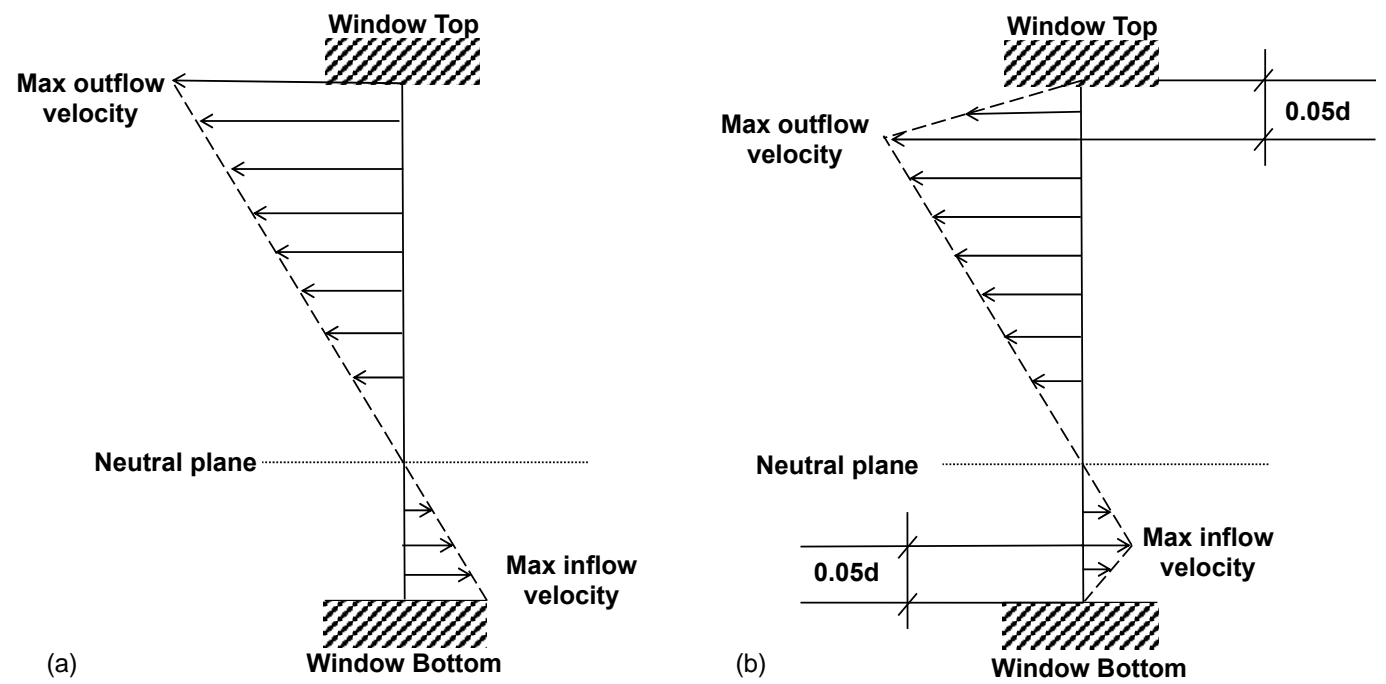

Fig. 4-13. Gas velocity distribution at the south opening, assumed with (a) maximum velocity at the window top edge and (b) no-slip boundary condition as suggested by Bryant (2009). 
Fig. 4-14 shows the convective heat loss through the south opening estimated using Eq. (4-1) and a comparison with measured heat loss at the duct of the $20 \mathrm{MW}$ calorimetry hood. The heat loss through the south opening was estimated slightly greater than the duct. The energy loss estimated using the linear scheme (Fig. 4-13a) was roughly 44 GJ, approx. $72 \%$ of the total heat energy (the area of the HRRburner versus time curve). The energy loss estimated using the multilinear scheme (Fig. 4-13b) resulted in 40 GJ, approx. $66 \%$ of the total heat energy. Fig. 4-15 shows the mass flow rate estimated using Eq. (4-2), the gas distribution in Fig. 4-13b, and temperatures of the opening thermocouples ( $\mathrm{SO} 2, \mathrm{SO} 4, \mathrm{SO} 5, \mathrm{NO} 1$ through $\mathrm{NO} 3)$. Both outflow and inflow rates at the compartment openings were comparable until approx. 8 min following the burner ignition but deviated afterward.

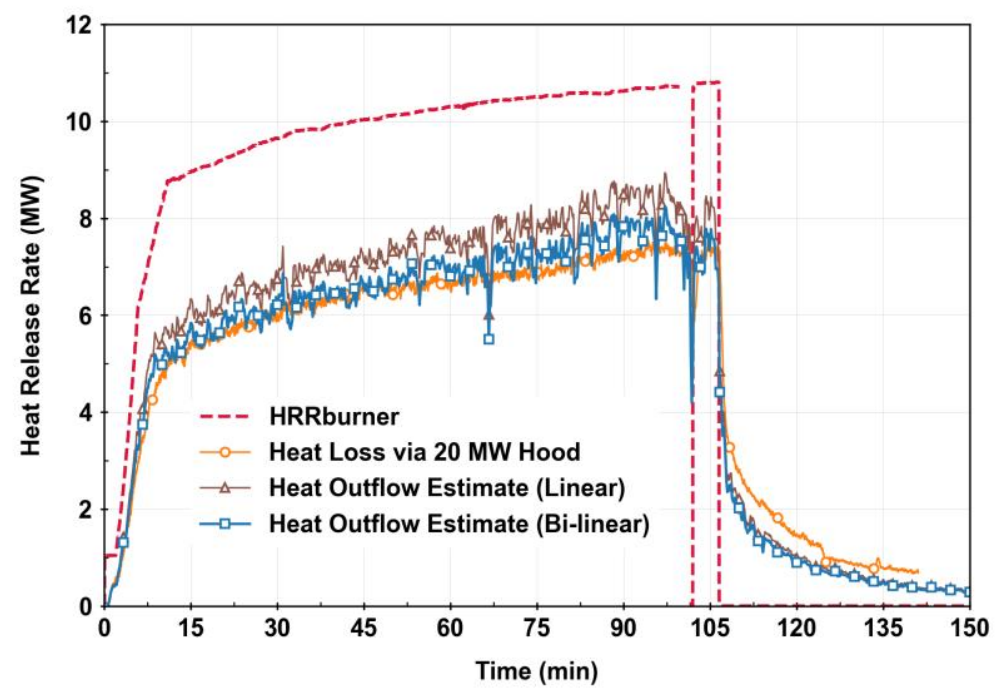

Fig. 4-14. Estimated convective heat loss.

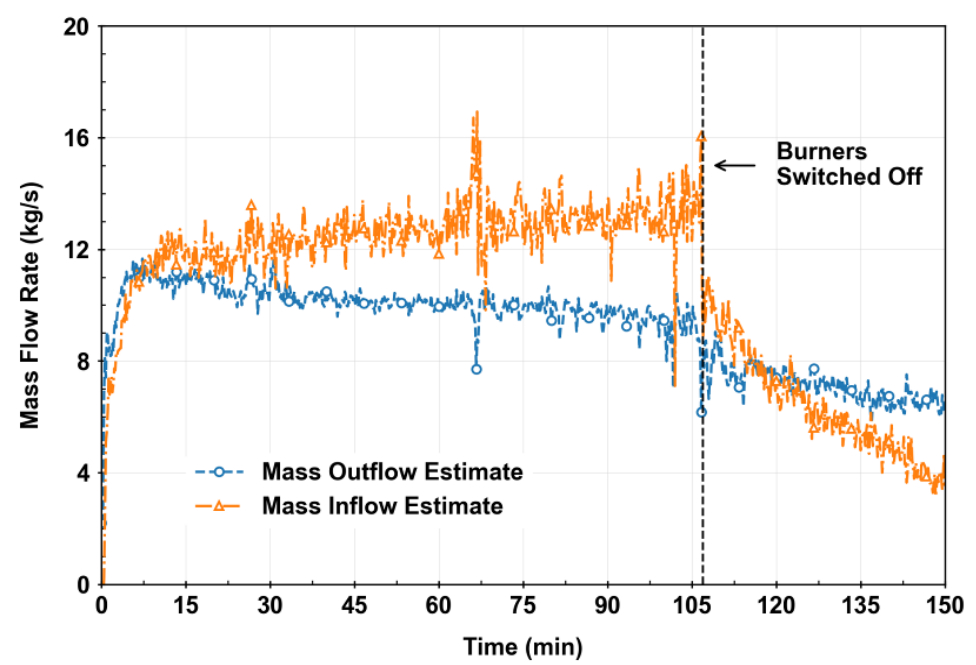

Fig. 4-15. Estimated mass flow rate at compartment openings. 


\subsection{Thermal Response}

This section presents measured temperatures of the test floor assembly at a variety of locations during the heating and cooling phase of the test compartment fire. Most data presented in this section are average temperatures measured by multiple thermocouples. All thermocouple locations and raw temperature data are reported in Appendix B.

\subsubsection{Concrete Slab}

The temperature change in the $15.9 \mathrm{~cm}$ deep and $8.3 \mathrm{~cm}$ deep sections of the profiled test floor slab is shown in Fig. 4-16. The plotted values are the average temperatures measured across the test floor slab at the same depth. The error bars on each graph indicate the maximum standard deviation of temperatures estimated during the heating and cooling phases of the test fire.

Some observations can be made as follows:

- Concrete temperature at the steel deck flute (TST_5*) indicated the hottest spot in excess of $900{ }^{\circ} \mathrm{C}$ before the test fire was extinguished.

- The spatial temperature variation was quite high $\left(>110^{\circ} \mathrm{C}\right)$ at the deck flute (TST_5*) and at the bottom of $8.3 \mathrm{~cm}$ deep sections (TST_7) as indicated by the large error bars. These temperatures could be more sensitive to delamination of the metal decking from the concrete surface, concrete cracking, and varying distances from fire source due to bending of the test floor slab.

- The north half of the test floor slab was hotter than the south half during heating because of a large vent opening of the south wall. The maximum temperature difference was approximately $130{ }^{\circ} \mathrm{C}$ at $107 \mathrm{~min}$.

- Concrete temperatures at the same height of the welded wire reinforcement were affected by varying thickness of the concrete slab on the profiled metal decking. A peak temperature of TST_1 (deep section) and TST_6 (shallow section) was $120{ }^{\circ} \mathrm{C}$ and 380 ${ }^{\circ} \mathrm{C}$, respectively.

- Concrete temperatures towards the top surface (TST_1, TST_5, or TST_6) and at the centroid of the deep section (TST_2) were affected by the moisture within the concrete. The moisture at these locations was driven out for a longer period than the bottom of the slab.

- Concrete temperatures of TST_1 and TST_5 continued to rise after the test fire was extinguished. The maximum temperature was in the range of $200{ }^{\circ} \mathrm{C}$ to $250{ }^{\circ} \mathrm{C}$ during cooling.

A total of eight thermocouples (TopSlab1 through TopSlab8) were mounted $3 \mathrm{~mm}$ below the top (unexposed) surface of the test floor slab, as shown in Fig. 4-17. The raw temperature data of these thermocouples are presented in Fig. 4-18. These temperatures continued to rise during the cooling phase (up to $1 \mathrm{~h}$ into cooling), ranging from $110^{\circ} \mathrm{C}$ to $180^{\circ} \mathrm{C}$. However, the temperature rise (near the top surface) was less uniform across the floor area due to varying thickness of the slab on the profiled decking. The top of the thick sections (TopSlab1, TopSlab2, TopSlab6, and TopSlab8) was heated more slowly and affected by prolonged evaporation of the moisture in the concrete. 

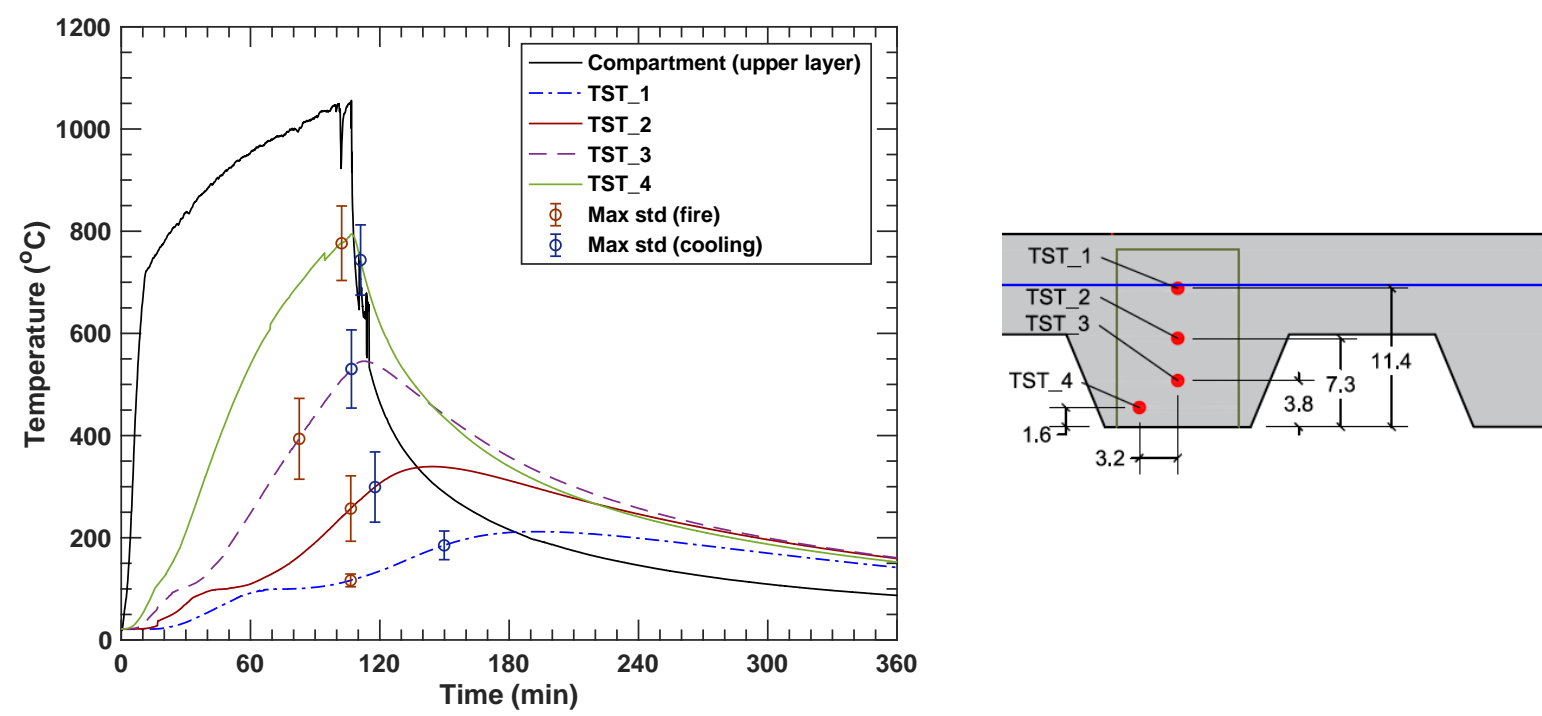

(a)
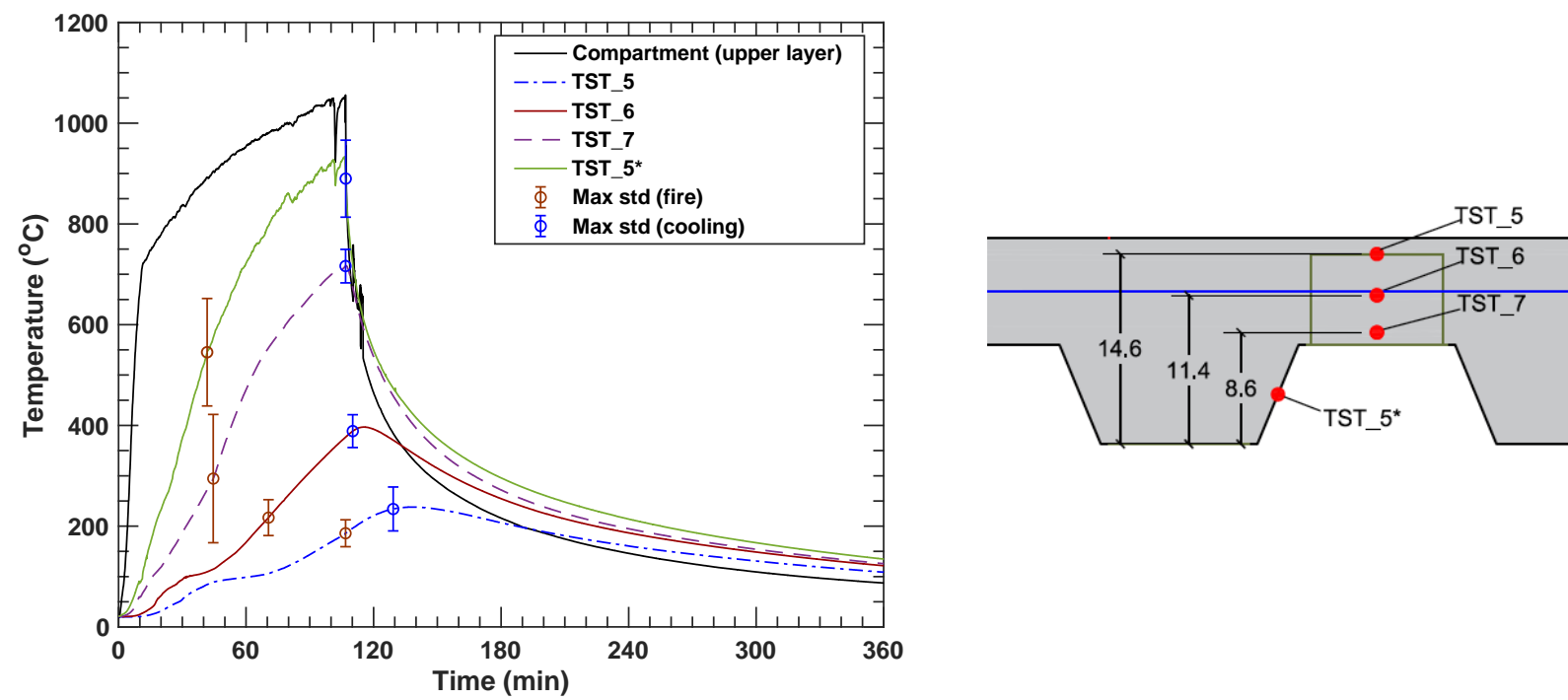

(b)

Fig. 4-16. Average temperatures measured at various locations within (a) $15.9 \mathrm{~cm}$ deep sections and (b) $8.3 \mathrm{~cm}$ deep sections of the concrete slab. Error bars indicate the maximum standard deviation of temperatures during fire or cooling after extinguishment. 


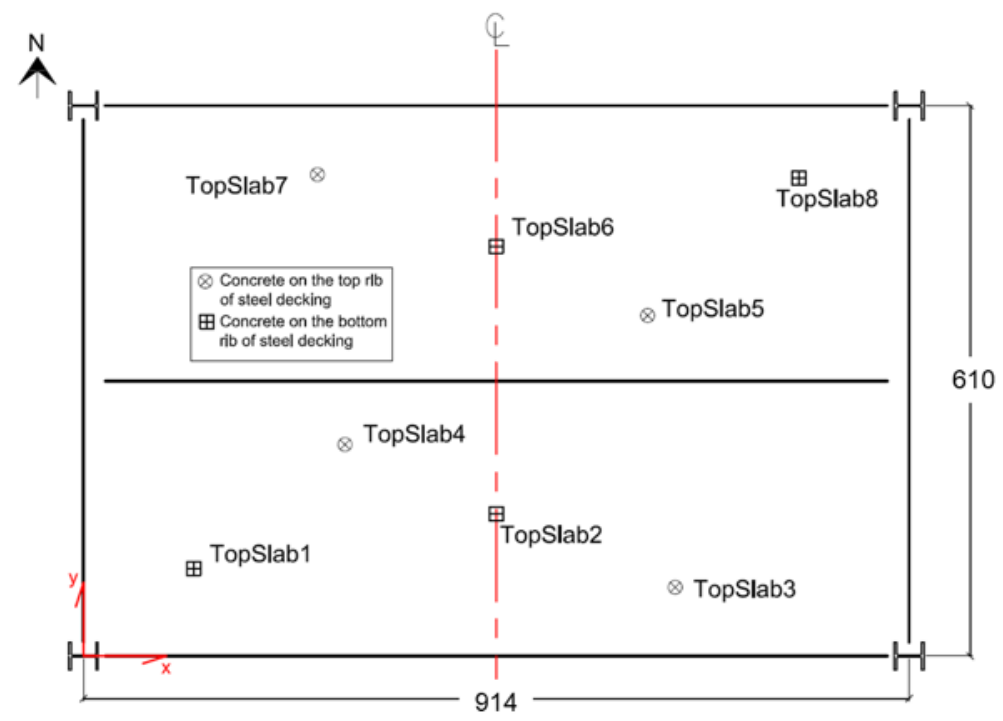

\begin{tabular}{|l|r|r|}
\hline Name/II & X East+ & Y North+ \\
\hline TopSlab1 & 122 & 97 \\
\hline TopSlab2 & 457 & 157 \\
\hline TopSlab3 & 655 & 76 \\
\hline TopSlab4 & 290 & 234 \\
\hline TopSlab5 & 625 & 377 \\
\hline TopSlab6 & 457 & 454 \\
\hline TopSlab7 & 259 & 533 \\
\hline TopSlab8 & 792 & 530 \\
\hline
\end{tabular}

Fig. 4-17. Locations of thermocouple probes $3 \mathrm{~mm}$ below the top (unexposed) surface of the test floor slab, unit in cm.

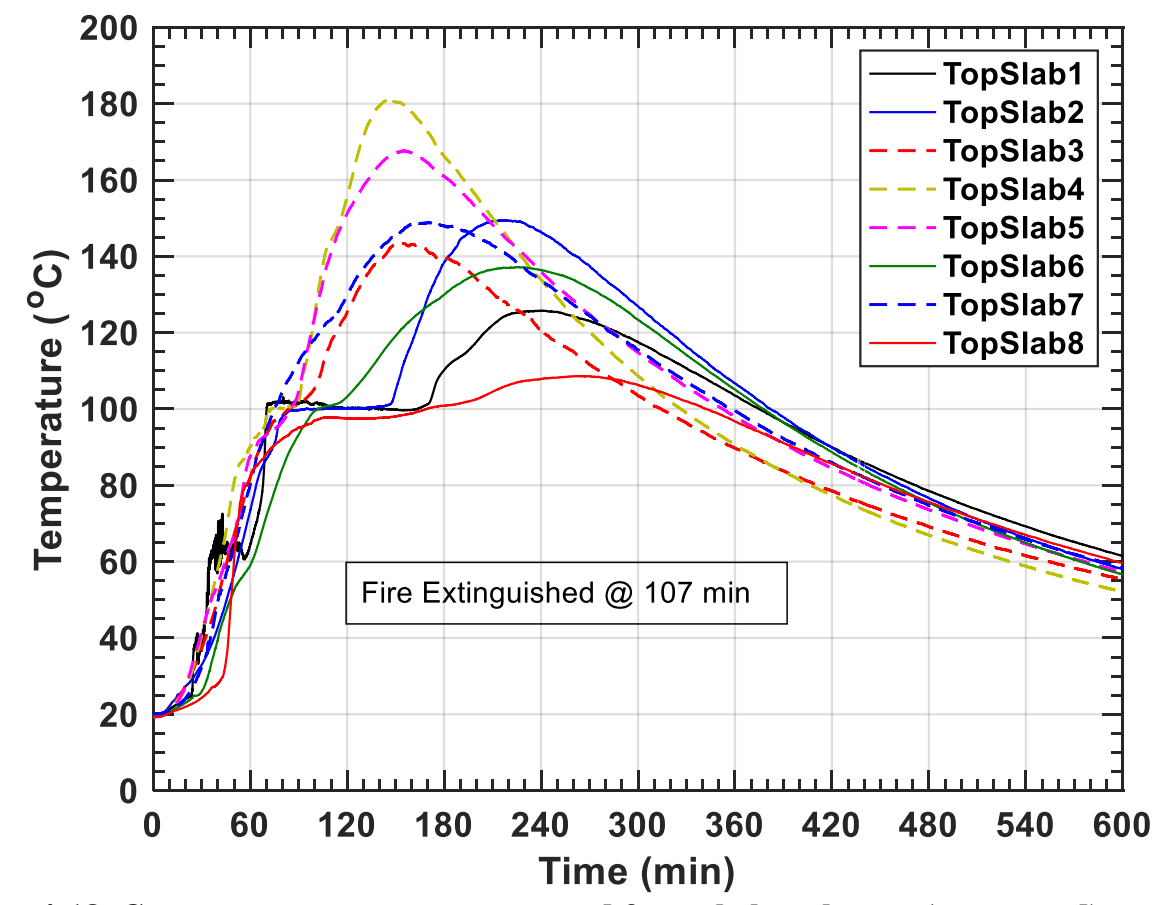

Fig. 4-18. Concrete temperatures measured $3 \mathrm{~mm}$ below the top (unexposed) surface of the test floor slab. 


\subsubsection{Composite Section}

Fig. 4-19 shows the average temperature of various parts within the mid-span cross sections of the $9.1 \mathrm{~m}$ long composite beams and $6.1 \mathrm{~m}$ long composite girders exposed to the test fire, along with the average upper layer gas temperature inside the fire test compartment. The steel shapes, W16 $\times 31$ and W18 $\times 35$, were protected with SFRM and the thickness of applied SFRM is presented in Sect. 2.1. In Fig. 4-19a, the bottom flange temperature recorded from 167 min to 213 min was affected by thermocouple failure.

For the $9.1 \mathrm{~m}$ long composite beams (See Fig. 4-19a), temperatures of the protected web and bottom flange of the $\mathrm{W} 16 \times 31$ shape reached $600{ }^{\circ} \mathrm{C}$ at $60 \mathrm{~min}$ and exceeded $800^{\circ} \mathrm{C}$ at $107 \mathrm{~min}$. On the other hand, the top flange was heated more slowly. The top flange temperature was approximately $320^{\circ} \mathrm{C}$ lower on average after $60 \mathrm{~min}$ into heating. Temperatures of the concrete at the deck flute increased to a peak value of $270{ }^{\circ} \mathrm{C}$ at $107 \mathrm{~min}$. Temperatures of the headed studs and welded wire reinforcement (WWR) remained below $400{ }^{\circ} \mathrm{C}$ and $200{ }^{\circ} \mathrm{C}$, respectively, during the heating phase.

For the $6.1 \mathrm{~m}$ long $\mathrm{W} 18 \times 35$ composite girders, the average temperature of the lower portion of the SFRM coated steel shape reached $450{ }^{\circ} \mathrm{C}$ at $60 \mathrm{~min}$ and exceeded $700{ }^{\circ} \mathrm{C}$ at $107 \mathrm{~min}$. The top flange temperature increased to $400{ }^{\circ} \mathrm{C}$ until the test fire was extinguished. The concrete at the steel decking, i.e., at location (3) in Fig. 4-19b, heated at a similar rate of the protected top flange and middle web. However, this concrete temperature decreased after $80 \mathrm{~min}$ in fire because of large concrete cracks. Temperatures of the headed studs remained below $300{ }^{\circ} \mathrm{C}$. Temperatures of the WWR increased to a peak value of $100{ }^{\circ} \mathrm{C}$ during heating and continued to rise over $1 \mathrm{~h}$ into cooling.

The middle or lower web of the protected steel beams or girders was the hottest spot. Temperature of the WWR increased to only $10 \%$ to $12 \%$ of the middle web temperature after $60 \mathrm{~min}$ in fire. Approximately $105 \mathrm{~min}$ into heating, temperatures of the entire steel section of the secondary beam and $70 \%$ to $80 \%$ of the steel sections in other composite beams and girders exceeded $600{ }^{\circ} \mathrm{C}$.

Among the three $\mathrm{W} 16 \times 31$ beams (north, south, and middle beams), the largest deviation in the temperatures was observed in the middle (secondary) beam, approximately $80^{\circ} \mathrm{C}$, whereas the other two beams had the temperature deviation in the range of $10{ }^{\circ} \mathrm{C}$ to $35^{\circ} \mathrm{C}$ at the same thermocouple location within the cross sections. For the $\mathrm{W} 18 \times 35$ girders, the temperature variation between two different sections ranged from $40{ }^{\circ} \mathrm{C}$ to $120^{\circ} \mathrm{C}$. There might be several factors influencing the protected steel temperatures, including but not limited to variability of the surrounding gas temperatures, SFRM thickness, or fire-induced fissures of the applied SFRM layers as these steel members deformed under fire. 

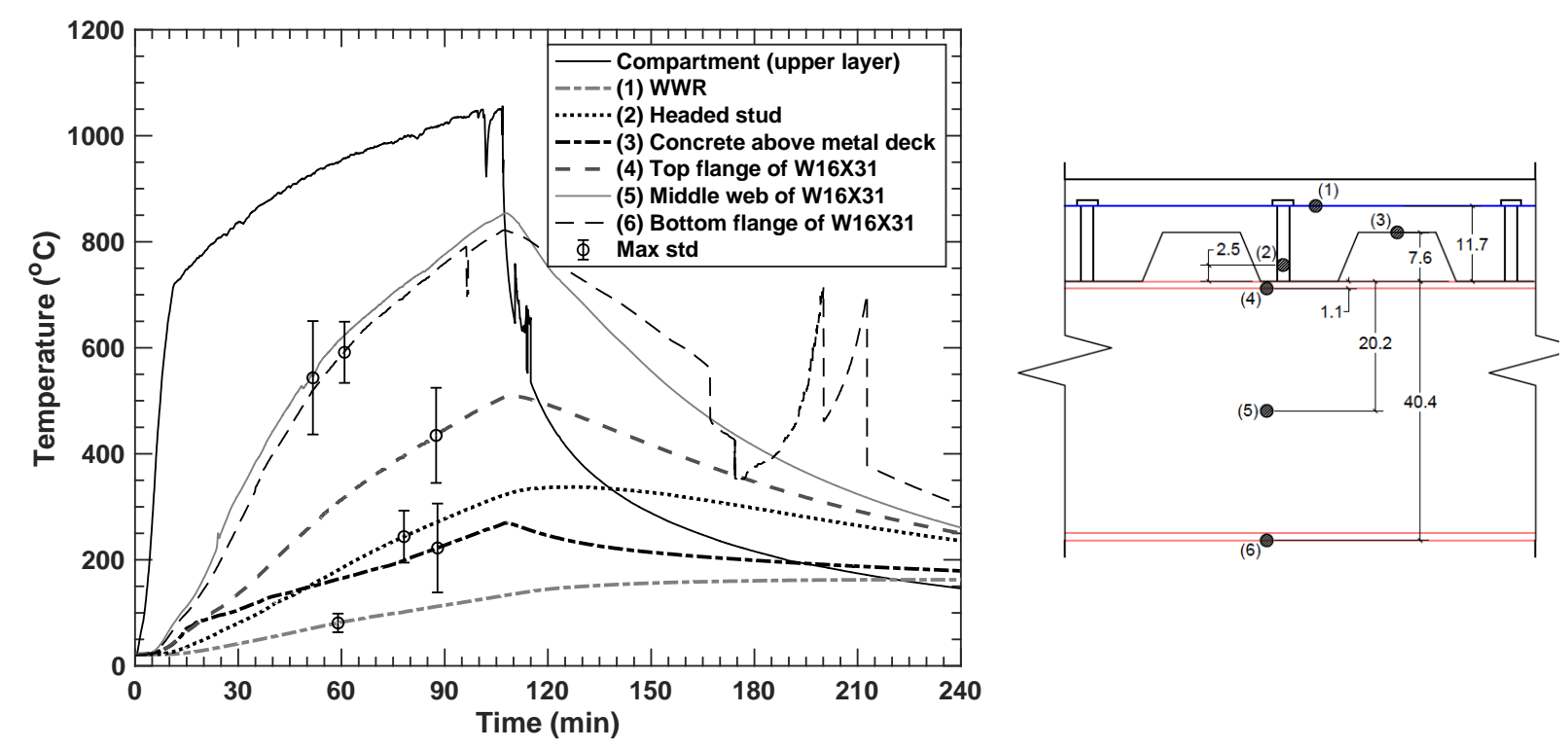

(a)
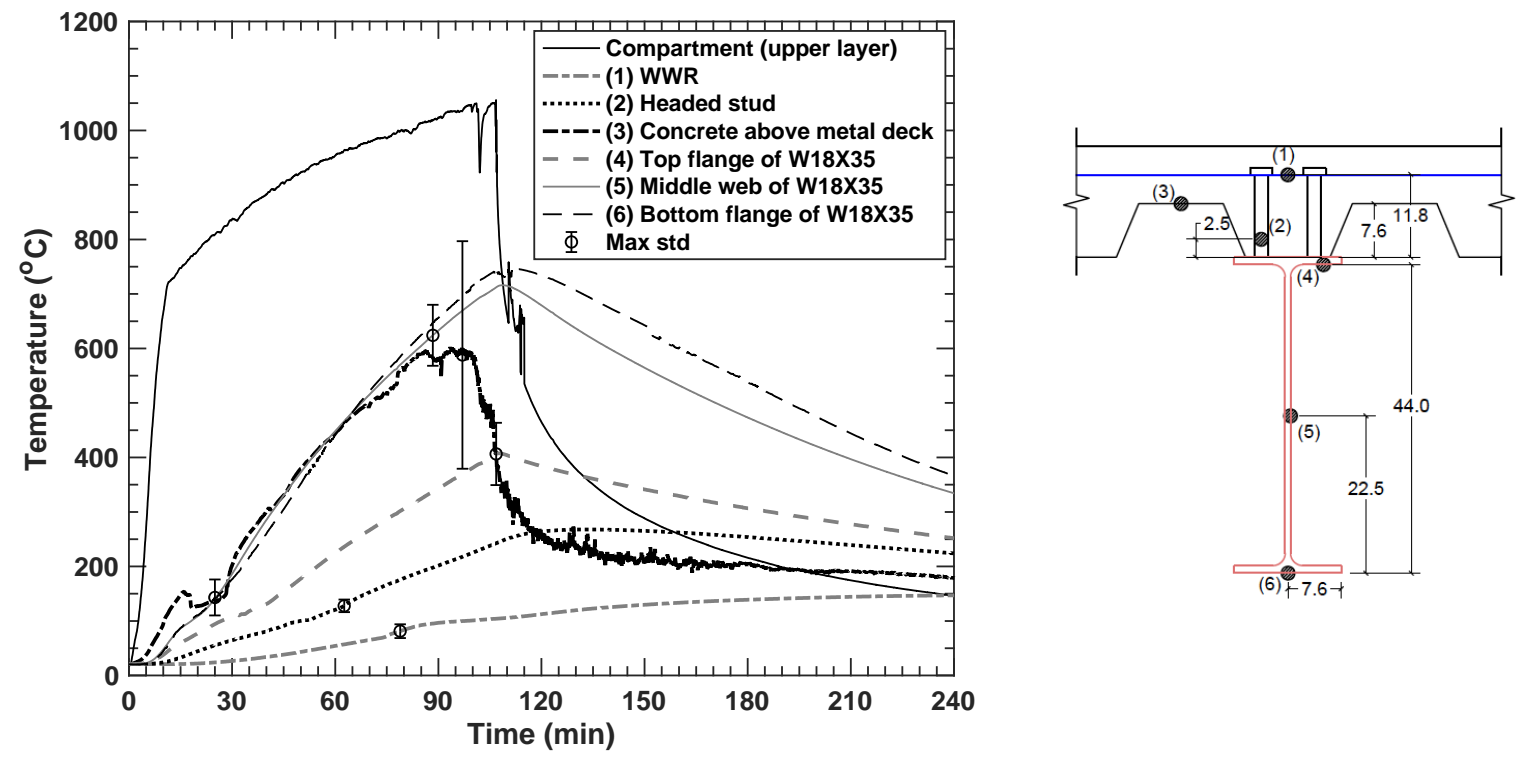

(b)

Fig. 4-19. Average temperatures of (a) $9.1 \mathrm{~m}$ long composite beams at midspan and (b) $6.1 \mathrm{~m}$ long composite girders at midspan. Error bars indicate the maximum variation in temperatures recorded using thermocouples mounted at the same height during fire loading. Thermocouple locations are in $\mathrm{cm}$. 


\subsubsection{End Connection Region}

Temperatures of the SFRM coated beam-end regions were measured using thermocouples mounted at various locations as illustrated in Fig. 4-20. Temperature data presented in Fig. 4-21 through Fig. 4-23 are the average temperature of each connection element with the error bars indicating a maximum value of the standard deviation.

For the standard shear tab connections used in the $\mathrm{W} 16 \times 31$ beams, the peak temperatures of the end webs, bolt heads, and shear tabs were $640{ }^{\circ} \mathrm{C}, 500{ }^{\circ} \mathrm{C}$, and $420^{\circ} \mathrm{C}$, respectively, with the standard deviation ranging from $25 \%$ to $30 \%$. For the extended shear tab connections used in the W18 $\times 35$ girders, the average peak temperatures of the end webs, bolt groups, shear tabs, and weld joints (to the column web) were $550{ }^{\circ} \mathrm{C}, 510{ }^{\circ} \mathrm{C}, 460{ }^{\circ} \mathrm{C}$, and $250{ }^{\circ} \mathrm{C}$, respectively. The standard deviation for this measurement was in the range of $10 \%$ to $24 \%$. Peak temperatures of the welded wire reinforcement (WWR) above the end connections ranged from $90^{\circ} \mathrm{C}$ to $110^{\circ} \mathrm{C}$; those of headed stud anchors were in the range of $170{ }^{\circ} \mathrm{C}$ to $340{ }^{\circ} \mathrm{C}$.

The west connection of the secondary beam $(\mathrm{C} 2)$ indicated the highest temperature compared with other exposed connections. In the middle beam, temperatures of the bolt heads, shear tabs and steel deck atop the $\mathrm{W} 16 \times 31$ beam rose at a similar rate up to $100 \mathrm{~min}$, reaching nearly 500 ${ }^{\circ} \mathrm{C}$ on average (Fig. 4-21). The beam web next to the shear tabs was much hotter with a peak temperature of $770{ }^{\circ} \mathrm{C}$ on average and also indicated the large temperature variation (approximately $145^{\circ} \mathrm{C}$ ) between its east and west ends. This is believed to be resulted from fissures of the applied SFRM as the beam ends locally buckled. Refer to Sect. 4.6.4 for local buckling at the beam ends.

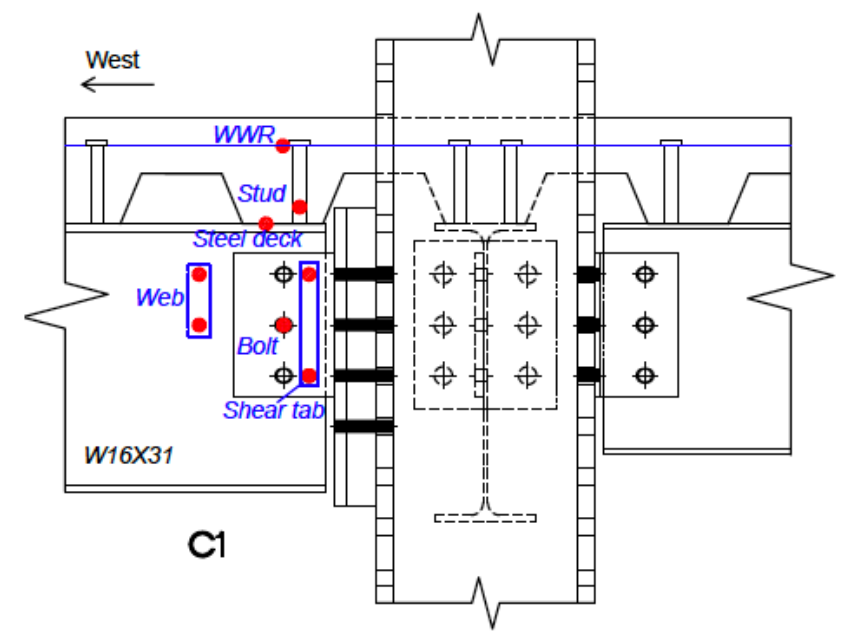

(a)

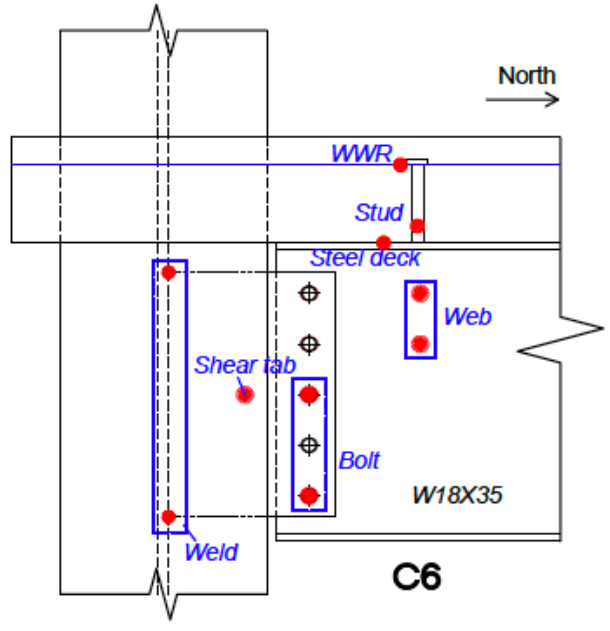

(b)

Fig. 4-20. Typical locations of temperature measurements in beam end regions of (a) the secondary beam and (b) the girder inside the fire test compartment. 


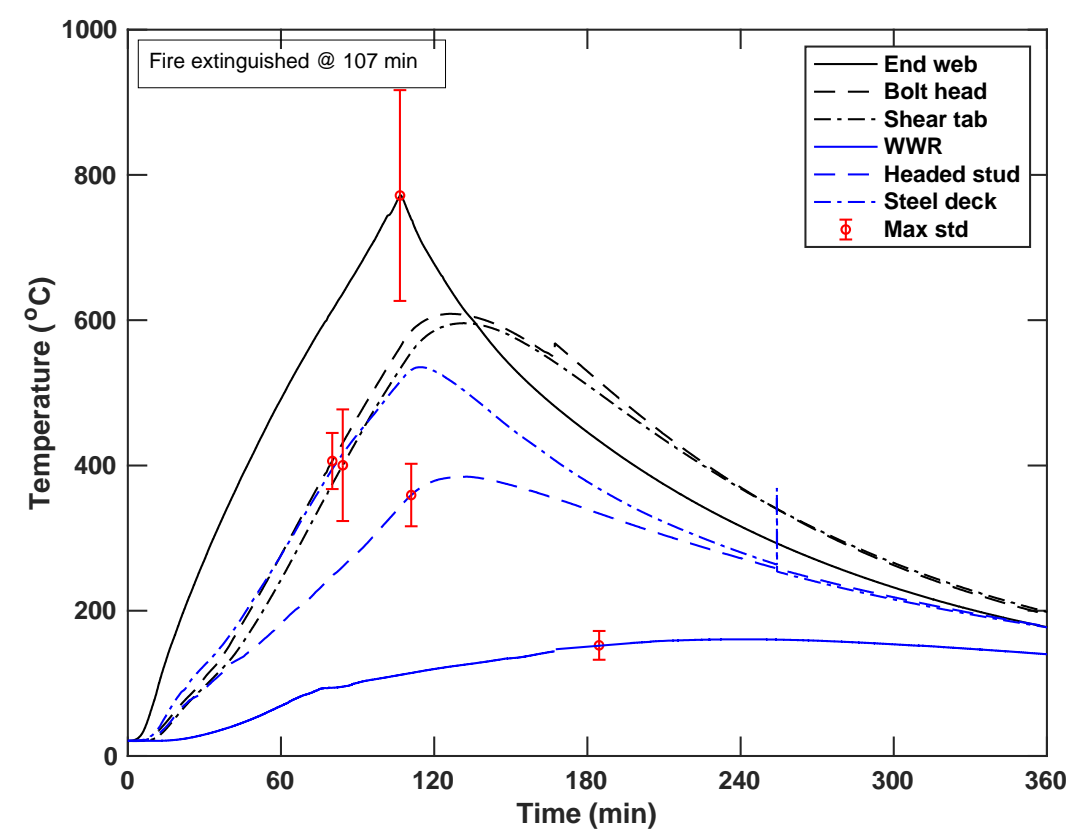

Fig. 4-21. Temperatures of shear tab connections used in the middle (secondary) W16×31 beam.

Between the south and north primary beams (Fig. 4-22), temperatures of each connection element were very similar. The average peak temperatures of the beam end web, bolt heads, and shear tabs were in excess of $500{ }^{\circ} \mathrm{C}, 400{ }^{\circ} \mathrm{C}$ and $300{ }^{\circ} \mathrm{C}$, respectively. In the north beam, temperature readings at the middle bolt became less smooth after $30 \mathrm{~min}$ (Fig. 4-22a), possibly due to cracks developed in the SFRM applied to this region. The standard deviation in temperature measurements of the shear tabs or end webs in these perimeter (primary) beams was less than $45^{\circ} \mathrm{C}$.

Temperatures of the extended shear tab connections were comparable between the east and west girders as shown in Fig. 4-23. The temperature difference between the east and west girders was approximately $50{ }^{\circ} \mathrm{C}$ on average in the end web or bolt heads. For the weld joints or shear tabs, the temperature difference between the east and west girders increased over the period of fire exposure. A peak temperature of the bolt heads reached greater than $500{ }^{\circ} \mathrm{C}$, and that of the welded joints ranged from $180{ }^{\circ} \mathrm{C}$ to $250{ }^{\circ} \mathrm{C}$ during fire loading. 


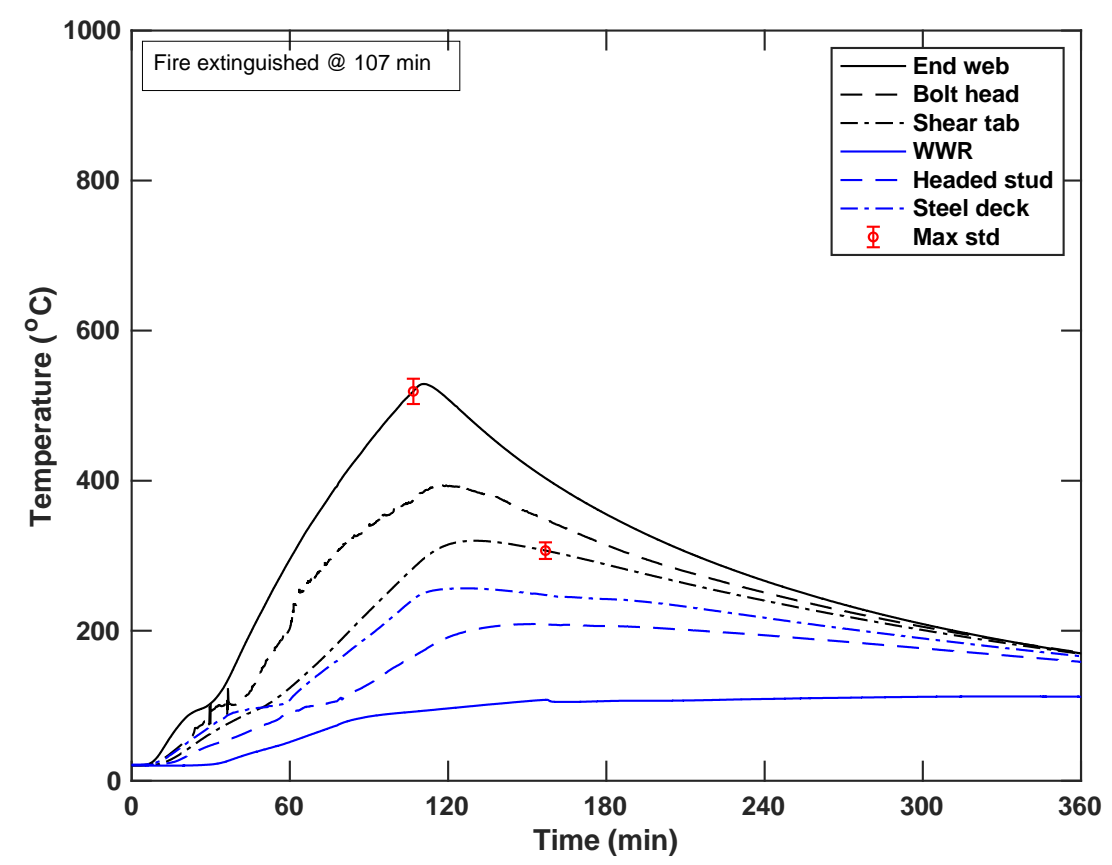

(a)

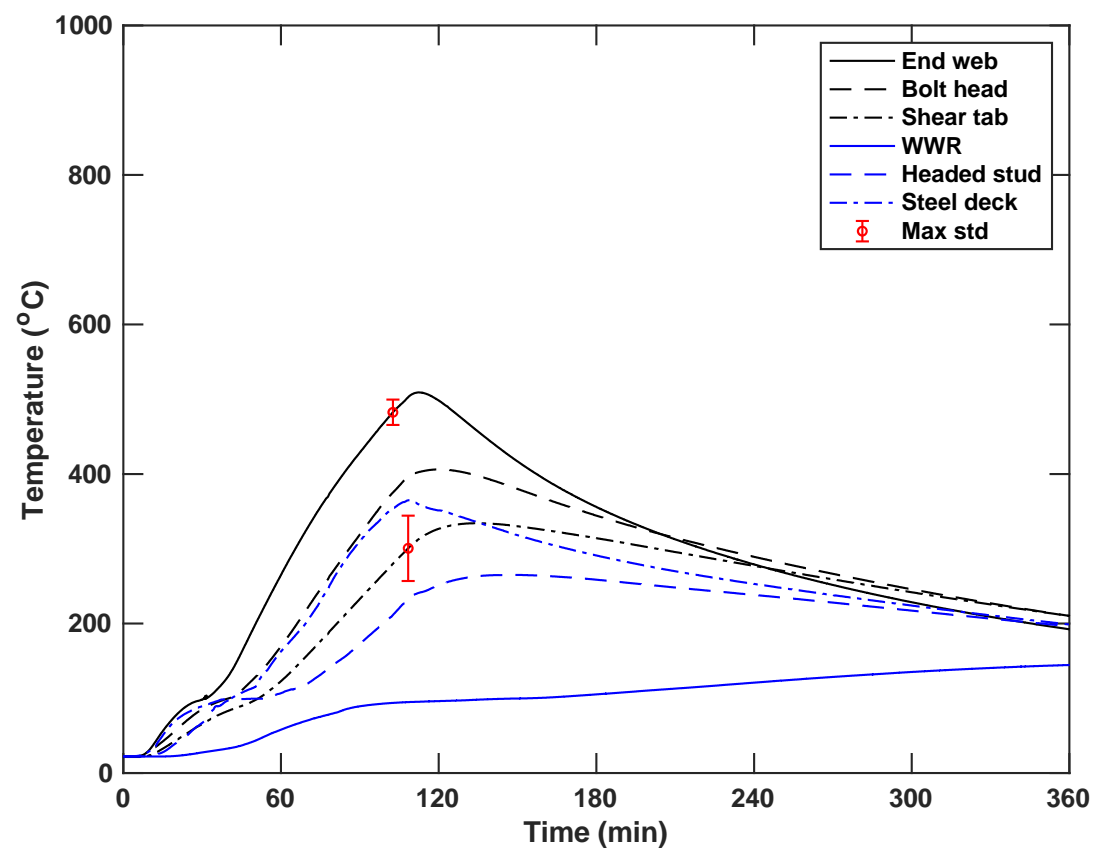

(b)

Fig. 4-22. Temperatures of shear tab connections used in (a) north and (b) south primary beams (W16 $\times 31)$. 


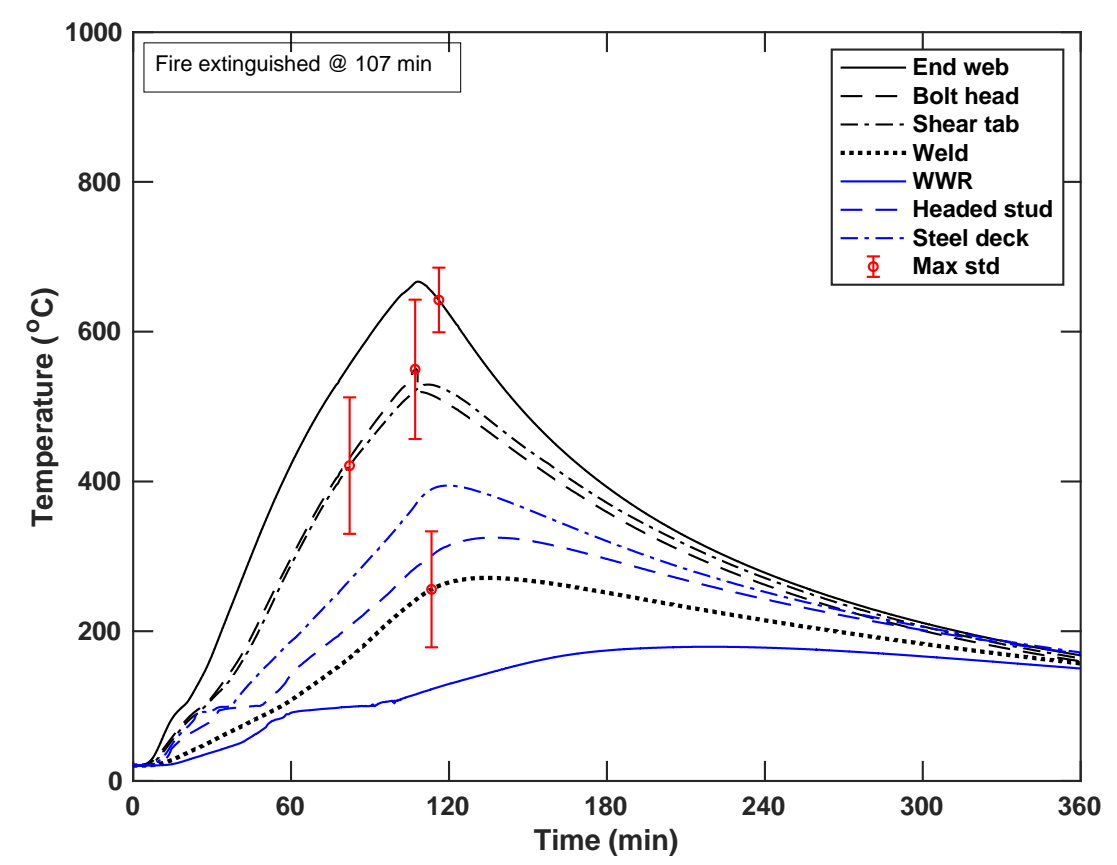

(a)

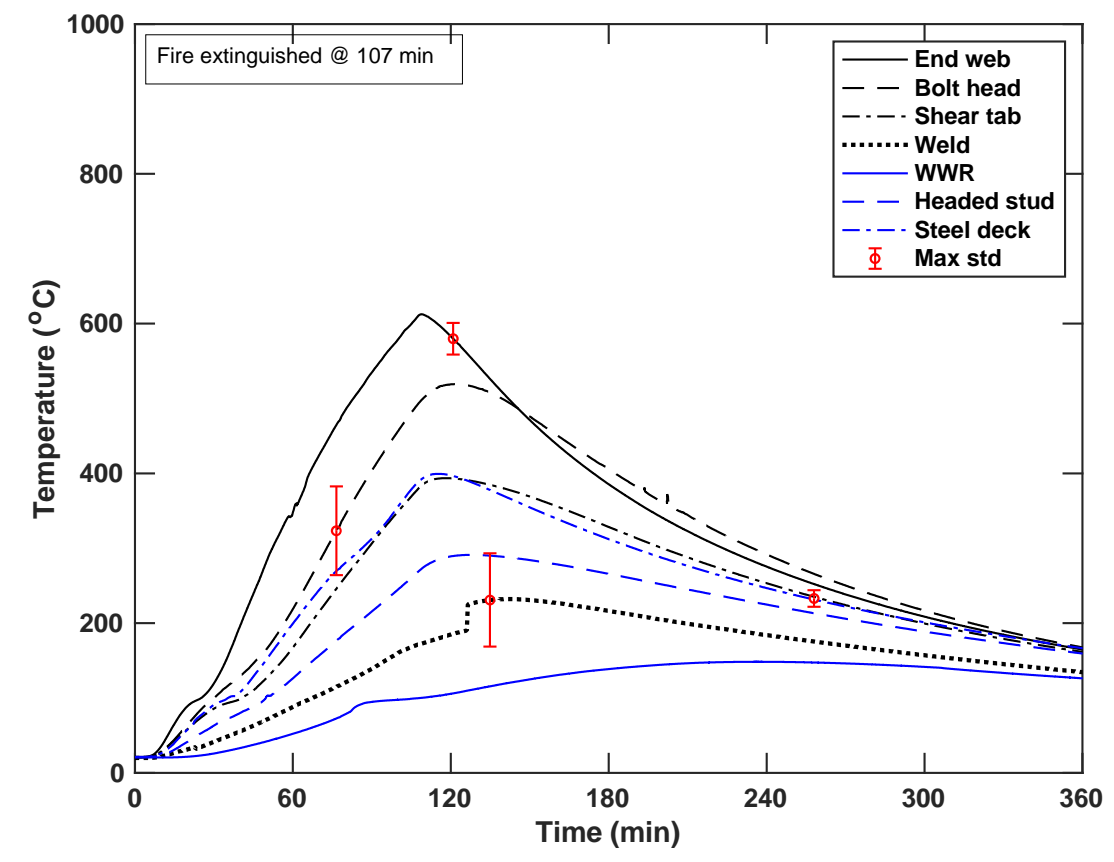

(b)

Fig. 4-23. Temperatures of extended shear tab connections used in (a) east and (b) west girders $(W 18 \times 35)$. 


\subsection{Structural Response}

This section presents the structural performance of the mechanically loaded test floor assembly when exposed to the test compartment fire and during cooling. Major events during the fire test are described here. Strains and displacements of the prototype building and the fire-exposed floor assembly were quantified during the heating and cooling phases of the test fire.

\subsubsection{Test Observations}

Table 4-2 presents a variety of events that were documented during the experiment and further verified against the multimedia data (e.g., recorded test videos and audio files). The reported times herein were recorded following the burner ignition and rounded to the nearest minute. A variety of snapshots from test videos are shown in Fig. 4-24 through Fig. 4-29. The term 'report' is used to describe a loud noise that occurred simultaneously with a noticeable change in structural data presented in the following subsections.

Table 4-2. Test observations following the burner ignition.

\begin{tabular}{|c|c|c|}
\hline Time (min) & Observations & Figures \\
\hline 5 & $\begin{array}{l}\text { A center seam of the steel decking began to separate, indicating failure of deck } \\
\text { fasteners in the mid panel. }\end{array}$ & Fig. 4-24a \\
\hline 9 & Buckling of the steel decking was visible. & Fig. $4-24 b$ \\
\hline 12 & $\begin{array}{l}\text { Buckling of north side of the steel decking (between the secondary beam and the } \\
\text { north primary beam) was visible, indicating delamination of steel decking. }\end{array}$ & Fig. 4-25 \\
\hline 18 & Water appeared on top of the slab through concrete cracks. & Fig. 4-26a \\
\hline 24 & Concrete cracks became clearly visible north of the north primary beam. & Fig. $4-26 b$ \\
\hline 41 & $\begin{array}{l}\text { A loud report was heard; several water-filled drums placed on the east surrounding } \\
\text { bay trembled; some strain and displacement data were shifted up or down, } \\
\text { simultaneously; concrete fractures around the perimeter of the heated slab were } \\
\text { visible; heavy (wet) steam appeared on top of the heated concrete. }\end{array}$ & Fig. $4-27 \mathrm{a}$ \\
\hline 69 & $\begin{array}{l}\text { A loud report was heard; some strain and displacement readings were shifted up or } \\
\text { down; concrete cracks appeared south of the secondary beam, propagating from the } \\
\text { midspan toward the east or west direction. }\end{array}$ & $\begin{array}{l}\text { Fig. } 4-27 b \\
\text { Fig. } 4-29 a\end{array}$ \\
\hline 82 to 90 & $\begin{array}{l}\text { The glowing steel deck became visible through mid-panel concrete fractures; the } \\
\text { gap between fractured concrete widened, indicating possible rupture of welded wire } \\
\text { fabric. }\end{array}$ & $\begin{array}{l}\text { Fig. 4-28a } \\
\text { Fig. 4-29b }\end{array}$ \\
\hline 95 to 100 & $\begin{array}{l}\text { Steam from the concrete was almost disappeared; intermittent flames appeared on } \\
\text { the concrete atop the beam-to-girder joints, indicating local deck and concrete } \\
\text { fractures. }\end{array}$ & Fig. $4-27 c$ \\
\hline 101 & $\begin{array}{l}\text { The values of HRRburner were affected by loss of the network connection used in } \\
\text { the natural gas fuel delivery system }\end{array}$ & \\
\hline 106 to 107 & Both fire and mechanical loading were removed. & $\begin{array}{l}\text { Fig. } 4-24 c \\
\text { Fig. } 4-28 b \\
\text { Fig. } 4-29 c\end{array}$ \\
\hline$>107$ & The test floor assembly did not collapse during cooling. & Fig. $4-28 \mathrm{c}$ \\
\hline
\end{tabular}

It should be noted that local buckling of the floor beams and other connection damage were also identified after the fire experiment but unable to observe during the test. The characteristics of these failures were investigated through displacement and strain data as well as the post-test inspections described in Sect. 4.6. 

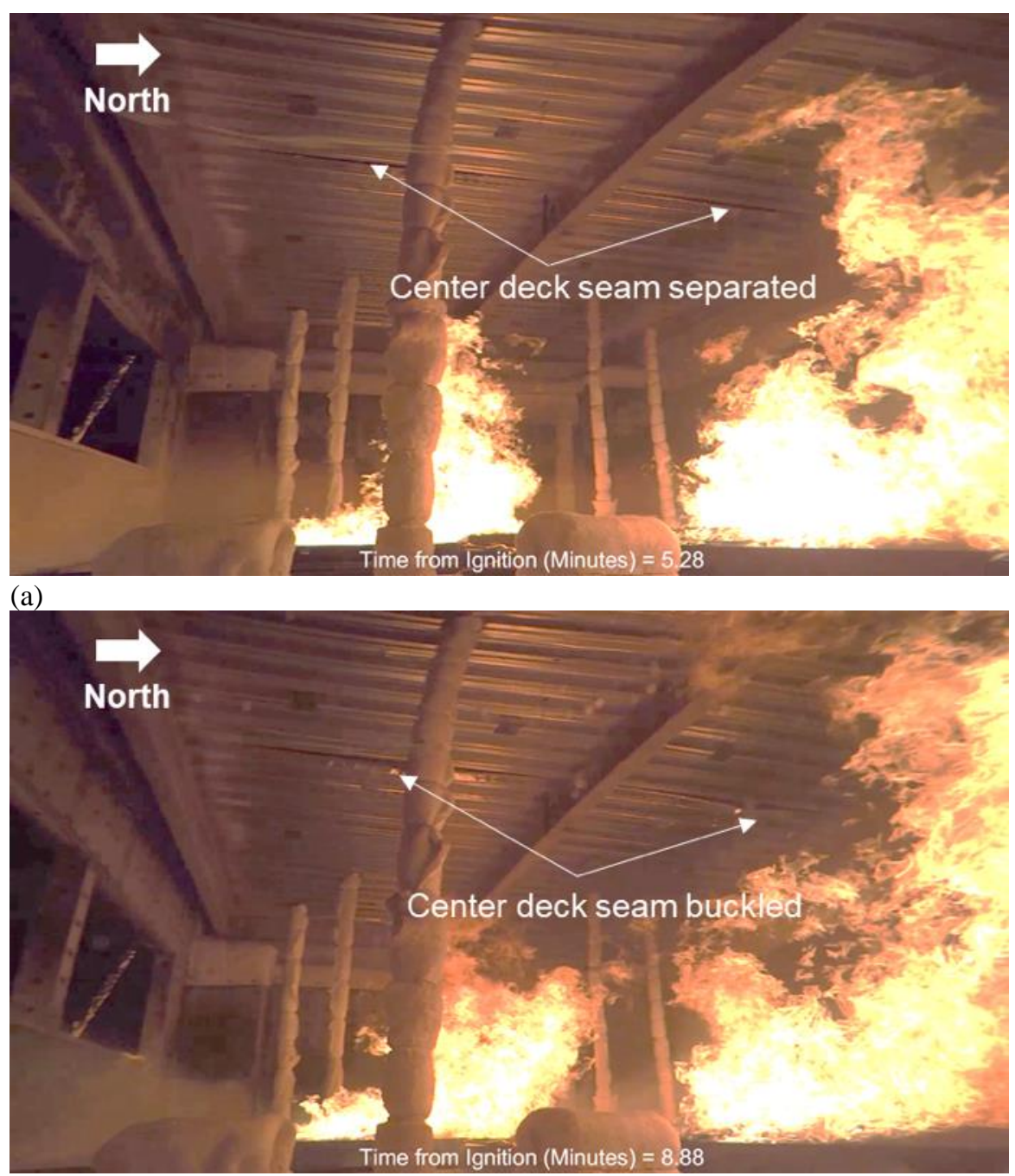

(b)

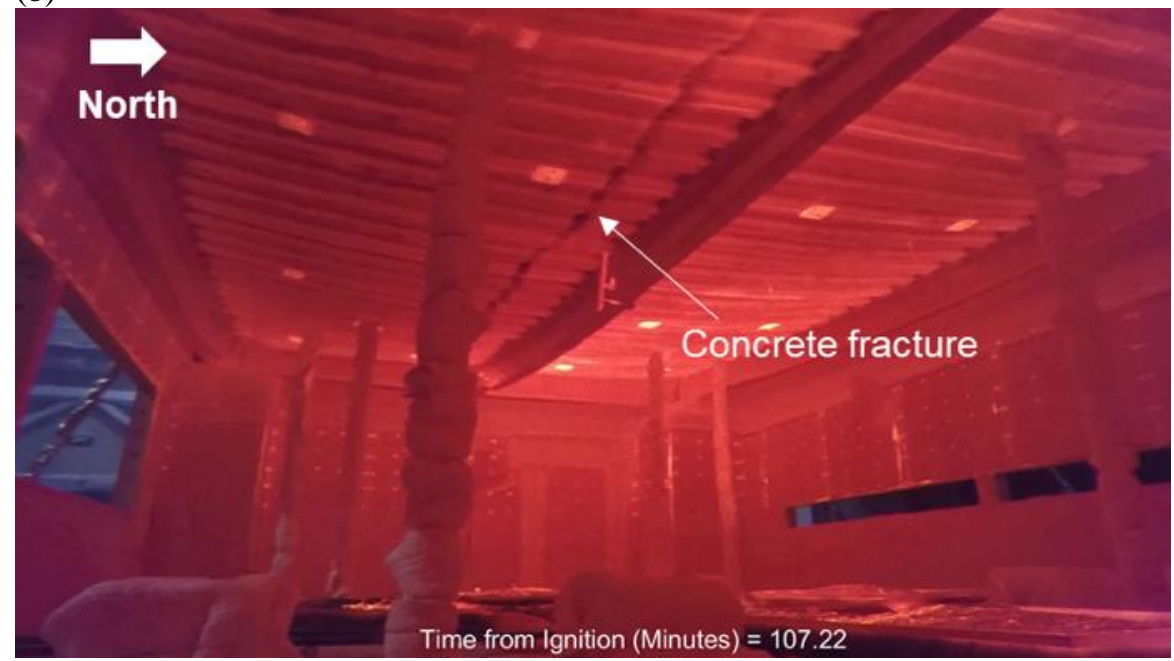

(c)

Fig. 4-24. Snapshots from the test video viewing inside the test compartment at about (a) $5 \mathrm{~min}$, (b) 9 min, and (c) $107 \mathrm{~min}$ after the burner ignition. 


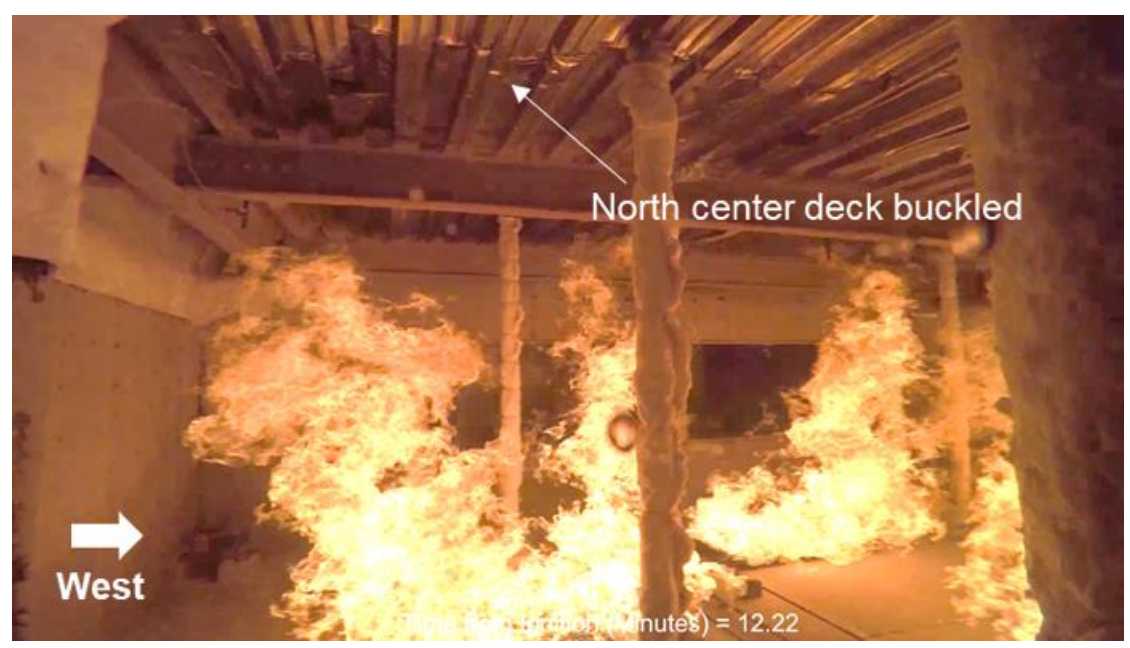

Fig. 4-25. A snapshot of the test video showing local buckling of the north steel deck at about 12 min.

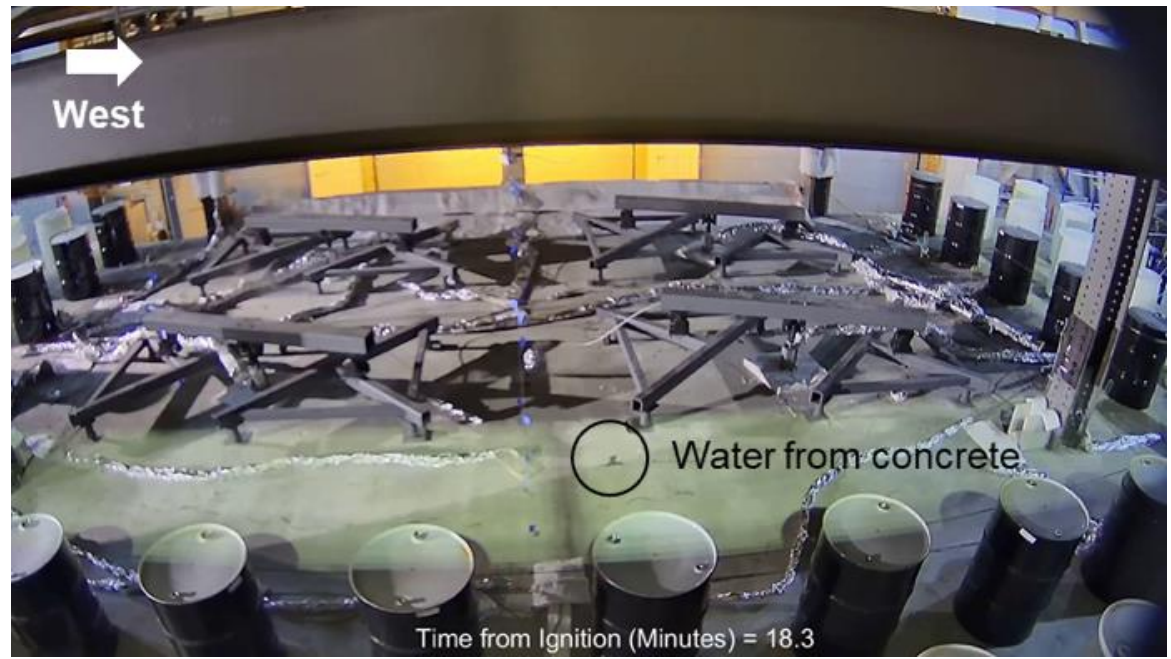

(a)

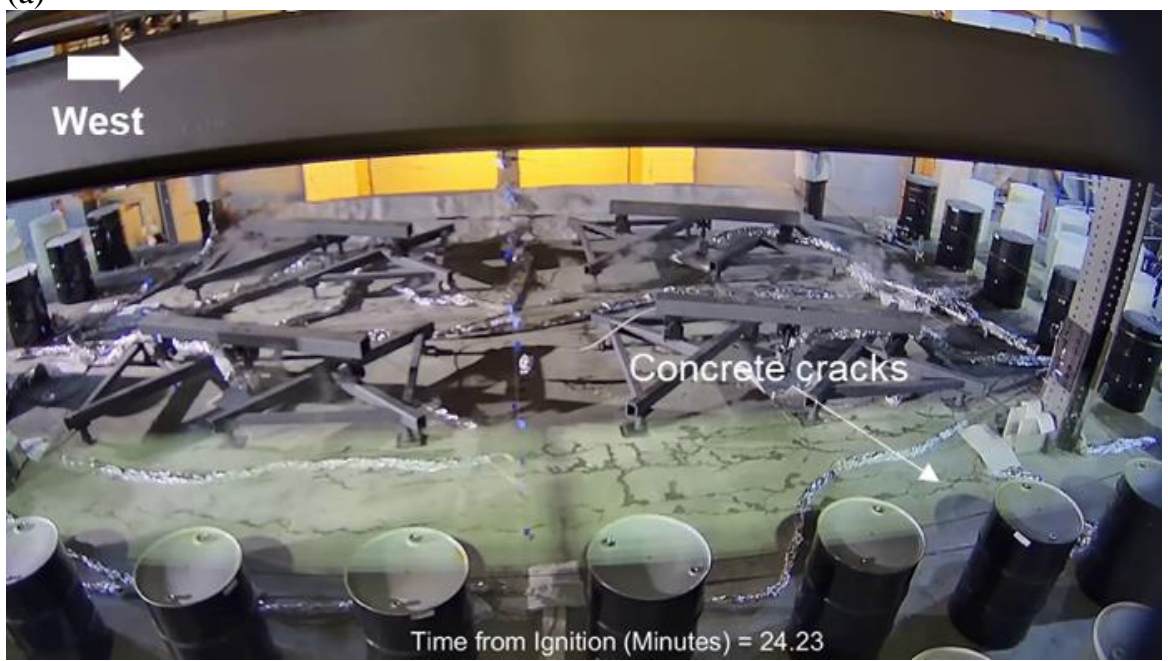

(b)

Fig. 4-26. Snapshots of the test video looking down on the top of the test floor assembly at about (a) $18 \mathrm{~min}$ and (b) $24 \mathrm{~min}$. 

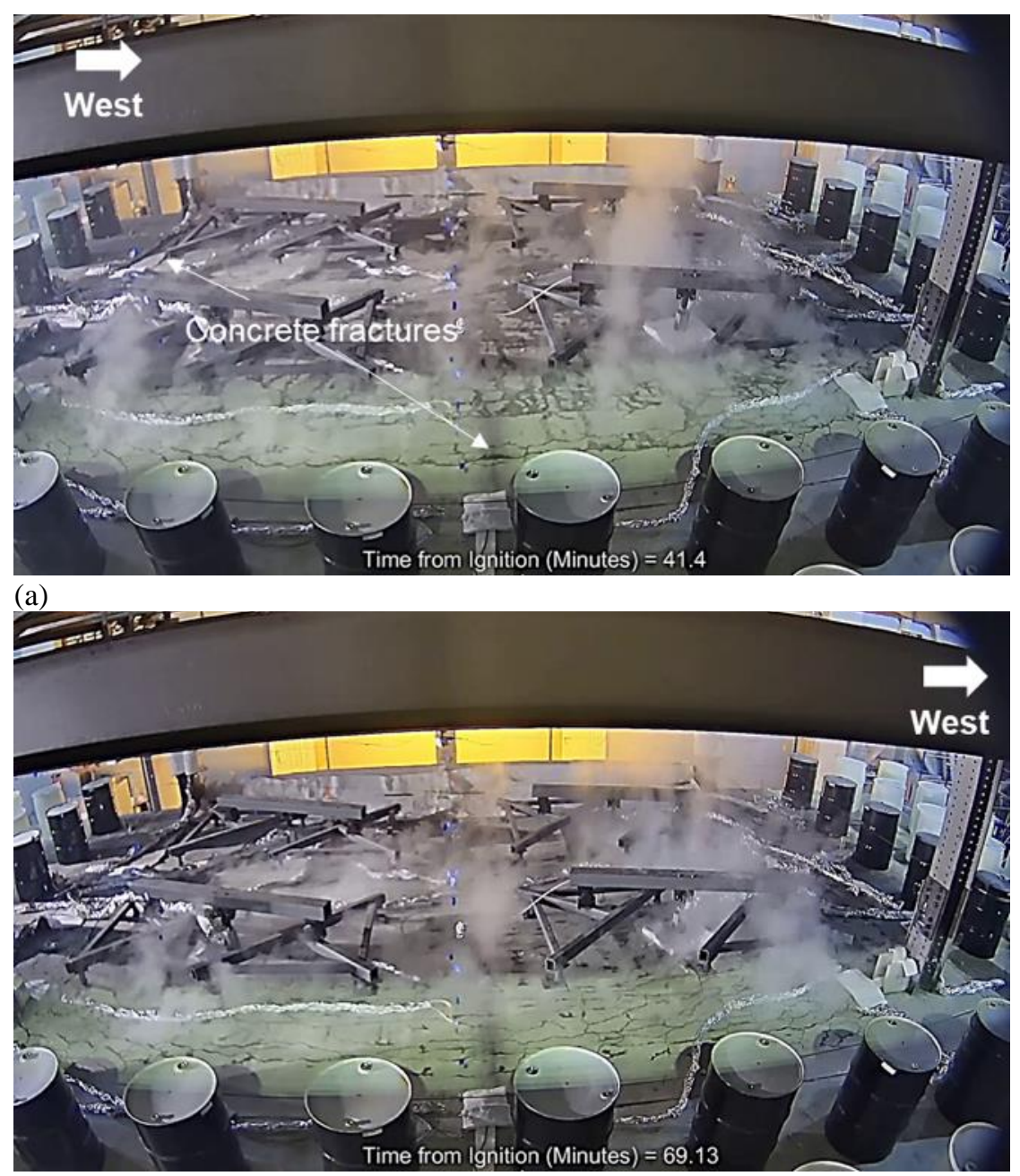

(b)

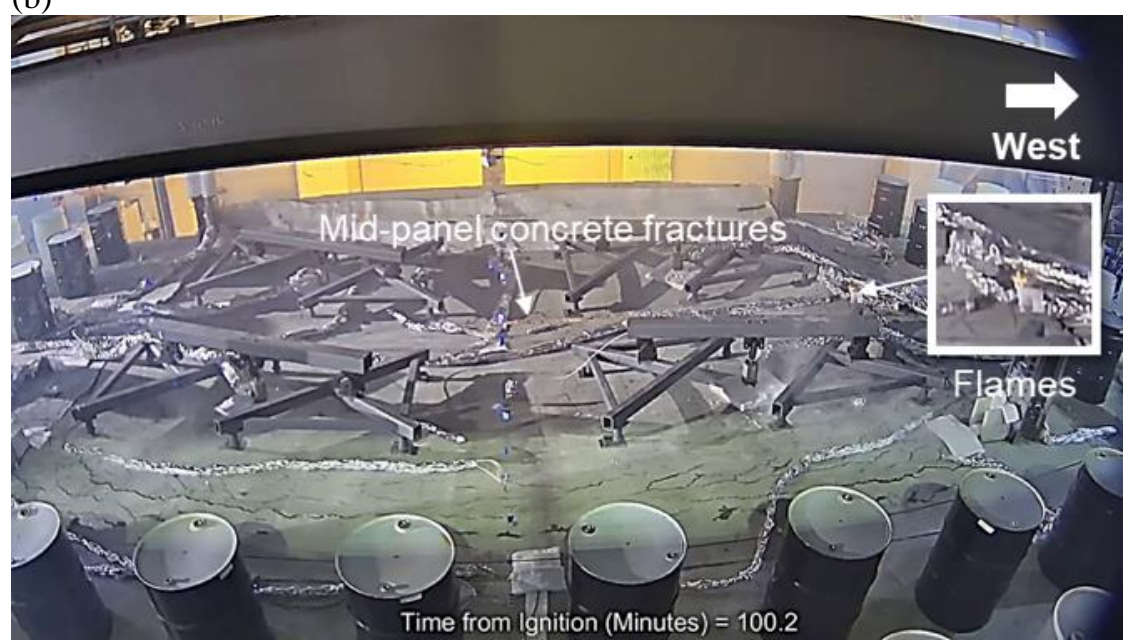

(c)

Fig. 4-27. Snapshots of the test video looking down on the top of the test floor assembly at about (a) 41 min, (b) $69 \mathrm{~min}$, and (c) $100 \mathrm{~min}$. 

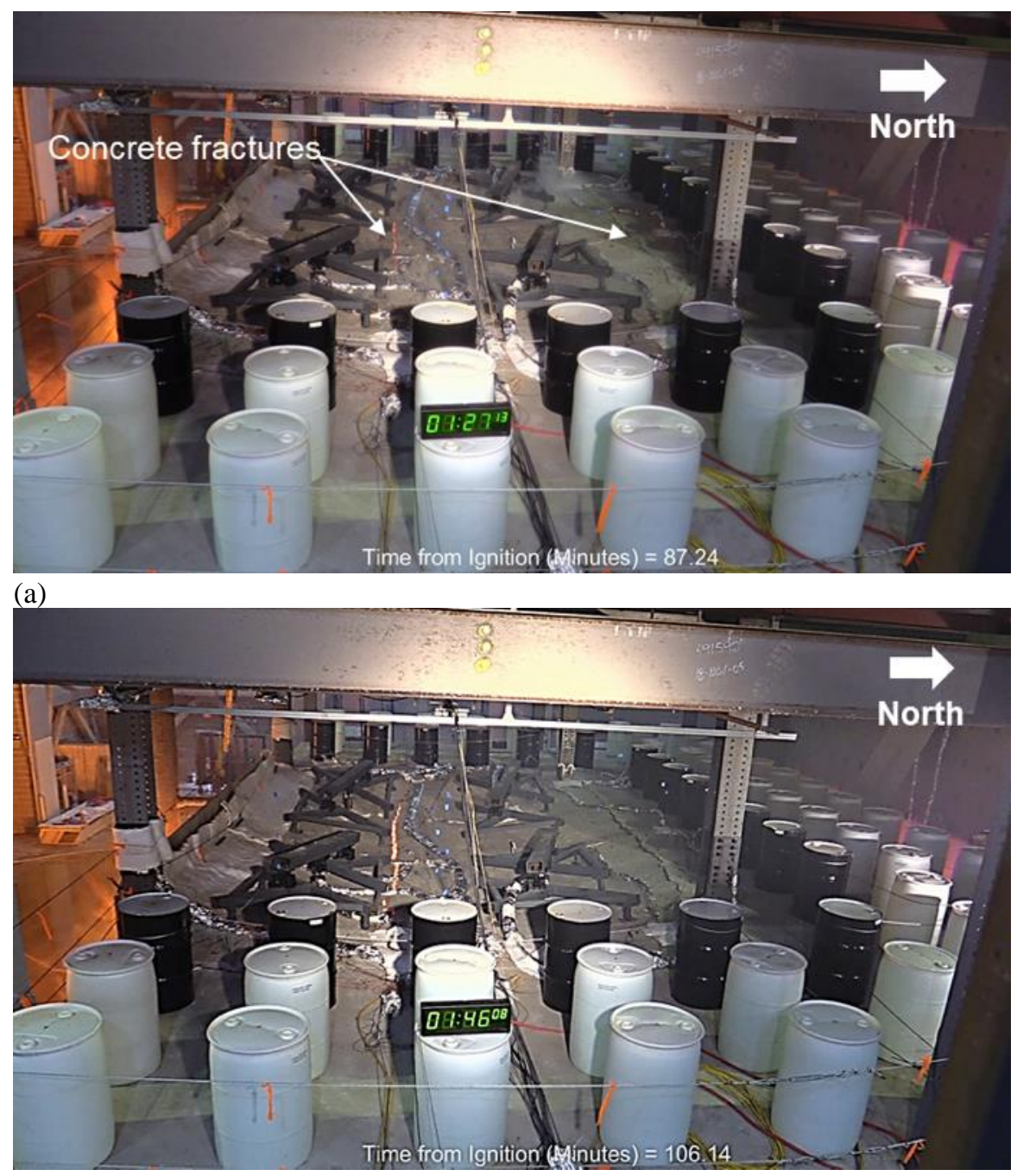

(b)

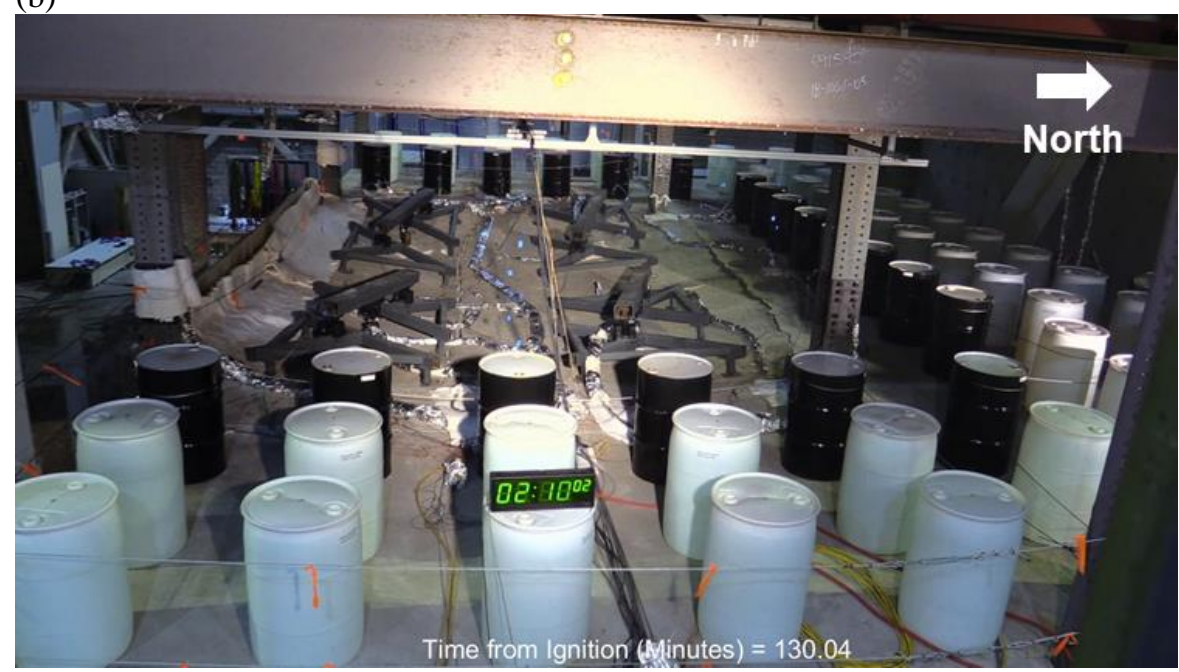

(c)

Fig. 4-28. Snapshots of the test video displaying the view from the east surrounding bay at (a) $87 \mathrm{~min}$, (b) 106 min, and (c) $130 \mathrm{~min}$ (cooling). 

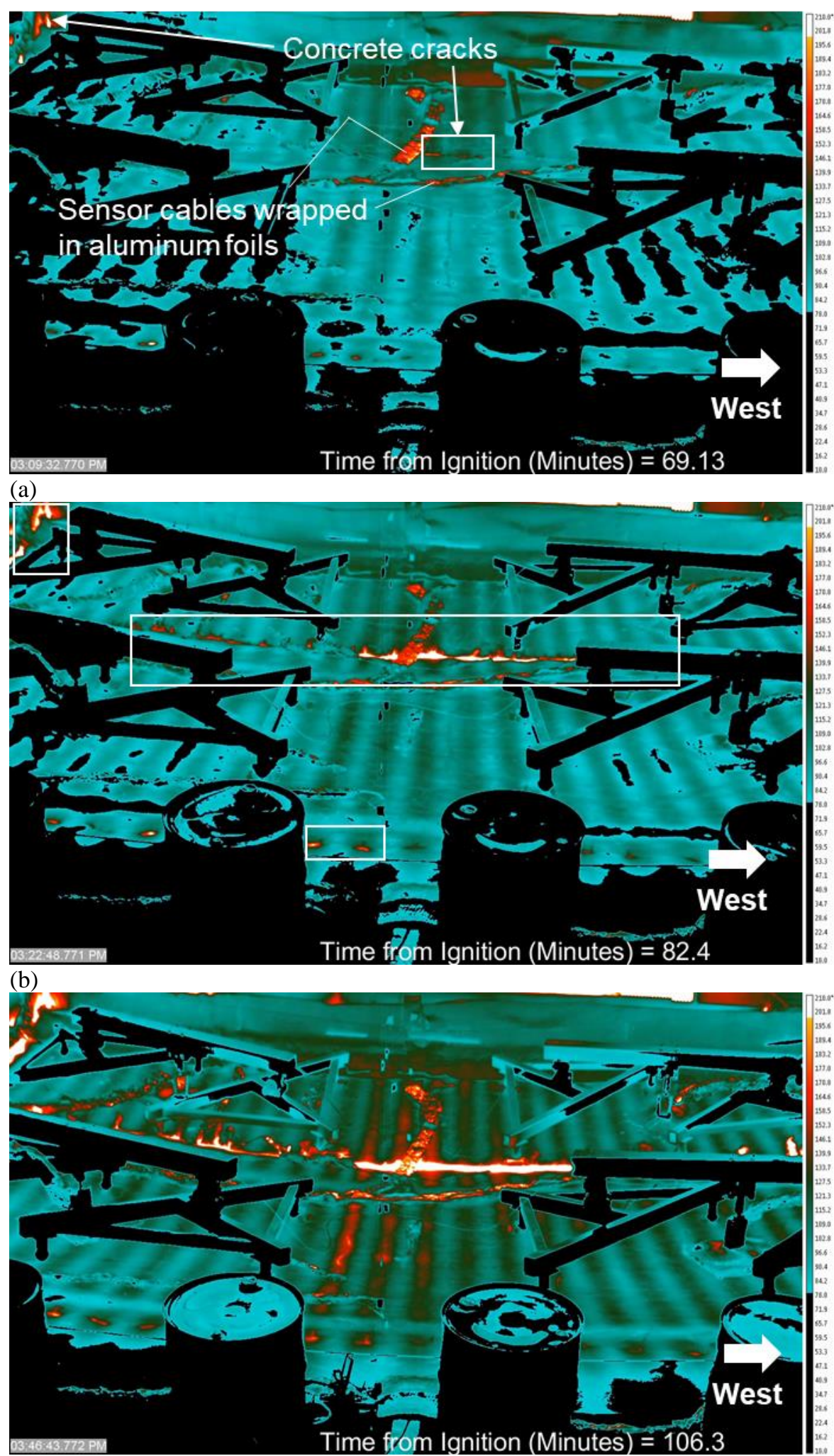

(c)

Fig. 4-29. Thermal images displaying top of the slab at (a) $69 \mathrm{~min}$, (b) $82 \mathrm{~min}$, and (c) $106 \mathrm{~min}$. 


\subsubsection{Vertical Displacement}

A total of fifteen string potentiometers (VD1 through VD 15) were deployed to measure the vertical displacement of the test floor assembly and the surrounding bays of the two-story prototype building: See the sensor locations in Fig. 4-30. All string potentiometers were mounted at a steel-aluminum frame isolated from the test building, except for VD11. This sensor (VD11) was intended to measure the relative vertical displacement between the first and second story girders at midspan. Temperatures of all string potentiometers remained below the maximum operating temperature specified by manufacturer. Appendix B reports the raw displacement data.

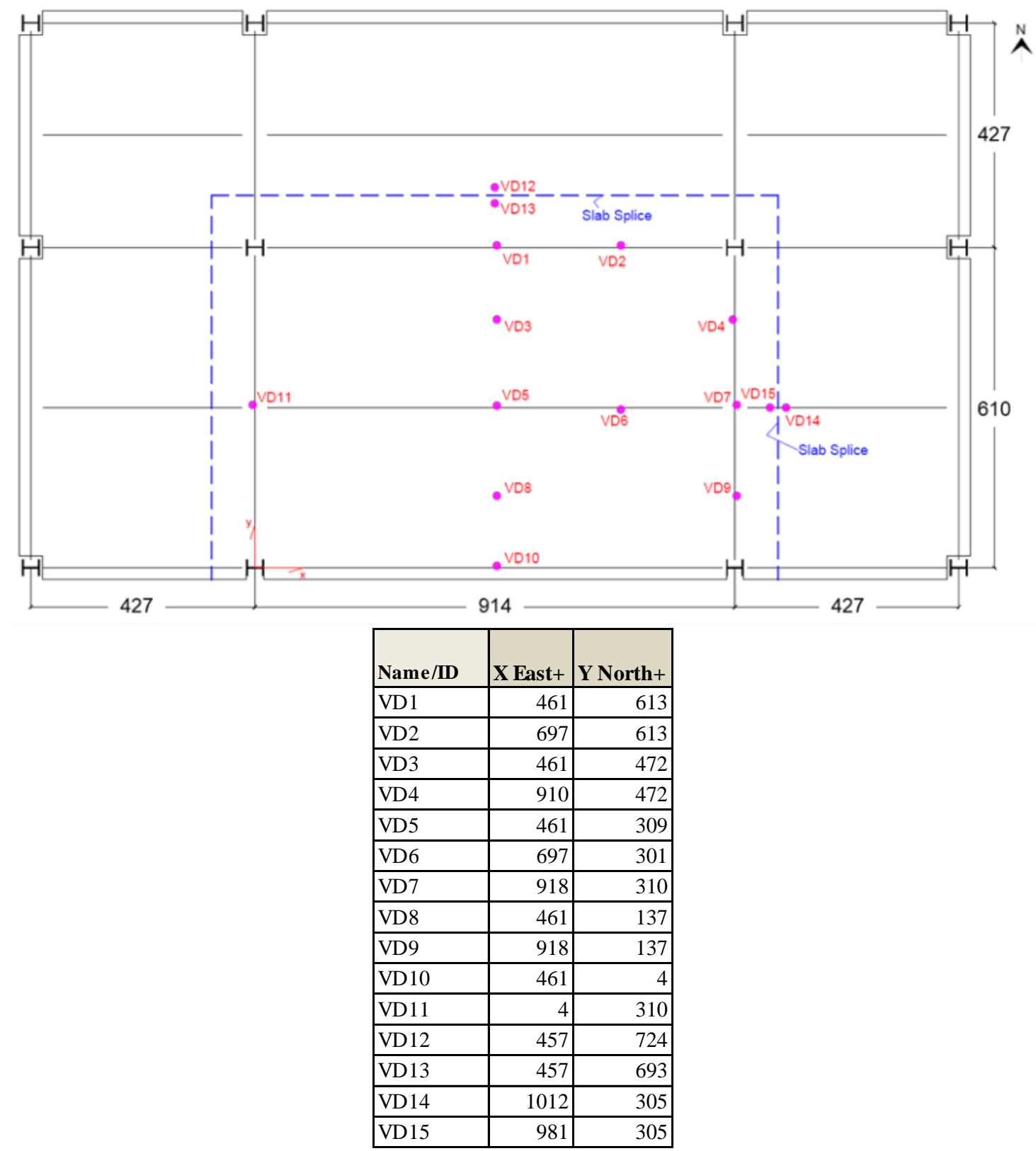

Fig. 4-30. Locations of vertical displacement measurement, unit in $\mathrm{cm}$. Measuring strings were attached to the eye bars embedded in the test floor slab. 
The measured vertical displacements as a function of fire exposure time and the average bottom flange temperatures of the floor beams or girders are illustrated in Fig. 4-31 and Fig. 4-32 respectively. The positive values of displacements reported herein indicate the downward vertical displacements as the test floor assembly sagged under fire exposure. Table 4-3 summarizes the maximum vertical displacement due to fire effects and their final values recorded at $19 \mathrm{~h}$ after the fire was extinguished.

As shown in Fig. 4-31a, the center of the test floor assembly began to sag following the burner ignition (0 min). During the first $10 \mathrm{~min}$ in fire, however, the midspan vertical displacement of the south edge beam (VD10) increased inversely, i.e., moving upward. For this beam, a free slab edge on its south side allowed less resistance to twisting as the mechanical load was applied north of this beam. During this early stage of fire exposure, hence, this edge beam was twisting while the center portion of the entire test floor sagged in response to thermal bowing.

As the compartment temperature continued to rise, all five steel members continuously deflected downward (Fig. 4-31, Fig. 4-32b). The vertical displacement of the middle beam (VD5) increased to its peak value of $580 \mathrm{~mm}$ (at $107 \mathrm{~min}$ ) or approximately a ratio of $\mathrm{L} / 16$, where $\mathrm{L}$ is the east-west span of the test floor assembly of $914 \mathrm{~cm}$. After cooling, this displacement was recovered to $350 \mathrm{~mm}(\mathrm{~L} / 26)$. The vertical displacements of the perimeter (primary) members (VD1, VD7, VD10 and VD11) did not increase much.

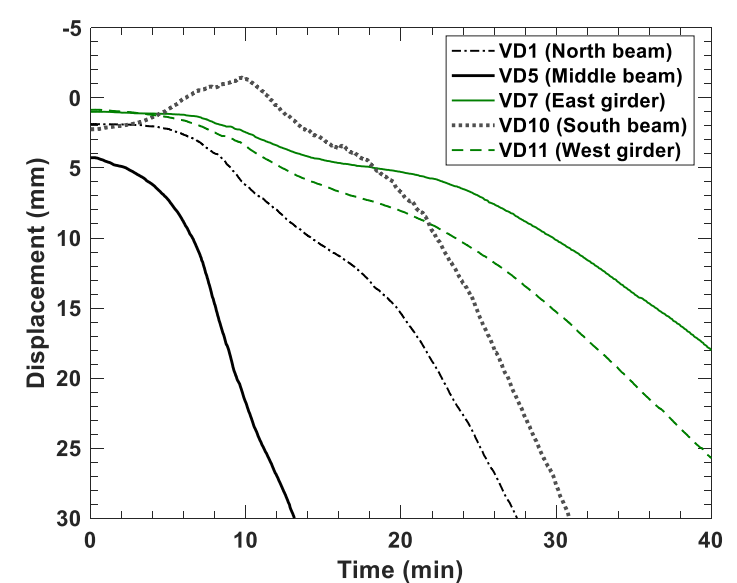

(a)

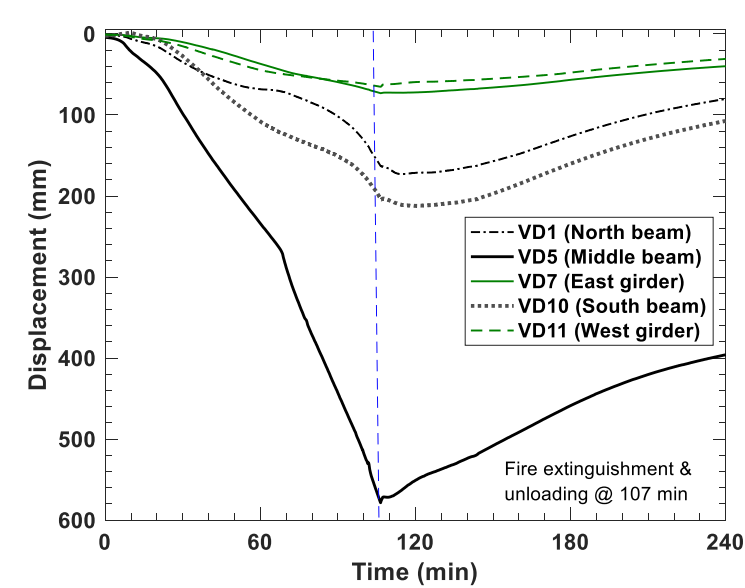

(b)

Fig. 4-31. Measured vertical displacements of the exposed steel members at midspan (a) up to 40 min and (b) up to $240 \mathrm{~min}$ including cooling (beginning at $107 \mathrm{~min}$ ).

As shown in Fig. 4-32, the vertical displacement of the secondary beam (W16×31) increased linearly as the average bottom flange temperatures increased up to $700{ }^{\circ} \mathrm{C}$. At this temperature, the longitudinal concrete fracture appeared south of this beam at 69 min (Refer to Sect. 4.5.1). Beyond $700{ }^{\circ} \mathrm{C}$, the vertical displacement of this beam still increased linearly with temperature but was much more sensitive to the temperature change, i.e., at a higher rate from $0.4 \mathrm{~mm} /{ }^{\circ} \mathrm{C}$ to $1.4 \mathrm{~mm} /{ }^{\circ} \mathrm{C}$. 
However, the vertical displacements of the perimeter (primary) beams (VD1, VD7, VD10 and VD11) increased much less with respect to the temperature change. There might be several factors that contributed to this behavior: (a) the early development of concrete fractures along the east and west edges of the test column grid (Refer to Sect. 4.5.1) prohibiting an effective load transfer on the east and west girders, (b) a smaller tributary area for mechanical loading on the south edge beam, or (c) a smaller applied load ratio for the east and west girders with the shorter span $(6.1 \mathrm{~m})$ and a larger steel shape $(\mathrm{W} 18 \times 35)$. In addition, provided that the steel decking was continuous in the north-south direction, the vertical displacement of the east and west girder (VD7 and VD11, respectively) appeared to be less responsive to the longitudinal concrete fractures (at $69 \mathrm{~min}$ ).

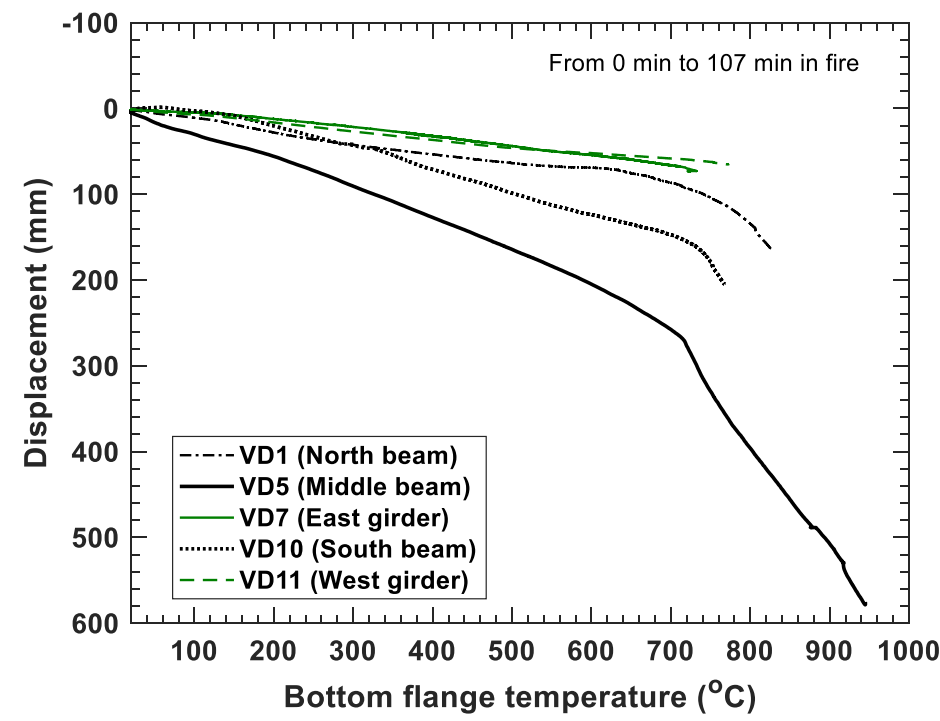

Fig. 4-32. Measured vertical displacements of the exposed steel members at midspan as a function of the bottom flange temperatures from $0 \mathrm{~min}$ to $107 \mathrm{~min}$.

Table 4-3 Maximum and final values of the vertical displacements of the fire exposed steel members at midspan, where the final values were recorded at 17 hours after the fire was extinguished at 107 min.

\begin{tabular}{|c|c|c|c|c|}
\hline $\begin{array}{l}\text { Fire-exposed beam } \\
\text { or girder }\end{array}$ & $\begin{array}{l}\text { Displacement } \\
\text { channel }\end{array}$ & $\begin{array}{l}\text { Temperature channels used } \\
\text { for averaging bottom flange } \\
\text { temperatures }\end{array}$ & $\begin{array}{l}\text { Maximum } \\
\text { displacements and } \\
\text { recorded test time }\end{array}$ & $\begin{array}{l}\text { Final reading } \\
\text { after cooling }\end{array}$ \\
\hline North primary beam & VD1 & TB10_3, TB11_5, TB11_6 & $212 \mathrm{~mm}(120 \mathrm{~min})$ & $70 \mathrm{~mm}$ \\
\hline Secondary beam & VD5 & $\begin{array}{l}\text { TB5_3, TB6_5, TB6_6, } \\
\text { TB7_3 }\end{array}$ & $578 \mathrm{~mm}(107 \mathrm{~min})$ & $353 \mathrm{~mm}$ \\
\hline East girder & VD7 & TB17_3, TB16_5, TB16_6 & $73 \mathrm{~mm}(107 \mathrm{~min})$ & $22 \mathrm{~mm}$ \\
\hline South primary beam & VD10 & TB1_3, TB2_5, TB2_6 & $173 \mathrm{~mm}(115 \mathrm{~min})$ & $50 \mathrm{~mm}$ \\
\hline West girder & VD11 & TB12_3, TB13_5, TB13_6 & $65 \mathrm{~mm}(107 \mathrm{~min})$ & $15 \mathrm{~mm}$ \\
\hline
\end{tabular}


The temporal change in the vertical displacement at the centerlines of the test floor assembly is shown in Fig. 4-33. The south half of the test floor slab was deflected slightly more than its north half during the heating phase. The value of VD5 was less than that of VD8 up to $50 \mathrm{~min}$ but exceeded afterward. The relative displacement between VD13 and VD12 or between VD14 and VD15 was deemed negligible, indicating no failure of slab splices.

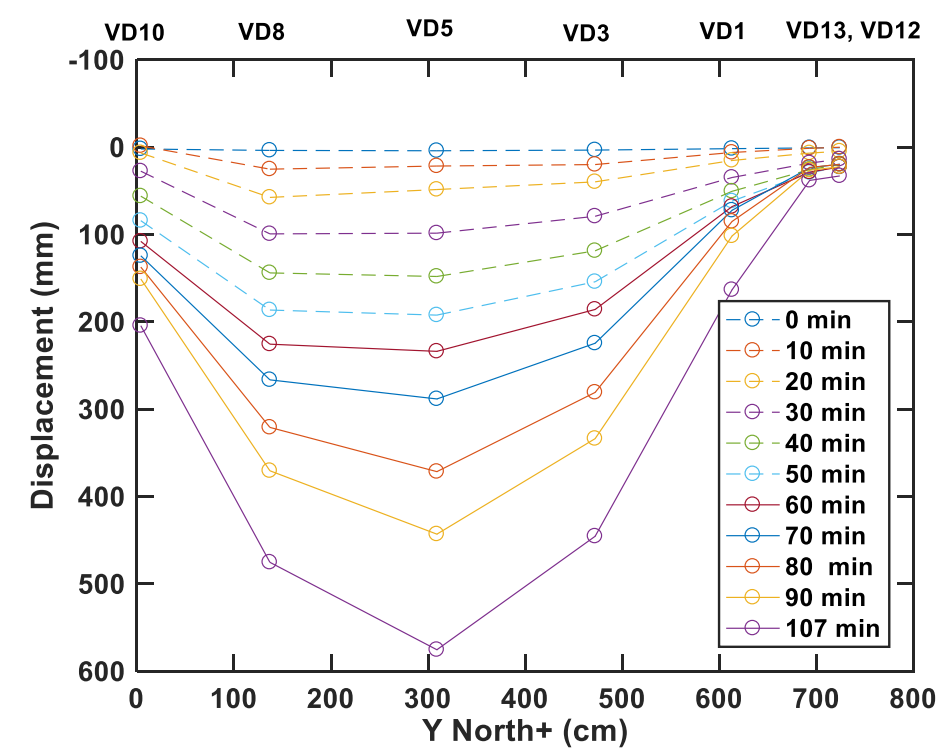

(a)

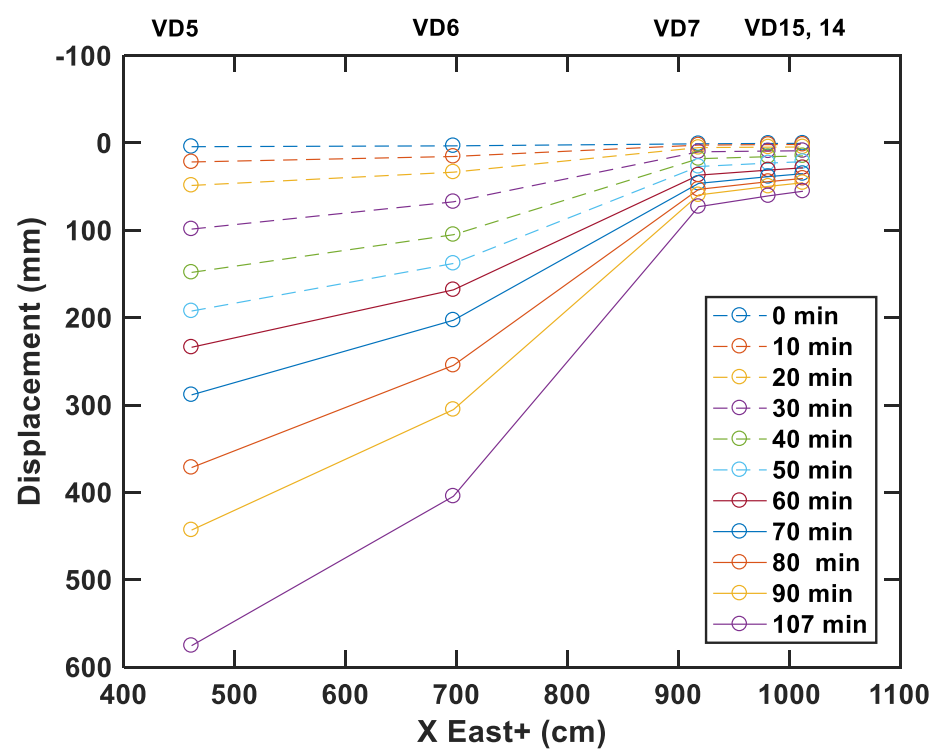

(b)

Fig. 4-33. Vertical displacement profile of the test floor assembly at (a) the north-south centerline and (b) the east-west centerline. The upper horizontal axes indicate the corresponding position of each vertical displacement sensors. 


\subsubsection{Horizontal Displacement}

A total of fifteen string potentiometers (HD1 through HD15) were employed to measure the horizontal (lateral) displacement of the test floor assembly and at the perimeter of the two-story prototype building; See Fig. 4-34. Except for HD4, HD6, and HD12, all remaining HD sensors were mounted outside of the test building. HD4 and HD6 sensors were used to measure thermal expansion at the north and east edges of the heated floor assembly, respectively; similarly, HD12 sensor was mounted at the second story level. The lateral displacements of the first-story columns (HD1 through HD3, HD5, and HD8 through HD10) as well as HD4 and HD6 were measured at $15 \mathrm{~cm}$ above the top surface of the test floor slab.

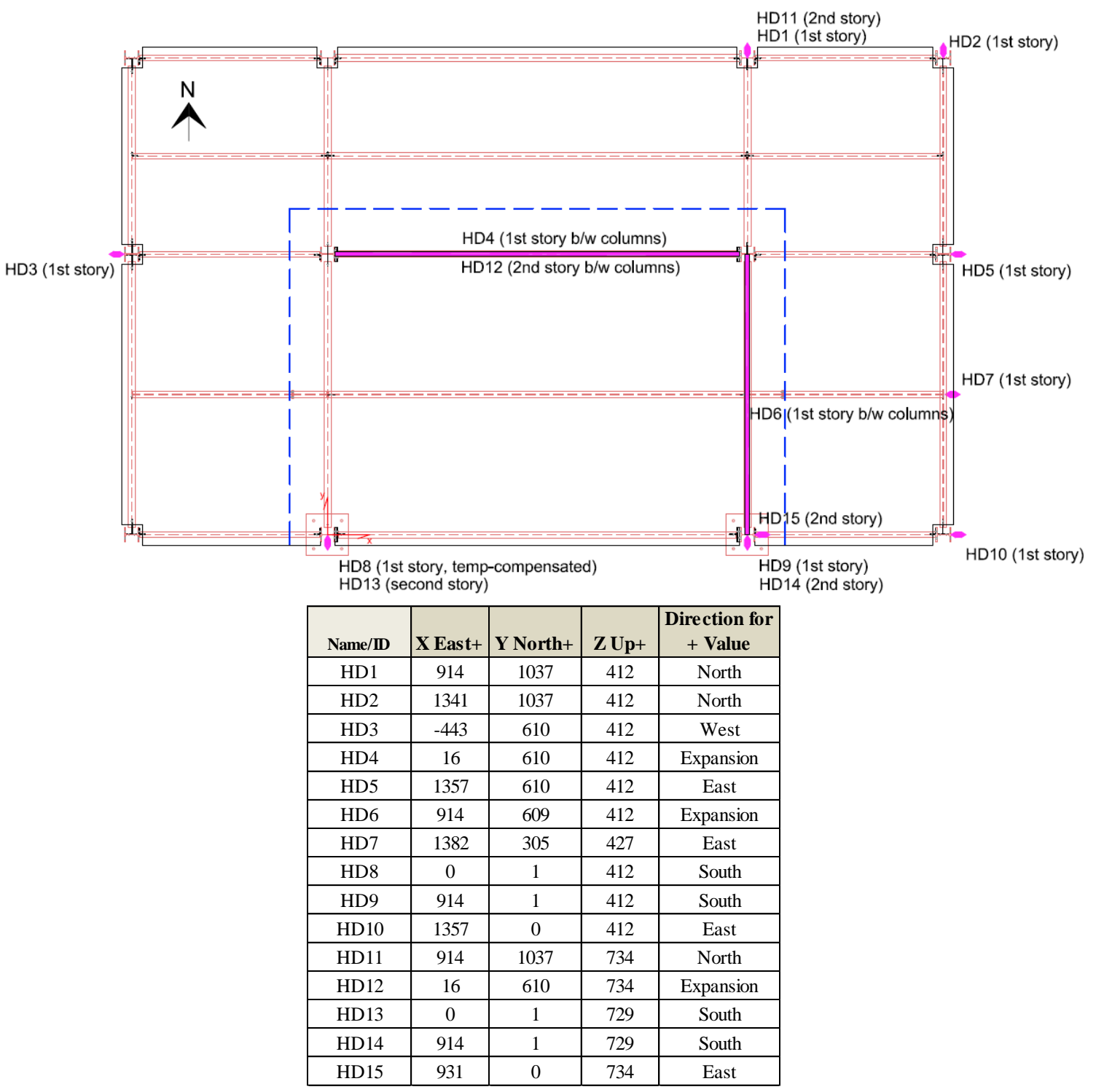

Fig. 4-34. Locations of horizontal displacement measurements, unit in $\mathrm{cm}$. The $\mathrm{XY}$ origin is defined at the center of the southwest column of the test bay; The $Z$ datum is defined at the laboratory strong floor. 
The time history of the horizontal (lateral) displacements measured at the first-story level is presented in Fig. 4-35. About five minutes into heating, as shown in Fig. 4-35a, the displacements began to increase in the east or west direction, responding to thermal expansion of the test floor assembly. At the same time, the lateral displacement of the southeast corner column of the test building (HD10) increased at a rate of $0.4 \mathrm{~mm} / \mathrm{min}$, more quickly than that of the other east exterior column or slab (e.g., HD5 or HD7). However, this trend was altered when a loud noise was heard at about $41 \mathrm{~min}$. At this moment, the value of HD10 suddenly decreased (approximately by $40 \%$ ), whereas the values of HD7 and HD5 slightly increased. As approaching 70 min into heating, the east-west horizontal displacements stopped increasing and then slowly decreased afterward. Note that the longitudinal concrete fracture occurred at the center of the heated slab around this time, Fig. 4-29a.

As shown in Fig. 4-35b, the first-story lateral displacements of the south exterior columns appeared not to be significantly affected by the concrete failure mentioned above. The values of HD6, HD8 and HD9 continuously increased for a longer period of the time, due to thermal elongation of the east and west girders toward the south. The peak value of HD8 or HD9 was recorded approximately $0.9 \%$ of the story height (at about $100 \mathrm{~min}$ ). The first story drift of the north exterior columns (HD1 or HD2) was much smaller. The value of HD1 did not increase until $20 \mathrm{~min}$ after the burner ignition and then increased in the north direction until $40 \mathrm{~min}$. After that, this column bent toward the south together with the south exterior columns. The northeast corner column of the test building (HD2) appeared to displace toward the north during fire exposure. However, the maximum displacement of this column was about $20 \%$ or less than the value of HD8.

The lateral displacements at various locations are plotted as a function of the bottom flange temperatures of the fire-exposed steel beams or girders in the test bay; See Fig. 4-36. HD3 through HD5 are plotted with the average bottom flange temperature of the north primary beam; HD7 is plotted with the average bottom flange temperature of the secondary beam; HD1, HD6, and HD9 are plotted with the average bottom flange temperature of the east girder; and HD8 is plotted with the average bottom flange temperature of the west girder. Some observations can be made as follow:

- Due to the east-west symmetricity of the beam framing, thermal elongation of the north edge of the test bay (HD4) was approximately two times the lateral displacement of the east or west exterior columns (HD3 or HD5) along the same line, as shown in Fig. 4-36a. These displacements stopped increasing around $600{ }^{\circ} \mathrm{C}$ to $700{ }^{\circ} \mathrm{C}$ followed by a descending trend with increasing temperatures. This result implicates that the compressive axial restraints against thermal elongation of the north primary beam started to decrease around this temperature range.

- With the presence of the north surrounding bay, the east and west girders of the test bay thermally elongated mostly toward the south. As shown in Fig. 4-36b, thermal elongation of the east girder (HD6) was very similar to the lateral displacement of the southeast and southwest column of the test bay (HD9 and HD8, respectively). However, around $700{ }^{\circ} \mathrm{C}$, HD6 and HD9 values began to decrease or become stabilized, indicating that fire-induced axial displacement increasing toward the south also began to diminish. 
During the cooling phase, as shown in Fig. 4-36c, thermal contraction of the middle portion and north edge of the test assembly (i.e., HD7 versus HD4) was similar, whereas that of the south edge of the test bay (HD10) was more sensitive to temperature changes. Thermal contraction of the east and west edge of the test floor (HD6 and HD8) was similar during cooling.

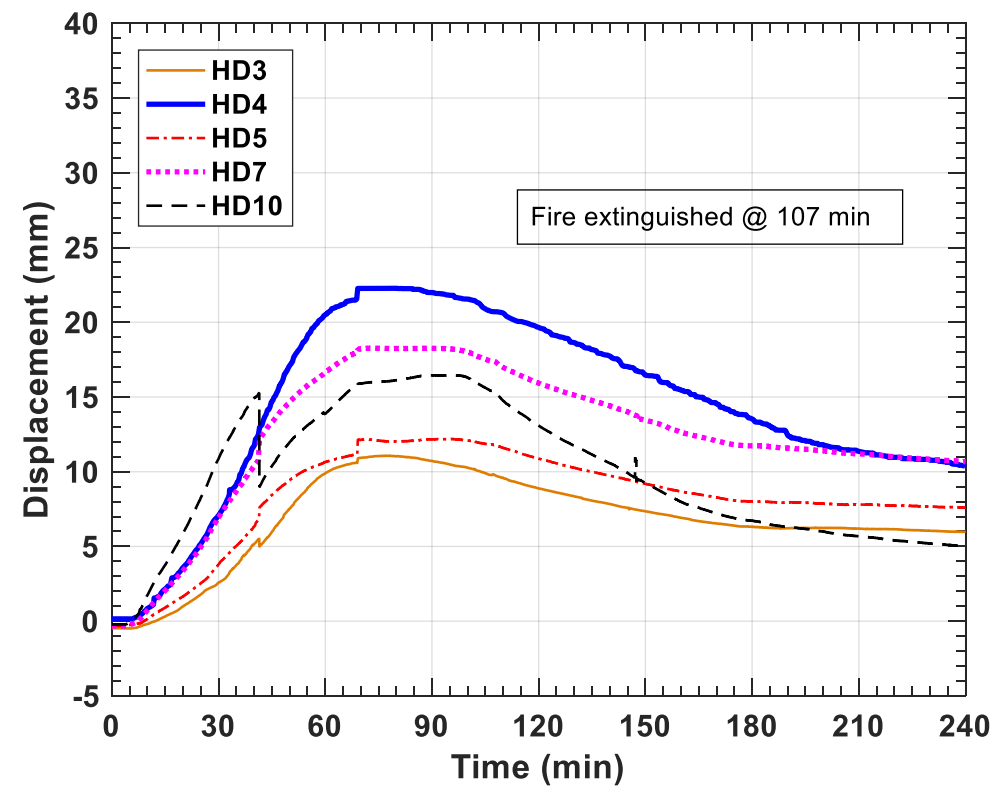

(a)

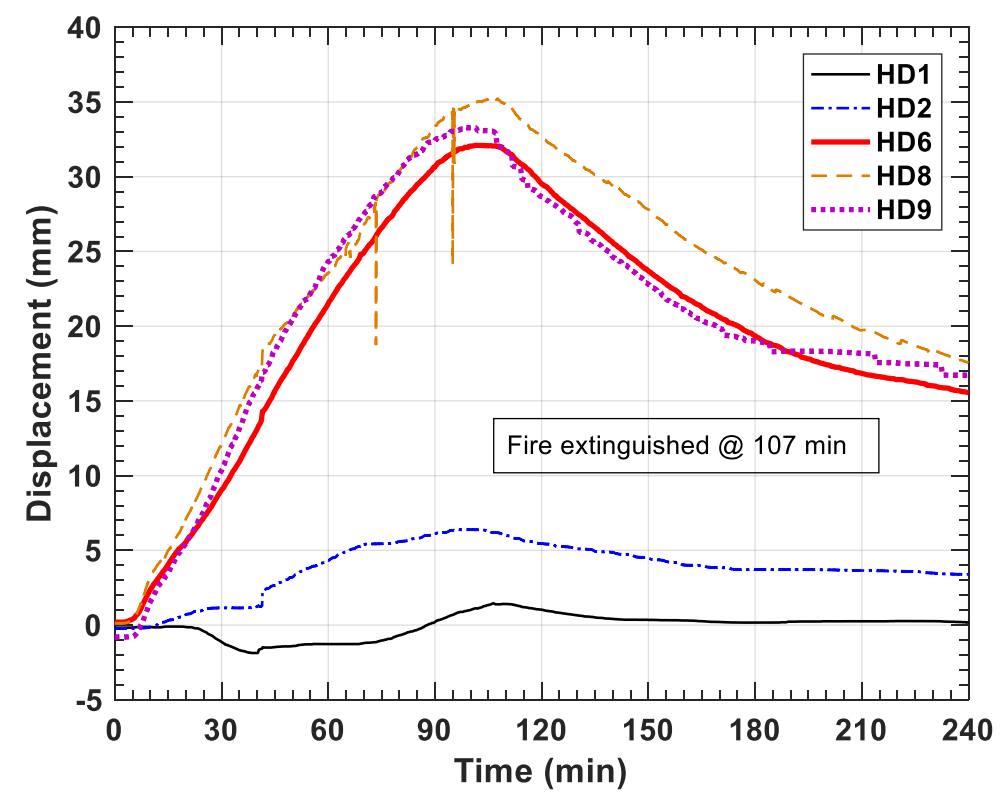

(b)

Fig. 4-35. Time history of lateral displacements measured (a) the east side and (b) the north side of the prototype building at the first-story level, compared with horizontal (axial) displacements measured along the edges of the test column grid (HD4 and HD6). 


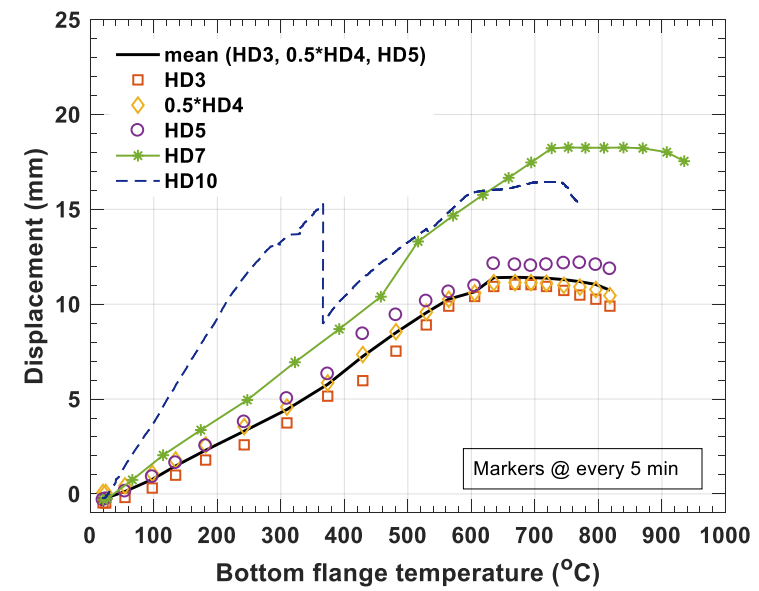

(a)

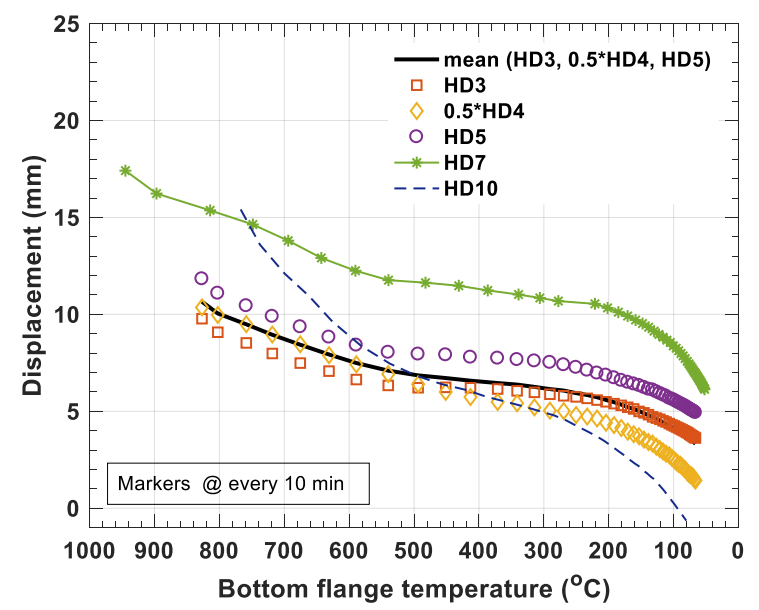

(c)

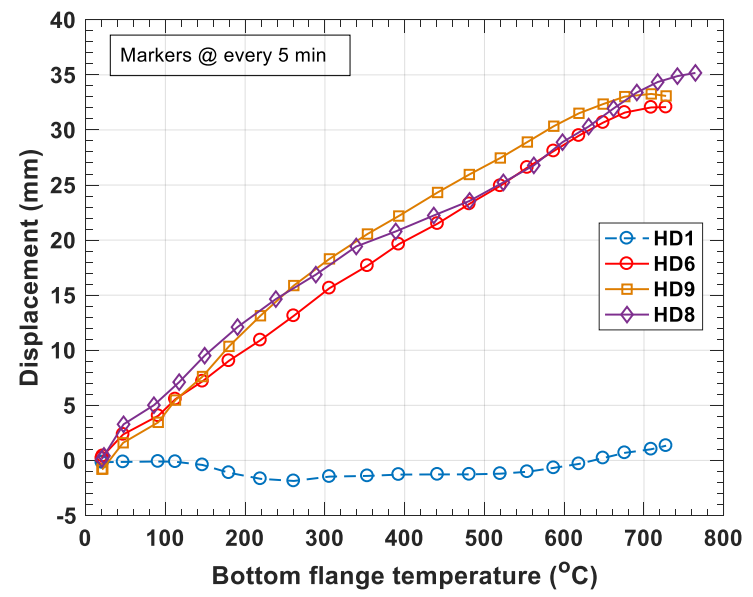

(b)

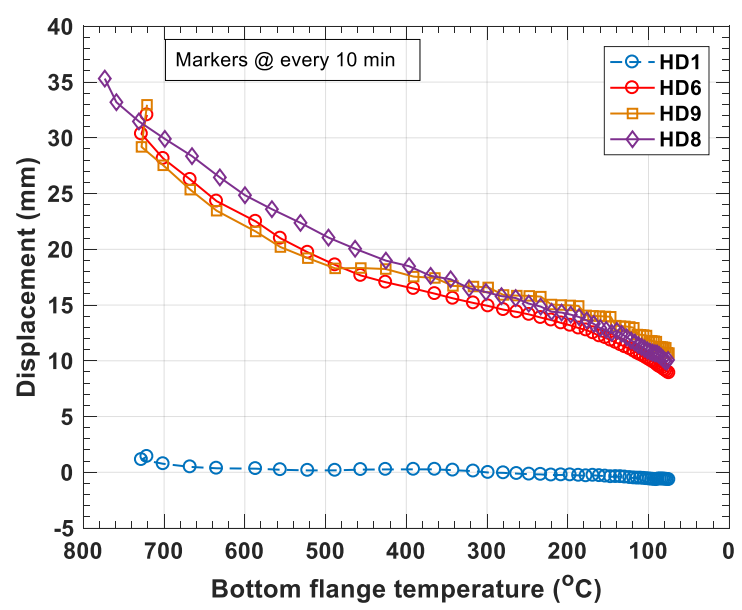

(d)

Fig. 4-36. Lateral displacements of the prototype building at the first-story level as a function of bottom flange temperatures in the test bay; (a) the east or west side during heating, (b) the north or south side during heating, (c) the east or west side during cooling, and (d) the north or south side during cooling.

The lateral drift of the northeast and southeast columns of the test bay can be presented in Fig. 4-37. The initial deflection of the southeast column (at $0 \mathrm{~min}$ ) was due to mechanical loading at ambient temperature. In Fig. 4-37a and Fig. 4-37b, the values in parentheses are the average bottom flange temperatures of the north primary beam; those of the east girder are used in Fig. 4-37c and Fig. 4-37d. As shown, the first and second story lateral displacement of the northeast column increased toward the east until $80 \mathrm{~min}$ in fire and then decreased afterward. The southeast column bent toward the south until about $100 \mathrm{~min}$ in fire and then decreased afterward. During the cooling phase, the lateral displacements of these columns were mostly recovered, except for the southeast column that might be permanently bent. However, the final values of lateral displacements are within the measurement uncertainty as described in Chapter 3. 


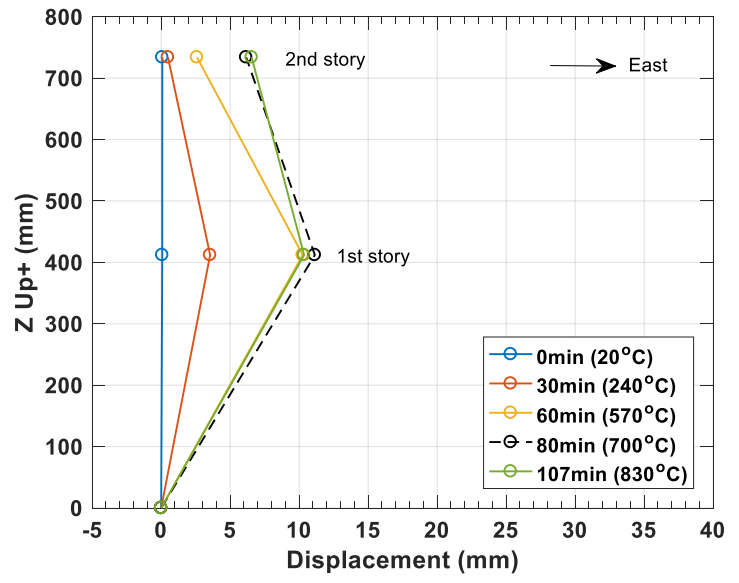

(a)

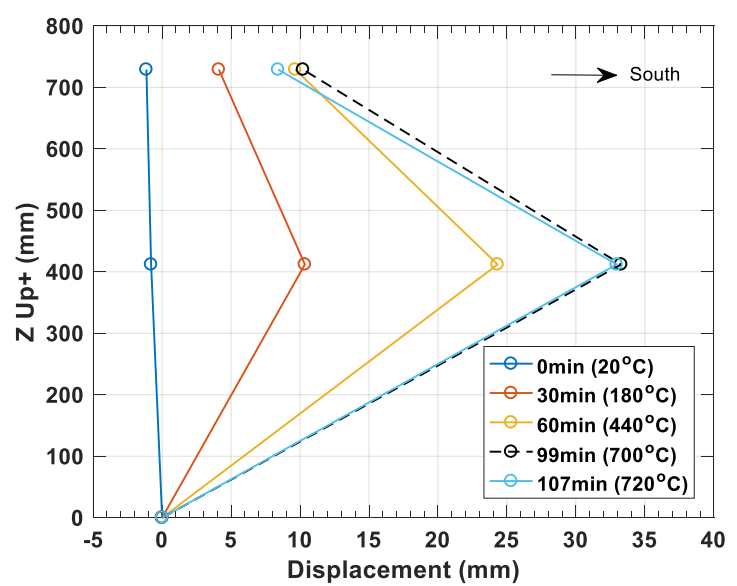

(c)

Fig. 4-37. Lateral displacements of the northeast column of the test column grid during (a) fire and (b) cooling; lateral displacements of the southeast column during (c) fire and (d) cooling.

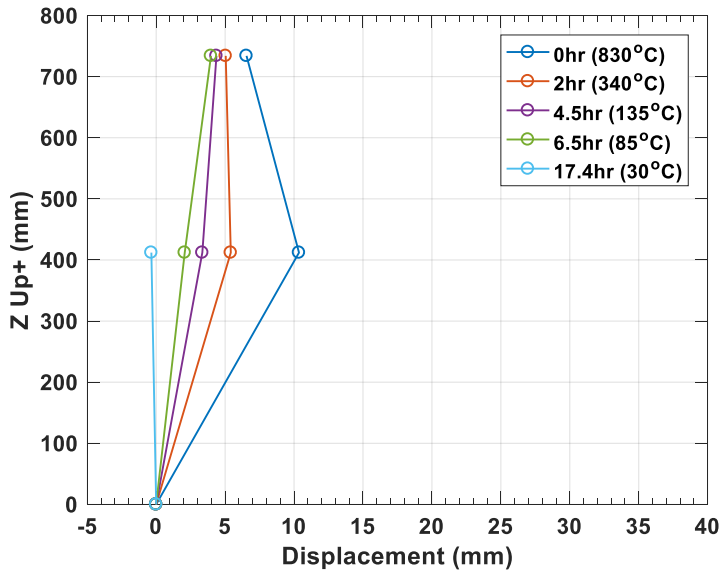

(b)

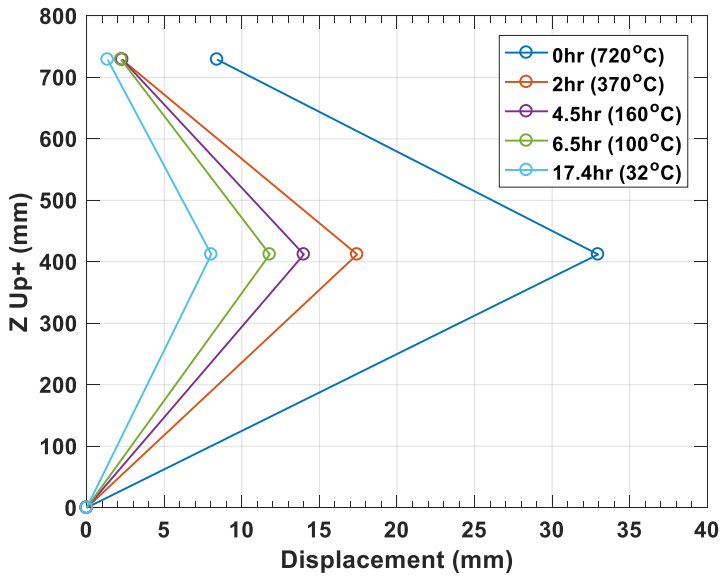

fhe test column grid during (a) fire and (b) 


\subsection{Structural Failure}

Several visual inspections were performed to examine the failure modes and final deflected shapes of the structural components and members constituting the fire-exposed test floor assembly after cool-down. This section presents the final fracture pattern of the concrete floor slab with welded wire reinforcement. In addition, some portion of the concrete atop the steel framing was saw-cut to further examine concrete breakout failure or any damage to headed stud anchors. The exposed surface of the steel decking was visually inspected to report the location of a localized tensile rupture or separation of deck joins. The final deflected shapes of the structural steel components, including beams, girders, welds, structural bolts, and shear tabs, are also presented.

\subsubsection{Concrete Floor Slab}

Some photographs of the final deflected shape and crack patterns of the test floor slab after cooling are shown in Fig. 4-38 and Fig. 4-39. Overall, the fire-exposed floor slab exhibited a dish-shaped deformation. Concrete cracks developed around the perimeter of the test-bay column grid $(9.1 \mathrm{~m} \times 6.1 \mathrm{~m})$ except for the south edge. In addition, the center concrete fracture developed south of the secondary beam. No concrete failure around the slab splice plates was discovered. Some characteristics of failures in the test floor slab are described as follows.

The east and west transverse cracks were located $90 \mathrm{~mm}$ to $100 \mathrm{~mm}$ inside the test-bay column grid (Fig. 4-38b). These cracks developed in the shallow section of the concrete slab cast on the fluted steel decking, next to the top flanges of the east and west girders. This is the critical section subjected to the maximum vertical shear and a hogging moment from gravity loading. In addition, these cracks appeared to be propagated from the south slab edges aligned with the flanges of the southeast and southwest columns of the test bay, locations 1 and 2 in Fig. 4-39. Much larger crack openings ( $25 \mathrm{~mm}$ or greater) were observed in the south half of the east and west cracks (i.e., between the south columns and the secondary beam). This indicates that those surface cracks occurred in the early stage of the test fire and continued to widen as the test floor slab sagged. Most of the welded wire reinforcement, placed perpendicular to those cracks, was ruptured except for the region around the interior columns, Fig. 4-38b.

The north longitudinal crack was developed approximately $370 \mathrm{~mm}$ north of the north primary beam centerline but still within the footprint of the fire test compartment, Fig. 4-38b. The north edge of the fire test compartment was located $480 \mathrm{~mm}$ north of the north primary beam centerline (Refer to Chapter 2). Concrete fracture planes were located near the south ends of the No.4 reinforcing bars extended from the slab splice plate. Larger cracks were visible around the center of the north primary beam, location 5 in Fig. 4-39. The welded wire reinforcement was ruptured across the crack openings. Much smaller cracks appeared toward the interior columns; See locations 3 and 4 in Fig. 4-39. Only hairline surface cracks were visible on the concrete slab over the south edge beam.

The center longitudinal cracks were located approximately $530 \mathrm{~mm}$ south of the secondary beam centerline (Fig. 4-38b). Some of these cracks were much wider around the mid panel, with the final crack width of $50 \mathrm{~mm}$ or greater after cooling, and thinner toward the east or west girders. This result matches with the test observation that the concrete cracks were developed from the center and propagated towards the east and west girders. The wire reinforcement across these crack openings was ruptured (location 6 in Fig. 4-39). 
The evidence of localized aggregate spalling was identified at the bottom surface of the concrete (away from the steel beam framing) and the surface of the round slab penetrations used for connecting water-cooled loading tubes, Fig. 4-40.
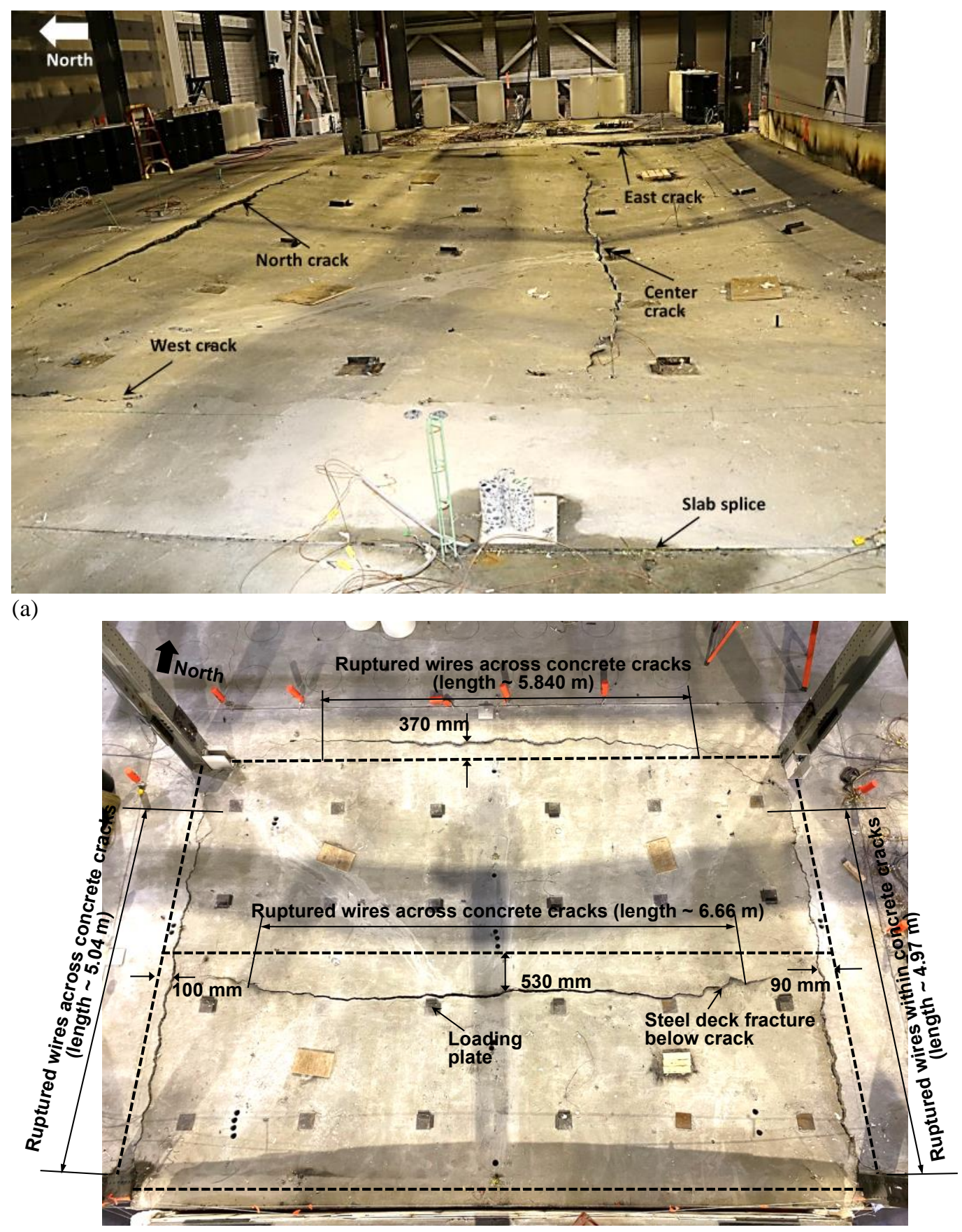

(b)

Fig. 4-38. Post-test photographs of (a) final deflected shape and (b) crack pattern of the test floor slab. 


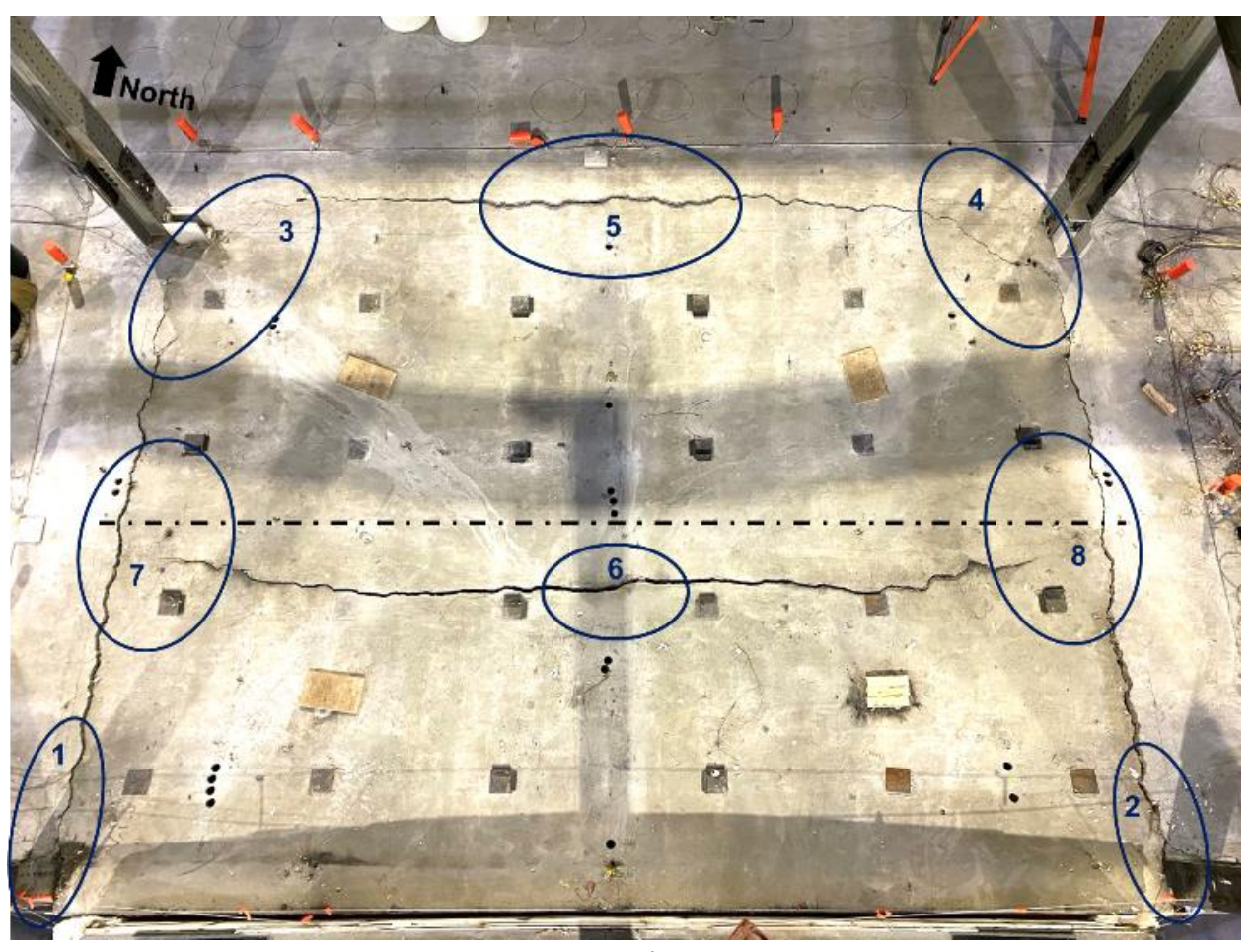

\section{Top View}
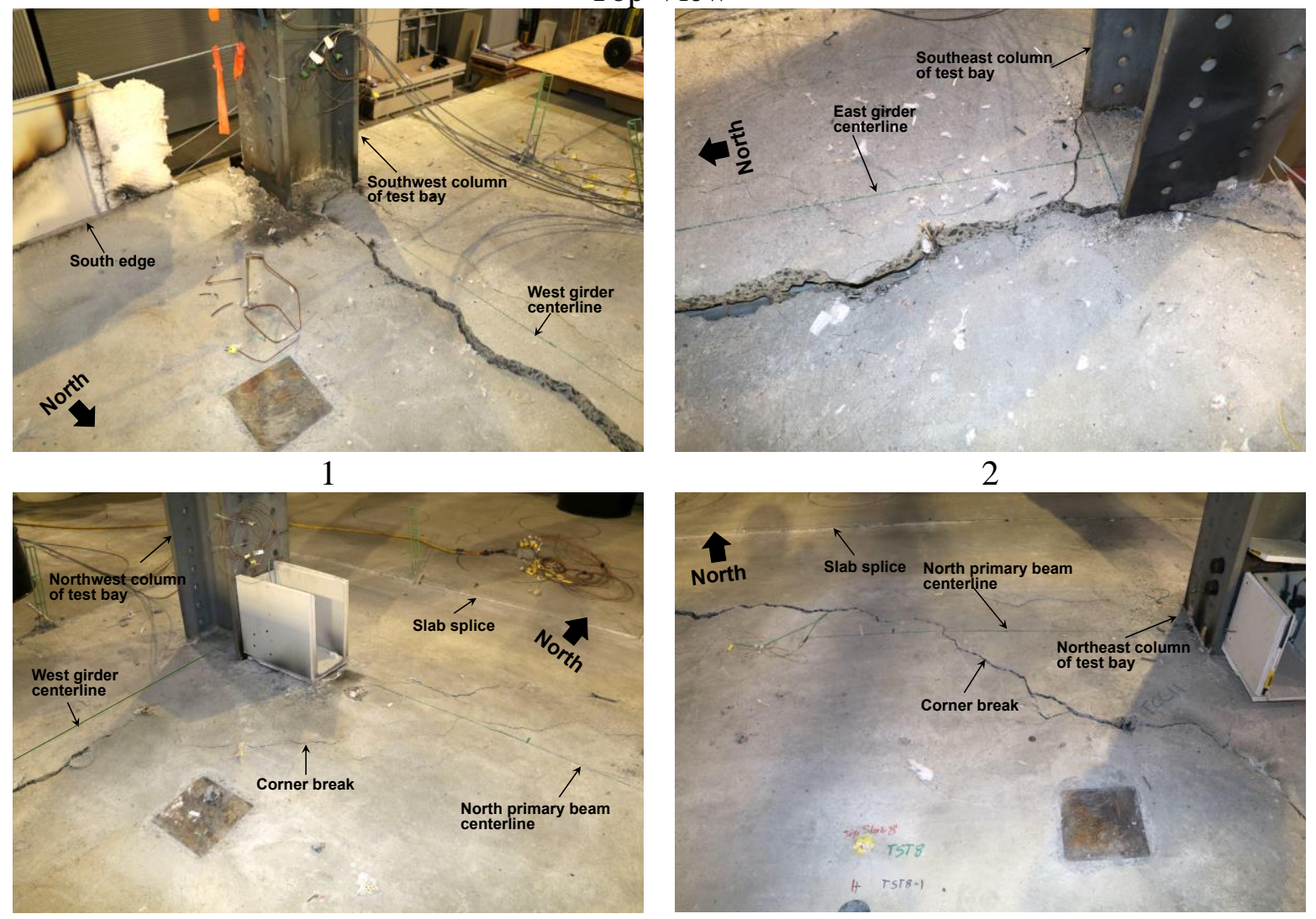


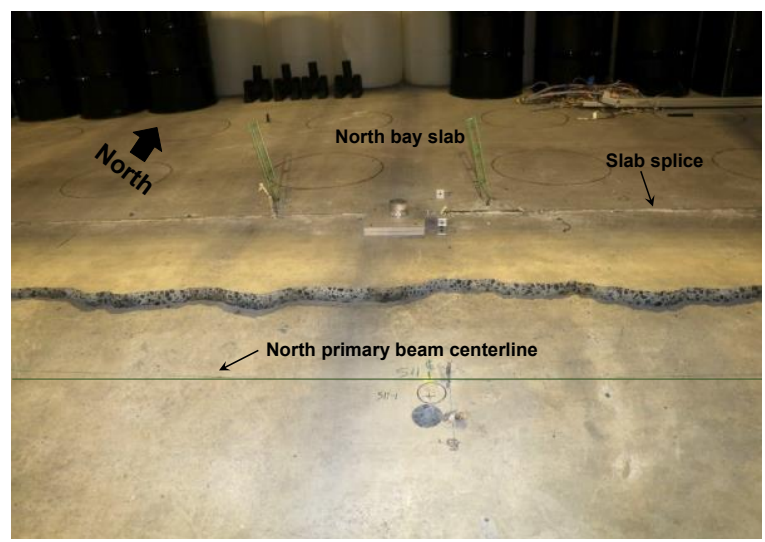

5

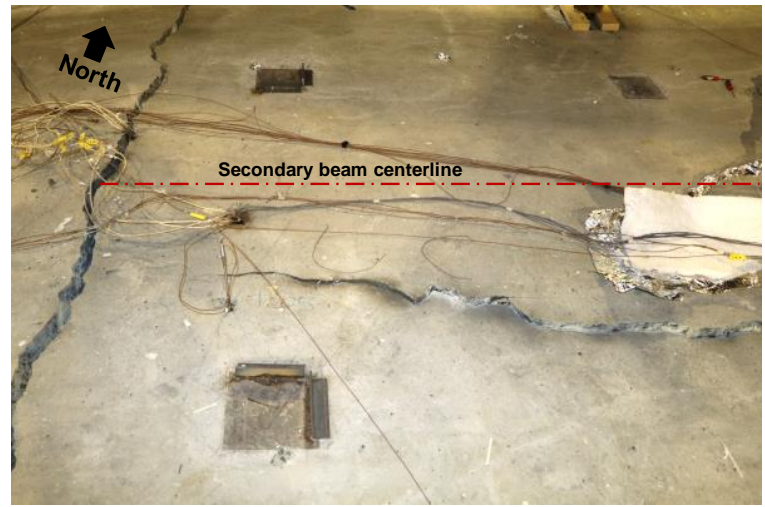

7
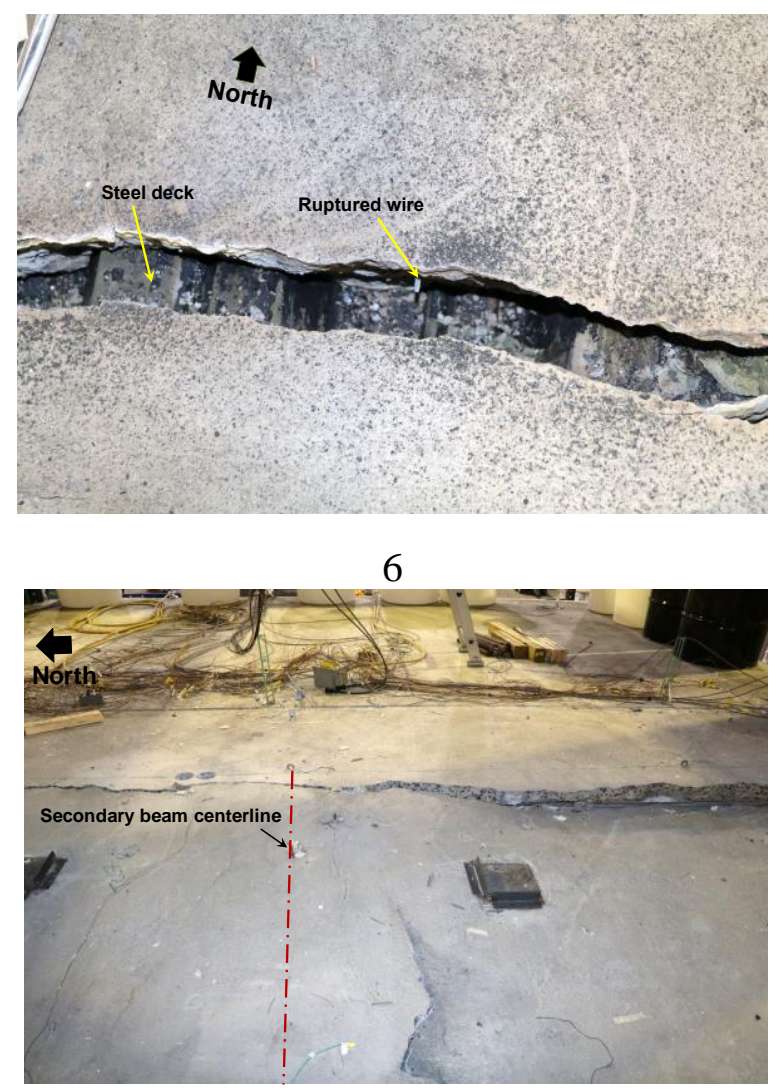

8

Fig. 4-39. Post-test photographs of the test floor slab; locations 1 through 8 are closeups of concrete fractures.

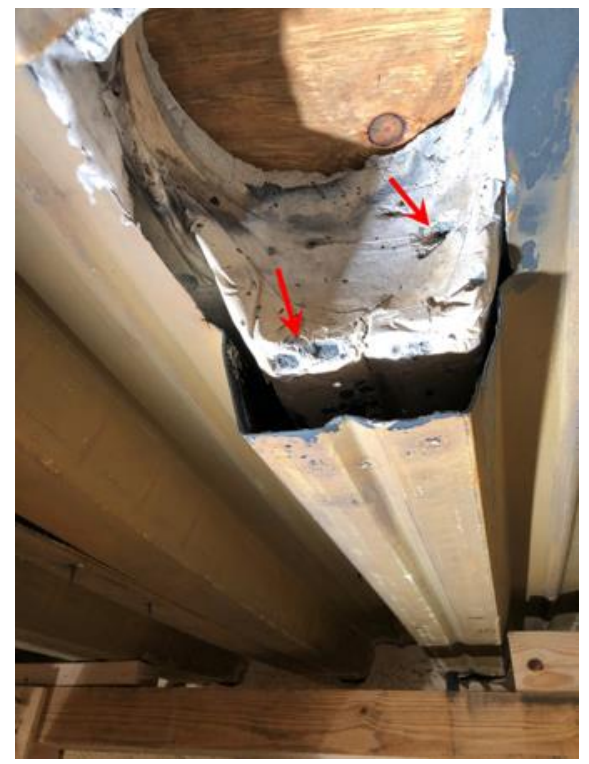

(a)

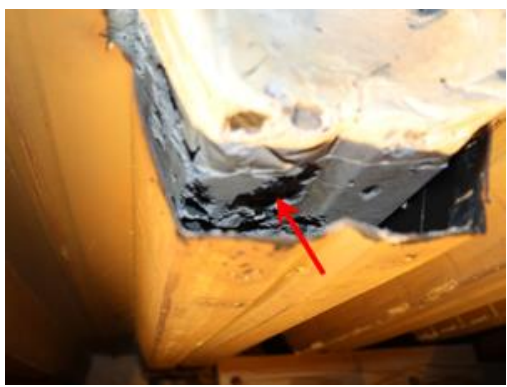

(b)

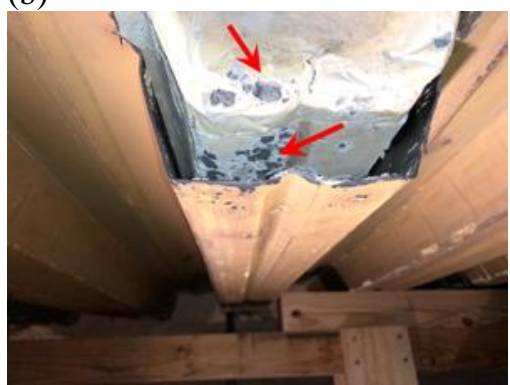

(c)

Fig. 4-40. Post-test photographs: (a) slab through-hole used for running a water-cooled loading tube; (b-c) deck delamination from concrete. Localized spalling is indicated by arrows. 


\subsubsection{Headed Stud Anchor}

The concrete slab over the secondary beam ends exhibited concrete breakout failure around the headed stud anchors, whereas these studs exhibited only minor shear deformations (Fig. 4-41). No apparent breakout failures were identified in the slab over the north and south primary beam ends. The stud anchors in those regions barely indicated shear deformation due to flexure. Neither breakout failures nor shear deformations of stud anchors were observed in the midspan region of all three $9.1 \mathrm{~m}$ long beams $(\mathrm{W} 16 \times 31)$. More post-test photographs are presented in Sect. B.10. The stud anchors of the $\mathrm{W} 18 \times 35$ girders were not inspected since the maximum vertical displacement of these girders was $70 \mathrm{~mm}$ (approximately equal to $1 \%$ of the girder length).

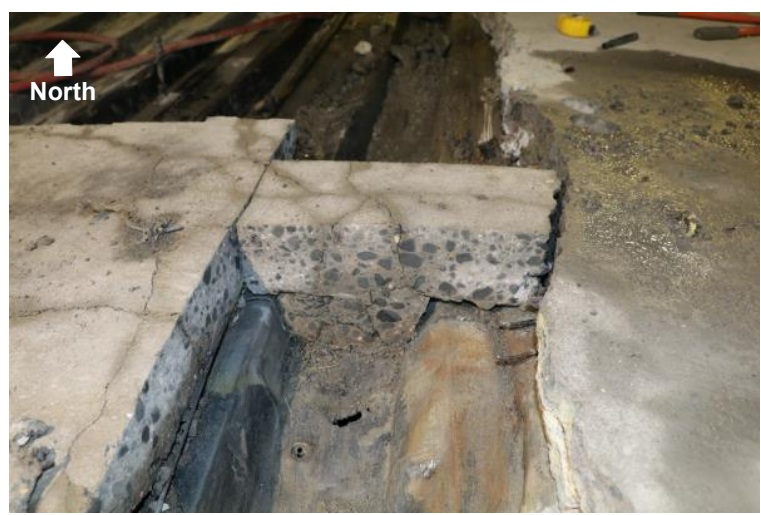

(a)

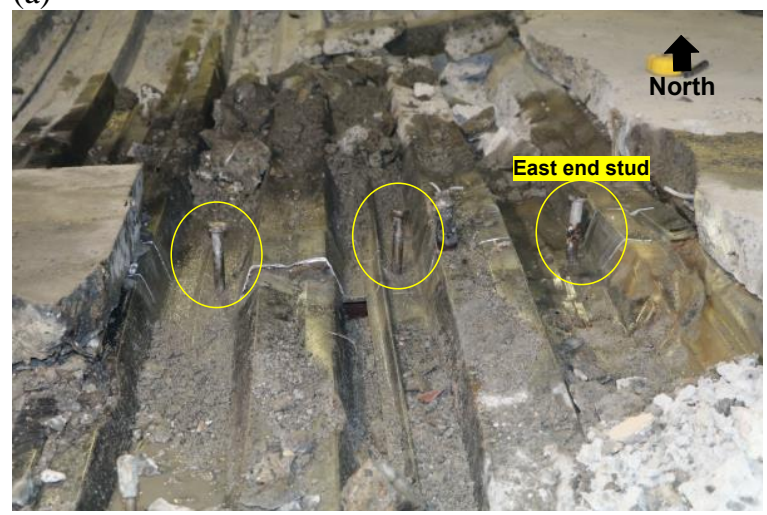

(c)

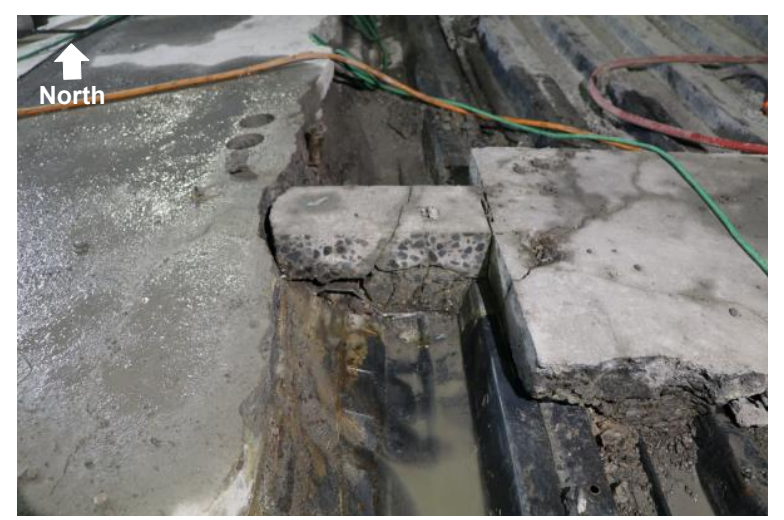

(b)

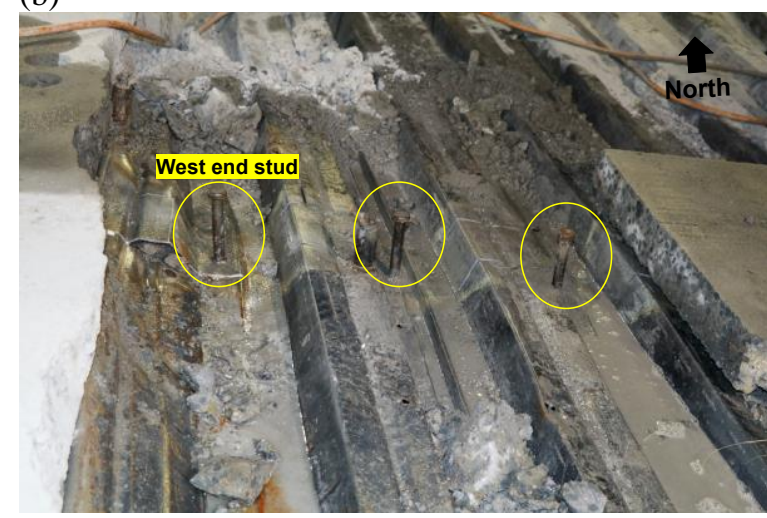

(d)

Fig. 4-41. Saw cut concrete over (a) east and (b) west ends of the secondary beam; three stud anchors at (c) east and (d) west ends of the secondary beam. 


\subsubsection{Steel Deck}

The fire-exposed steel deck after cooling is shown in Fig. 4-42. The color of the north side of the exposed deck was different from that of the south side. Overall, the decking exhibited good integrity and ductility (Fig. 4-42b). There were only localized ruptures below the east end of the longitudinal concrete crack (Fig. 4-38b). These ruptures were approximately $140 \mathrm{~mm}$ long (Fig. 4-42c). As reported in Sect. 4.5.1, a small flame was penetrated through concrete cracks in the region where localized deck rupture was visible.

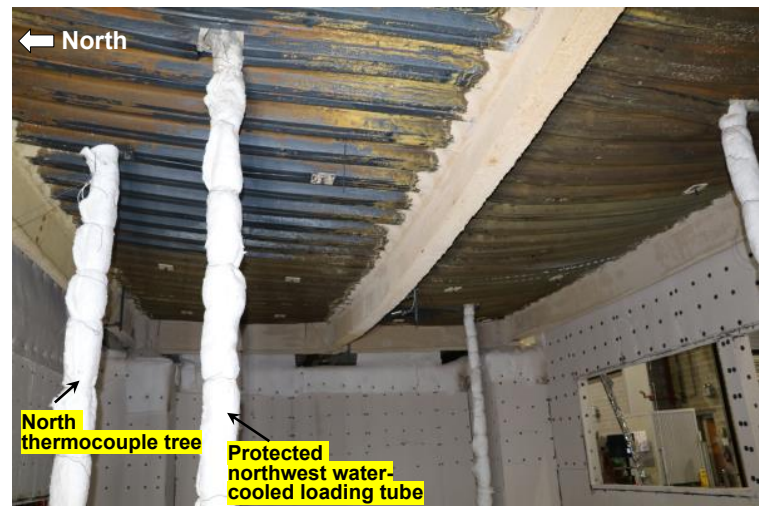

(a)

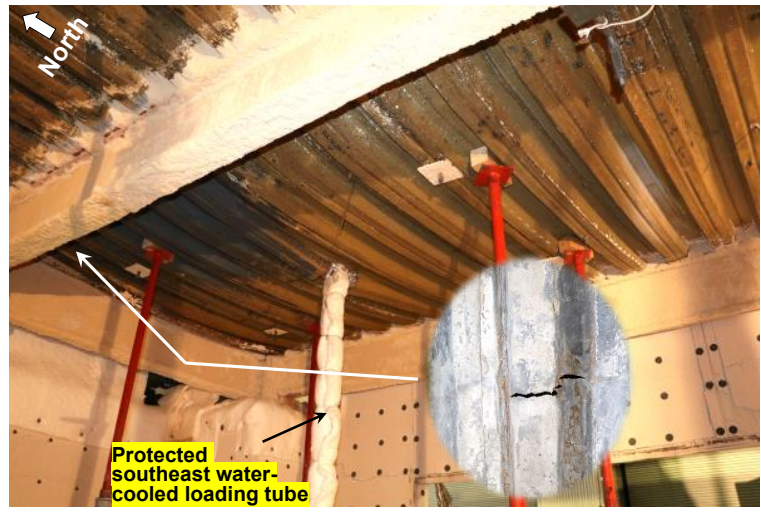

(c)

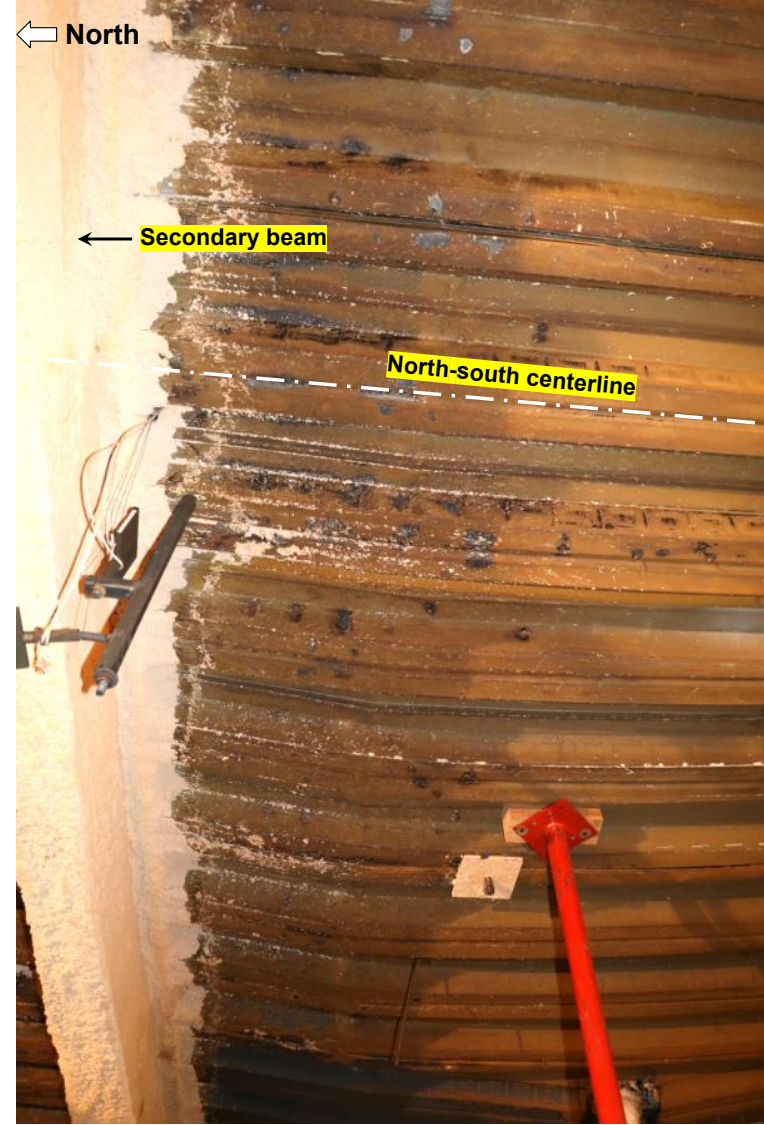

(b)

Fig. 4-42. Post-test photographs: (a) overall deflected shape and color of the exposed decking; (b) closeup of the steel decking south of the secondary beam; (c) southeast corner of the steel decking. 


\subsubsection{Steel Floor Beam}

All exposed $9.1 \mathrm{~m}$ long beams and $6.1 \mathrm{~m}$ long girders exhibited permanent deformations in a variety of ways as shown in Fig. 4-43. The final value of the vertical displacement at midspan (after cooling) was measured $350 \mathrm{~mm}$ for the secondary beam (W16 $\times 31$ ), $50 \mathrm{~mm}$ for the north primary beam, and $70 \mathrm{~mm}$ for the south primary beam. The midspan vertical deflection of the secondary beam recovered to approximately $40 \%$ of its peak value measured during heating. In addition, the north and south primary beams exhibited lateral deformations and twisting, whereas the secondary beam was mostly bent in its strong axis.

The west and east girders (W18×35) had the permanent vertical deflection of $20 \mathrm{~mm}$ and $15 \mathrm{~mm}$, respectively. These girders were seldom deflected laterally. Photographs of the five steel members after demolition of the concrete slab are shown in Fig. 4-44.

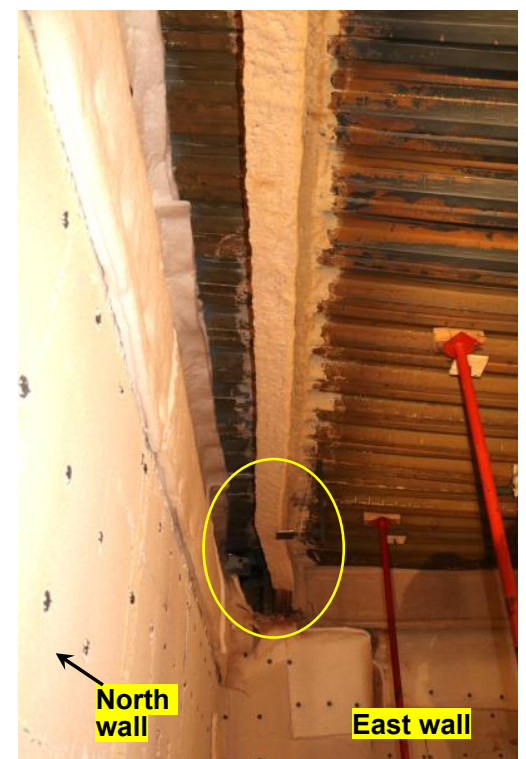

(a)

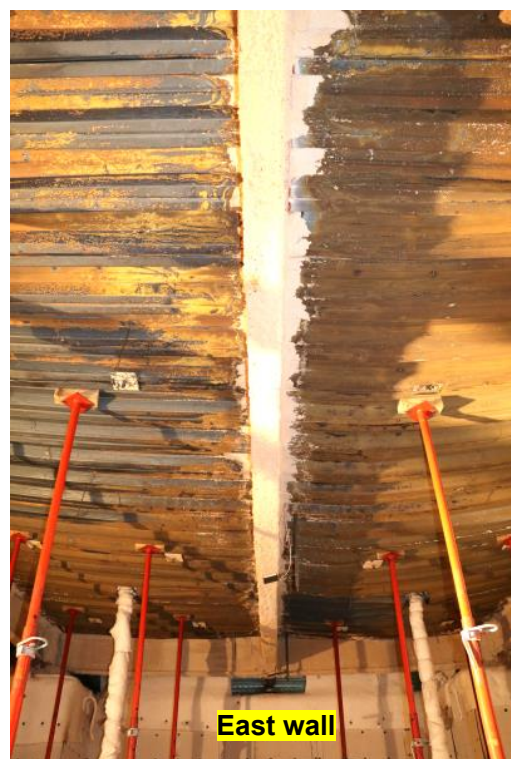

(d)

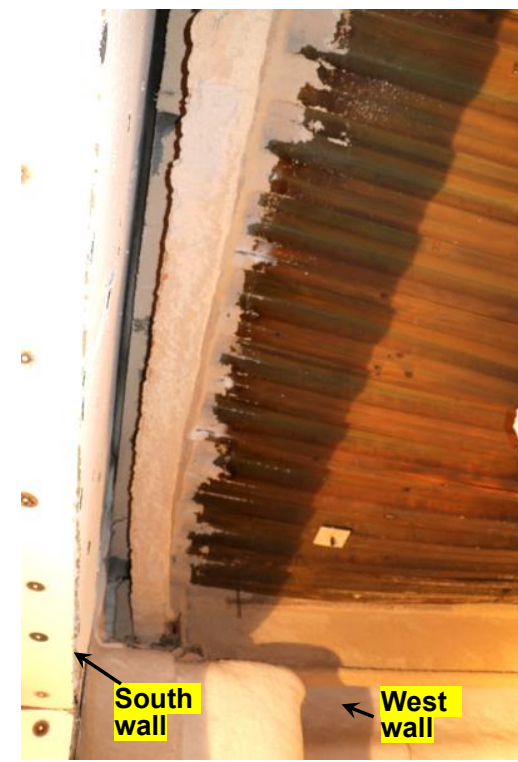

(c)

Fig. 4-43. Post-test photographs: (a) north primary beam; (b) secondary beam; (c) south primary beam.

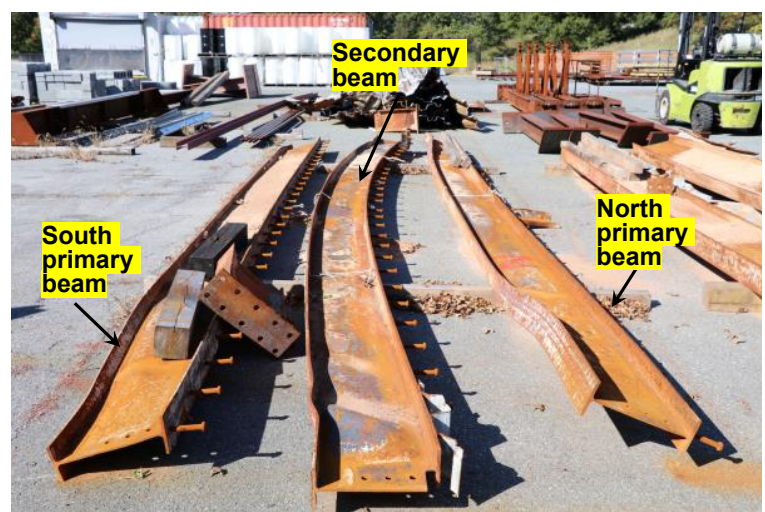

(a)

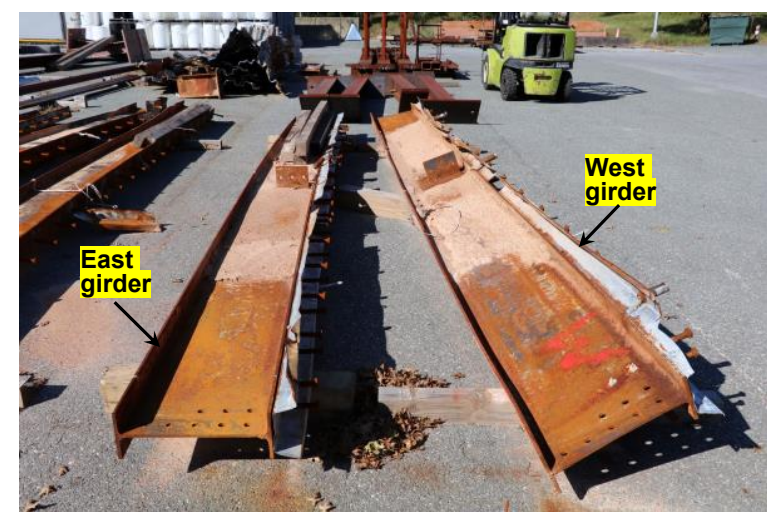

(b)

Fig. 4-44. Post-test photographs: (a) W16×31 beams; (b) W18×35 girders. 
The north primary and secondary W16 $\times 31$ beams also exhibited local buckling at the web and bottom flange toward their beam-end connections, Fig. 4-45. The region affected by local buckling was about $70 \mathrm{~cm}$ from the ends of the members. However, the W18 $\times 35$ girders and the south primary W16×31 beam were barely buckled near their ends, Fig. 4-46.

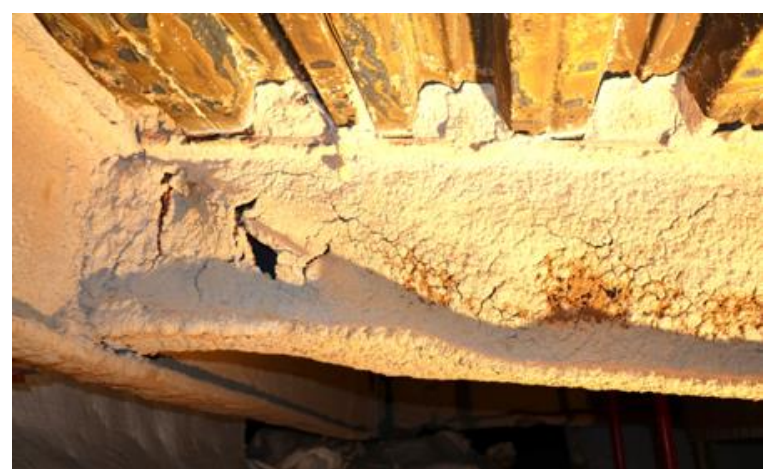

(a)

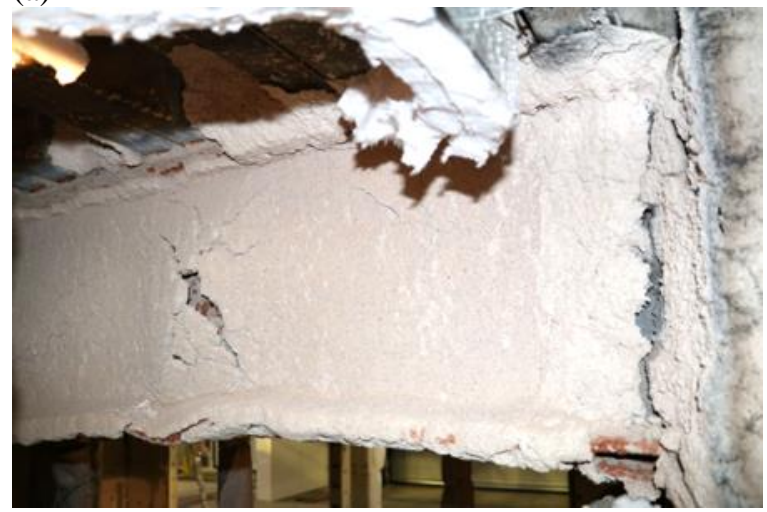

(c)

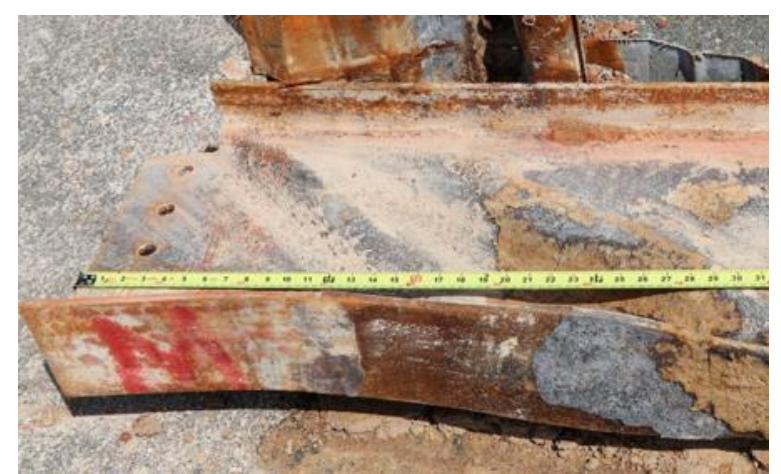

(b)

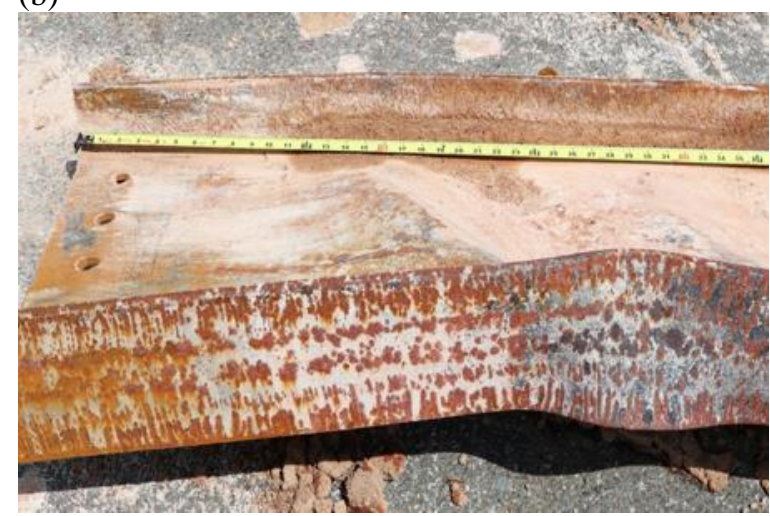

(d)

Fig. 4-45. Post-test photographs: (a-b) west end of secondary beam; (c-d) west end of north beam.
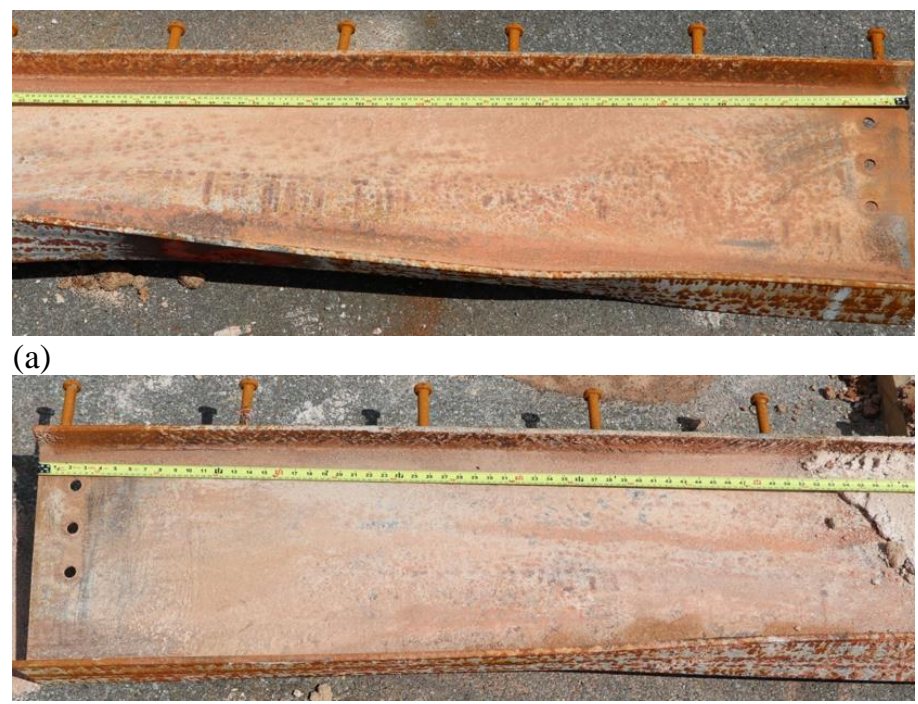

(b)

Fig. 4-46. Post-test photographs: (a) east and (b) west ends of south primary beam. 


\subsubsection{Steel Connection}

Post-test photographs of the standard shear tabs of the secondary beam $($ W16 $\times 31)$ are shown in Fig. 4-47. Although local buckling was present at the beam ends, damage in the connecting shear tabs and bolts appeared to be minor. There was no apparent indication of weld joint failures. Similar observations were made in the standard shear tab connections of the north and south primary beams.

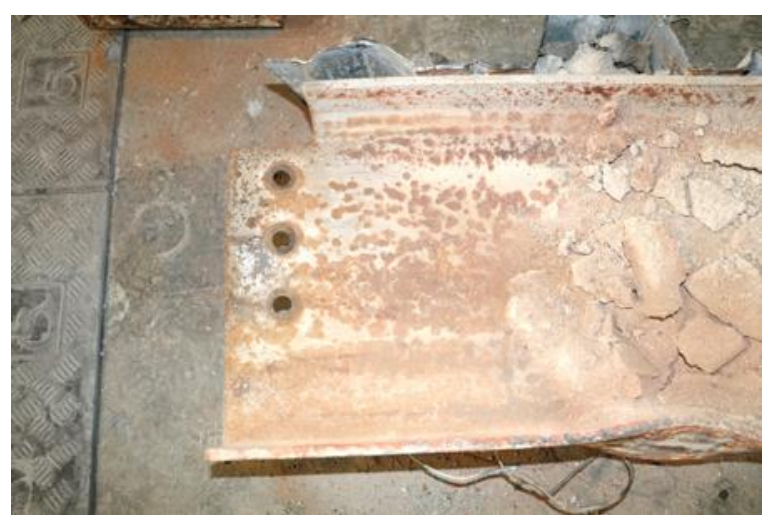

(a)

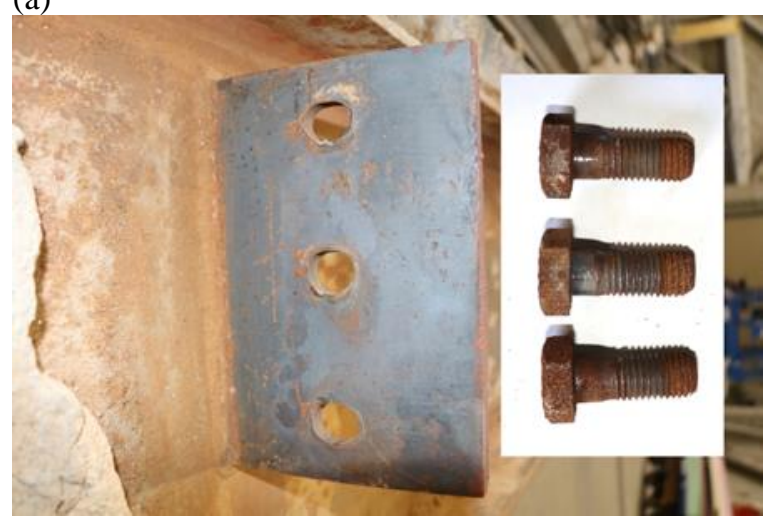

(c)

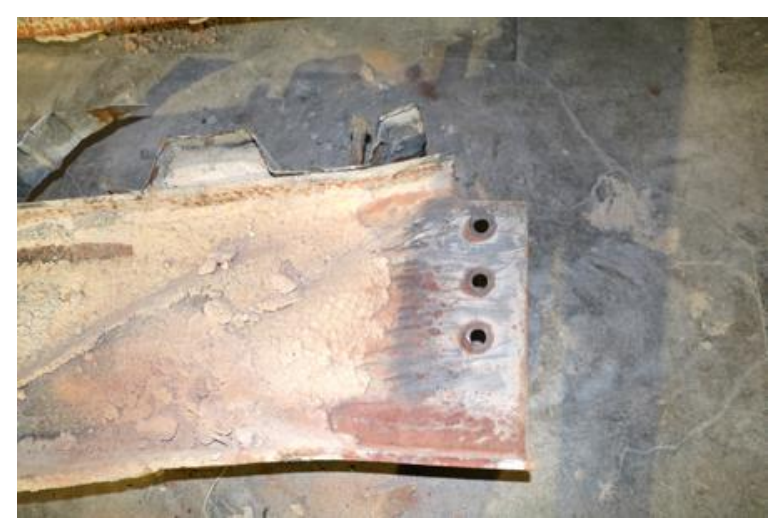

(b)

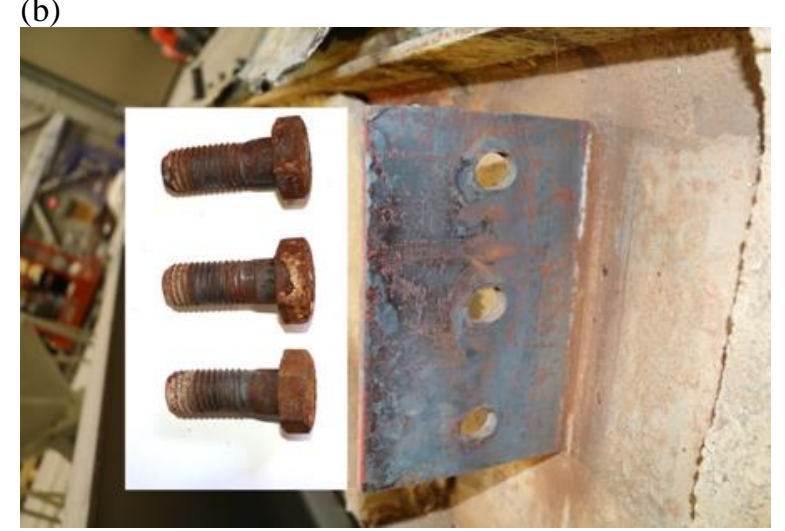

(d)

Fig. 4-47. Post-test photographs of the end connections of the secondary beam: (a) east beam web; (b) west beam web; (c) east shear tab connection; (d) west shear tab connection.

Some photographs of the extended shear tab connections are shown in Fig. 4-48. It can be seen that the deformed shape of the connecting plate was highly affected by the lateral support conditions of W12×106 columns. The extended shear tabs welded to the interior northeast and northwest columns displayed out-of-plane deformations. However, those used in the exterior southeast and southwest columns maintained their original shapes after fire exposure. The bottom three bolts connected to the southeast column web displayed partial shear ruptures, while those connected to the north end of the same girder barely deformed. The welded joint appeared to be structurally sound regardless of locations of the columns. 


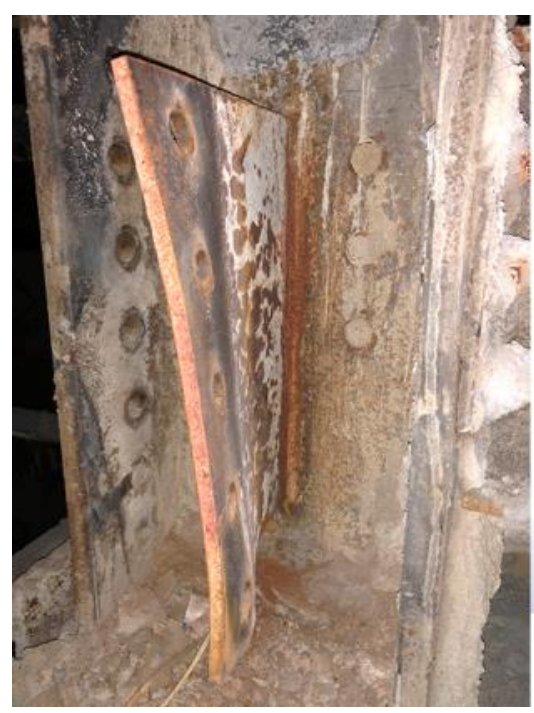

(a)

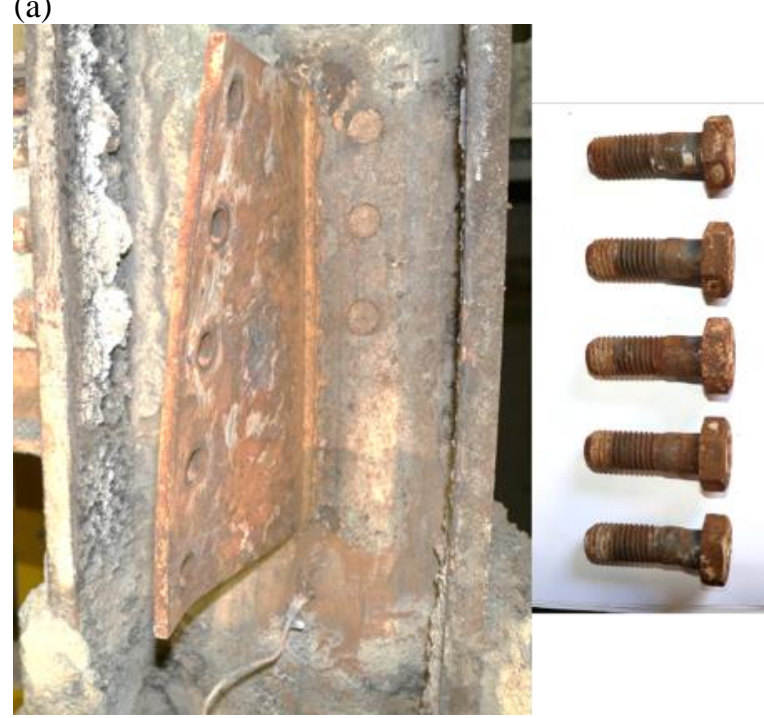

(c)

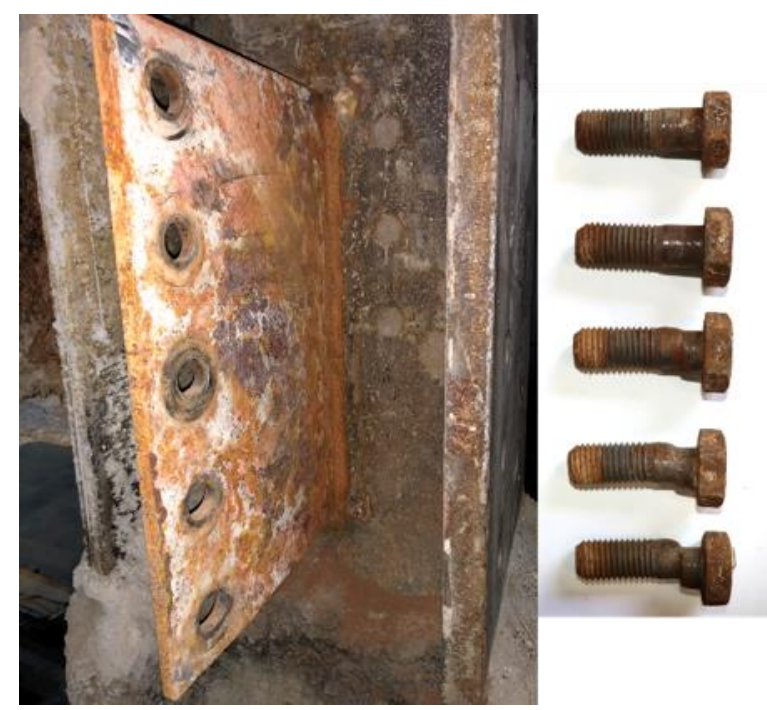

(b)

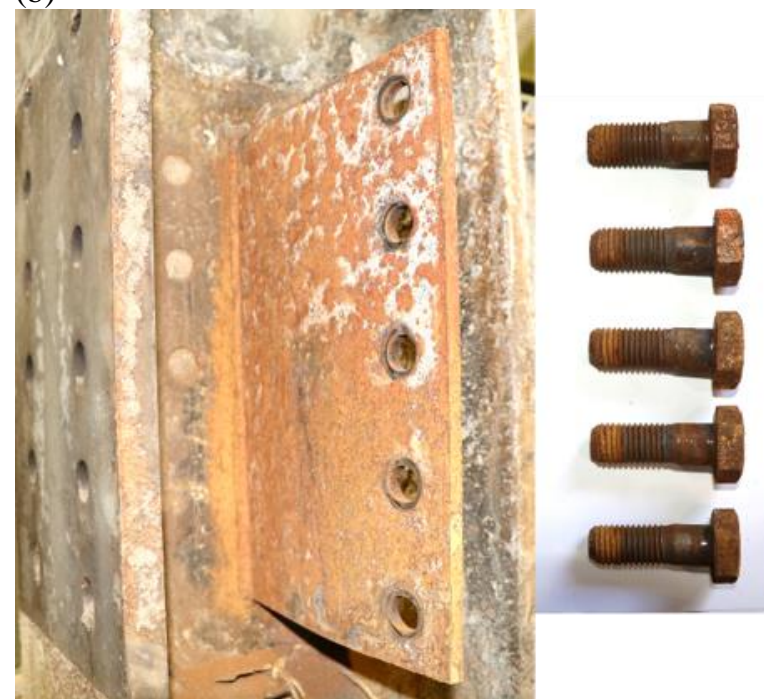

(d)

Fig. 4-48. Post-test photographs of extended shear tab (girder-to-column) connections: (a) north end of the east girder; (b) south end of the east girder; (c) north end of the west girder; (d) south end of the west girder. 


\subsection{Comparison with ASTM E119 Criteria}

The intent of standard fire testing with a furnace is to provide a consensus-based method to evaluate the duration for which an isolated floor assembly contains a fire while retaining its structural stability, the so-called fire-resistance rating expressed in minutes or hours. This testing is typically performed using a test assembly with limited size with two end support conditions, either restrained or unrestrained, as described in the ASTM E119 standard. A test assembly is required to resist its ambient temperature maximum load conditions while subjected to furnace heating that increases following the specified time-temperature relationship.

The fire-resistance rating of a test assembly is usually determined based on limiting temperatures and displacements. For the 2-hour restrained assembly fire-resistance rating, the test specimen must meet a specified combination of the following conditions:

i. Sustaining the applied loads with no ignition of cotton waste placed on the top of the heated concrete slab during the full rating period,

ii. The average temperature on unexposed surface less than $139^{\circ} \mathrm{C}$ above its initial temperature during the full rating period,

iii. A peak temperature of structural steel members below $704^{\circ} \mathrm{C}$ during the first hour,

iv. The average temperature at any section of structural steel members below $593{ }^{\circ} \mathrm{C}$ during the first hour,

v. As an alternative to (iii) and (iv), during the first hour when the specimen is tested under unrestrained conditions, the maximum total displacement less than the value of $L c^{2} / 400 d$ where $L c=$ beam clear span, $d=$ depth of composite beam, or the corresponding displacement rate less than the value of $L c^{2} / 9000 d$ after the maximum total displacement value of $L c^{2} / 400 d$ is reached

A comparison of the measured temperatures in this study with the ASTM E119 acceptance criteria is summarized in Fig. 4-49. As shown, the protected individual W16×31 beams and W18 $\times 35$ girders of the test assembly were deemed to successfully meet the ASTM E119 limiting temperature and displacement criteria. The average concrete surface temperature measured by eight thermocouples distributed across the test assembly was approximately $120^{\circ} \mathrm{C}$ prior to extinguishment of the test fire. Although displacements of the secondary beam exceeded the ASTM E119 limit during fire, a displacement rate was measured $40 \%$ less than the ASTM E119 limit. It is to be noted that the total gravity load used in this study was determined from the ASCE 7 load combination of $1.2 \times$ dead load $+0.5 \times$ live load, which is only $30 \%$ of the gravity load prescribed in the ASTM E119 standard. If the higher ASTM E119 load had been used instead, then it stands to reason that the displacement and displacement rate of the test floor would have been greater.

More importantly, this fire experiment revealed some potential issues related to the integrity of a composite floor assembly as part of compartmentation under fire loading. As reported in Sect.4.5.1, the center breach in the test floor slab, initiated prior to the specified rating period of $120 \mathrm{~min}$, was accompanied by ruptures of the wire reinforcement in tension at the mid-panel displacement of $350 \mathrm{~mm}$ (the $L / 26$ ratio) or greater. A minimum code-required amount of shrinkage reinforcement $\left(60 \mathrm{~mm}^{2} / \mathrm{m}\right)$ used in the test assembly was insufficient to resist 
thermally induced tension during the investigated fire. Although the steel deck continuously running in the transverse (north-south) direction of the test assembly appeared to be ductile at large vertical displacements, failure of side deck joints (fastener failure at the decking overlap), local deck ruptures, exposure of the heated decking units within concrete cracks allowed the penetration of flames and hot gases beyond the test compartment. This condition could have potentially ignited cotton waste placed on the unexposed surface, failing to meet the standard fire testing criterion ' $i$ ' as mentioned above.
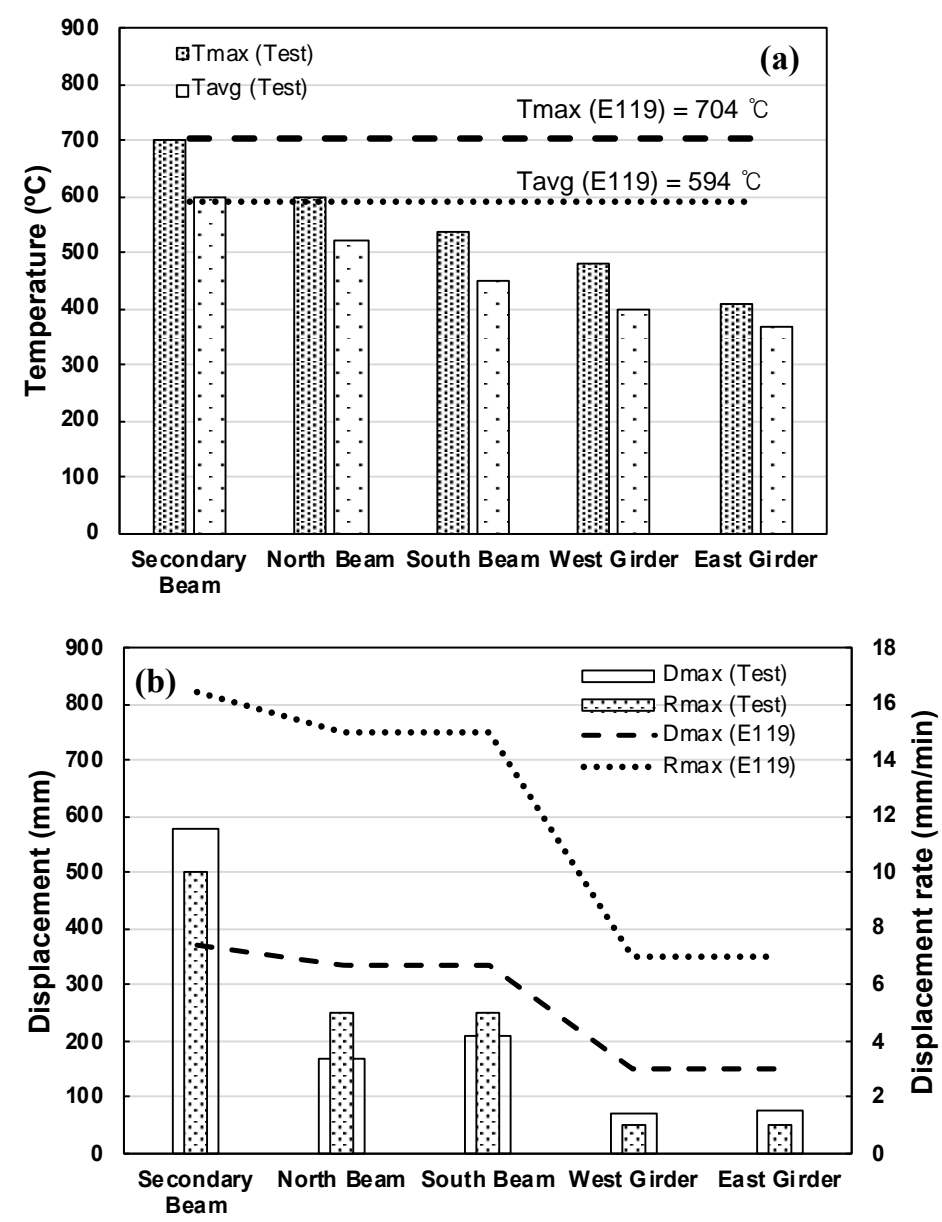

Fig. 4-49. Comparisons of the test results with (a) limiting temperatures and (b) limiting displacements and displacement rates, where Dmax = maximum displacement and $\mathrm{Rmax}=$ maximum displacement rate. 


\section{Summary and Conclusions}

The first of four planned compartment fire experiments (Test \#1) was conducted on the $9.1 \mathrm{~m}$ by $6.1 \mathrm{~m}$ composite floor system under the $20 \mathrm{MW}$ exhaust hood at the NFRL. The objective of this experiment was to (i) measure the structural and thermal responses of a full-scale composite floor system designed and constructed following the current U.S. prescriptive approach and to (ii) evaluate its system-level fire resistance using the ASTM E119 acceptance criteria. This report has described details of the experimental design, including design and construction of the test structure, measurement systems, and the fire test conditions (the test fire and mechanical loading). The experimental test data and results from the post-test visual inspections are also presented. The technical information provided in this report will serve as baseline of other forthcoming composite floor experiments at the NFRL.

The test building used in this study represented a full-scale two-story steel gravity frame, two bays by three bays in plan, designed and constructed following the current U.S. construction practice. The concrete slab with formed steel decking was constructed on the first floor only, while the identical steel floor framing consisting of W14×22, W16 $\times 26$, W $16 \times 31$ and W18×35 shapes (rolled with ASTM A992 steel) was erected both at the first and second floor levels. All support columns were W12 $\times 106$ shapes anchored to the laboratory strong floor. The fire test compartment $(10 \mathrm{~m} \times 6.9 \mathrm{~m} \times 3.8 \mathrm{~m})$ with the main vent opening on the south (exterior) wall was built on the ground floor in the south-middle bay of the test building.

The test floor assembly was constructed with a lightweight aggregate concrete slab with the $76 \mathrm{~mm}$ deep ribbed steel deck supported by three $9.1 \mathrm{~m}$ long W16×31 beams and two $6.1 \mathrm{~m}$ long W18 $\times 35$ girders. The steel beams and girders were partially composite with the concrete slab through the $19 \mathrm{~mm}$ diameter steel headed stud anchors, providing a composite action of $65 \%$. The standard shear tabs with three $19 \mathrm{~mm}$ diameter bolts were used for the beam-to-column flange or beam-to-girder connections; the extended shear tabs with five bolts were selected for the girder-to-column web connections. The steel beam framing within the test compartment was protected with a medium density SFRM for the $2 \mathrm{~h}$ fire-resistance rating. However, the steel decking remained unprotected since the topping concrete was $83 \mathrm{~mm}$ thick conforming to the $2 \mathrm{~h}$ fire-resistance rating. The welded wire reinforcement $(6 \times 6 \mathrm{~W} 1.4 \times \mathrm{W} 1.4)$ was placed at the midheight of the topping concrete as a minimum shrinkage steel as specified in the relevant U.S. design standard. The moisture content of the concrete at time of the fire testing (approximately 5 months after the concrete placement) was measured at $7.5 \%$ by mass.

The fire experiment was conducted such that the test floor assembly was loaded using hydraulic actuators and simultaneously exposed to the test fire. The mechanical load was distributed at twenty-four points across the test floor. The magnitude of the floor load was equivalent to the ASCE 7 load combination for extraordinary events $(1.2 \times$ dead load $+0.5 \times$ live load $)$, approximately $5.2 \mathrm{kPa}$ including the floor specimen self-weight. The test fire environment was created using natural gas burners, simulating the upper layer compartment temperature similar to the standard furnace temperature-time relationship. In this experiment, the test fire lasted about 107 min with a peak heat release rate of $10.8 \mathrm{MW}$. A total heat energy of $63 \mathrm{GJ}$ was measured at the exhaust hood, and the fuel load density was estimated at $920 \mathrm{MJ} / \mathrm{m}^{2}$.

A variety of measurement systems were deployed to characterize the responses of the fireexposed floor assembly and various parts of the two-story prototype building. The test floor 
assembly exhibited diverse structural and thermal performances under combined mechanical loading and fire exposure and revealed various features of failure after cooldown. Some important observations and conclusions drawn from Test \#1 are summarized as follows:

1) About 15 min following the burner ignition, the average upper layer gas temperature became more closely related to the ISO 834 temperature-time curve than ASTM E119 temperaturetime curve. The peak temperature reached $1060^{\circ} \mathrm{C}$ at $107 \mathrm{~min}$. The standard deviation in temperature measurements (from twelve thermocouples) was less than $50^{\circ} \mathrm{C}$, indicating practically uniform heating conditions beneath the test floor assembly.

2) The web and bottom flange temperatures of the SFRM-protected $\mathrm{W} 16 \times 31$ steel beams increased to $600{ }^{\circ} \mathrm{C}$ at $60 \mathrm{~min}$ and exceeded $800{ }^{\circ} \mathrm{C}$ at $107 \mathrm{~min}$, whereas those of the SFRMprotected W18 $\times 35$ steel girders increased to $450{ }^{\circ} \mathrm{C}$ at $60 \mathrm{~min}$ and $700{ }^{\circ} \mathrm{C}$ at $107 \mathrm{~min}$. The spatial variability of temperatures within the same steel member ranged from $30{ }^{\circ} \mathrm{C}$ to 110 ${ }^{\circ} \mathrm{C}$. The steel temperature appeared to be sensitive to various factors, including but not limited to variability of the applied SFRM thickness prior to fire, fissures developed in the SFRM during fire, proximity to the burners (due to variable vertical and lateral deflections of the steel floor frame and relative distance from the burners). Despite all these issues, the SFRM-coated steel beams and girders met the temperature acceptance criteria specified in the ASTM E119 standard.

3) The temperature change in the concrete slab not only varied through its depth and was affected by a moisture content that migrated toward the top surface during fire. The average temperature of the welded wire reinforcement increased to $120{ }^{\circ} \mathrm{C}$ in the deep section of the concrete slab and to $380{ }^{\circ} \mathrm{C}$ in the shallow section (with the trapezoidal steel decking). The top (unexposed) surface temperature continued to rise during the cooling phase (up to $1 \mathrm{~h}$ following the fire extinguishment), in the range of $140{ }^{\circ} \mathrm{C}$ to $180{ }^{\circ} \mathrm{C}$. The average temperature on the unexposed surface, measured using eight thermocouples randomly distributed across the test floor, did not exceed the ASTM E119 limiting temperature (i.e., $139{ }^{\circ} \mathrm{C}$ above the initial temperature) during fire.

4) The loaded test floor assembly continuously sagged during heating but never exhibited runaway displacement. The mid-panel vertical displacement increased to nearly $58 \mathrm{~cm}$, equivalent to the ratio of a longitudinal span displacement ratio to 16. The horizontal (axial) displacement of the test assembly varied with the fire exposure time and between the eastwest (longitudinal) and north-south (transverse) directions. A thermal elongation along the north primary beam reached a peak value of approximately $2 \mathrm{~cm}$ at $70 \mathrm{~min}$ and then decreased followed by local buckling at the beam ends. However, the east and west girders continuously elongated mostly toward the south reaching a peak displacement over $3 \mathrm{~cm}$ until the test fire was extinguished. Because of the girder elongation, some bolts used in the southeast girder-to-column web connection (the extended shear tab connection) were partially ruptured.

5) Although the test floor assembly did not collapse within the period of a test fire (107 min), this fire experiment demonstrated a potential fire hazard associated with slab integrity failure prior to the specified rating period of $2 \mathrm{~h}$. The test floor slab reinforced with the $3.4 \mathrm{~mm}$ diameter steel wires $\left(60 \mathrm{~mm}^{2} / \mathrm{m}\right)$ began to develop large crack openings along the interior 
edges (hogging moment regions) of the test column grid less than $30 \mathrm{~min}$ into the fire. The center cracks appeared at south of the secondary beam at $70 \mathrm{~min}$, exposing the glowing hot deck underneath the slab through enlarged crack openings. The primary cause of this main breach was catenary action of the wire-reinforced concrete slab in the north-south direction after loss of slab continuity over the east and west test-bay girders. Provided that the north edge crack occurred north of the north primary beam (i.e., outside the test column grid), the headed stud anchors on all three $9.1 \mathrm{~m}$ long beams provided anchorage of the concrete slab in the north-south direction. With excessive vertical deflections under fire exposure, the concrete slab reinforced with steel wires failed in tension.

This initial experiment suggests that the minimum required steel reinforcement for composite slabs specified in the U.S. design standard may not be sufficient to maintain structural integrity during the 2-hour standard fire. Further study is recommended to evaluate the fire hazard of relatively 'thin' slab details currently permitted in the construction of steel composite floors spanning longer than $6 \mathrm{~m}$. As future work, the second fire test (Test \#2) of this experimental program will focus on studying the influence of enhanced slab design on the fire resilience of composite floor systems. 


\section{References}

ACI Committee 318 (2014) Building code requirements for structural concrete and commentary. (American Concrete Institute, Farmington Hills, MI)

AISC (2003) Design Guide 19: Fire Resistance of Structural Steel Framing (AISC, Chicago, IL). AISC (2016) ANSI/AISC 360-16: Specification for Structural Steel Buildings (AISC, Chicago, IL).

AISC (2020) Industry Statistics and Market Conditions. Available at https://www.aisc.org/membership/members-only/industry-statistics-and-marketconditions/

ASCE (2005) ASCE 29-05 Standard Calculation Methods for Structural Fire Protection (ASCE, Reston, VA).

ASCE (2016) ASCE 7-16 Minimum Design Loads for Buildings and Other Structures (ASCE, Reston, VA).

ASCE (2018) Structural Fire Engineering (ASCE, Reston, VA).

ASTM International (2013) ASTM C642-13, Standard Test Method for Density, Absorption, and Voids in Hardened Concrete, (ASTM International, West Conshohocken, PA), https://doi.org/10.1520/C0642-13.

ASTM International (2014) ASTM C469 / C469M-14e1, Standard Test Method for Static Modulus of Elasticity and Poisson's Ratio of Concrete in Compression. (ASTM International, West Conshohocken, PA), https://doi.org/10.1520/C0469_C0469M-14E01.

ASTM International (2016) C1603-16 Standard Test Method for Measurement of Solids in Water. (ASTM International, West Conshohocken, PA), https://doi.org/10.1520/C160316

ASTM International (2017) ASTM C138 / C138M-17a, Standard Test Method for Density (Unit Weight), Yield, and Air Content (Gravimetric) of Concrete. (ASTM International, West Conshohocken, PA) https://doi.org/10.1520/C0138_C0138M-17A.

ASTM International. (2017). ASTM C496 / C496M-17, Standard Test Method for Splitting Tensile Strength of Cylindrical Concrete Specimens, ASTM International, West Conshohocken, PA. https://doi.org/10.1520/C0496_C0496M-17.

ASTM International (2018) ASTM C33 / C33M-18, Standard Specification for Concrete Aggregates. (ASTM International, West Conshohocken, PA), https://doi.org/10.1520/C0033_C0033M-18

ASTM International (2018) ASTM C1602 / C1602M-18, Standard Specification for Mixing Water Used in the Production of Hydraulic Cement Concrete. (ASTM International, West Conshohocken, PA), https://doi.org/10.1520/C1602_C1602M-18

ASTM International. (2018). ASTM A1064/A1064M-18a, Standard Specification for CarbonSteel Wire and Welded Wire Reinforcement, Plain and Deformed, for Concrete. (ASTM International, West Conshohocken, PA), https://doi.org/10.1520/A1064_A1064M-18A. 
ASTM International (2019) F3125/F3125M-19e2 Standard Specification for High Strength Structural Bolts and Assemblies, Steel and Alloy Steel, Heat Treated, Inch Dimensions $120 \mathrm{ksi}$ and $150 \mathrm{ksi}$ Minimum Tensile Strength, and Metric Dimensions $830 \mathrm{MPa}$ and 1040 MPa Minimum Tensile Strength. (ASTM International, West Conshohocken, PA), https://doi.org/10.1520/F3125_F3125M-19E02.

ASTM International (2019) ASTM A36/A36M-19, Standard Specification for Carbon Structural Steel (ASTM International, West Conshohocken, PA), https://doi.org/10.1520/A0036_A0036M-19.

ASTM International (2019) E605/E605M-19 Standard Test Methods for Thickness and Density of Sprayed Fire-Resistive Material (SFRM) Applied to Structural Members. (ASTM International, West Conshohocken, PA). https://doi.org/10.1520/E0605_E0605M-19.

ASTM International (2019) ASTM C618-19, Standard Specification for Coal Fly Ash and Raw or Calcined Natural Pozzolan for Use in Concrete. (ASTM International, West Conshohocken, PA), https://doi.org/10.1520/C0618-19

ASTM International (2019) C192/C192M-19 Standard Practice for Making and Curing Concrete Test Specimens in the Laboratory. (ASTM International, West Conshohocken, PA), https://doi.org/10.1520/C0192_C0192M-19.

ASTM International (2020) A992/A992M-20 Standard Specification for Structural Steel Shapes (ASTM International, West Conshohocken, PA), https://doi.org/10.1520/A0992_A0992M-20.

ASTM International (2020) A29/A29M-20 Standard Specification for General Requirements for Steel Bars, Carbon and Alloy, Hot-Wrought. (ASTM International, West Conshohocken, PA), https://doi.org/10.1520/A0029_A0029M-20.

ASTM International (2020) ASTM E119-20 - Standard Test Methods for Fire Tests of Building Construction and Materials (West Conshohocken, PA).

ASTM International. (2020) ASTM C143 / C143M-20, Standard Test Method for Slump of Hydraulic-Cement Concrete. (ASTM International, West Conshohocken, PA) https://doi.org/10.1520/C0143_C0143M-20.

ASTM International (2020) ASTM E119-20, Standard Test Methods for Fire Tests of Building Construction and Materials, (ASTM International, West Conshohocken, PA), https://doi.org/10.1520/E0119-20.

ASTM International (2021) ASTM C150 / C150M-20, Standard Specification for Portland Cement. (ASTM International, West Conshohocken, PA), https://doi.org/10.1520/C0150_C0150M-20

ASTM International (2021) E8/E8M-21 Standard Test Methods for Tension Testing of Metallic Materials. (ASTM International, West Conshohocken, PA), https://doi.org/10.1520/E0008_E0008M-21.

ASTM International (2021) ASTM C39 / C39M-21, Standard Test Method for Compressive Strength of Cylindrical Concrete Specimens. (ASTM International, West Conshohocken, PA), https://doi.org/10.1520/C0039_C0039M-21. 
ASTM International (2021) ASTM A500/A500M-21 Standard Specification for Cold-Formed Welded and Seamless Carbon Steel Structural Tubing in Rounds and Shapes, (ASTM International, West Conshohocken, PA), https://doi.org/10.1520/A0500_A0500M-21.

Bailey CG (2000) Design of steel structures with composite slabs at the fire limit state (The Building Research Establishment, Garston, Unite Kingdom) Final Report No. 81415.

Bailey CG (2001) Steel structures supporting composite floor slabs: design for fire (The Building Research Establishment, Garston, United Kingdom) BRE Digest 462.

Bailey CG (2003) Efficient arrangement of reinforcement for membrane behavior of composite floor sin fire conditions. Journal of Constructional Steel Research, 59. No. 7, 931-949.

Bentz D, Peltz M, Durán-Herrera A, Valdez P, and Juárez C (2011) Thermal properties of highvolume fly ash mortars and concretes. Journal of Building Physics, 34(3), 263-275.

Bisby L, Gales J, Maluk C (2013) A contemporary review of large-scale non-standard structural fire testing, Fire Science Reviews, 2:1

British Steel (1999) The Behavior of Multi-Story Steel Frame Buildings in Fire (Rotherham, United Kingdom).

Bryant RA (2009) A Comparison of Gas Velocity Measurements in a Full-Scale Enclosure Fire, Fire Safety Journal, 44 (5), pp. 793-800.

Bryant RA and Bundy MF (2019) The NIST 20 MW Calorimetry Measurement System for Large-Fire Research. (National Institute of Standards and Technology, Gaithersburg, MD), NIST Technical Note (TN) 2077, https://doi.org/10.6028/NIST.TN.2077.

Bundy M, Hamins A, Gross J, Grosshandler W, Choe L (2016) Structural fire experimental capabilities at the NIST National Fire Research Laboratory, Fire Technology, 52, 959-966

CEN (2004) BS EN 1992-1-2:2004 - Eurocode 2: Design of concrete structures - Part 1.2: General rules - Structural fire design. European Committee for Standardization, Brussels

Choe L, Ramesh S, Hoehler M, Seif M, Gross J, Zhang C, Bundy M (2018) National Fire Research Laboratory Commissioning Project: Testing Steel Beams under Localized Fire Exposure, (National Institute of Standards and Technology, Gaithersburg, MD), NIST Technical Note (TN) 1983, https://doi.org/10.6028/NIST.TN.1983.

Choe L, Ramesh S, Grosshandler W, Hoehler M, Seif M, Gross J, \& Bundy M. (2020) Composite floor beams with simple shear connections subject to compartment fires: experimental evaluation, J. of Str Eng., 146, pp. 1-14. https://doi.org/10.1061/(ASCE)ST.1943-541X.0002627.

Clifton G, Gillies A, Mago N (2010) The slab panel method: Design of composite floor systems for dependable inelastic response to severe fires, 6th Structures in Fire (Lancing, MI), pp 492-499.

Gustafsson SE (1991) Transient plane source techniques for thermal conductivity and thermal diffusivity measurements of solid materials. Review of Scientific Instruments, 62(3), 797 804. 
Häggkvist A, Sjöström J, Wickström U (2012) Using plate thermometer measurements to calculate incident heat radiation. Journal of Fire Sciences, https://doi.org/10.1177/0734904112459264

ICC (2018) International Building Code. Country Club Hills, IL. Available at https://codes.iccsafe.org/content/IBC2018

ISO (2019) Fire-Resistance Tests - Elements of Building Construction, ISO 834-2:2019, Geneva. Available at https://www.iso.org/standard/75137.html.

Log T and Gustafsson SE (1995) Transient plane source (TPS) technique for measuring thermal transport properties of building materials. Fire and Materials, 19(1), 43-49.

Maluk C, Bisby L, Terrasi GP (2017) Effects of polypropylene fibre type and dose on the propensity for heat-induced concrete spalling. Engineering Structures, 141, pp. 584-595. https://doi.org/10.1016/j.engstruct.2017.03.058.

McCaffrey BJ, Heskestad G (1976) Robust Bidirectional Low-Velocity Probe for Flame and Fire Application, Combustion and Flame, 26, pp. 125-127.

McGrattan K, Hostikka S, McDermott R, Floyd J, Weinschenk C, \& Overholt K (2018) Fire Dynamics Simulator, User's Guide. National Institute of Standards and Technology, Gaithersburg, Maryland, USA, and VTT Technical Research Centre of Finland, Espoo, Finland), sixth edition.

Murray T, Allen D, Ungar E, Davis (2016) AISC Steel Design Guide 11 (Second Edition): Vibrations of Steel Framed Structural Systems due to Human Activity. 2nd Ed. (AISC, Chicago, IL).

Newman GM, Robinson JT, and Bailey CG (2006) Fire Safety Design: A New Approach to Multi-Storey Steel-Framed Buildings (The Steel Construction institute, Ascot, United Kingdom) SCI Publication P288.

NFPA (2017) Total Cost of fire in the United States. (Fire Protection Research Foundation, Quincy, MA). Available at https://www.nfpa.org/News-and-Research/Data-research-andtools/US-Fire-Problem/Total-cost-of-fire-in-the-United-States

NFPA (2021) Building Construction and Safety Code (NFPA, Quincy, MA).

Pour-Ghaz M, Castro J, Kladivko EJ, and Weiss J (2012) Characterizing lightweight aggregate desorption at high relative humidities using a pressure plate apparatus. J Mater Civil Eng, 24(8). https://doi.org/10.1061/(ASCE)MT.1943-5533.0000422.

Ramesh S, Choe L, Seif M, Hoehler M, Grosshandler W, Sauca A, Bundy M, Luecke W, Bao Y, Klegseth M, Chen G, Reilly J, \& Glisic B (2019) Compartment fire experiments on longspan composite beams with simple shear connections, Part 1: experimental design and beam behavior at ambient temperature (NIST, Gaithersburg, MD), NIST Technical Note (TN) 2054, https://doi.org/10.6028/NIST.TN.2054

Sauca A, Zhang C, Grosshandler W, Choe L \& Bundy M (2019) Development of a standard fire condition for a large compartment floor assembly, (National Institute of Standards and Technology, Gaithersburg, MD), NIST Technical Note (TN) 2070, https:// doi.org/10.6028/NIST.TN.2070. 
SDI (2017). C-2017 Standard for composite steel floor deck-slabs. ANSI/SDI C-17, https://www.sdi.org/wp-content/uploads/2017/02/ANSI-SDI-C-2017-Standard.pdf.

Taylor BN, Kuyatt CE (1994) Guidelines for Evaluating and Expressing the Uncertainty of NIST Measurement Results, (National Institute of Standards and Technology, Gaithersburg, MD), NIST Technical Note (TN) 1297, 1994 Ed.

UL (2011) Fire Resistance Ratings - ANSI/UL 263. Design NO. N791. (Underwriters Laboratory, Northbrook, IL)

UL (2011) Fire Resistance Ratings - ANSI/UL 263. Design NO. D949. (Underwriters Laboratory, Northbrook, IL)

Vassart O, Zhao B, Hamerlink R, Hauke B et al. (2014) Membrane action in fire design of composite slab with solid and cellular steel beams - valorisation (MACS+)", EUR 26682, European Commission, Luxembourg.

Wald F, Simoes da Silva L, Moore DB, Lennon T, Chaldna M, Santiago M, Benes M, Borges L (2006) Experimental behaviour of a steel structure under natural fire. Fire Safety Journal 41(7):509-522. doi:10.1016/j.firesaf.2006.05.006

Zhang C, Grosshandler W, Sauca A, and Choe L (2019) Design of an ASTM E119 fire environment in a large compartment, Fire Tech., pp. 1-23. https://doi.org/10.1007/s10694-019-00924-7.

Zhao B, Roosefid M, Vassart O (2008) Full scale test of a steel and concrete composite floor exposed to ISO fire and corresponding numerical investigation, Eurosteel 2008 (Graz, Austria)

Zhao B and Roosefid M (2011) Experimental and numerical investigations of steel and concrete composite floors subjected to ISO fire condition. Journal of Structural Fire Engineering 2(4) https://doi.org/10.1260/2040-2317.2.4.301 


\section{Appendix A Experimental Design - Supplemental Materials}

\section{A.1. Structural Steel Frame}

Table A-1 shows the list of various simple shear connections used in the two-story test building. The labels of each beam and girder of the test building are shown in Fig. A-1 through Fig. A-3.

Table A-1. Floor framing connections.

\begin{tabular}{|c|c|c|}
\hline Connection Label & Connection Type & Beam / Girder Label \\
\hline Conn-1 & $\begin{array}{l}\text { All-bolted single angles } \\
(\mathrm{L} 5 \times 5 \times 0.375 ; \mathrm{A} 36)\end{array}$ & $\begin{array}{l}\left.\text { Beam- } 1 \text {, Beam-3, Beam-5 ( } 1^{\text {st }} \text { floor }\right), \text { Beam-6, Beam- } \\
\left.8 \text { ( } 2^{\text {nd }} \text { floor }\right)\end{array}$ \\
\hline Conn-2 & $\begin{array}{l}\text { All-bolted single angles } \\
(\mathrm{L} 5 \times 3 \times 0.375 ; \mathrm{A} 36)\end{array}$ & Beam-2, Beam-4, Beam-7, Beam-9 ( $2^{\text {nd }}$ floor $)$ \\
\hline Conn-3 & $\begin{array}{l}\text { All-bolted double angles } \\
(2 \mathrm{~L} 5 \times 5 \times 0.375 ; \mathrm{A} 36)\end{array}$ & Beam-5 ( $2^{\text {nd }}$ floor $)$, Beam-10 ( $2^{\text {nd }}$ floor $)$ \\
\hline Conn-4 & $\begin{array}{l}\text { Shear tabs } \\
(\mathrm{PL} 6 \times 8.5 \times 0.375 ; \mathrm{A} 36)\end{array}$ & $\begin{array}{l}\left.\text { Beam-8 ( } 1^{\text {st }} \text { floor }\right), \text { Beam-9 }\left(1^{\text {st }} \text { floor }\right), \text { Beam-10 }\left(1^{\text {st }}\right. \\
\text { floor) }\end{array}$ \\
\hline Conn-5 & $\begin{array}{l}\text { Extended shear tabs } \\
(\mathrm{PL} 12.375 \times 8.5 \times 0.5 ; \mathrm{A} 36)\end{array}$ & $\begin{array}{l}\left.\text { Girder- } 1 \text {, Girder- } 2 \text {, Girder-3 ( } 2^{\text {nd }} \text { floor }\right) \text {, Girder- } 4 \text { ( } 2^{\text {nd }} \\
\text { floor) }\end{array}$ \\
\hline Conn-6 & $\begin{array}{l}\text { Extended shear tabs } \\
(\mathrm{PL} 9.875 \times 14.5 \times 0.375 ; \mathrm{A} 36)\end{array}$ & Girder-3 ( $1^{\text {st }}$ floor $)$ and Girder-4 ( $1^{\text {st }}$ floor $)$ \\
\hline
\end{tabular}

The end connections of the south edge beams (Beam-5 and Beam-10) on the second floor were double-angle connections (Conn-2) in order to prevent premature failure of the second floor framing due to thermal expansion of the test floor assembly on the first floor.

Conn-4 shear tab was welded to a sacrificial plate $(\mathrm{PL} 12 \times 18 \times 0.75)$ and then attached to the column flange using ten structural steel bolts ( $\varnothing 19 \mathrm{~mm}$; F3125). A bearing plate (PL12.75 $\times 18 \times 1.75)$ was placed between this sacrificial plate and the column flange to minimize any local failure of the column during the fire experiment.

All girder-end connections were initially fabricated using Conn-5. However, the connections of Girder-3 and Girder- 4 on the first floor were replaced with Conn- 6 during the construction. This decision was made after industry consultation in which Conn-5 (i.e., two lines of bolts in an extended shear tab) was found to be less commonly used in construction practice. The end connections of all girders on the second floor remained unchanged, i.e., Conn-5 was used.

The shear tab of Conn- 6 was directly welded to the column web, whereas that of Conn-5 was welded to a sacrificial plate (PL8.5 $\times 10 \times 0.5)$ which was then bolted to the column web using six structural steel bolts (

Bolt holes on all angles or shear tabs were short slot holes $(\varnothing 20 \mathrm{~mm} \times 25 \mathrm{~mm})$. 


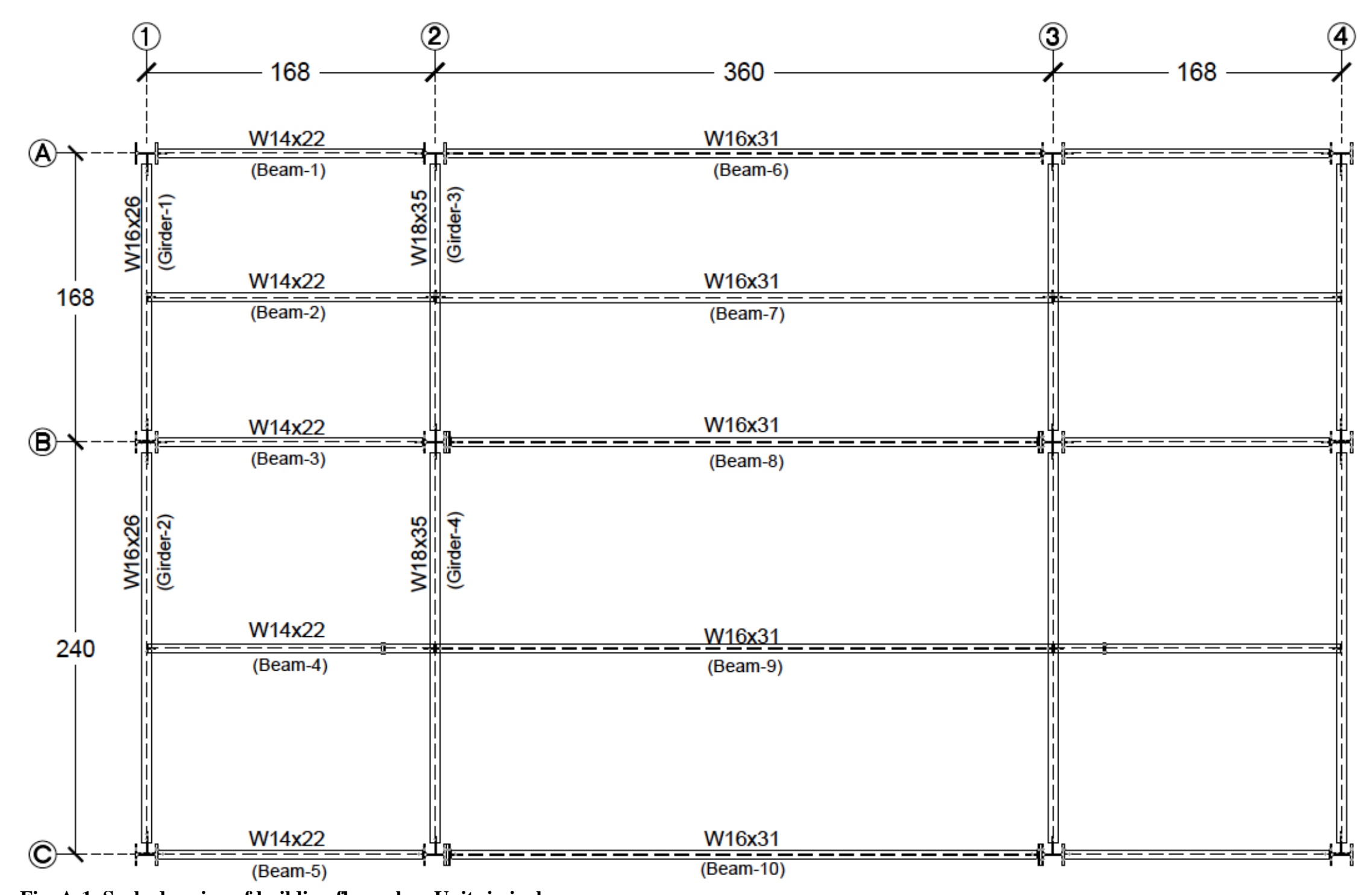

Fig. A-1. Scale drawing of building floor plan. Units in inch. 


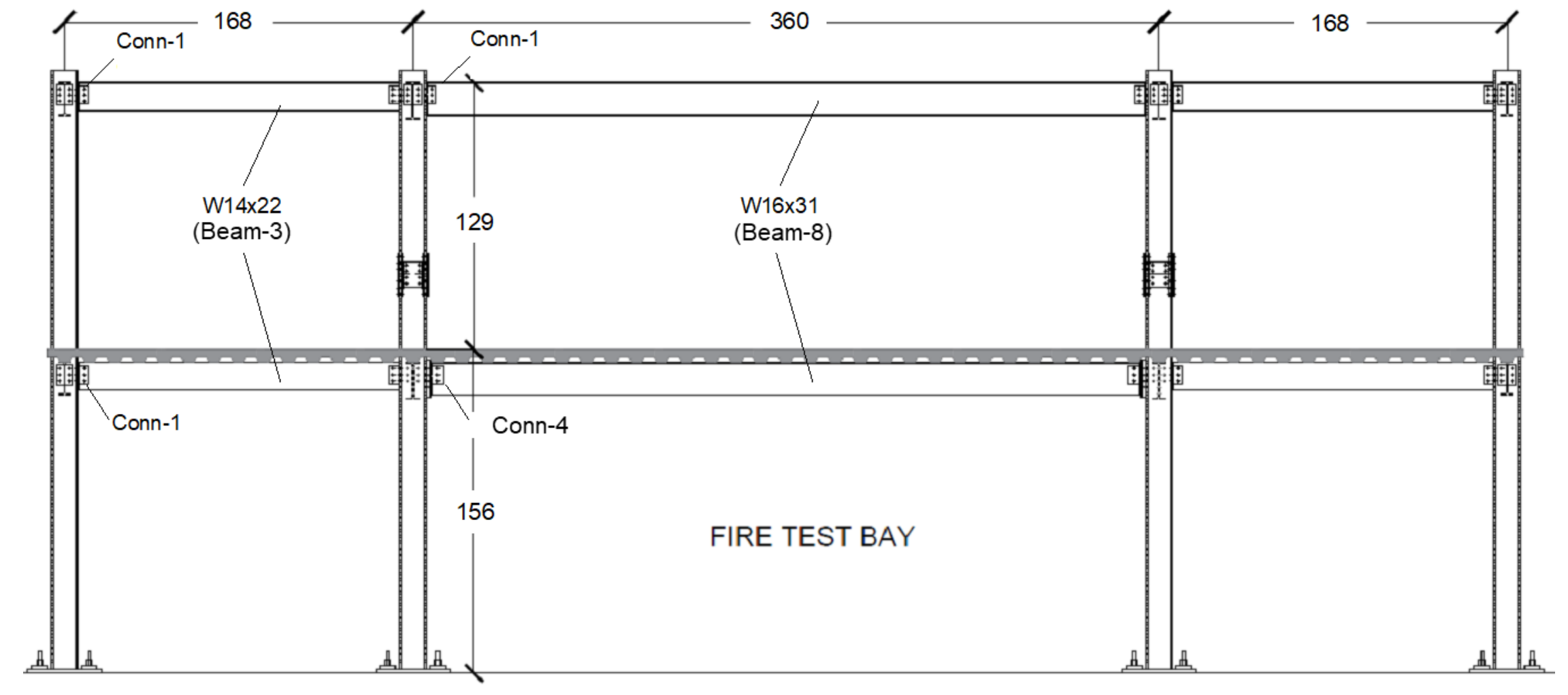

Fig. A-2. Scale drawing of the two-story steel frame along line B in Fig. A-1. Dimensions in inch. 


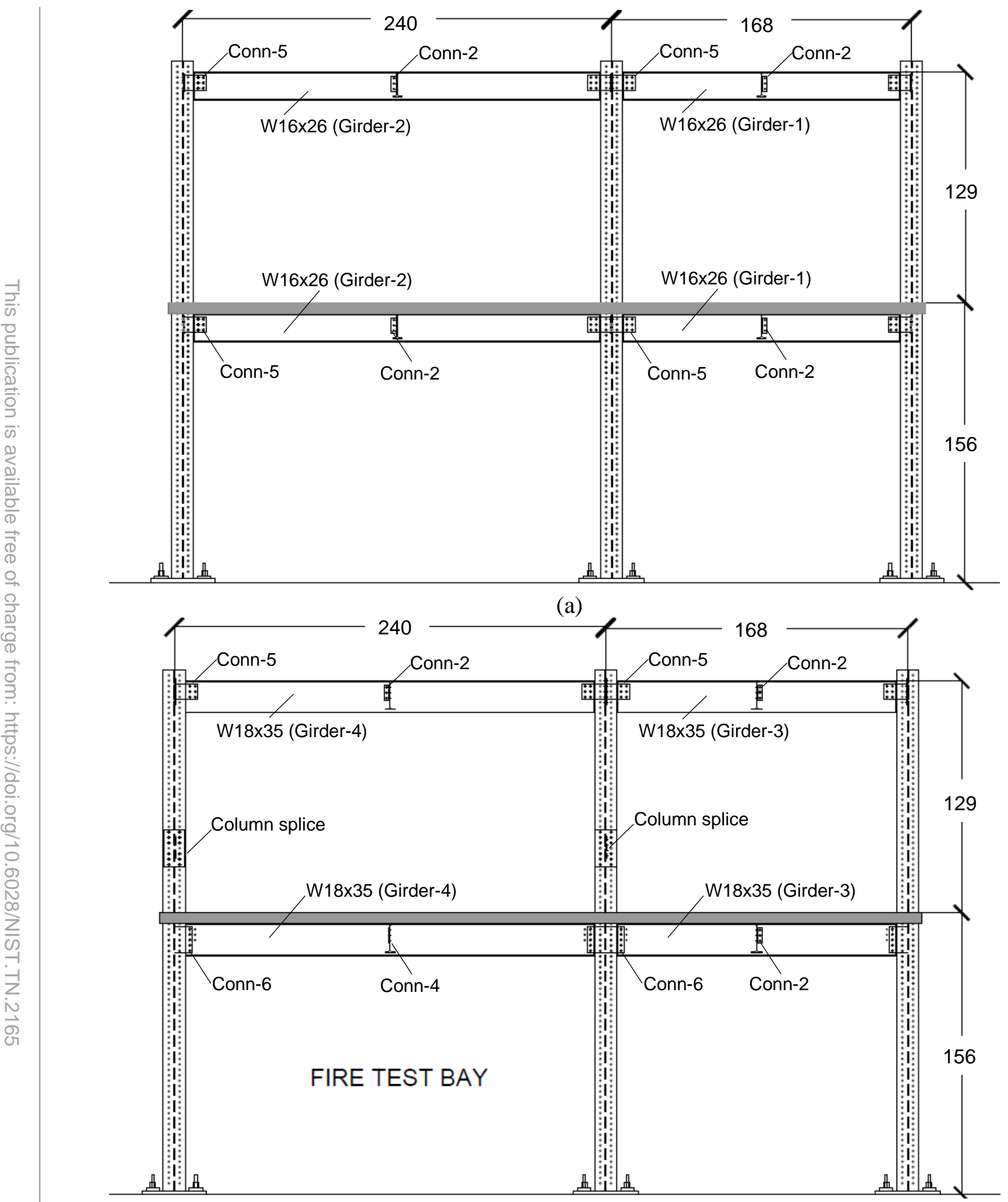

(b)

Fig. A-3. Scale drawing of the two-story steel frame along (a) line 1 and (b) line 2 shown in Fig. A-1. Dimensions in inch. 


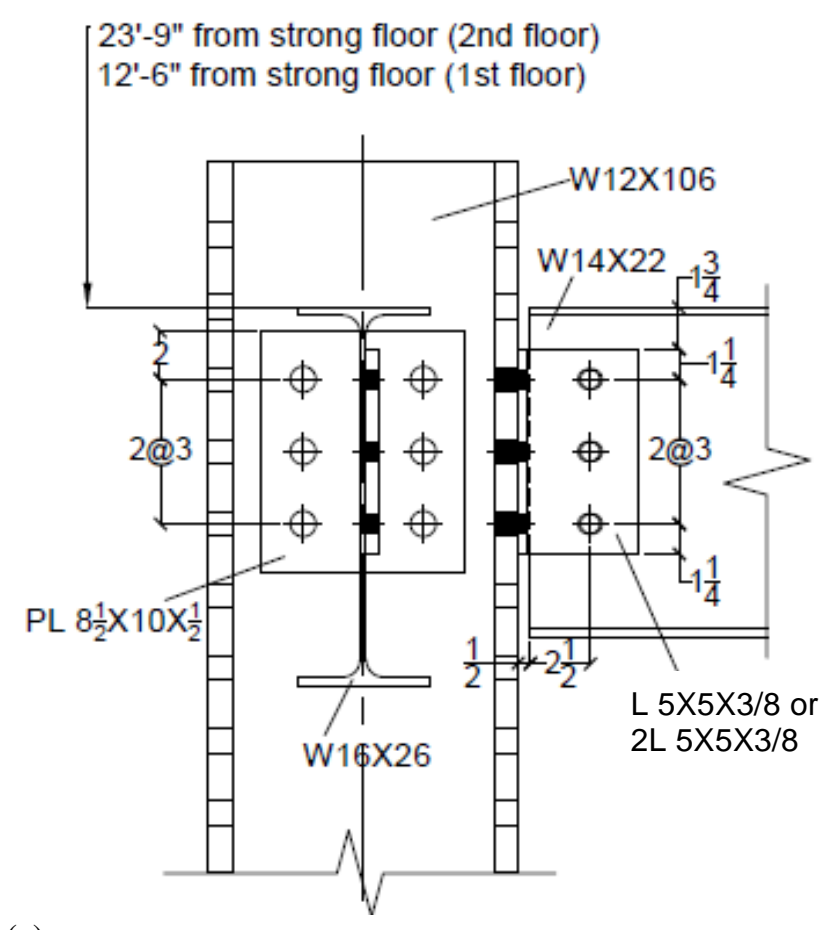

(a)

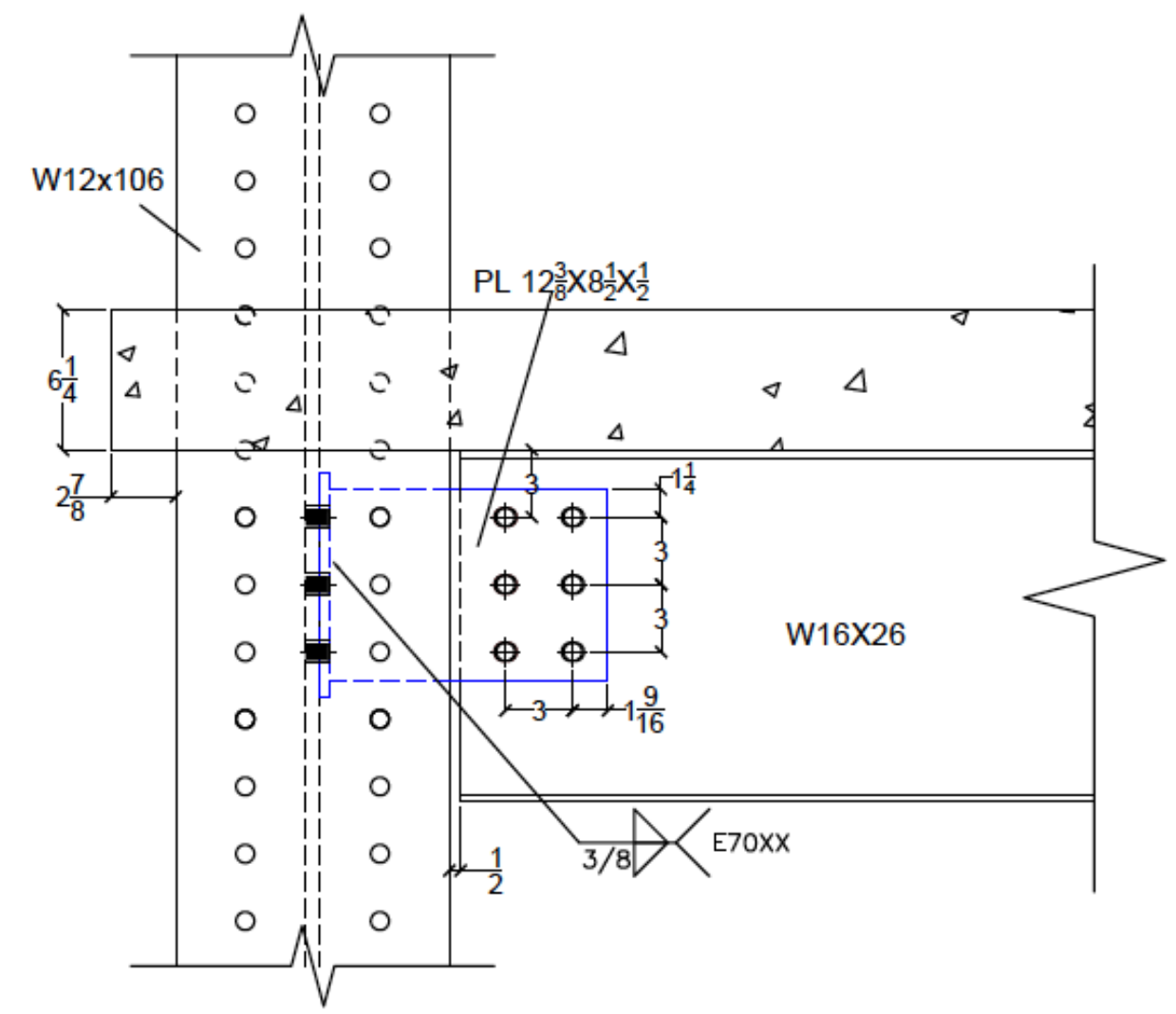

(b)

Fig. A-4. Scale drawings of typical frame connections in the surrounding bay: (a) angle connection (b) extended shear tab connection. Dimensions in inch. 


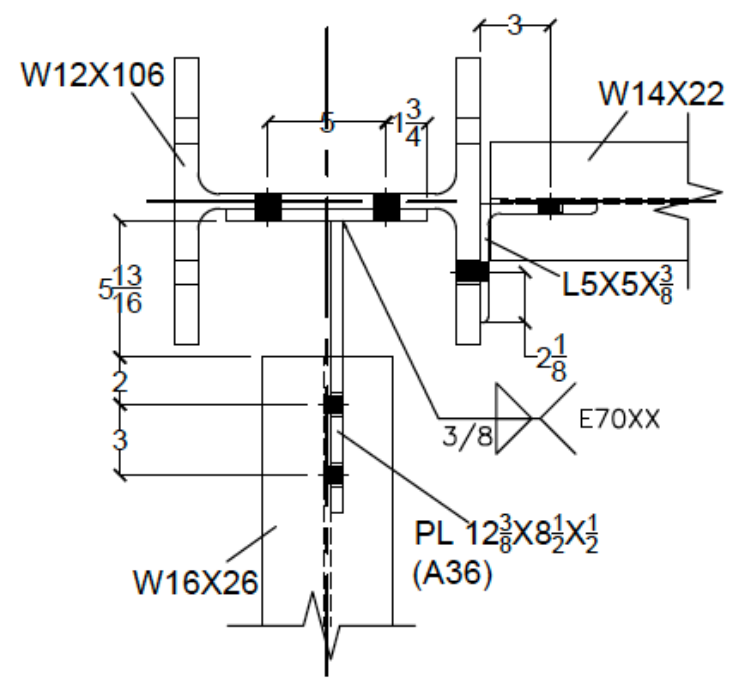

(a)

Fig. A-5. Plan view of beam and girder connections to exterior columns: (a) column A1 and (b) column B1. Units in inch.

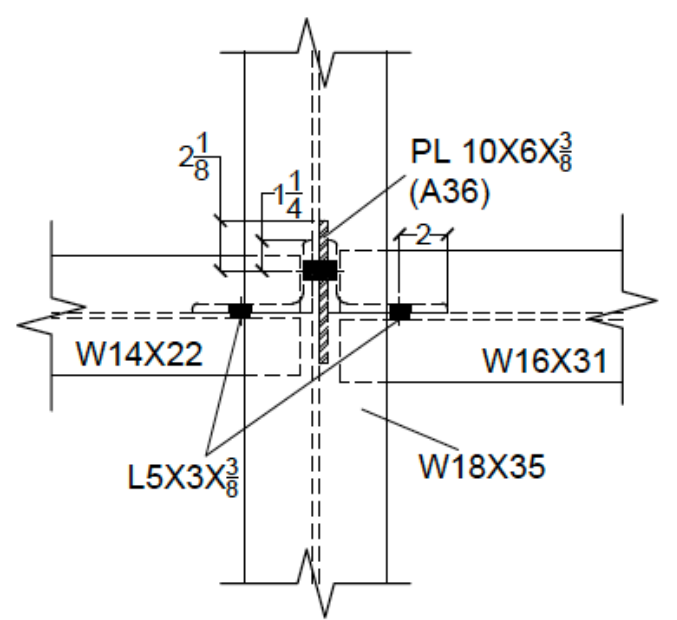

(a)

Fig. A-6. Scale drawing of the beam-to-girder connecti Units in inch.

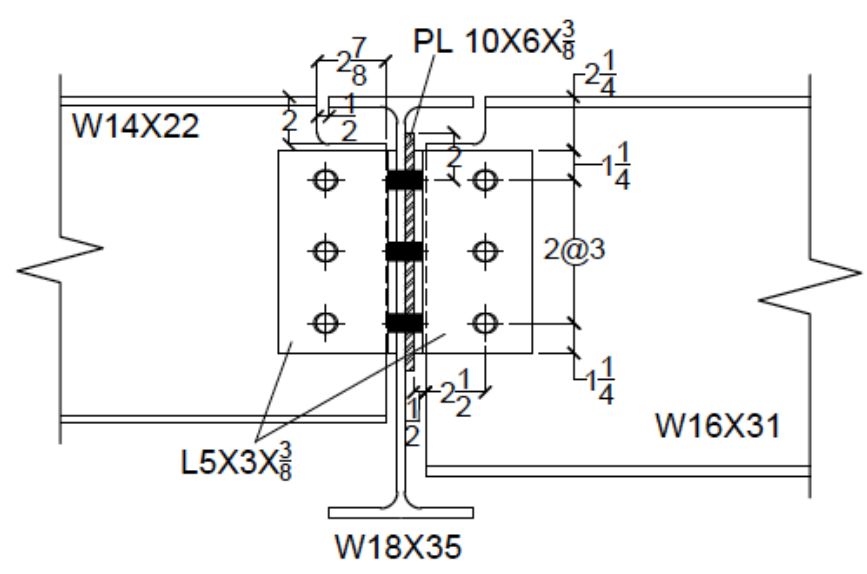

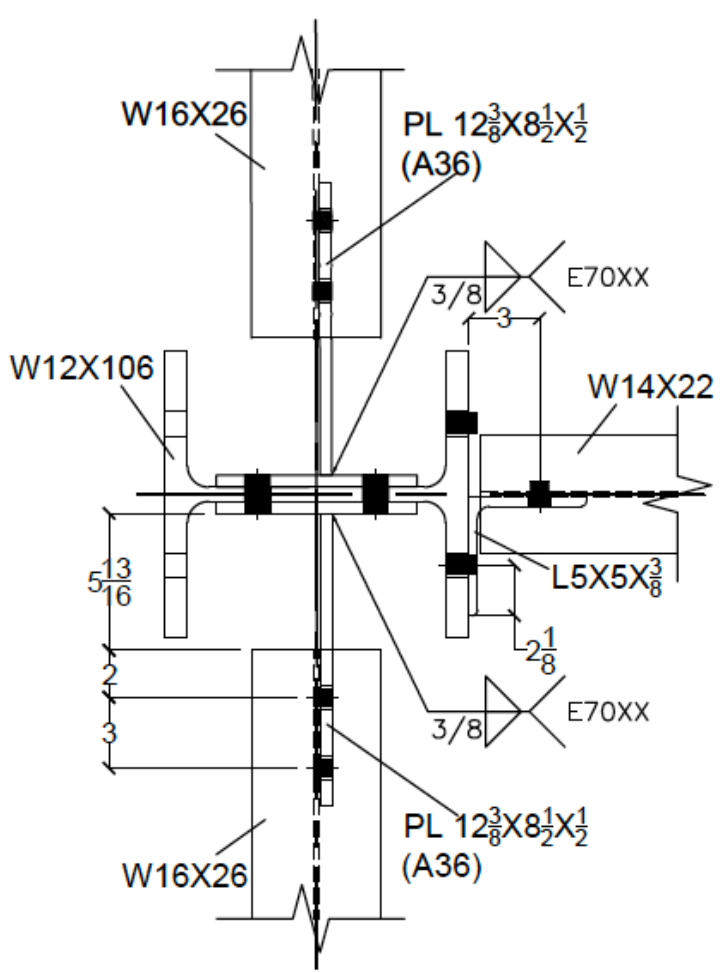

(b) 


\section{A.2. Slab Reinforcement}

Fig. A-7 shows the steel reinforcement layout of the composite slab used in the test building. The welded wire reinforcement (WWR) $6 \times 6 \mathrm{~W} 1.4 \times \mathrm{W} 1.4$ was placed throughout the entire slab as the shrinkage reinforcement. The north, east, and west bay slabs were further reinforced with No. 4 bars, which were placed directly above the welded wire reinforcement. The clear cover of the No. 4 bars was approximately $2.5 \mathrm{~cm}$ (1 in.). These bars were added to minimize concrete damage (in the surrounding bays) as the test floor assembly sagged during the fire exposure. The surrounding slabs will be re-used for subsequent experiments. The No. 4 hooked bars with the length of $98 \mathrm{~cm}$ ( $38.5 \mathrm{in}$.) were placed at the perimeter of the floor slab to minimize any pull-out failures of the slab from the edge beams. The clear cover of the hooked bars was approximately $5.1 \mathrm{~cm}$ ( 2 in.). These bars were typically spaced at $31 \mathrm{~cm}$ (12 in.) except for the north corner slabs where the bar spacing of $76 \mathrm{~cm}$ (30 in.) was used since these corner slabs were expected to have negligible influence from the heated test floor assembly. 


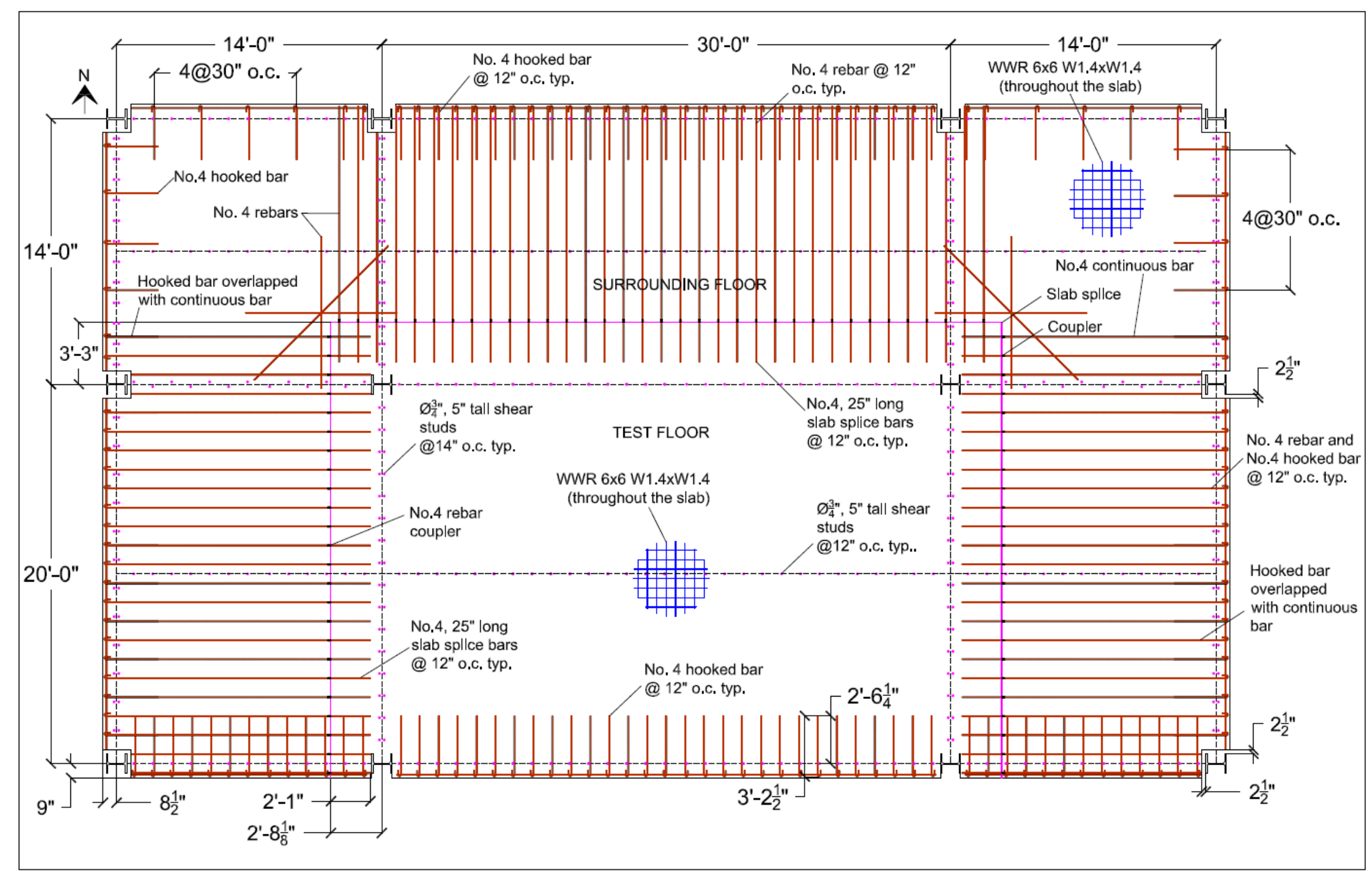

Fig. A-7. Scale drawing of the steel reinforcement layout (U.S. customary units). 


\section{A.3. Gravity Loading System}

The four sets of the gravity loading system were used to simulate prescribed gravity loads on the test floor assembly when subjected to a compartment fire. The location of each loading system is shown in Fig. A-8. This arrangement allowed uniform floor loads distributed at twenty-four points across the test floor. The weight of each loading system was equally distributed at each of twenty-four loading points, approximately equal to $1 \mathrm{kN}$.

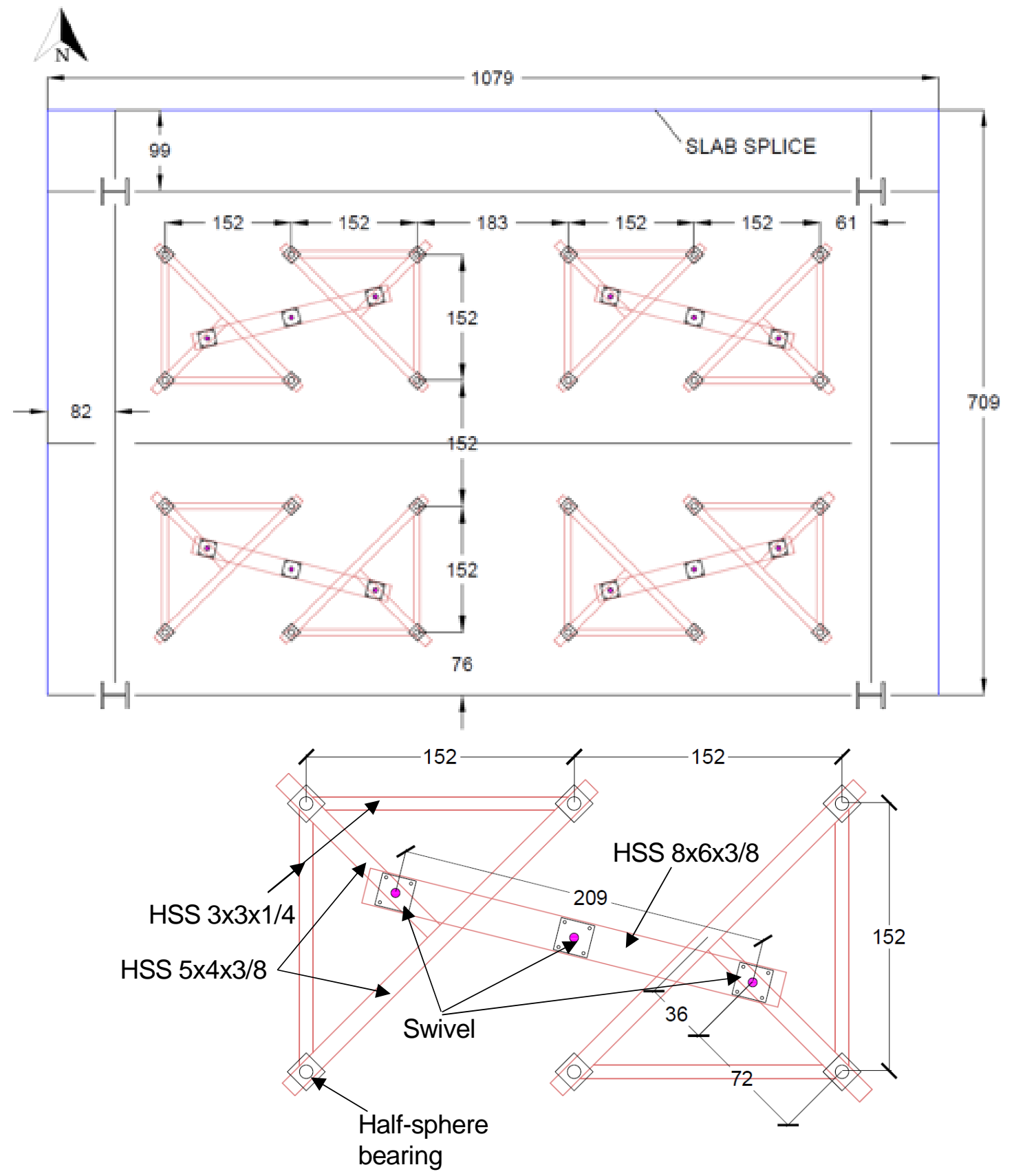

Fig. A-8. Scale drawings of gravity loading system. Dimensions in $\mathrm{cm}$. 


\section{A.4. Fire Test Compartment}

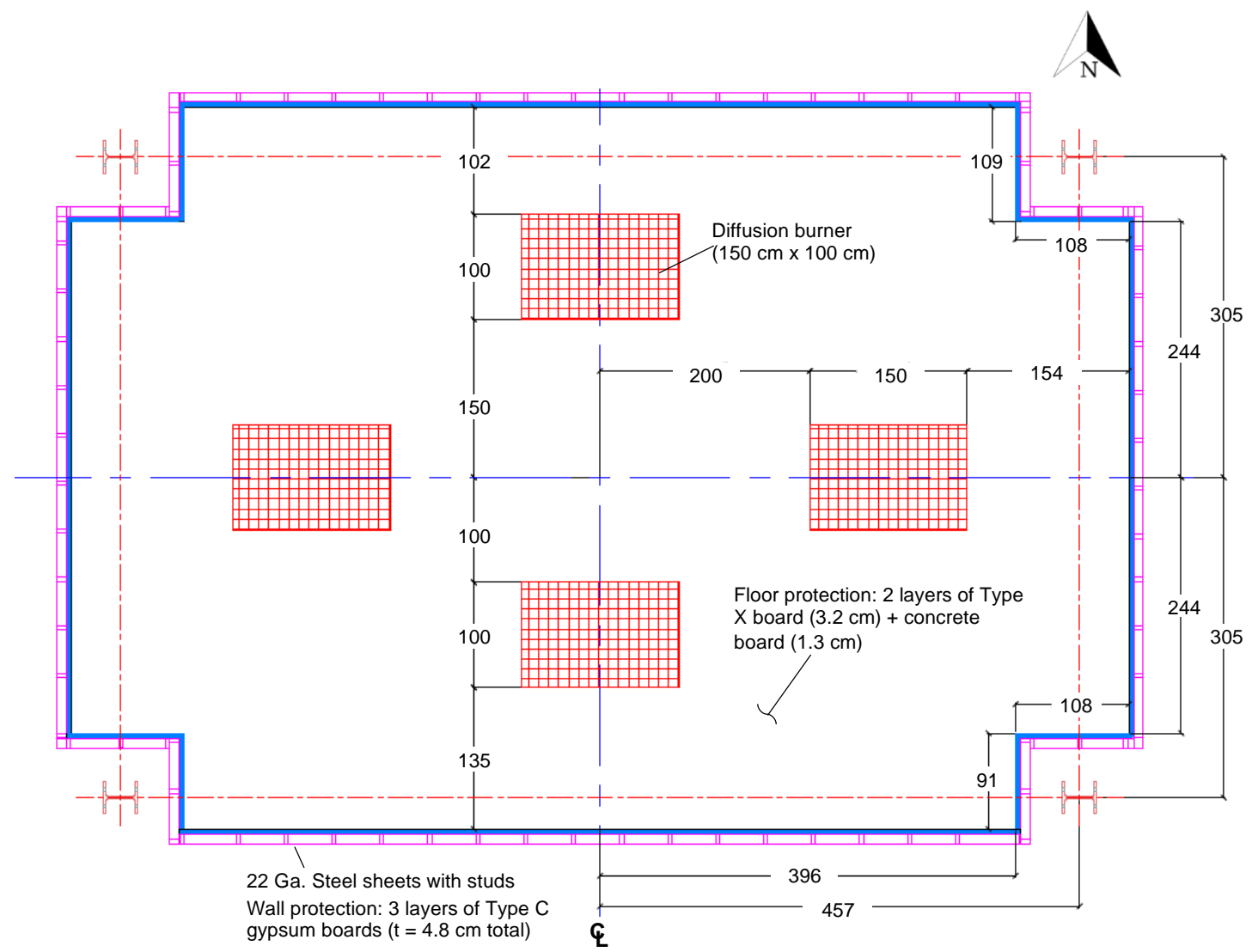

(a)

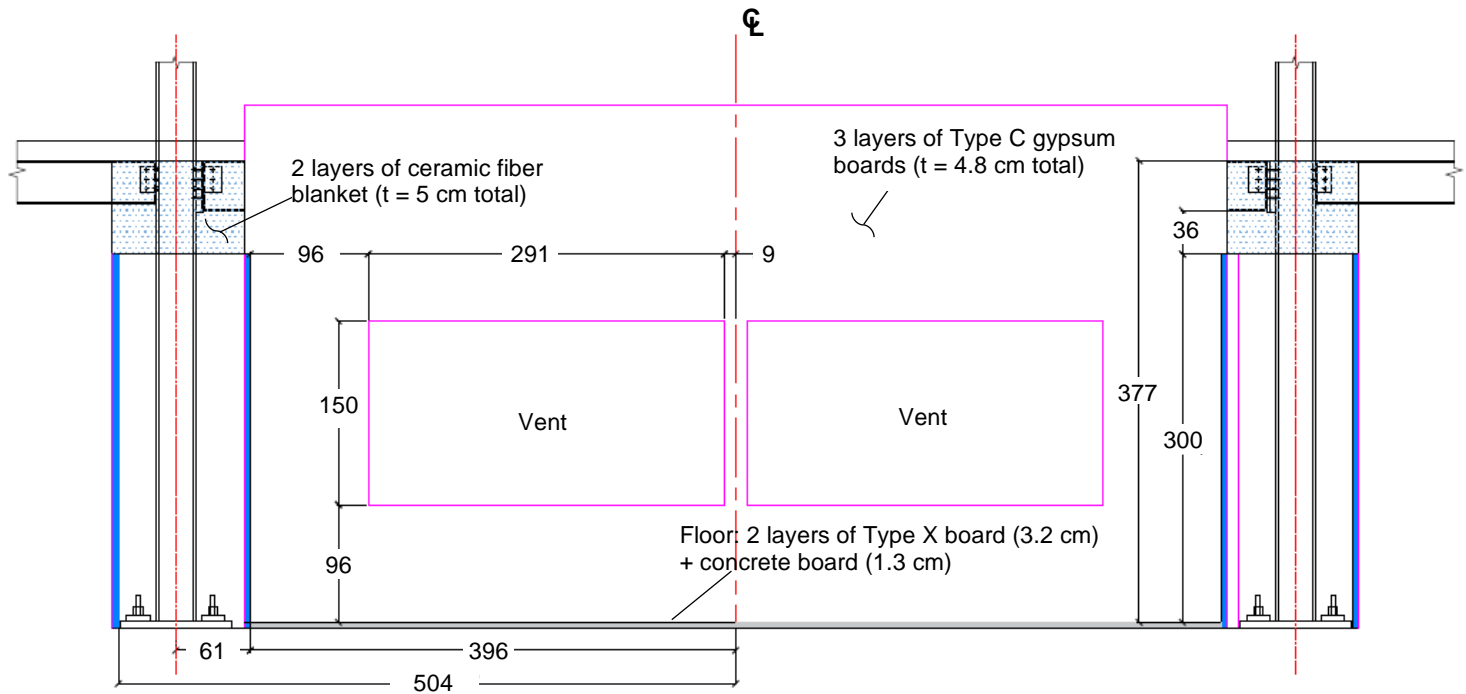

(b)

Fig. A-9. Scale drawings of (a) compartment floor plan and (b) south wall. Dimensions in $\mathrm{cm}$. 


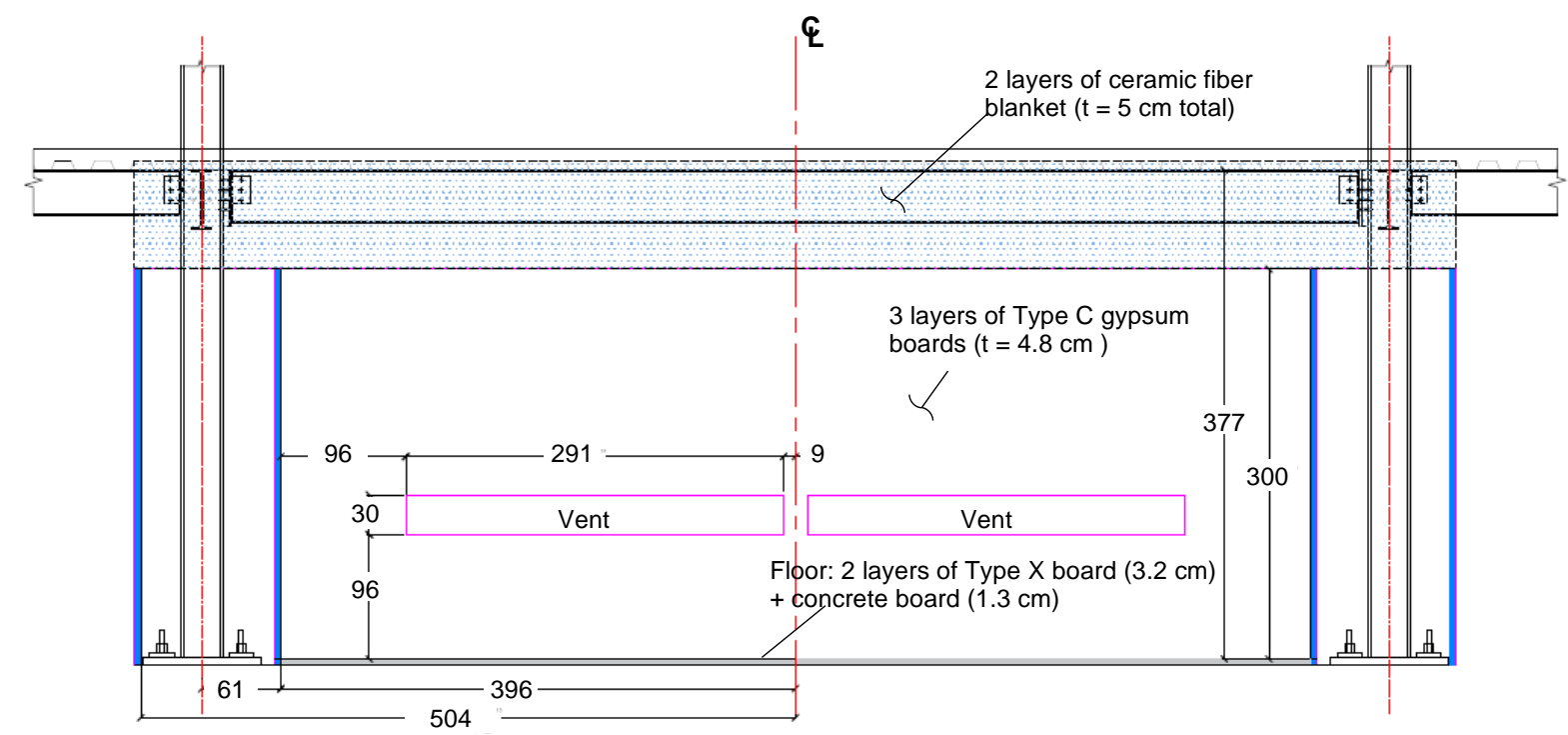

(a)

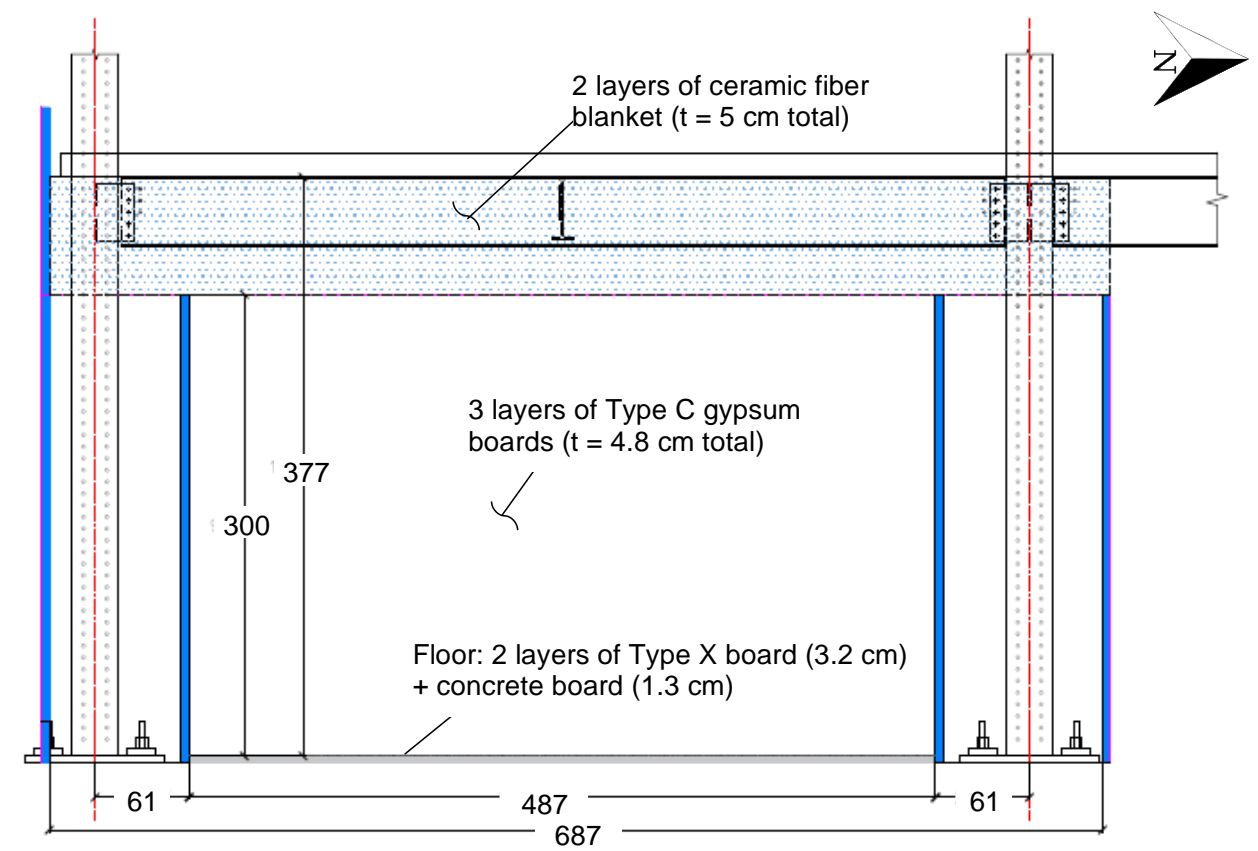

(b)

Fig. A-10. Scale drawings of (a) north wall and (b) east wall. Dimensions in $\mathrm{cm}$. 


\section{Appendix B Instrumentation and Raw Data}

\section{B.1. Mechanical Loading}

The test floor assembly was loaded by four actuators mounted at the basement. Mechanical loads and displacements measured using those actuators are presented in Fig. B-1.

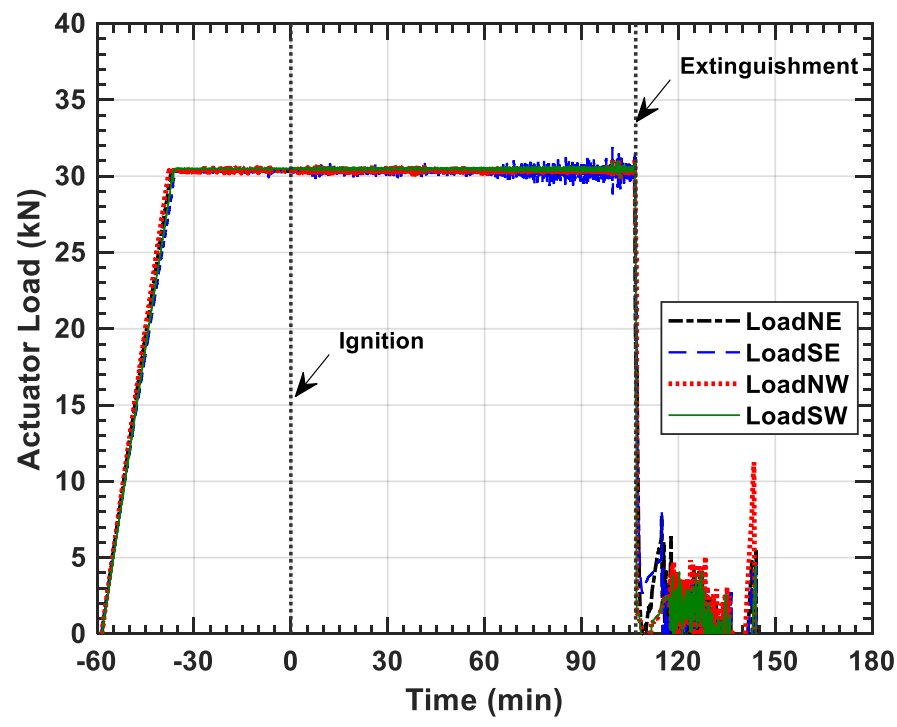

(a)

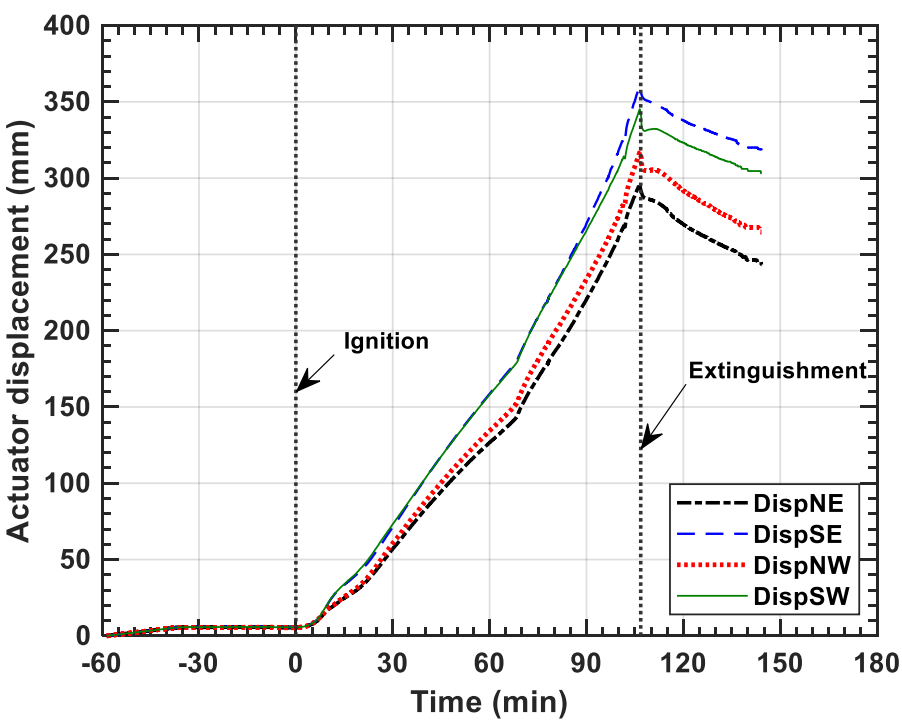

(b)

Fig. B-1. Hydraulic actuator data: (a) mechanical load and (b) stroke displacement of four actuators named each as NE, SE, NW, and SW. 


\section{B.2. Test-Bay Beam Strains Prior to Fire Exposure}

Strains of the secondary beam (B6) as well as the east and west girders (B13 and B16, respectively) at their midspan were measured as the test floor slab was hydraulically loaded at ambient temperature, as shown in Fig. B-2. The total mechanical load is equal to the sum of mechanical loads applied by all four actuators.

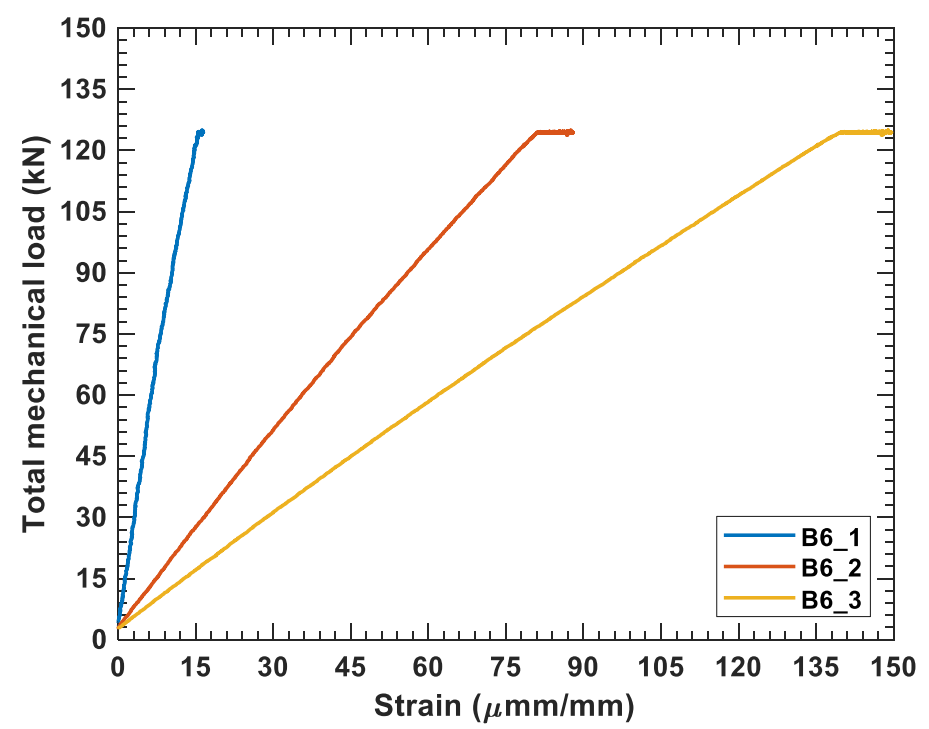

(W16x31)

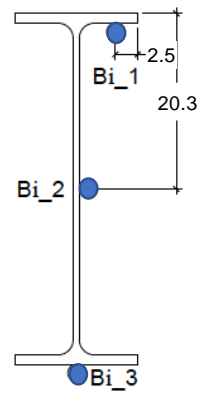

(a)
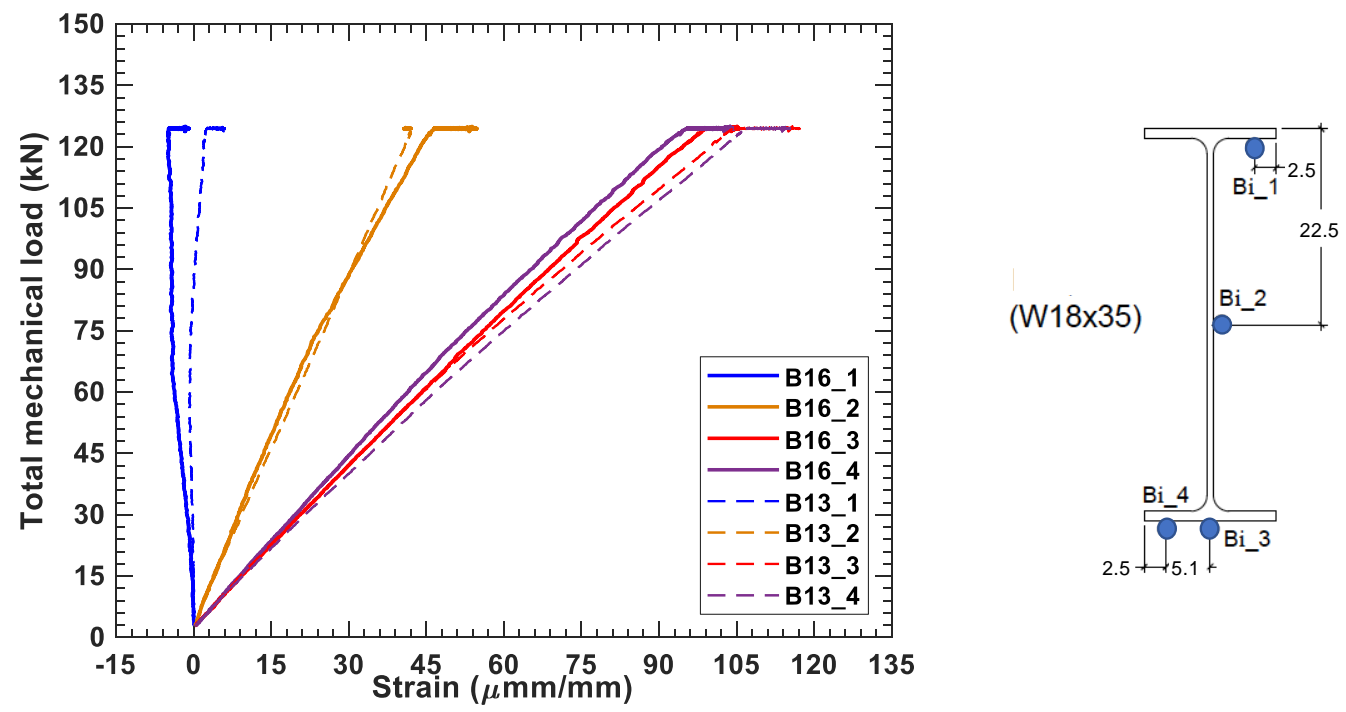

(b)

Fig. B-2. Measured beam strains during mechanical loading at ambient temperature: (a) secondary (W16 $\times 31)$ beam; east and west $(\mathrm{W} 18 \times 35)$ girders at midspan. 


\section{B.3. Compartment Temperatures}

A total of twelve thermocouple probes (TCC1 through TCC12) were mounted $30.5 \mathrm{~cm}$ below the steel deck flute to measure temperatures in the upper layer of the test compartment. Fig. B-3 shows the distribution of TCC1 through TCC12 across the test floor assembly.

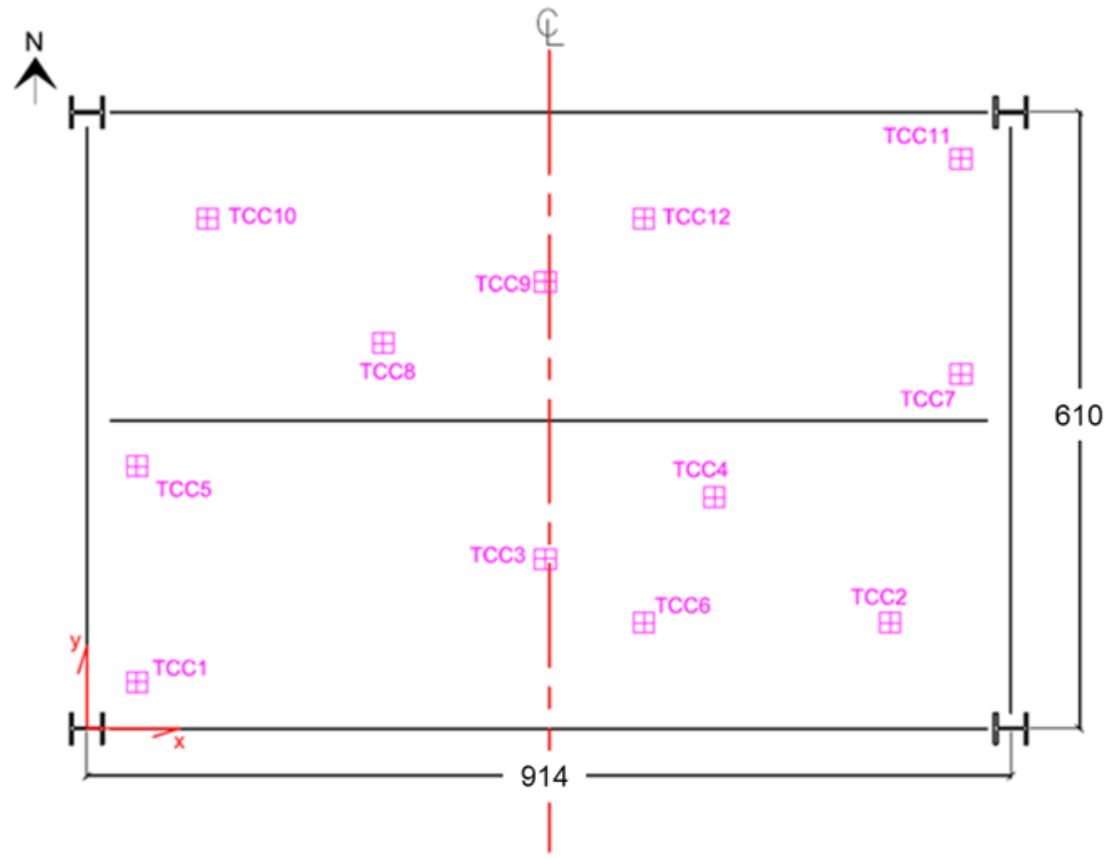

\begin{tabular}{|l|r|r|}
\hline Name/ID & X East+ & Y North+ \\
\hline TCC1 & 50 & 46 \\
\hline TCC2 & 795 & 105 \\
\hline TCC3 & 453 & 168 \\
\hline TCC4 & 621 & 229 \\
\hline TCC5 & 50 & 259 \\
\hline TCC6 & 551 & 105 \\
\hline TCC7 & 865 & 351 \\
\hline TCC8 & 293 & 381 \\
\hline TCC9 & 453 & 442 \\
\hline TCC10 & 119 & 505 \\
\hline TCC11 & 865 & 564 \\
\hline TCC12 & 551 & 505 \\
\hline
\end{tabular}

Fig. B-3. Distribution of thermocouple probes for measurements of upper layer gas temperatures within the test bay. The distance between a thermocouple probe and the steel deck flute is $30.5 \mathrm{~cm}$.

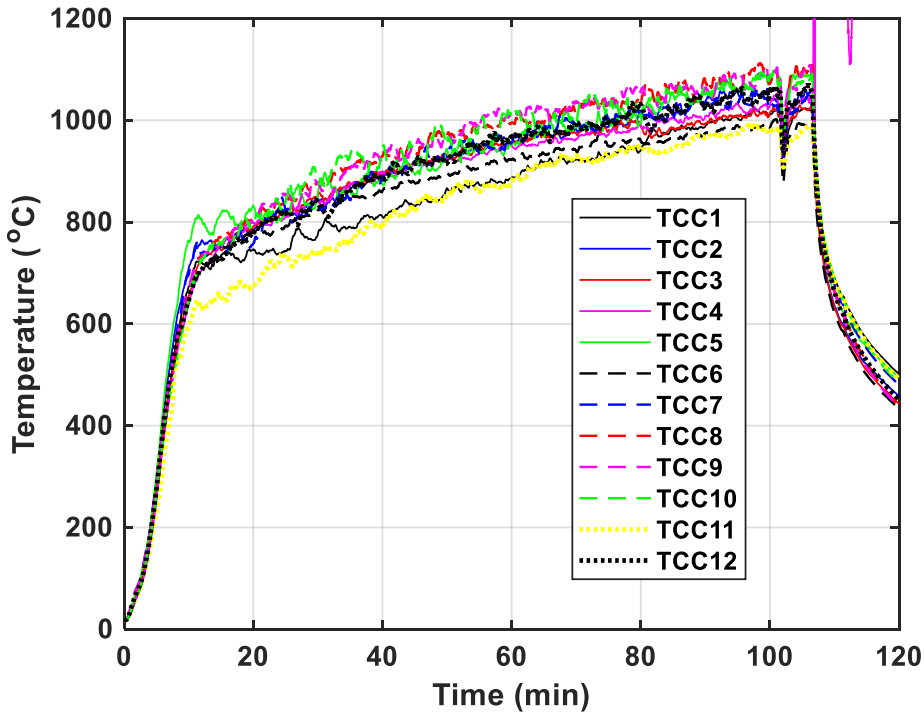

Fig. B-4. Compartment temperatures measured at $30.5 \mathrm{~cm}$ below the composite floor soffit. 
Fig. B-5 shows distribution of thermocouple trees and four natural gas burners placed within the test compartment. Each thermocouple tree had three OMEGACLAD thermocouple probes mounted at various heights. Note that NorthTC1 was malfunctioned from the beginning of the test so temperatures of this thermocouple were not reported.

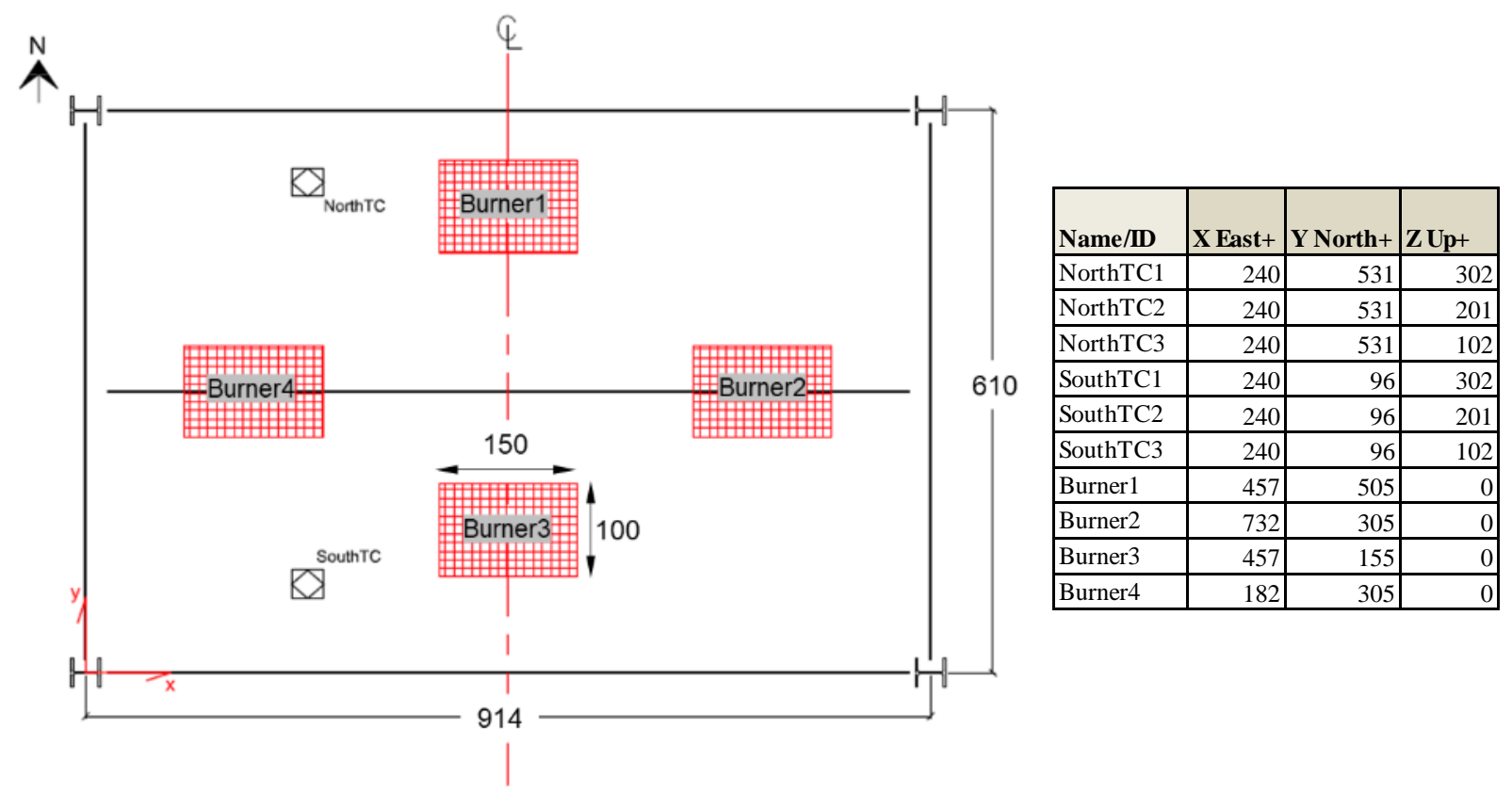

Fig. B-5. Locations of natural gas burners and thermocouple trees in the test bay. The $x$ and $y$ coordinates of the burners indicate the center of each burner. The floor of the test compartment was at $Z=0 \mathrm{~cm}$.

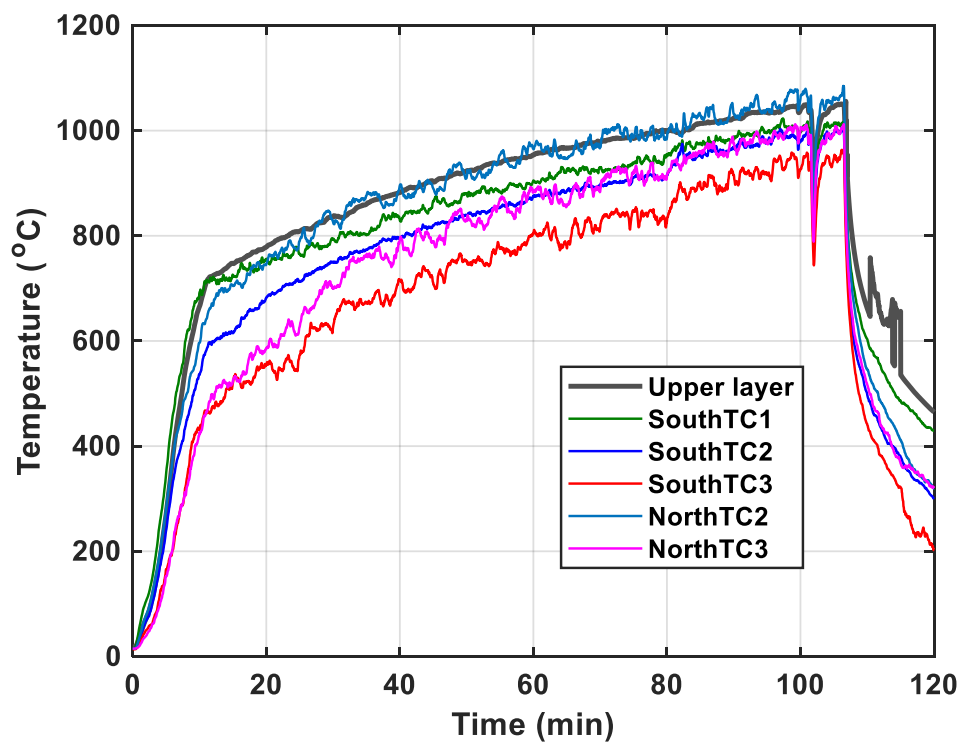

Fig. B-6. Gas temperature measured using South TC and North TC trees. 


\section{B.4. Heat Fluxes on Exposed Walls}

Three Gardon gauges were mounted at the northwest and southeast corners of the test compartment, as shown in Fig. B-7. The distance from the sensor to the strong floor was $305 \mathrm{~cm}$. The sensor temperatures remained below $60{ }^{\circ} \mathrm{C}$ during heating. Fig. B- 8 shows the measured heat fluxes during the test.

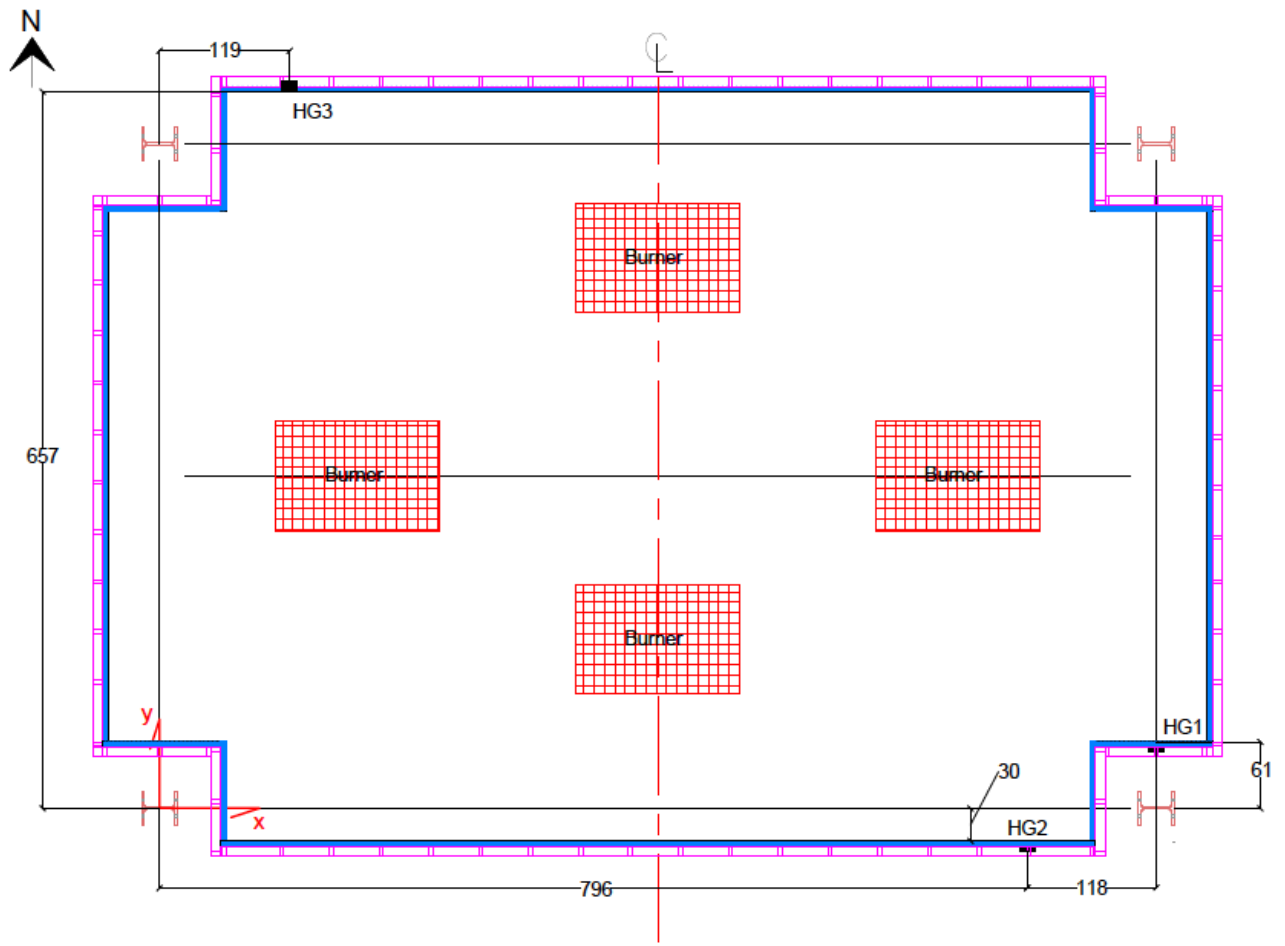

Fig. B-7. Locations of heat flux gauges (HG1 through HG3).

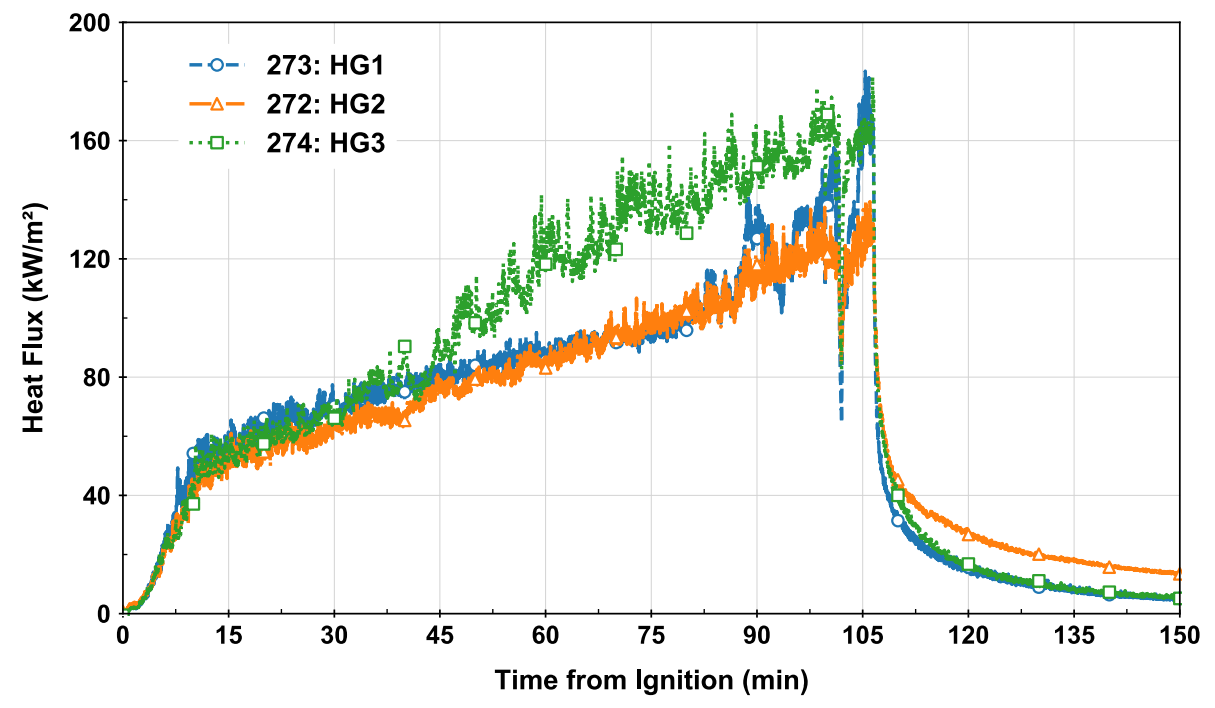

Fig. B-8. Measured heat fluxes on exposed wall surfaces. 


\section{B.5. Concrete Temperatures}

A total of ten thermocouple trees, made of the $10 \mathrm{~cm}$ diameter concrete cylinders, were placed in the test floor slab. Locations of these cylinders (TST1 through TST8) are shown in Fig. B-9. In each cylinder, two to four thermocouples were secured at various depths of the slab, except for TSTi_5* mounted $3 \mathrm{~mm}$ from the steel deck where $\mathrm{i}=$ cylinder number. All thermocouple probes measured temperatures of the concrete poured in the test bay, neither cylinders nor the deck pan. The raw temperature data are presented in Fig. B-10. Some temperature readings were affected by evaporation of the moisture in the concrete, concrete cracking, debonding of the steel decking from the concrete, or combination of multiple phenomena.

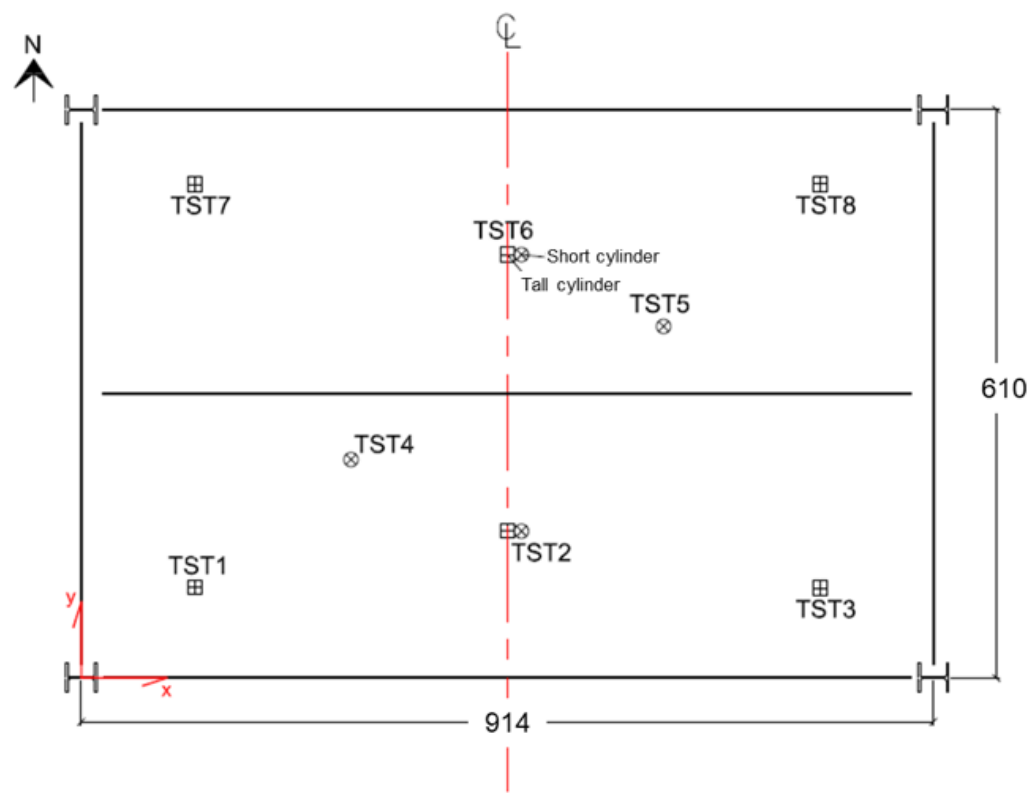

TST4 \& TST5

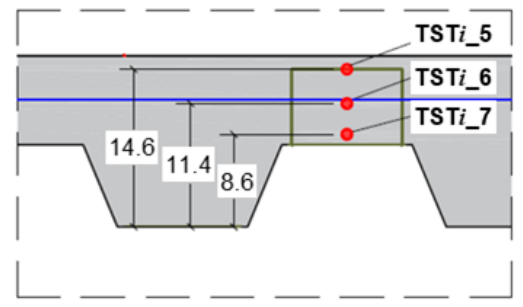

TST1, TST3, TST7 \& TST8

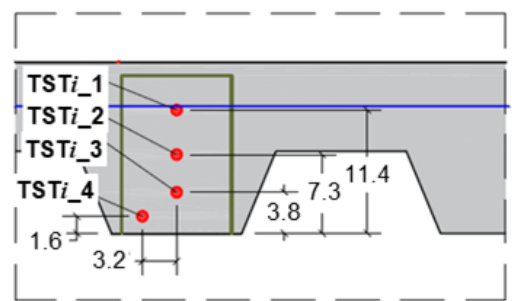

TST2 \& TST6
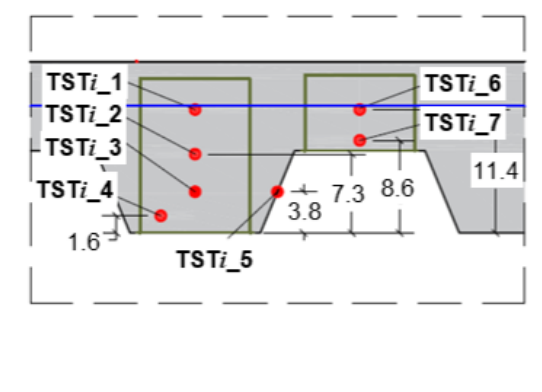

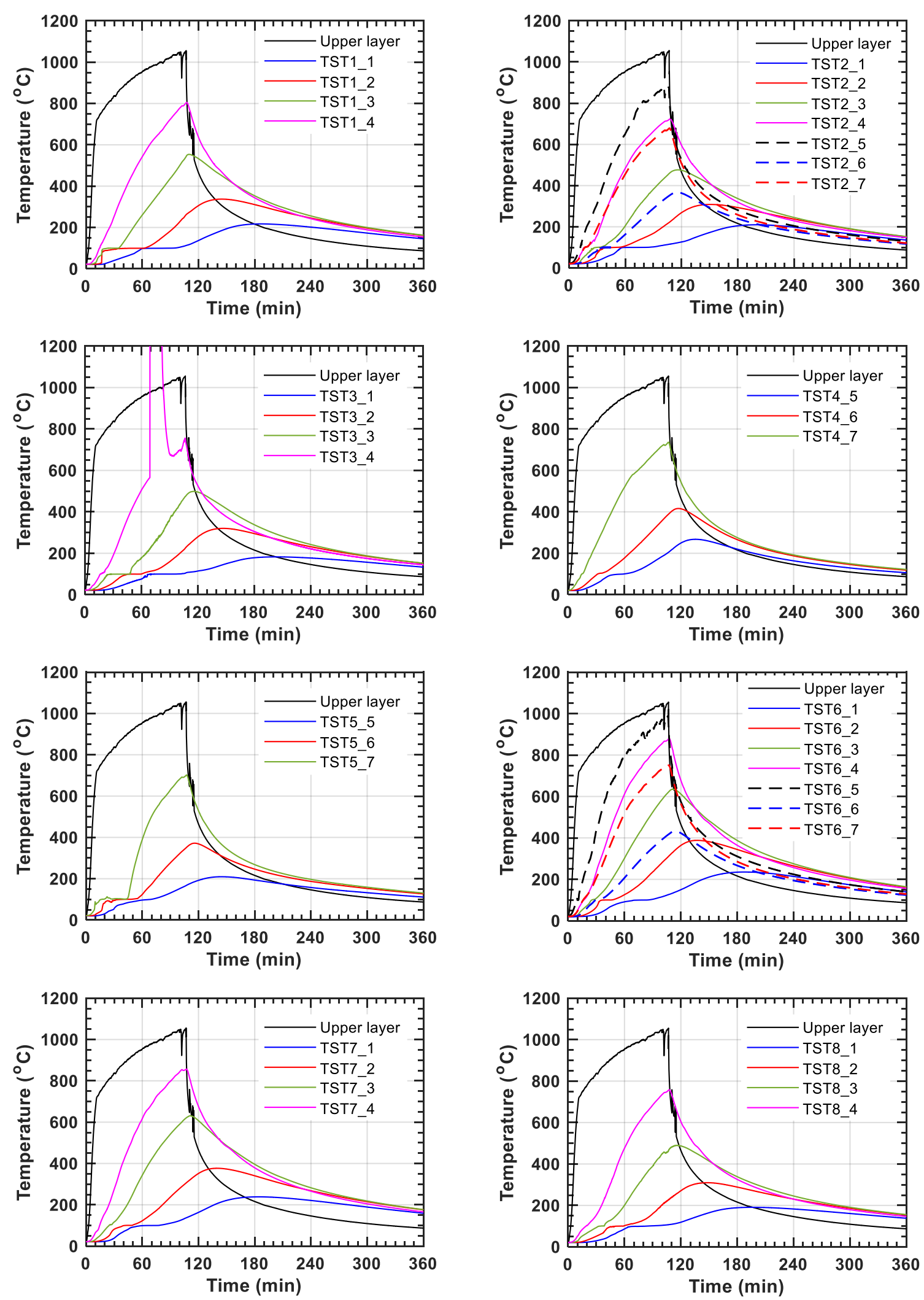

Fig. B-10. Slab temperatures measured at various locations (TST1 through TST 8). The upper layer temperature is the average value of compartment temperatures measured using TCC channels. 


\section{B.6. Composite Section Temperatures}

Fig. B-11 shows locations of the temperature measurement at five midspan composite sections of the test floor assembly. Table B-1 shows the corresponding X, Y, and Z coordinates of mounted thermocouple beads; the top surface of steel members is defined at $Z=0 \mathrm{~cm}$. The timedependent thermal gradients across the composite beam sections at midspan are illustrated in Fig. B-14.
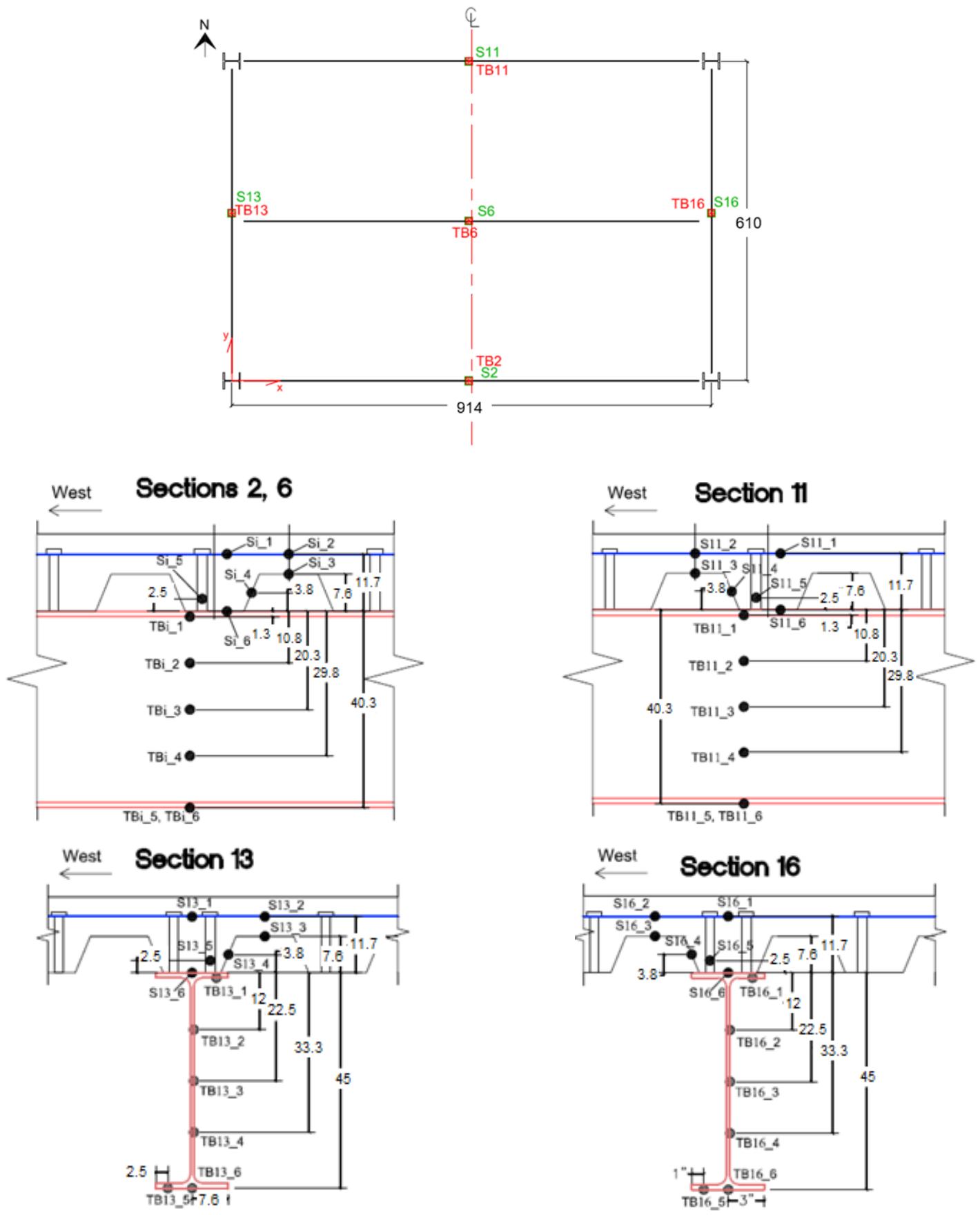

Fig. B-11. Locations of thermocouples mounted at the midspan composite sections, where $i$ is the section number. 
Table B-1 The coordinates of thermocouple locations where the $\mathbf{Z}$ datum is at the top flange surface of steel members.

\begin{tabular}{|l|r|r|r|}
\hline Name/ID & X East+ & Y North+ & Z Up+ \\
\hline S2_1 & 460 & 8 & 11.7 \\
\hline S2_2 & 472 & 8 & 11.7 \\
\hline S2_3 & 472 & 8 & 7.6 \\
\hline S2_4 & 465 & 8 & 3.8 \\
\hline S2_5 & 455 & 0 & 2.5 \\
\hline S2_6 & 460 & 8 & 0.0 \\
\hline TB2_1 & 452 & 4 & -1.3 \\
\hline TB2_2 & 452 & 0 & -10.8 \\
\hline TB2_3 & 452 & 0 & -20.3 \\
\hline TB2_4 & 452 & 0 & -29.8 \\
\hline TB2_5 & 452 & -4 & -40.3 \\
\hline TB2_6 & 452 & 0 & -40.3 \\
\hline S6_1 & 460 & 297 & 11.7 \\
\hline S6_2 & 472 & 309 & 11.7 \\
\hline S6_3 & 472 & 309 & 7.6 \\
\hline S6_4 & 465 & 309 & 3.8 \\
\hline S6_5 & 455 & 305 & 2.5 \\
\hline S6_6 & 460 & 305 & 0.0 \\
\hline TB6_1 & 452 & 300 & -1.3 \\
\hline TB6_2 & 452 & 304 & -10.8 \\
\hline TB6_3 & 452 & 304 & -20.3 \\
\hline TB6_4 & 452 & 304 & -29.8 \\
\hline TB6_5 & 452 & 309 & -40.3 \\
\hline TB6_6 & 452 & 305 & -40.3 \\
\hline S11_1 & 460 & 602 & 11.7 \\
\hline S11_2 & 442 & 602 & 11.7 \\
\hline S11_3 & 442 & 607 & 7.6 \\
\hline S11_4 & 450 & 610 & 3.8 \\
\hline S11_5 & 455 & 610 & 2.5 \\
\hline S11_6 & 460 & 602 & 0.0 \\
\hline & & & \\
\hline
\end{tabular}

\begin{tabular}{|l|r|r|r|}
\hline Name/ID & X East+ & Y North+ & Z Up+ \\
\hline TB11_1 & 452 & 605 & -1.3 \\
\hline TB11_2 & 452 & 609 & -10.8 \\
\hline TB11_3 & 452 & 609 & -20.3 \\
\hline TB11_4 & 452 & 609 & -29.8 \\
\hline TB11_5 & 452 & 614 & -40.3 \\
\hline TB11_6 & 452 & 610 & -40.3 \\
\hline S13_1 & 0 & 323 & 11.7 \\
\hline S13_2 & 15 & 328 & 11.7 \\
\hline S13_3 & 15 & 328 & 7.6 \\
\hline S13_4 & 8 & 331 & 3.8 \\
\hline S13_5 & 4 & 323 & 2.5 \\
\hline S13_6 & 0 & 323 & 0.0 \\
\hline TB13_1 & 5 & 320 & -1.0 \\
\hline TB13_2 & 0 & 320 & -12.1 \\
\hline TB13_3 & 0 & 320 & -22.5 \\
\hline TB13_4 & 0 & 320 & -33.3 \\
\hline TB13_5 & -5 & 320 & -45.1 \\
\hline TB13_6 & 0 & 320 & -45.1 \\
\hline S16_1 & 914 & 323 & 11.7 \\
\hline S16_2 & 899 & 326 & 11.7 \\
\hline S16_3 & 899 & 326 & 7.6 \\
\hline S16_4 & 907 & 326 & 3.8 \\
\hline S16_5 & 911 & 323 & 2.5 \\
\hline S16_6 & 914 & 323 & 0.0 \\
\hline TB16_1 & 909 & 320 & -1.0 \\
\hline TB16_2 & 914 & 320 & -12.1 \\
\hline TB16_3 & 914 & 320 & -22.5 \\
\hline TB16_4 & 914 & 320 & -33.3 \\
\hline TB16_5 & 919 & 320 & -45.1 \\
\hline TB16_6 & 914 & 320 & -45.1 \\
\hline & & & \\
\hline
\end{tabular}



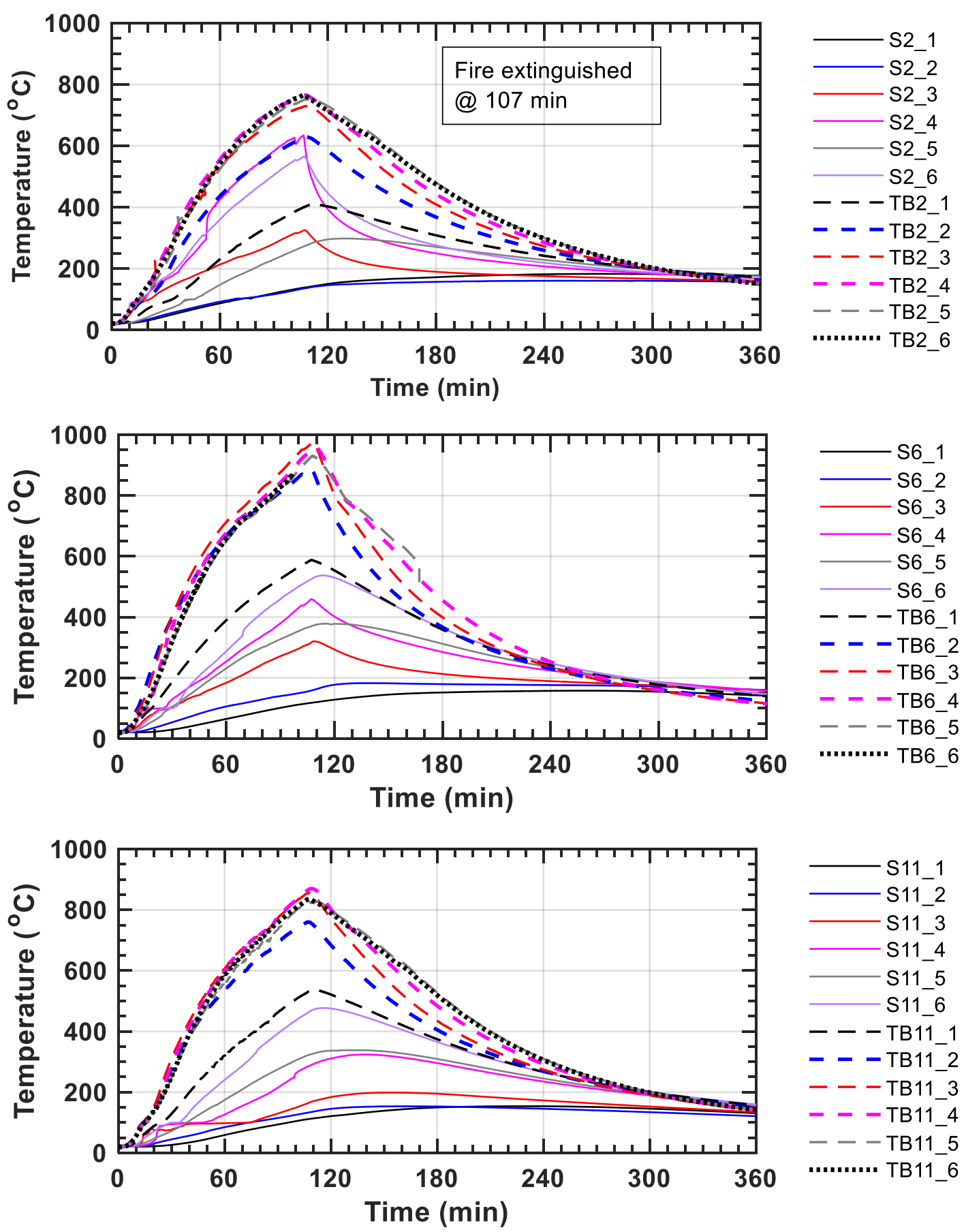

Fig. B-12. Composite section temperature at midspan of south primary beam (section 2); secondary beam (section 6); north primary beam (section 11). 

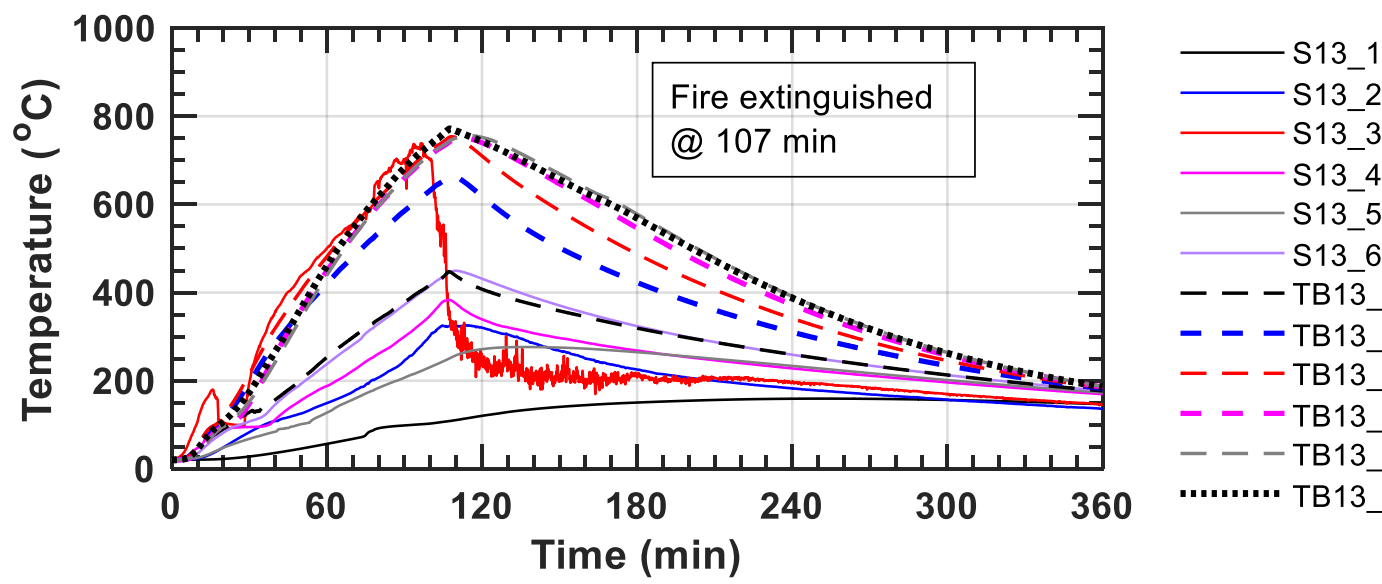

- - - TB13_1

- - TB13_2

- - - TB13_3

- - -TB13_4

$---T B 13+5$

(.,.....'TB13_6
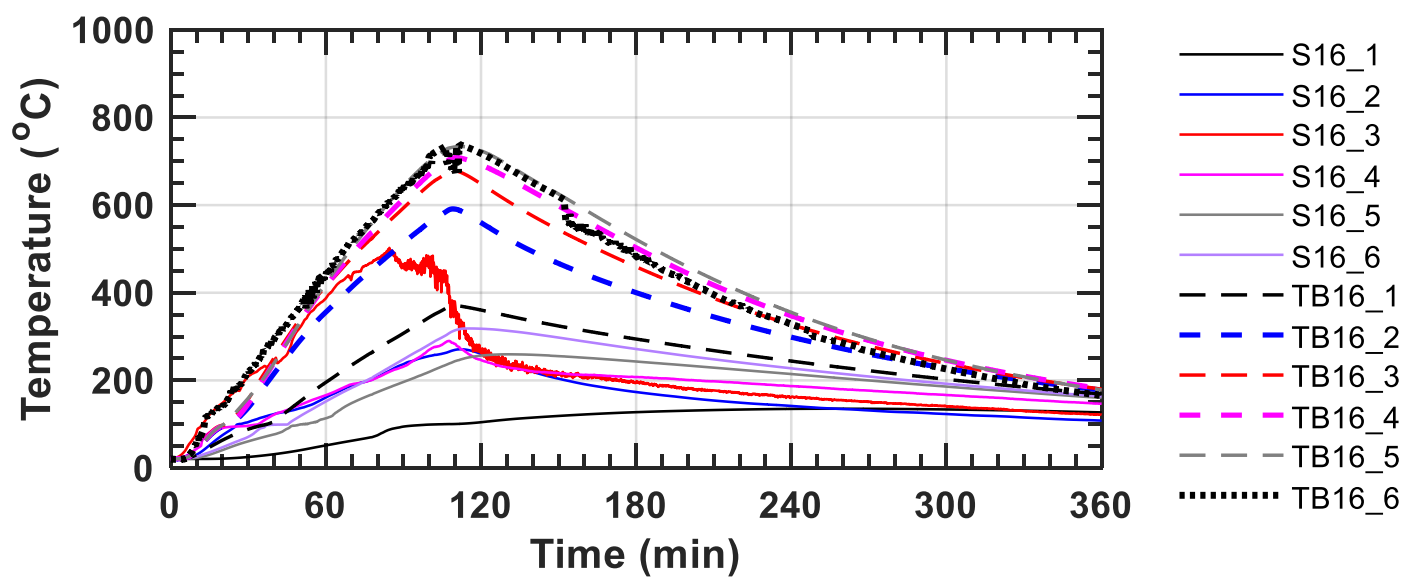

Fig. B-13. Composite section temperature at midspan of west girder (section 13) and east girder (section 16). 


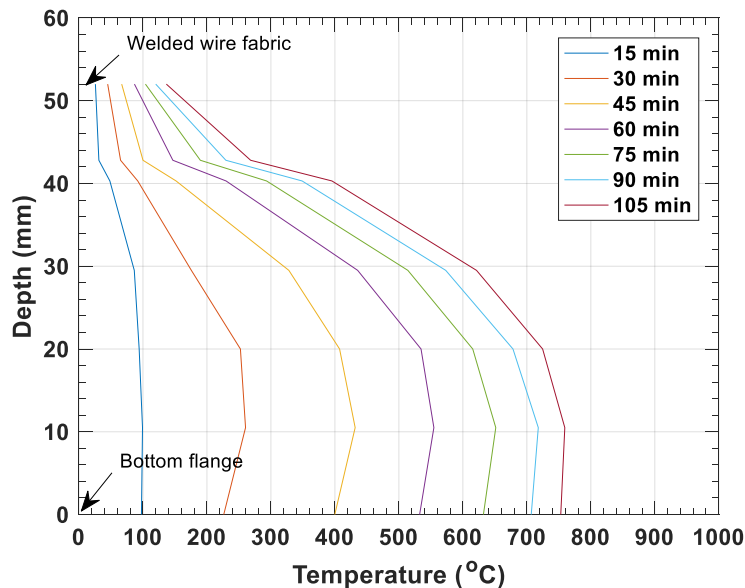

(a) Section 2

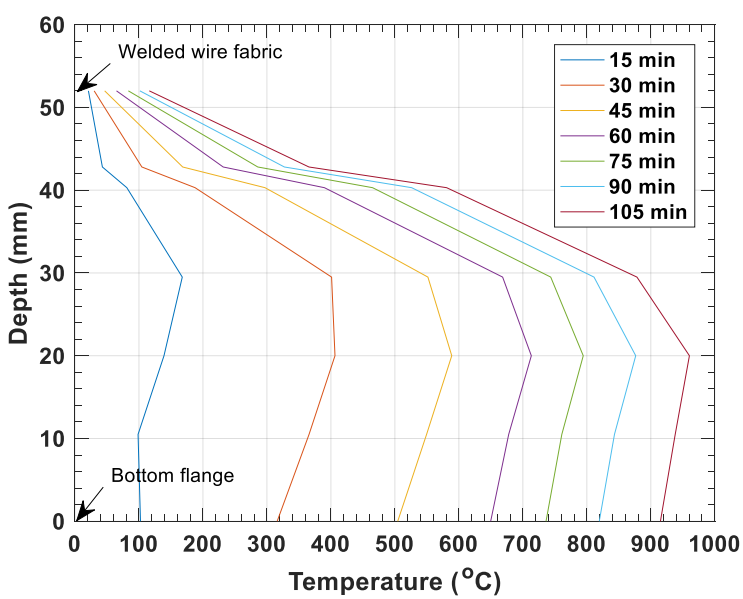

(b) Section 6

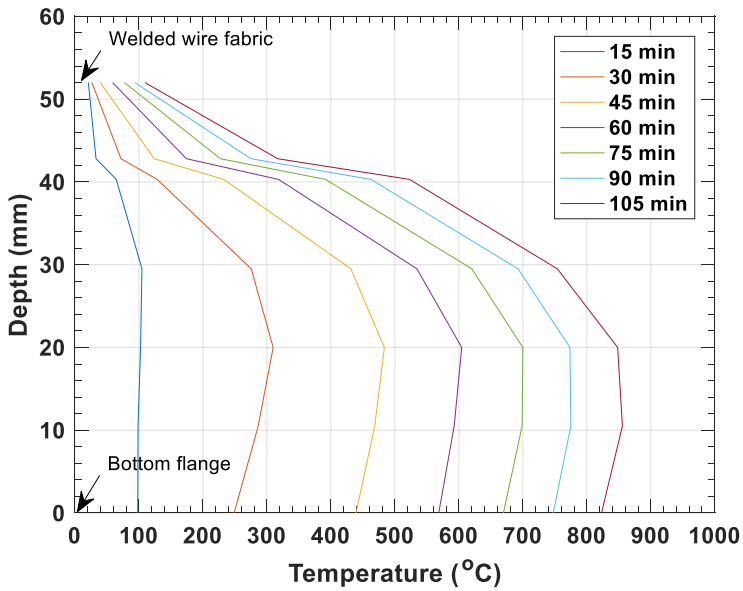

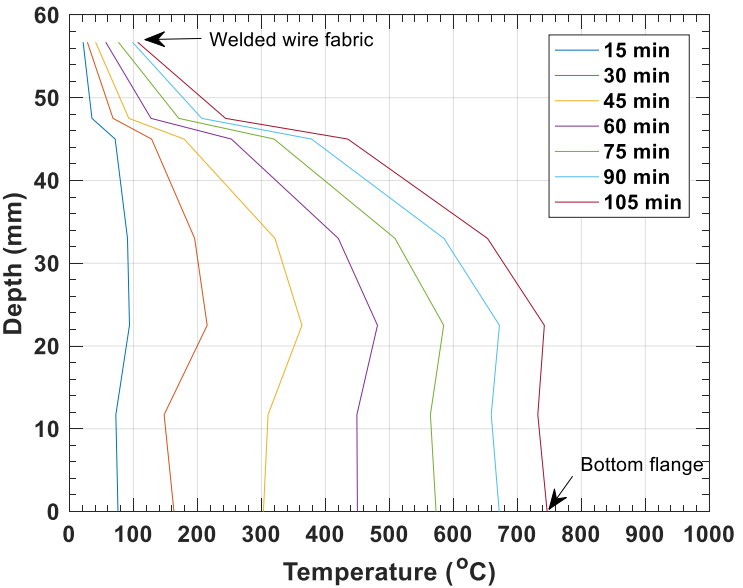

(d) Section 13

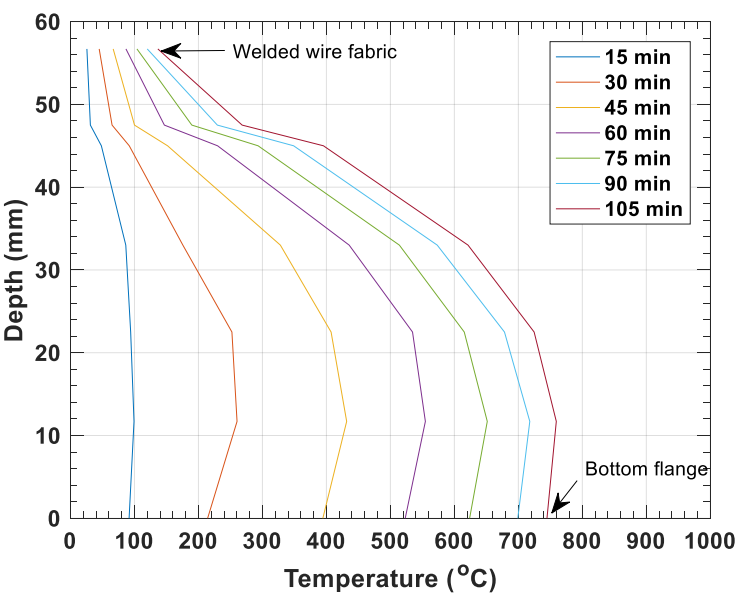

(e) Section 16

(c) Section 11

Fig. B-14. Change in thermal gradients through the depth of the midspan composite sections of (a) south primary beam, (b) secondary beam, (c) north primary beam, (d) west girder, and (e) east girder during heating. 


\section{B.7. Steel Beam and Girder Temperatures}

Temperatures of the SFRM-protected steel beams $(\mathrm{W} 16 \times 31)$ and steel girders $(\mathrm{W} 18 \times 35)$ were measured at various locations, Fig. B-15. Note that the coordinates of thermocouples at midspan sections (TB2, TB6, TB11, TB13, and TB16) are presented in Table B-1.

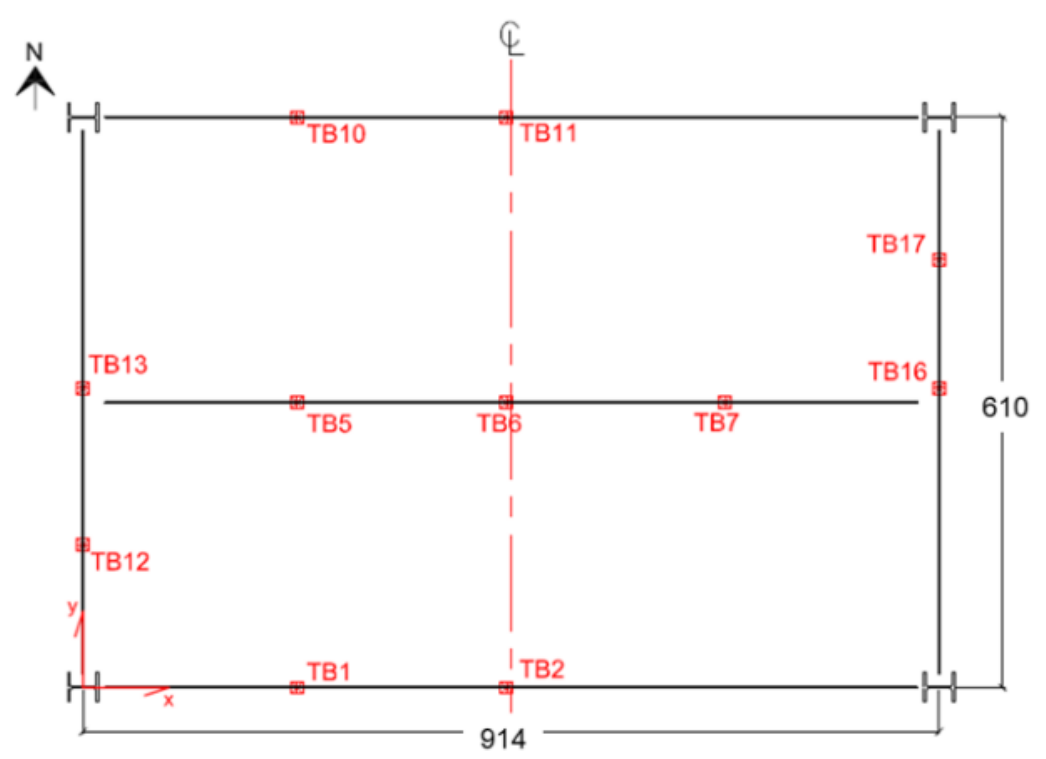

\begin{tabular}{|l|r|r|r|}
\hline Name/ID & \multicolumn{1}{l|}{$\begin{array}{l}\text { X } \\
\text { East+ }\end{array}$} & North+ & Z Up+ \\
\hline TB1_1 & 229 & 4 & -1.3 \\
\hline TB1_2 & 229 & 0 & -20.3 \\
\hline TB1_3 & 229 & -4 & -40.3 \\
\hline TB5_1 & 229 & 300 & -11.7 \\
\hline TB5_2 & 229 & 304 & -20.3 \\
\hline TB5_3 & 229 & 309 & -40.3 \\
\hline TB7_1 & 686 & 300 & -11.7 \\
\hline TB7_2 & 686 & 304 & -20.3 \\
\hline TB7_3 & 686 & 309 & -40.3 \\
\hline TB10_1 & 229 & 605 & -11.7 \\
\hline TB10_2 & 229 & 609 & -20.3 \\
\hline TB10_3 & 229 & 614 & -40.3 \\
\hline TB12_1 & 5 & 152 & -0.9 \\
\hline TB12_2 & 0 & 152 & -22.5 \\
\hline TB12_3 & -5 & 152 & -45.0 \\
\hline TB17_1 & 909 & 457 & -0.9 \\
\hline TB17_2 & 914 & 457 & -22.5 \\
\hline TB17_3 & 919 & 457 & -45.0 \\
\hline
\end{tabular}

(a)
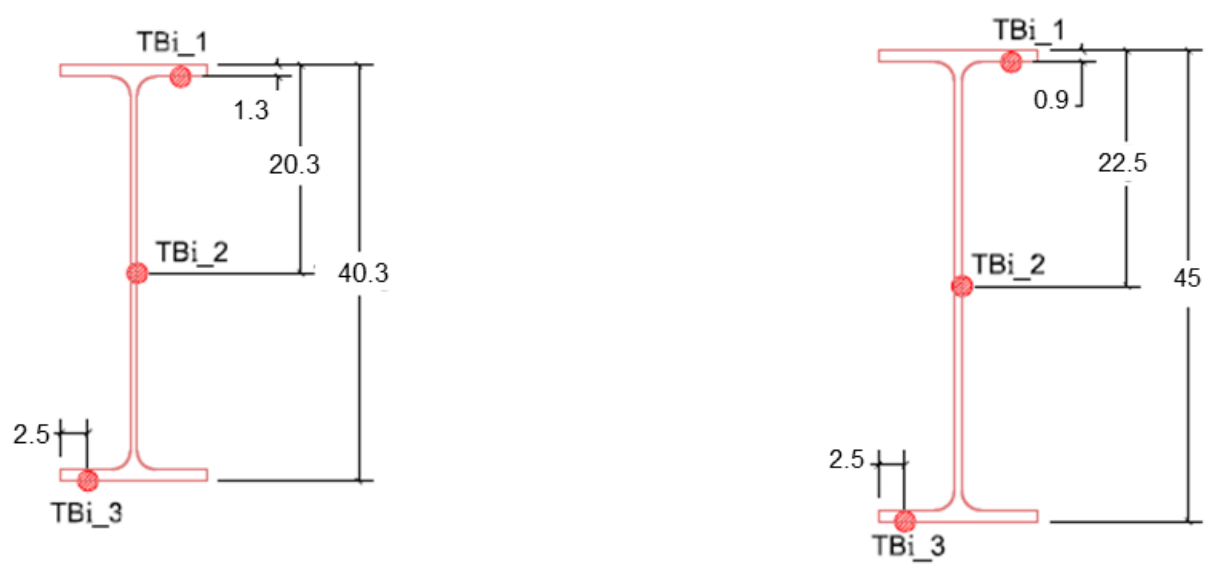

(b) TB1, TB5, TB7, TB10 (W16×31)

(c) TB12, TB17 (W18×35)

Fig. B-15. Locations of (a) steel temperature measurements where the $Z$ datum is located at top of the steel members and thermocouples mounted to (b) W16 $\times 31$ beams (TB1, TB5, TB7, and TB10 sections) and (c) W18×35 girders (TB12 and TB17 sections). $i=$ section number shown in (a). 

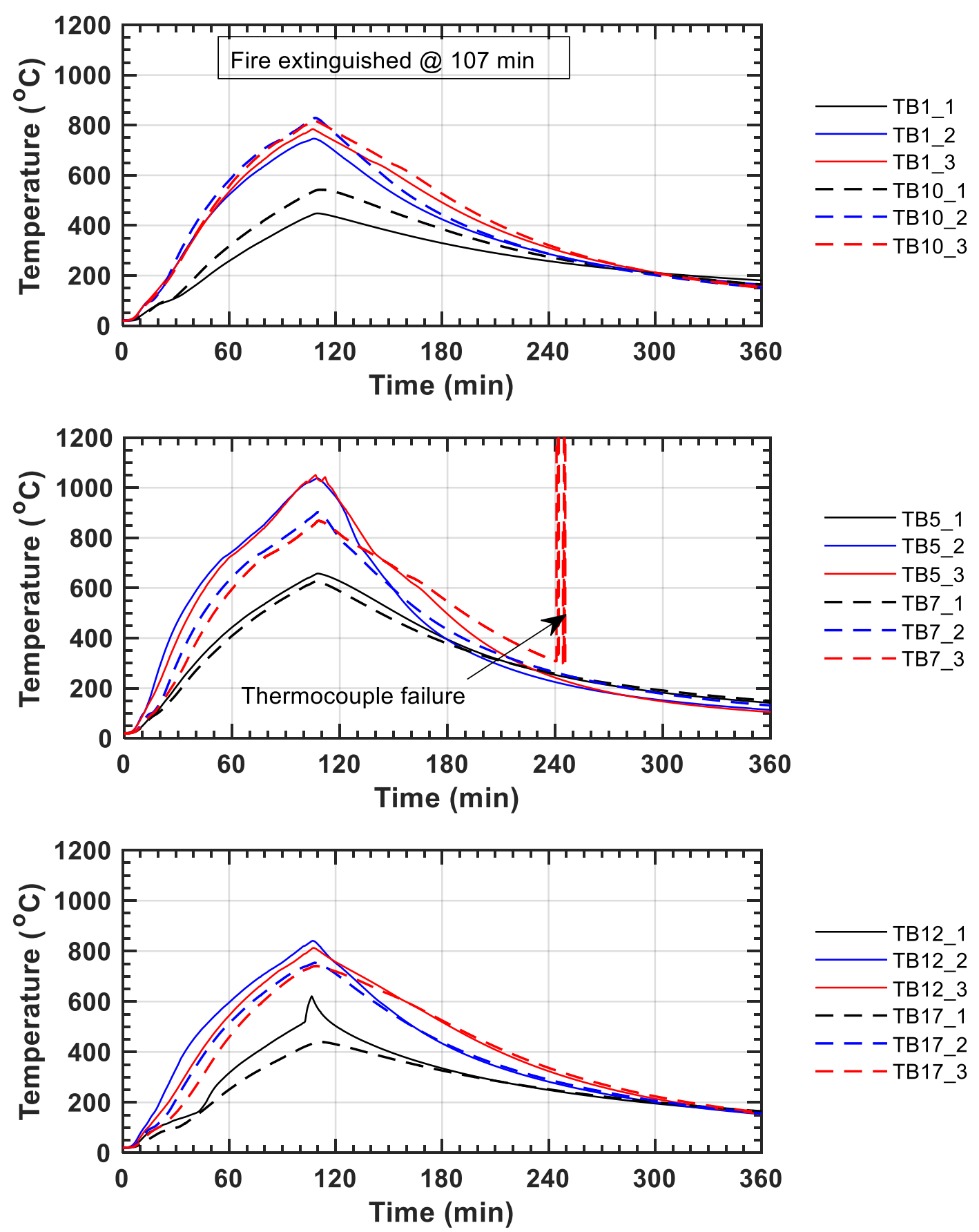

Fig. B-16. Protected steel beam and girder temperatures: W16 $\times 31$ primary beams (sections 1 and 10); W16×31 secondary beam (sections 5 and 7 ) and $W 18 \times 35$ girders (sections 12 and 17). 


\section{B.8. Steel Connection Temperatures}

A total of sixty-one thermocouples were mounted in the beam-end connection regions as shown in Fig. B-17. Thermocouples with $\mathrm{C}$ group were used to measure temperatures of the steel connection elements protected with SFRM; those with SC group were attached to the welded wire reinforcement as well as the steel deck in contact with concrete. Table B-2 shows the corresponding $\mathrm{X}, \mathrm{Y}$, and $\mathrm{Z}$ coordinates of mounted thermocouple beads; the top surface of steel members is defined at $Z=0 \mathrm{~cm}$. Raw temperature data are plotted in Fig. B-18 as a function of the fire exposure time. Note there were several thermocouples failed, including C3_4 at 167 min; C6_5 at $107 \mathrm{~min}$; C9_6 at $23 \mathrm{~min}$ to $127 \mathrm{~min}$. The peak temperature of various parts in the connection region during heating is reported in Table B-3.
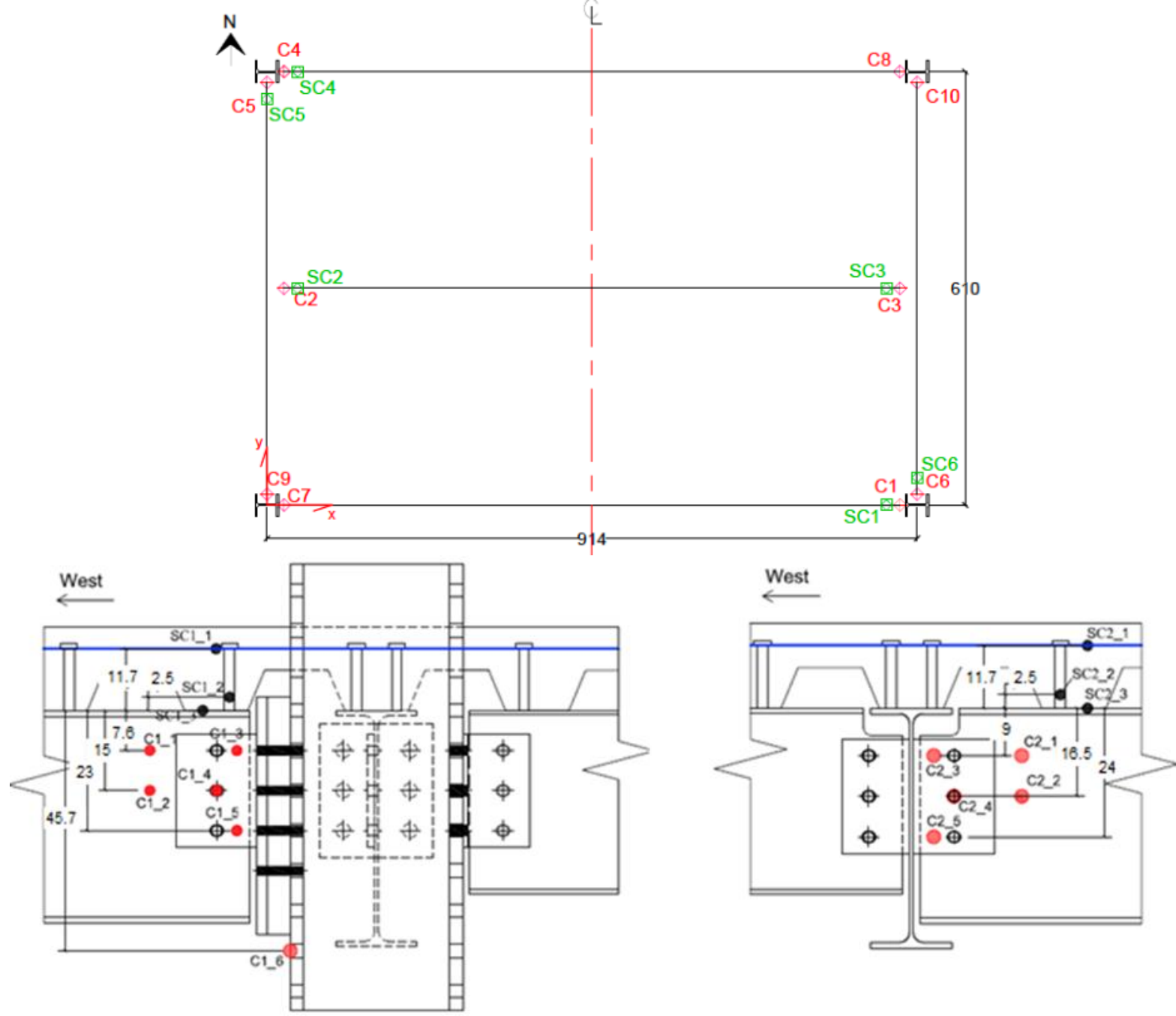

$\mathrm{C} 1 \& \mathrm{SC} 1$

$\mathrm{C} 2 \& \mathrm{SC} 2$ 

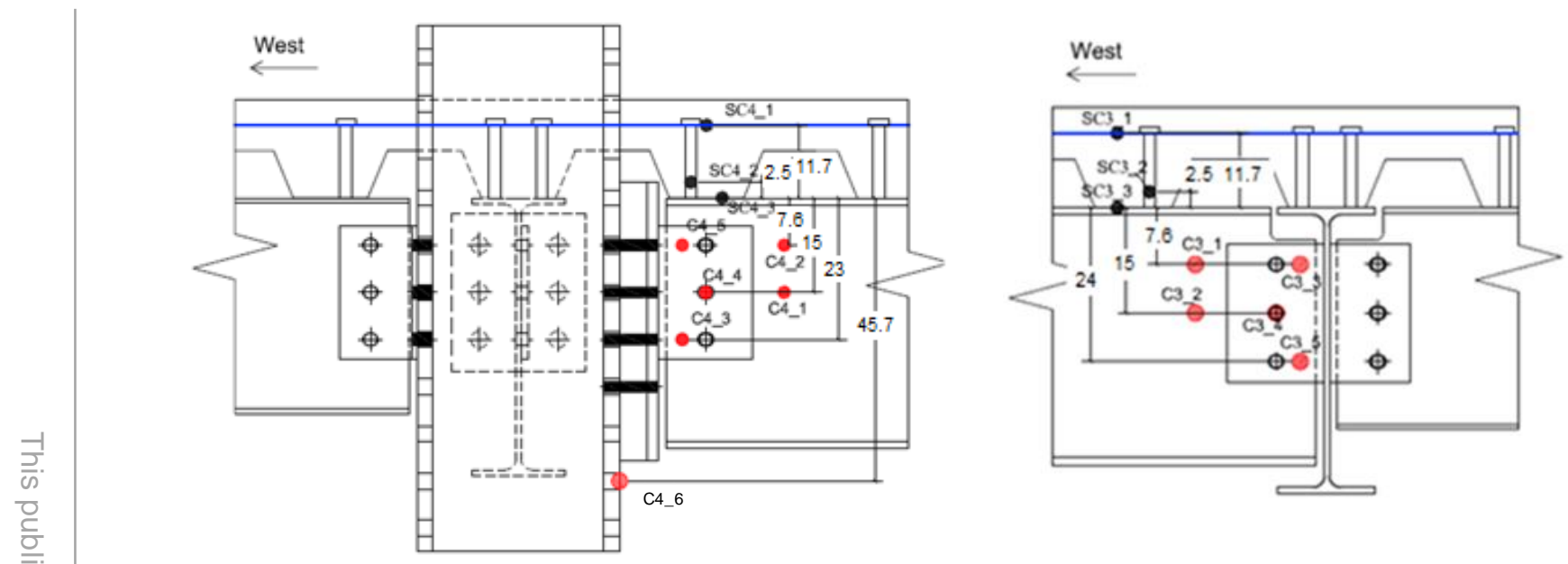

C4 \& SC4

C3 \& SC3

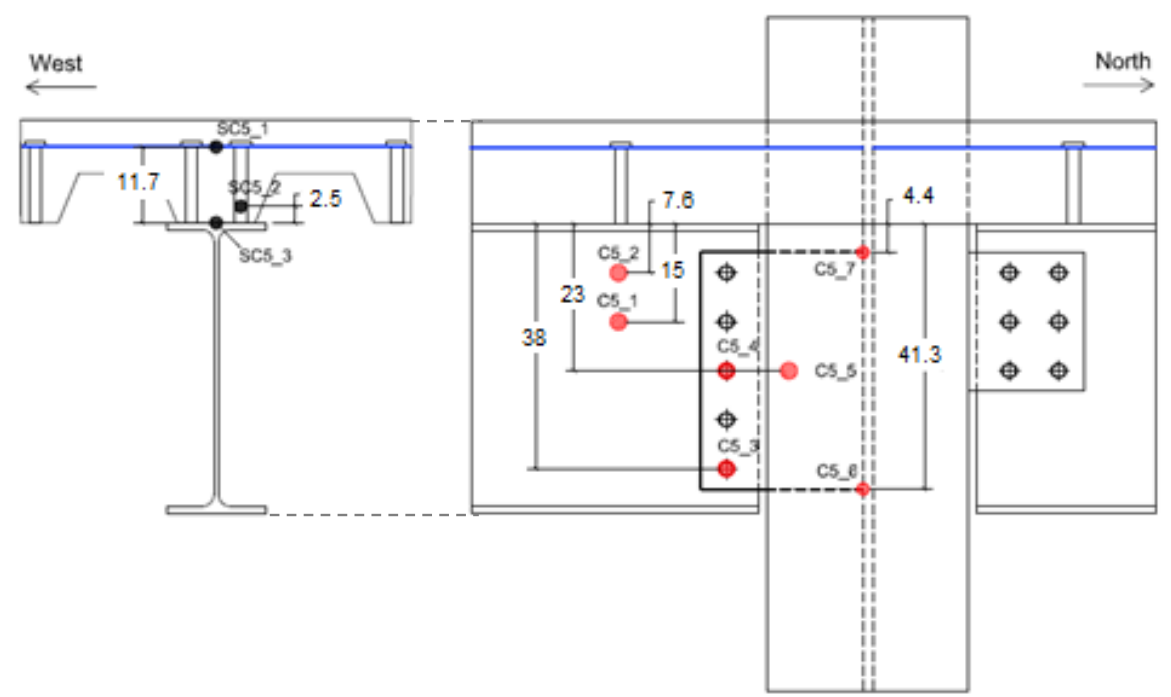

C5 \& SC5

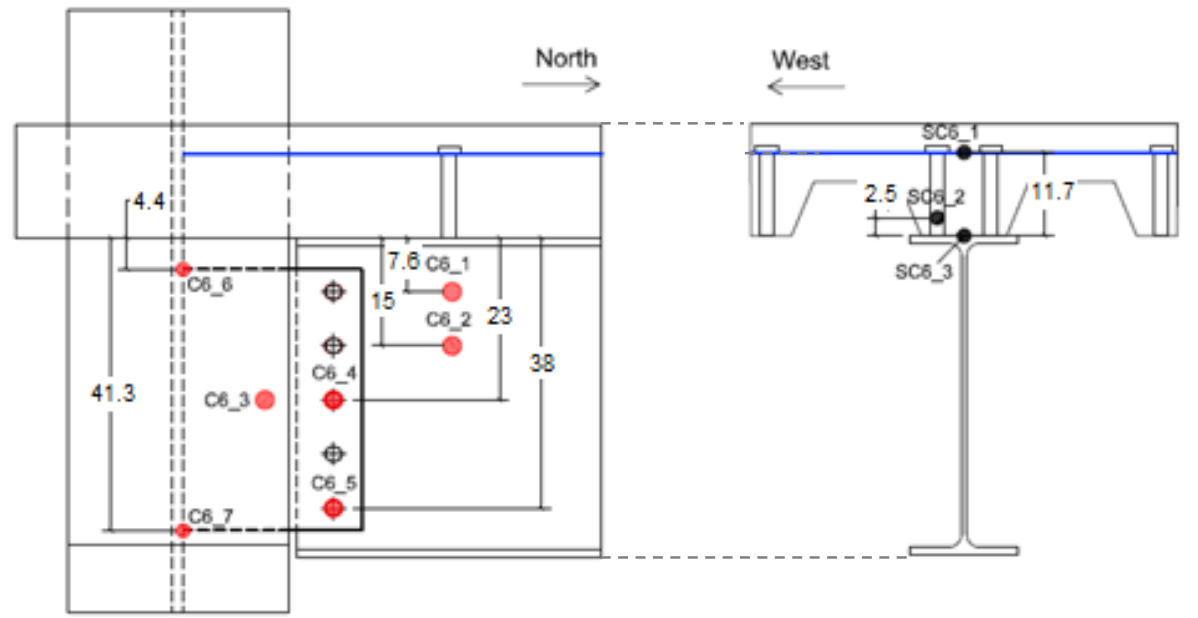

C6 \& SC6 

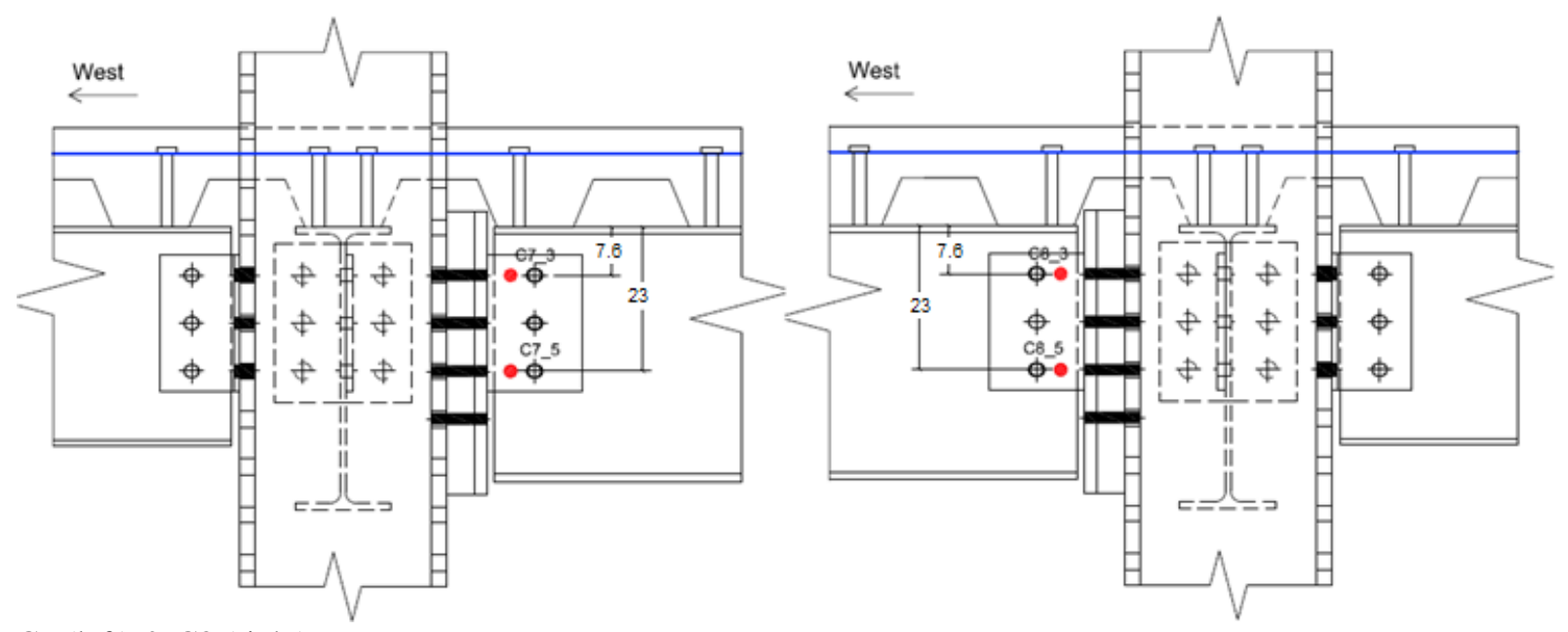

C7 (left) \& C8 (right)
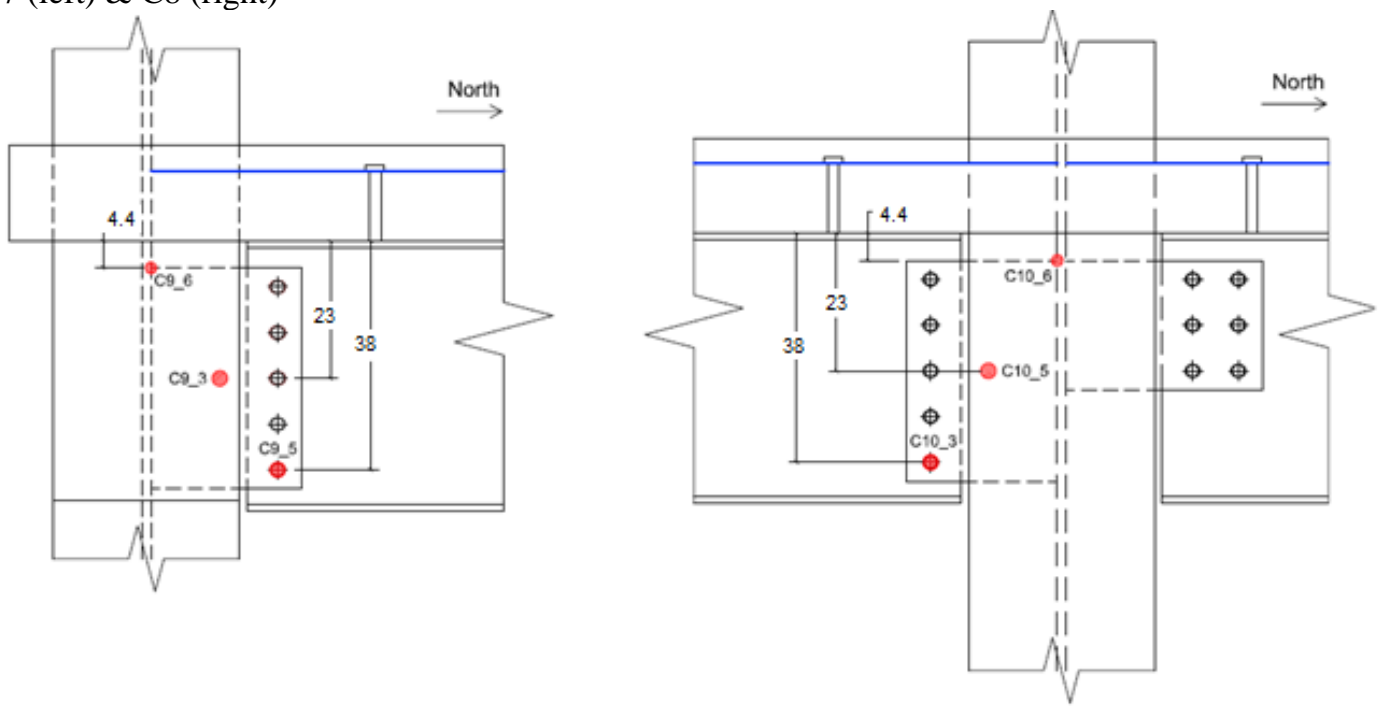

C9 (left) \& C10 (right)

Fig. B-17. Locations of thermocouples mounted at the ends of composite beams and girders in the test bay. 
Table B-2. Coordinates of thermocouples mounted in member connection regions, where the origin of the $x$ and $y$ coordinates is shown in Fig. B-17 and the $z$ datum is located at the top flange of steel members.

\begin{tabular}{|l|r|r|r|}
\hline Name/ID & X East+ & Y North+ & Z Up+ \\
\hline C1_1 & 871 & 0 & -7.6 \\
\hline C1_2 & 871 & 0 & -15 \\
\hline C1_3 & 888 & 1 & -7.6 \\
\hline C1_4 & 884 & 1 & -15 \\
\hline C1_5 & 888 & 1 & -23 \\
\hline C1_6 & 898 & 0 & -45.7 \\
\hline SC1_1 & 884 & 0 & 11.7 \\
\hline SC1_2 & 886 & 0 & 2.5 \\
\hline SC1_3 & 881 & 4 & 0.0 \\
\hline C2_1 & 21 & 304 & -9 \\
\hline C2_2 & 21 & 304 & -16.5 \\
\hline C2_3 & 4 & 304 & -9 \\
\hline C2_4 & 8 & 304 & -16.5 \\
\hline C2_5 & 4 & 304 & -24 \\
\hline SC2_1 & 33 & 602 & 11.7 \\
\hline SC2_2 & 28 & 610 & 2.5 \\
\hline SC2_3 & 33 & 610 & 0.0 \\
\hline C3_1 & 894 & 304 & -9 \\
\hline C3_2 & 894 & 304 & -16.5 \\
\hline C3_3 & 910 & 304 & -9 \\
\hline C3_4 & 906 & 304 & -16.5 \\
\hline C3_5 & 910 & 304 & -24 \\
\hline SC3_1 & 881 & 297 & 11.7 \\
\hline SC3_2 & 886 & 305 & 2.5 \\
\hline SC3_3 & 881 & 309 & 0.0 \\
\hline C4_1 & 43 & 609 & -15 \\
\hline C4_2 & 43 & 609 & -7.6 \\
\hline C4_3 & 27 & 608 & -23 \\
\hline C4_4 & 30 & 608 & -15 \\
\hline C4_5 & 27 & 608 & -7.6 \\
\hline C4_6 & 21 & 610 & -45.7 \\
\hline & & & \\
\hline
\end{tabular}

\begin{tabular}{|l|r|r|r|}
\hline Name/ID & X East+ & Y North+ & Z Up+ \\
\hline SC4_1 & 30 & 610 & 11.7 \\
\hline SC4_2 & 28 & 610 & 2.5 \\
\hline SC4_3 & 33 & 606 & 0.0 \\
\hline C5_1 & 0 & 571 & -15 \\
\hline C5_2 & 0 & 571 & -7.6 \\
\hline C5_3 & 1 & 588 & -38 \\
\hline C5_4 & 1 & 588 & -23 \\
\hline C5_5 & 1 & 597 & -23 \\
\hline C5_6 & 4 & 609 & -41 \\
\hline C5_7 & 4 & 609 & -4.4 \\
\hline SC5_1 & 0 & 572 & 11.7 \\
\hline SC5_2 & 4 & 572 & 2.5 \\
\hline SC5_3 & 0 & 572 & 0.0 \\
\hline C6_1 & 914 & 39 & -7.6 \\
\hline C6_2 & 914 & 39 & -15 \\
\hline C6_3 & 913 & 12 & -23 \\
\hline C6_4 & 913 & 22 & -23 \\
\hline C6_5 & 913 & 22 & -38 \\
\hline C6_6 & 911 & 1 & -4.4 \\
\hline C6_7 & 911 & 1 & -41.3 \\
\hline C7_3 & 27 & 1 & -7.6 \\
\hline C7_5 & 27 & 1 & -23 \\
\hline C8_3 & 888 & 608 & -7.6 \\
\hline C8_5 & 888 & 608 & -23 \\
\hline C9_3 & 1 & 12 & -23 \\
\hline C9_5 & 1 & 22 & -38 \\
\hline C9_6 & 4 & 1 & -4.4 \\
\hline C10_3 & 913 & 597 & -38 \\
\hline C10_5 & 913 & 588 & -23 \\
\hline C10_6 & 911 & 609 & -4.4 \\
\hline & & & \\
\hline
\end{tabular}



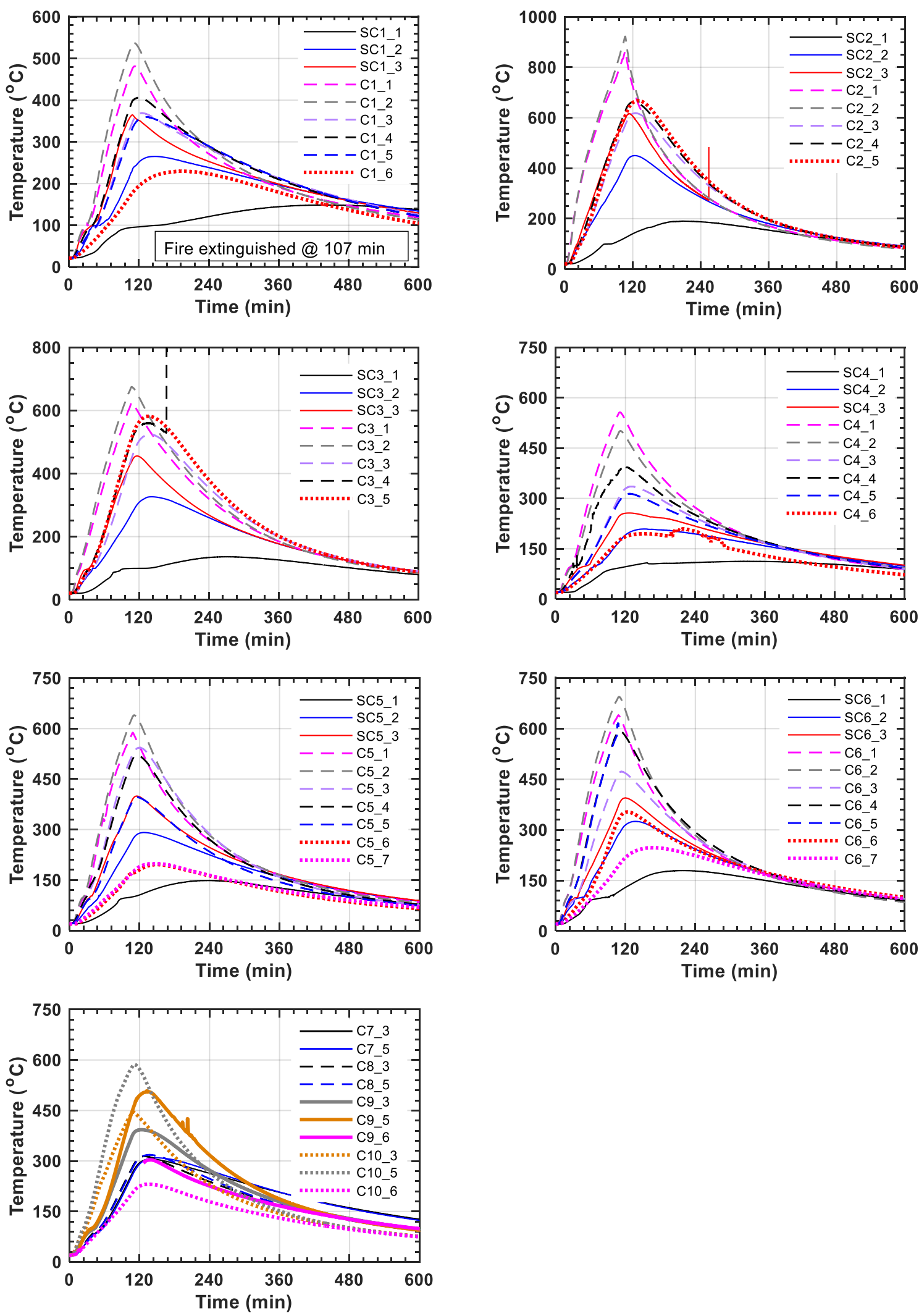

Fig. B-18. Temperatures of the beam-end connection regions. 
Table B-3. List of thermocouples used in steel connection regions and peak values of average temperatures during fire loading. The value after \pm symbol is the standard deviation of temperatures from grouped thermocouples.

\begin{tabular}{|c|c|c|c|}
\hline Member & Connection & Data channel (thermocouple) & Max. temperature $\left({ }^{\circ} \mathbf{C}\right)$ \\
\hline \multirow{6}{*}{$\begin{array}{l}\text { Secondary beam } \\
(\mathrm{W} 16 \times 31)\end{array}$} & Web & C2_1, C2_2, C3_1, C3_2 & $770 \pm 140$ \\
\hline & Shear tab & $\mathrm{C} 2 \_3, \mathrm{C} 2 \_5, \mathrm{C} 3 \_3, \mathrm{C} 3 \_5$ & $530 \pm 70$ \\
\hline & Bolt head & C2_4, C3_4 & $560 \pm 40$ \\
\hline & WWR & SC2_1, SC3_1 & $110 \pm 10$ \\
\hline & Stud & SC2_2, SC3_2 & $340 \pm 40$ \\
\hline & Steel deck & $\mathrm{SC} 2 \_3, \mathrm{SC} 3 \_3$ & $520 \pm 50$ \\
\hline \multirow{6}{*}{$\begin{array}{l}\text { South edge beam } \\
(\mathrm{W} 16 \times 31)\end{array}$} & Web & $\mathrm{C} 1 \_1, \mathrm{C} 1 \_2$ & $500 \pm 20$ \\
\hline & Shear tab & C1_3, C1_5, C7_3, C7_5 & $290 \pm 40$ \\
\hline & Bolt head & $\mathrm{C} 1 \_4$ & 390 \\
\hline & WWR & $\mathrm{SC} 1 \_1$ & 90 \\
\hline & Stud & $\mathrm{SC} 1 \_2$ & 230 \\
\hline & Steel deck & $\mathrm{SC} 1 \_3$ & 360 \\
\hline \multirow{6}{*}{$\begin{array}{l}\text { North edge beam } \\
(\mathrm{W} 16 \times 31)\end{array}$} & Web & C4_1, C4_2 & $520 \pm 20$ \\
\hline & Shear tab & C4_3,C4_5, C8_3, C8_5 & $280 \pm 10$ \\
\hline & Bolt head & C4_4 & 370 \\
\hline & WWR & SC4_1 & 90 \\
\hline & Stud & SC4_2 & 170 \\
\hline & Steel deck & SC4_3 & 240 \\
\hline \multirow{7}{*}{$\begin{array}{l}\text { West girder } \\
(\mathrm{W} 18 \times 35)\end{array}$} & Web & C5_1, C5_2 & $610 \pm 10$ \\
\hline & Shear tab & C5_5, C9_3 & $380 \pm 10$ \\
\hline & Bolt head & C5_3, C5_4, C9_5 & $490 \pm 40$ \\
\hline & Weld & C5_6, C5_7, C9_6 & $170 \pm 10$ \\
\hline & WWR & SC5_1 & 100 \\
\hline & Stud & SC5_2 & 270 \\
\hline & Steel deck & SC5_3 & 390 \\
\hline \multirow{7}{*}{$\begin{array}{l}\text { East girder } \\
(\mathrm{W} 18 \times 35)\end{array}$} & Web & C6_1, C6_2 & $660 \pm 40$ \\
\hline & Shear tab & C6_3, C10_5 & $520 \pm 80$ \\
\hline & Bolt head & C6_5*,C6_4, C10_3 & $550 \pm 90$ \\
\hline & Weld & C6_6, C6_7, C10_6 & $240 \pm 70$ \\
\hline & WWR & SC6_1 & 110 \\
\hline & Stud & SC6_2 & 280 \\
\hline & Steel deck & SC6_3 & 370 \\
\hline
\end{tabular}

*Thermocouple C6_5 failed at 107 min. 


\section{B.9. Displacements}

Fig. B-19 shows the displacement data not presented in Sect. 5.3. Refer to Sect. 5.3 for details of the displacement measurement. The positive sign on the y axes indicates the vertical displacement toward the strong floor or the horizontal displacement of the test building at various locations pulling away from the fire test bay.
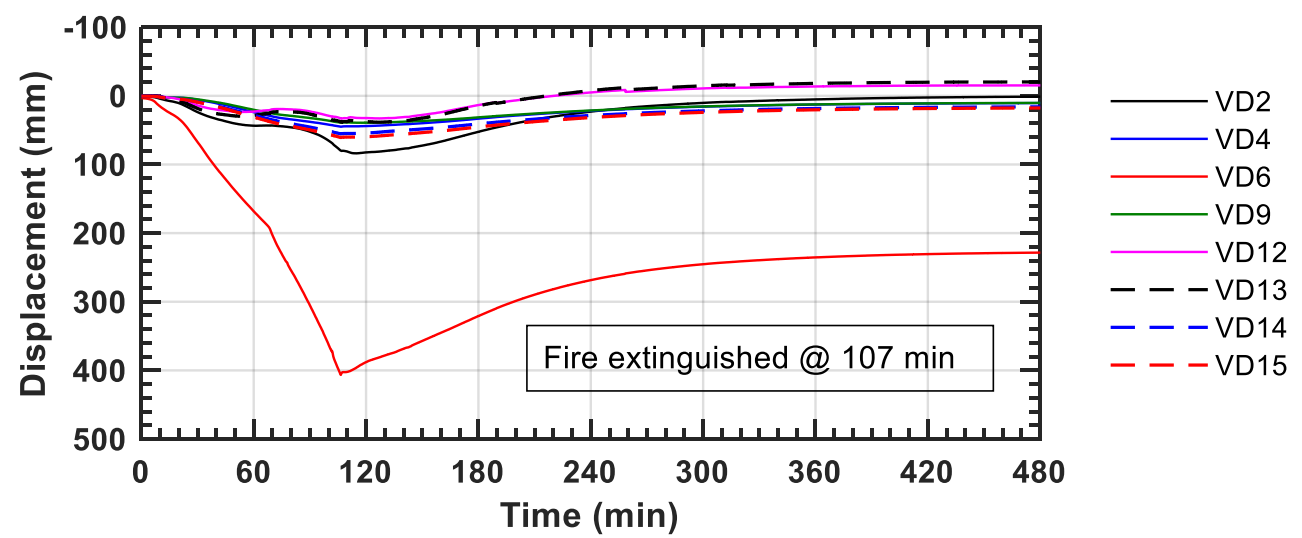

(a)
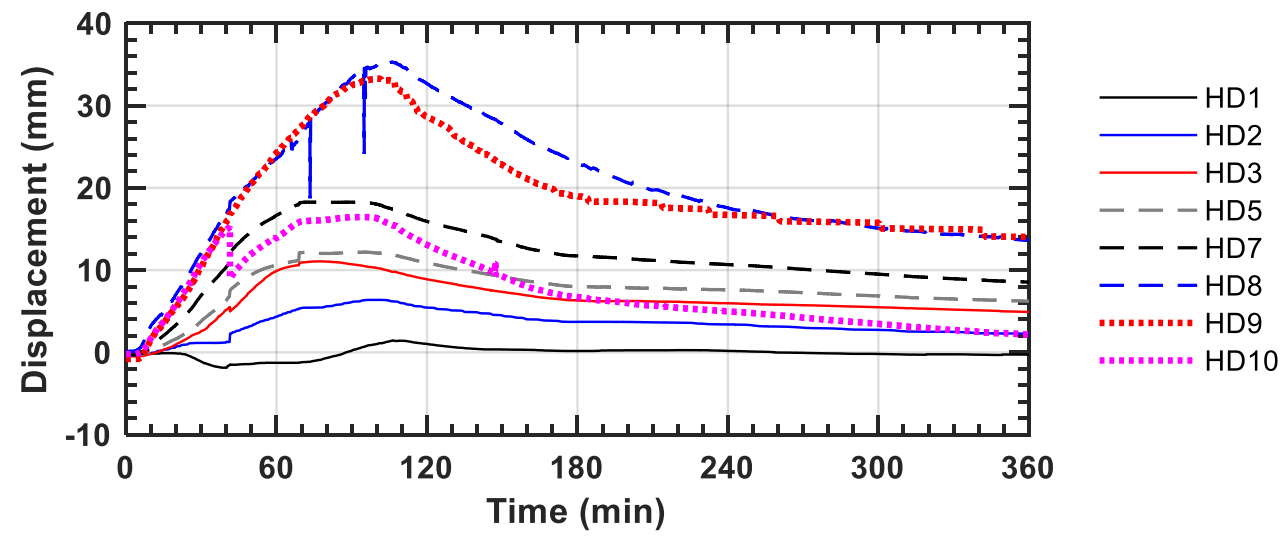

(b)
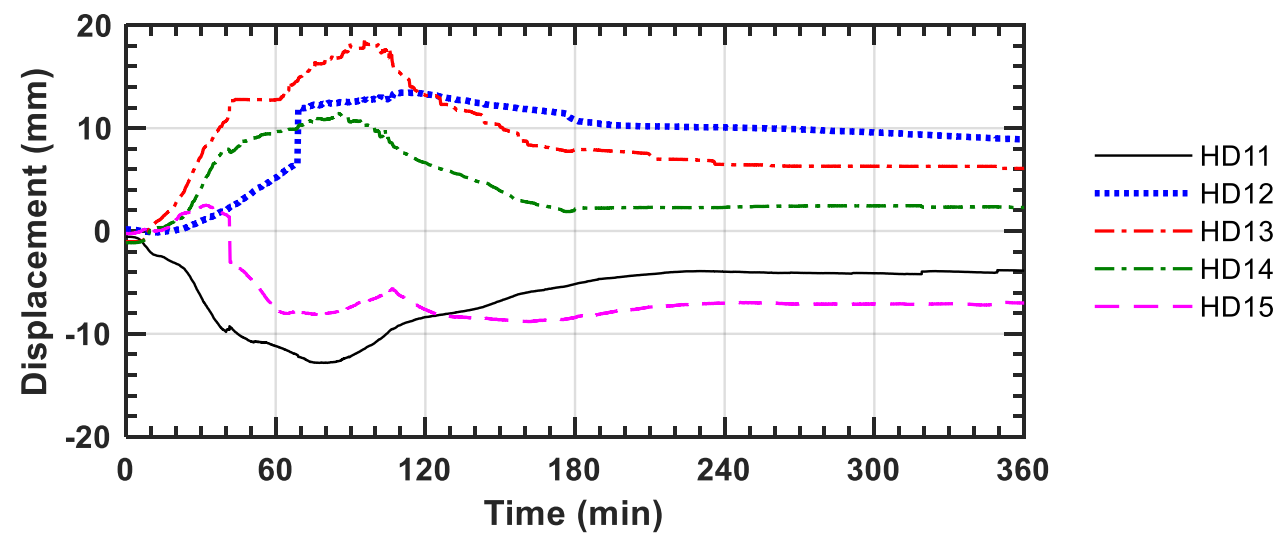

(c)

Fig. B-19. (a) Vertical displacement, (b) horizontal displacement measured at the first story level, and (c) horizontal displacement measured at the second story level. 


\section{B.10. Strains of the Surrounding Structures}

Strain gauges were mounted on the south edge and secondary beams in the west bay as well as near base of the columns not directly exposed to a test fire, as shown in Fig. B-20. The column strains were measured at $5 \mathrm{~cm}$ from the top surface of the $5 \mathrm{~cm}$ thick column base plates anchored to the strong floor; CW and SW strains (W14×22 shapes at midspan) were measured at the test floor level.

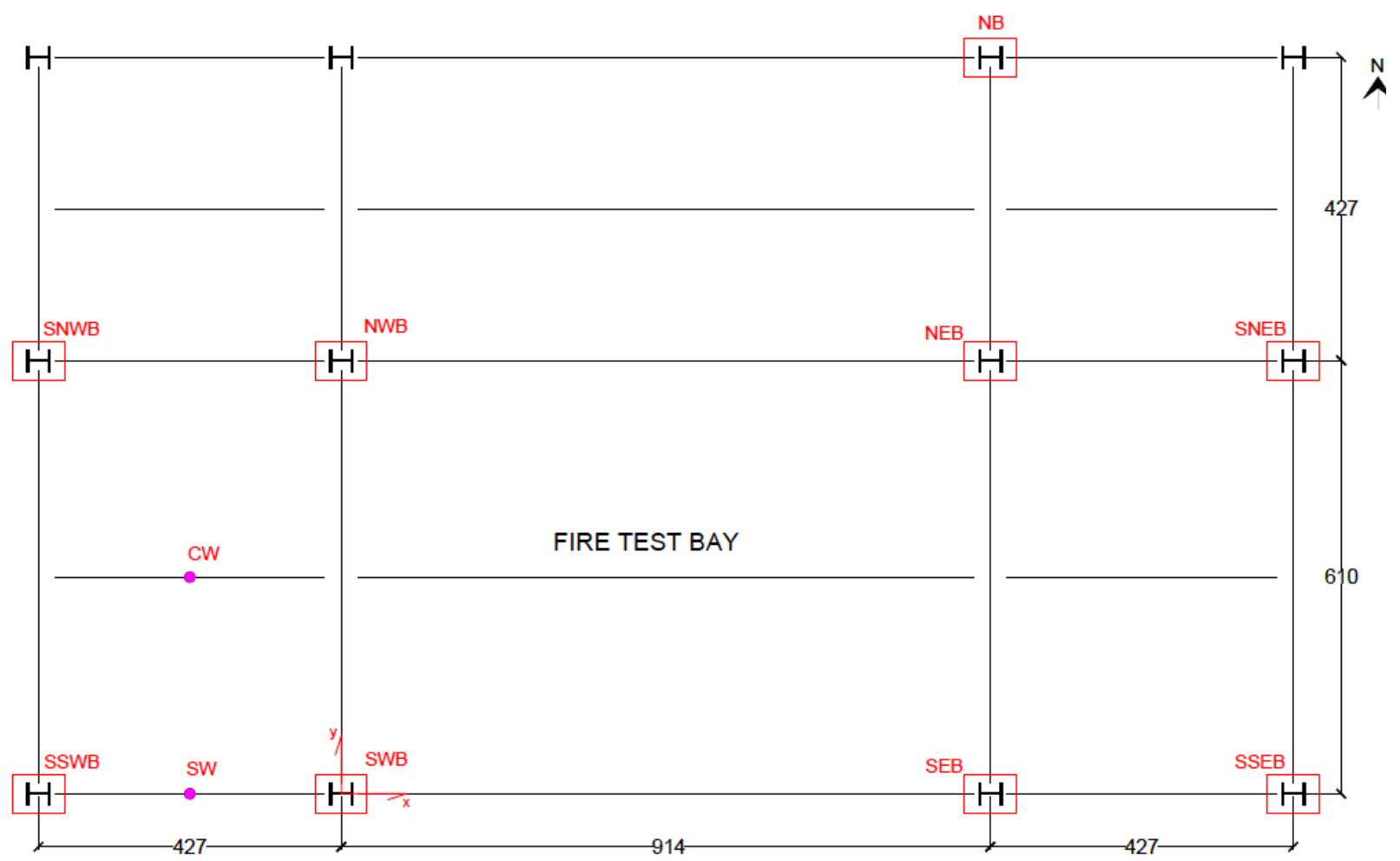

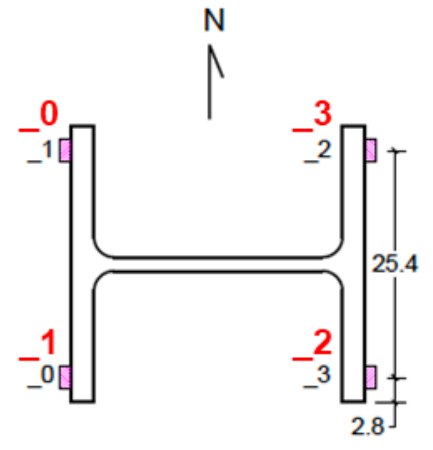

NWB, SWB, NEB,SEB, SSWB, SSEB (W12×106)

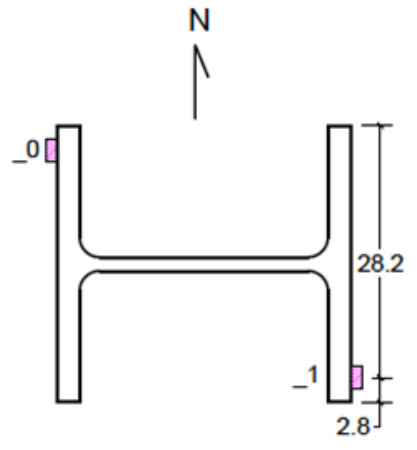

SNWB, SNEB, NB (W12x106)

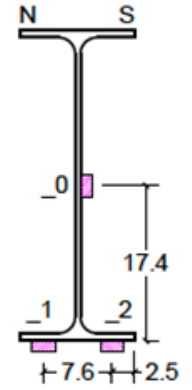

$\mathrm{CW}, \mathrm{SW}$ (W14×22)

Fig. B-20. Locations of strain measurement. Note that strain gauges of SSWB and SSEB sections are lettered in red. 
The column strains at a variety of locations are plotted in Fig. B-21. As shown, the columns were subjected to variable bi-directional bending moments in response to thermal expansion or contraction of the test floor assembly. Based on the magnitude of strains, the northeast and northwest columns of the fire test bay were subjected to thermally induced lateral forces relatively smaller than those applied to the southeast and southwest columns. The interior columns were framing into more steel members in the surrounding bays and restrained by the concrete all around, enabling more effective force distribution to the surrounding structures. However, this restrained condition also caused local buckling of the connected (north) beam in the test bay, which appeared to happen around $60 \mathrm{~min}$, at peak strains of NWB and NEB.

The south exterior columns mostly pushed toward the south as the test-bay girders elongated in the same direction during heating. As reported in Sect. 4.6, no apparent local buckling was identified in these girders. Three bolts in the extended shear tab connection to the southeast column might have partially ruptured when some strains in SWB and SEB reached their peak values around $100 \mathrm{~min}$.

The strains in the west-bay beams at midspan are shown in Fig. B-22. In the west-bay secondary beam, compressive forces increased until $60 \mathrm{~min}$ into heating and then began to decrease. No permanent deformation of this beam, including local buckling, was identified during post-test inspections. It can be seen that this strain reversal was caused by local buckling at the ends of the test-bay secondary beam at $60 \mathrm{~min}$. On the other hand, the midspan strains at the south edge beam in the west bay seemed to be more affected by bending of the connected columns, indicating the increase in tensile strains until $40 \mathrm{~min}$ and then reversed afterward. 

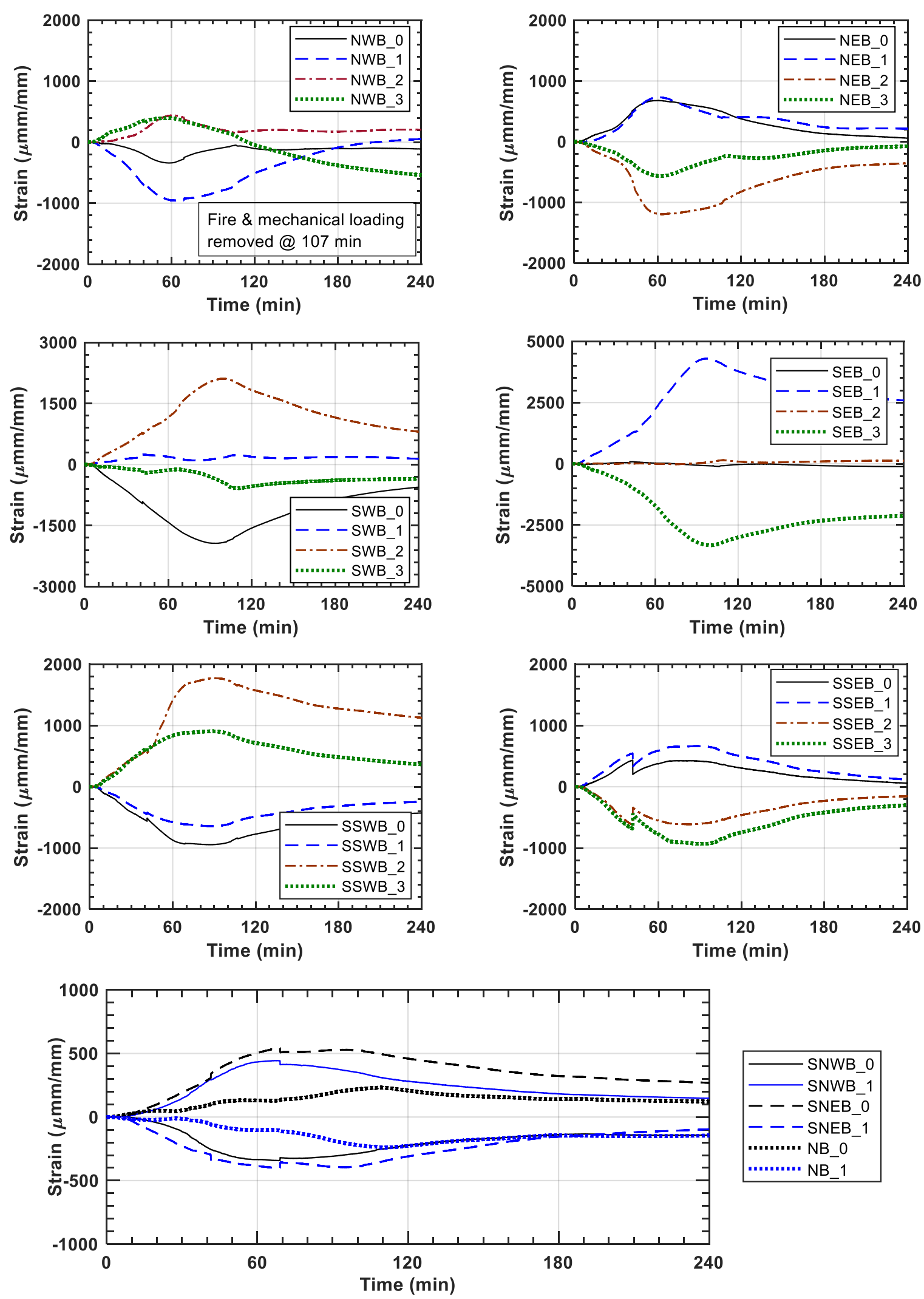

Fig. B-21. Column strain data 


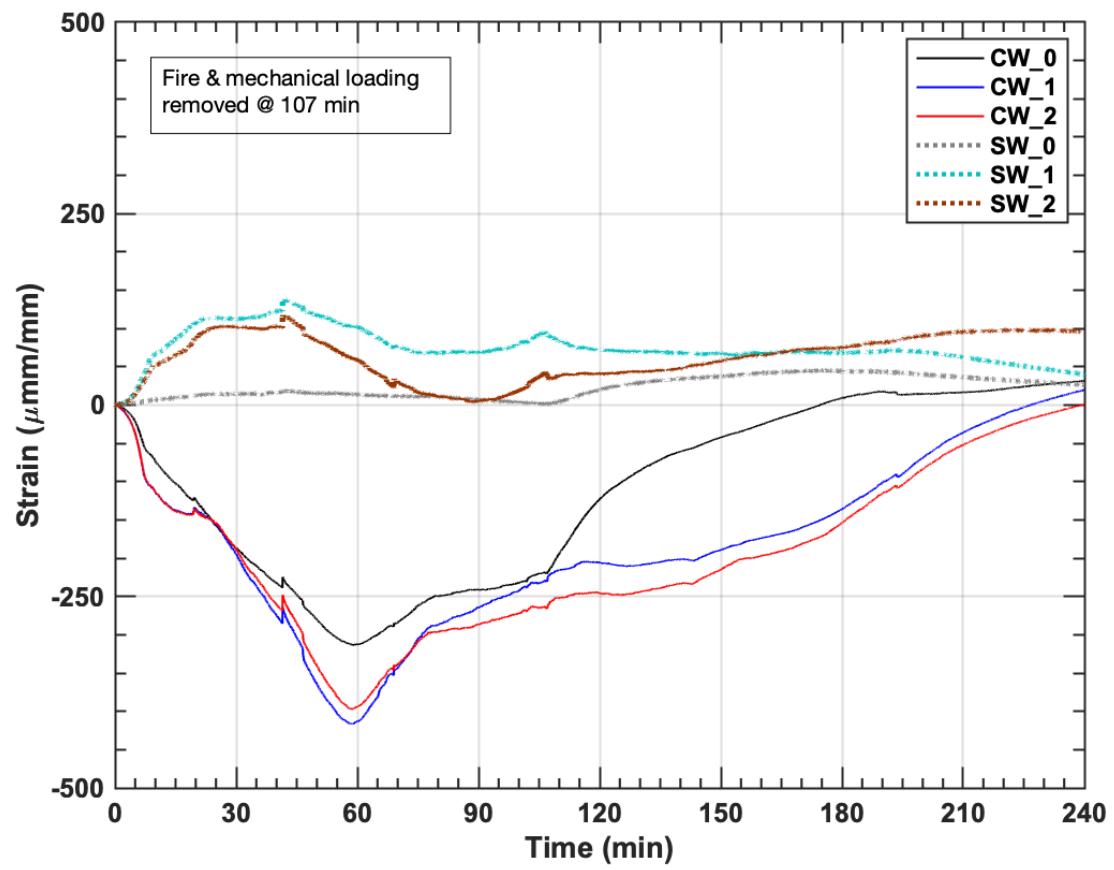

Fig. B-22. Measured strains of the west-bay beams. 


\section{B.11. Additional Post-Test Photographs}
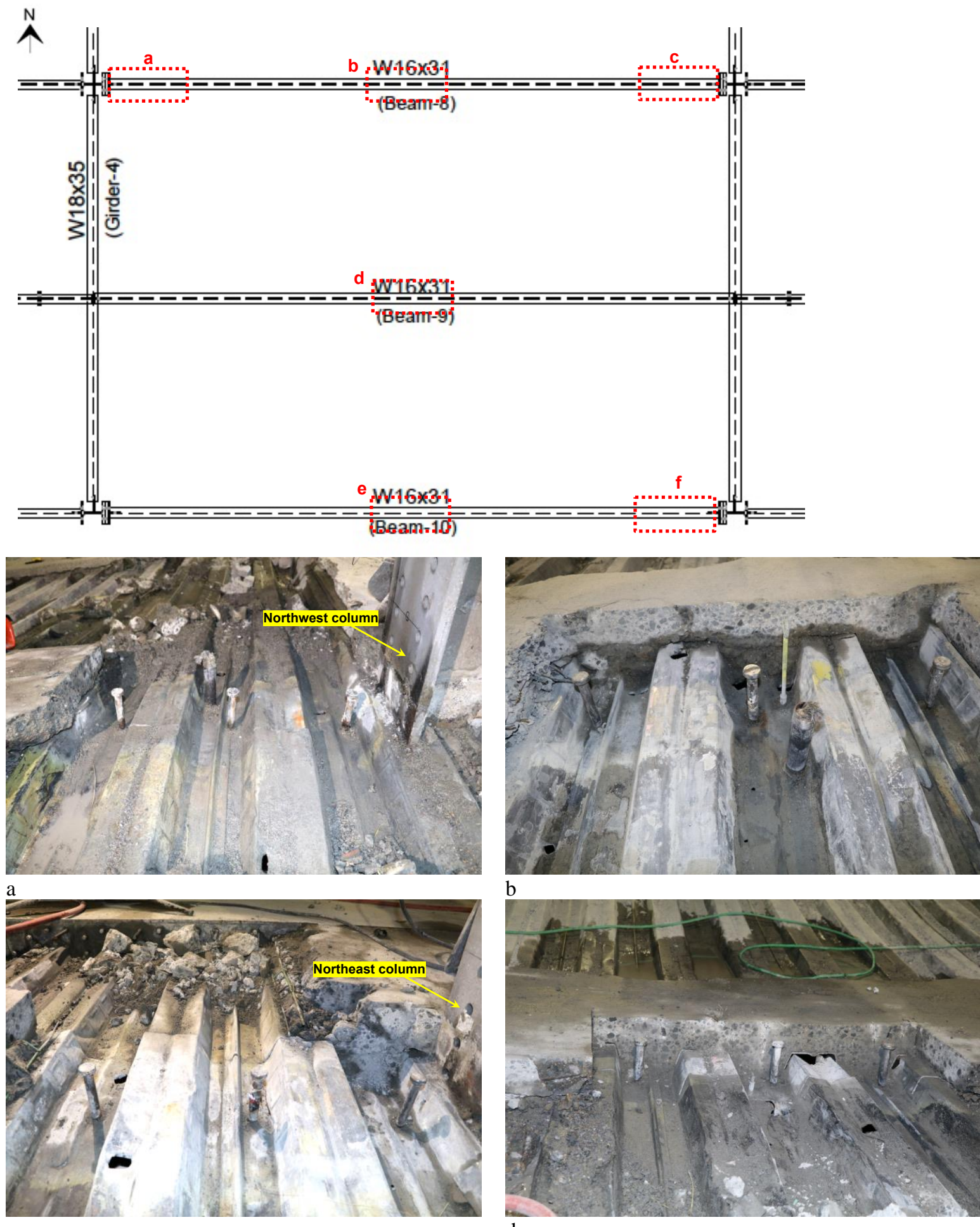

b

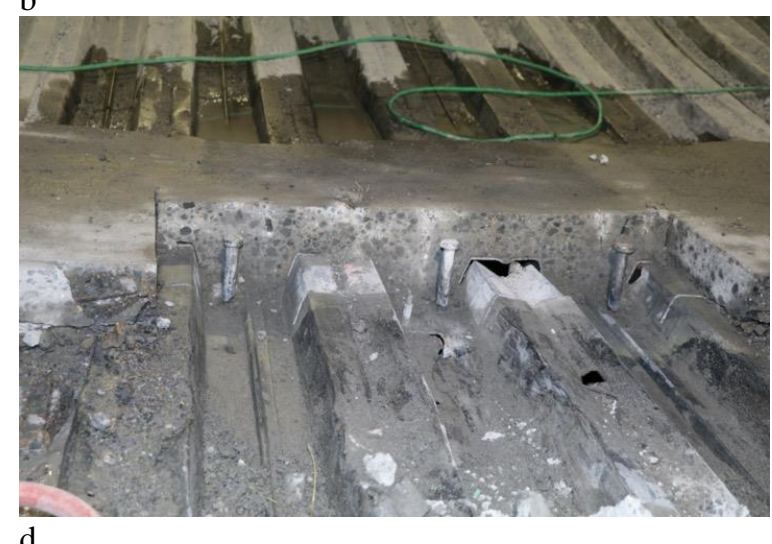




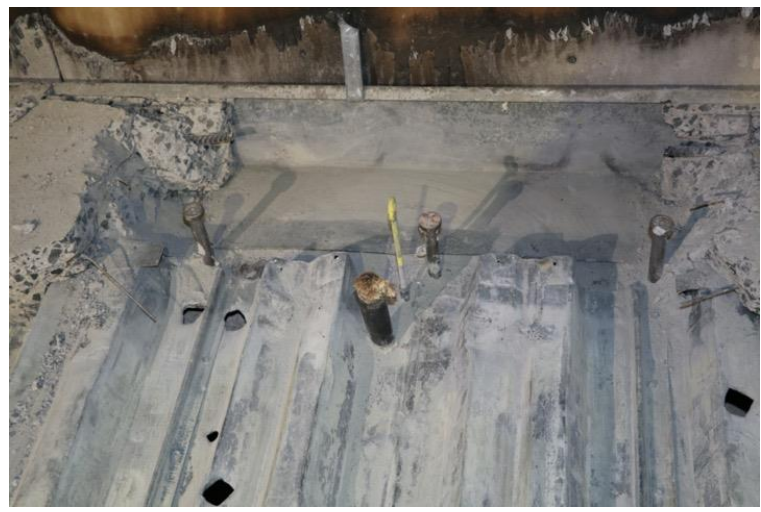

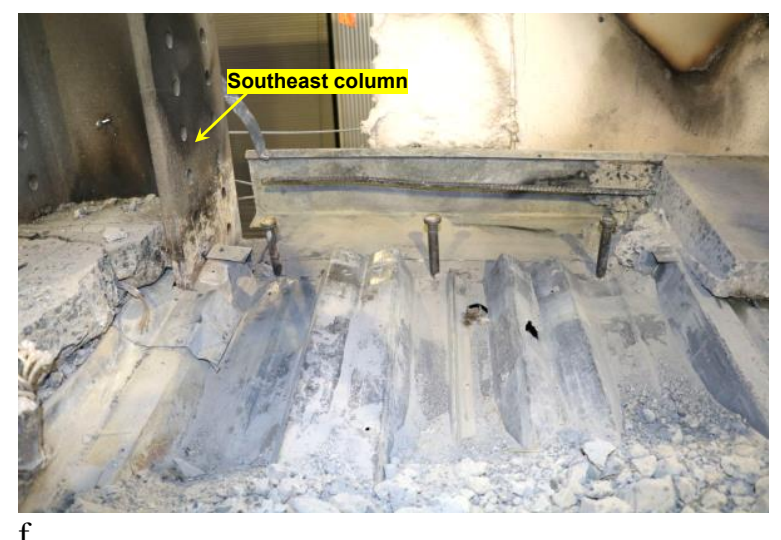

$f$

Fig. B-23. Post-test photographs of headed stud anchors in the test bay.

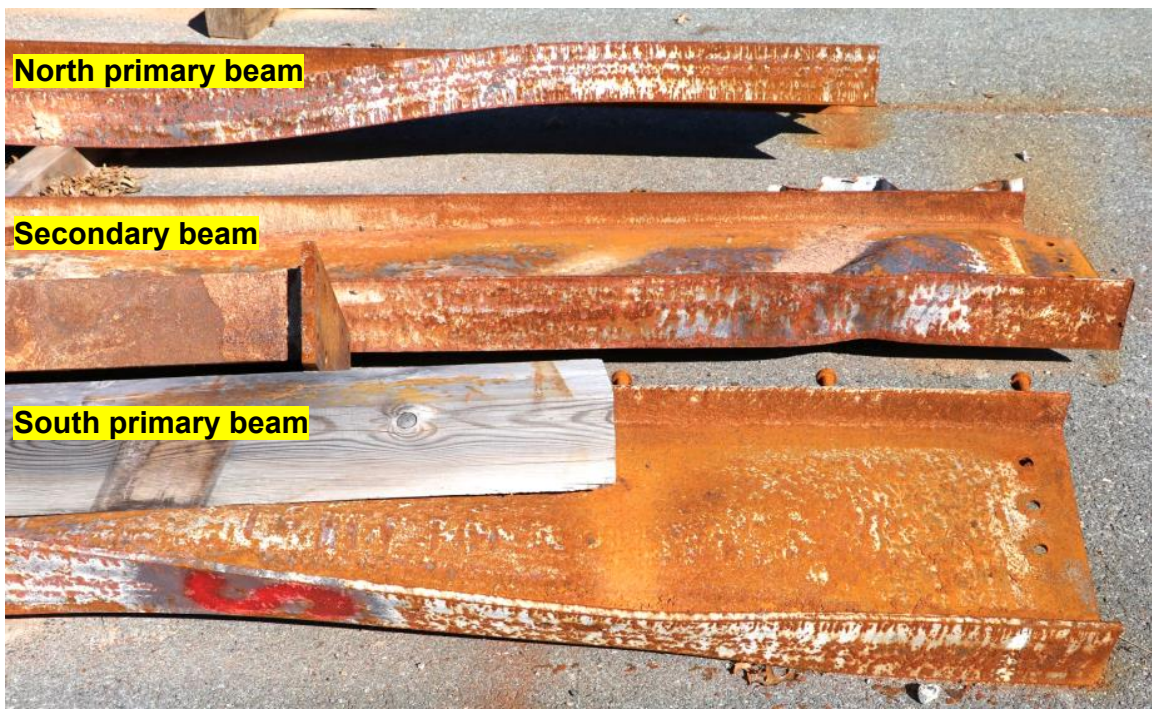

(a)

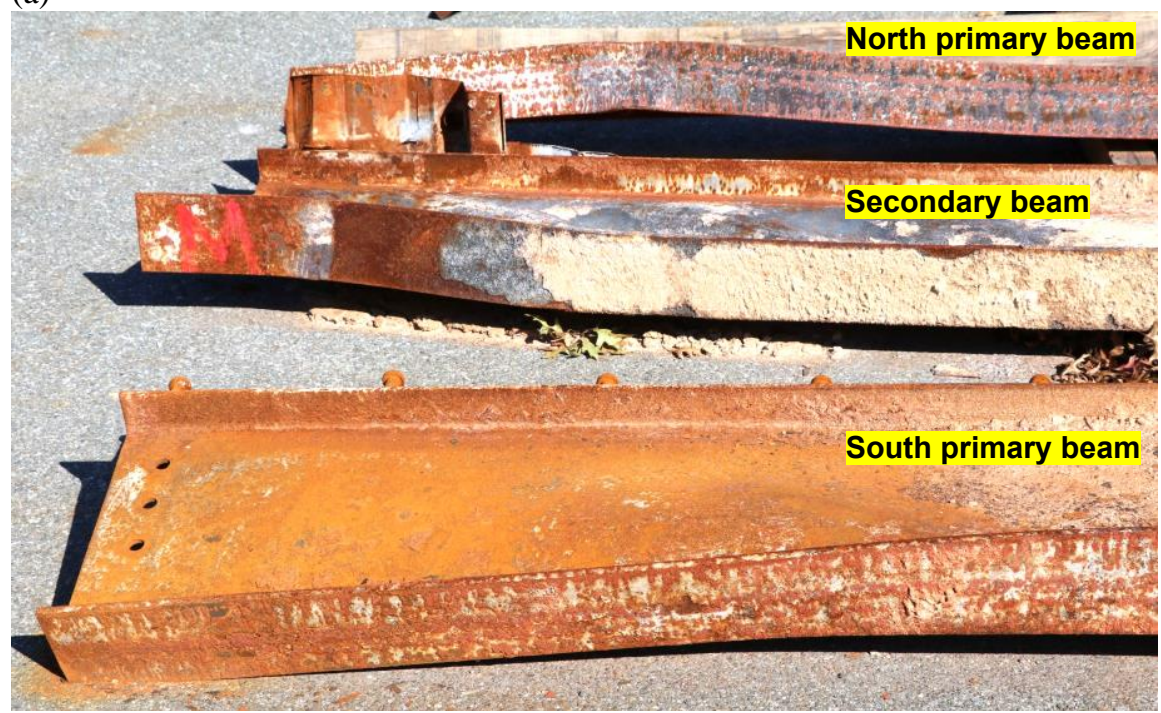

(b)

Fig. B-24. Post-test photographs of W16×31 beams in the test bay; (a) east end and (b) west end. 

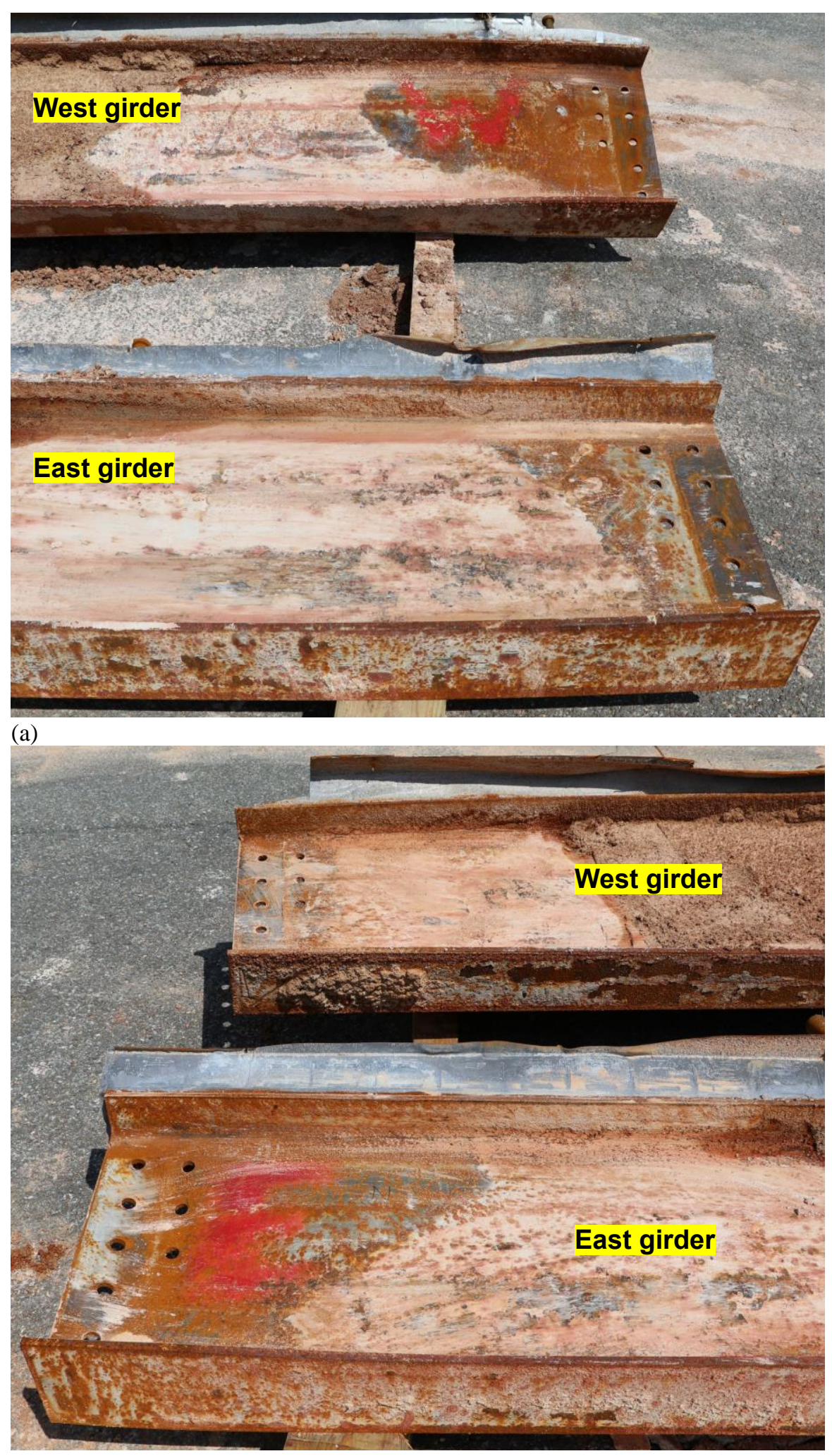

(b)

Fig. B-25. Post-test photographs of W18 $\times 35$ girders in the test bay; (a) north end and (b) south end. 

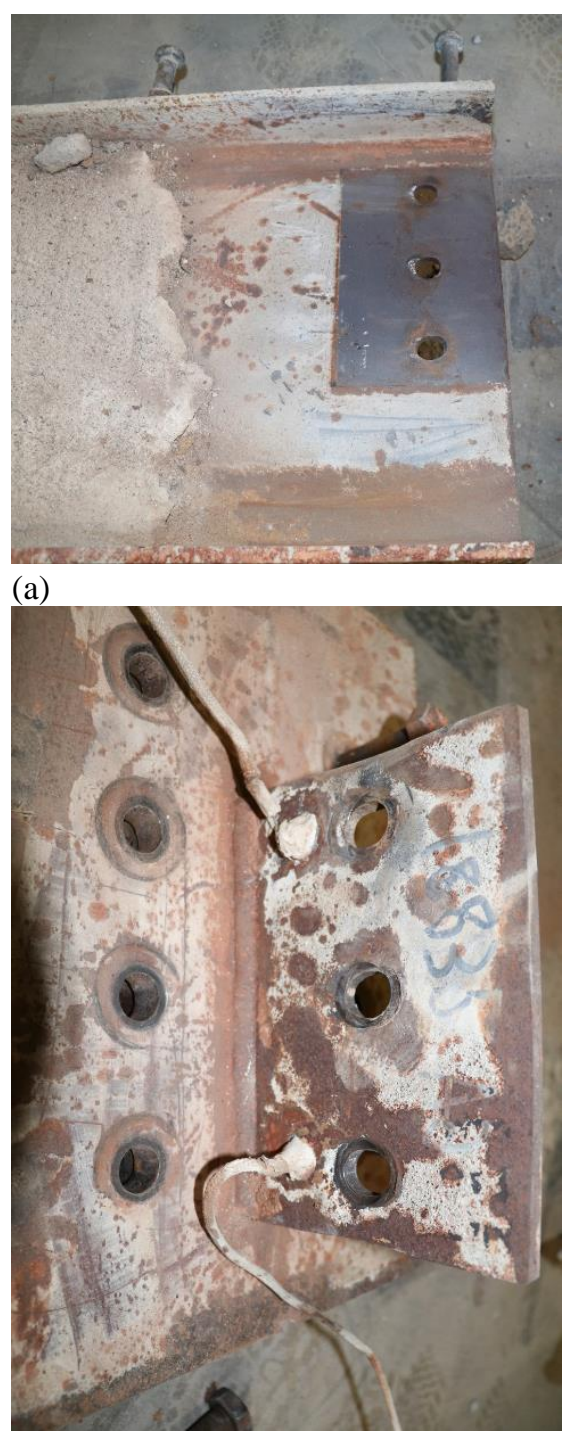

(b)

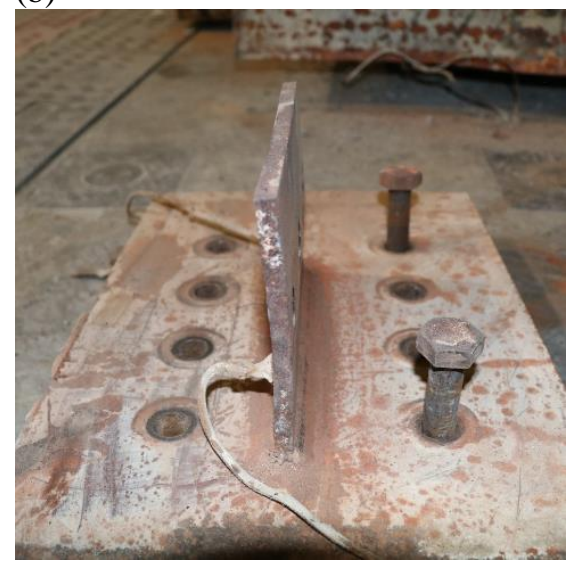

(c)

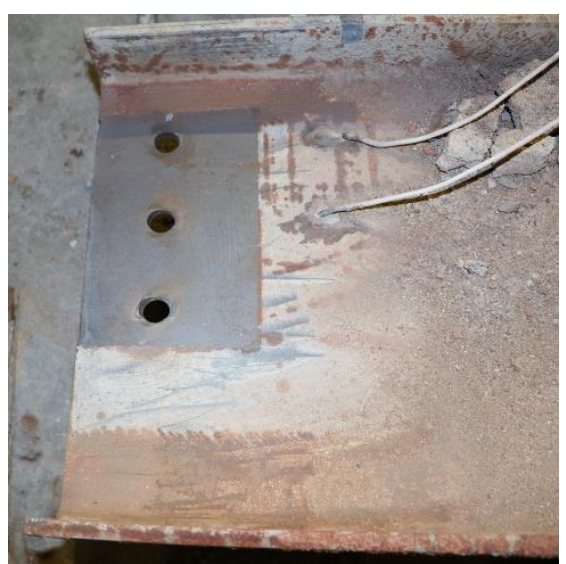

(d)

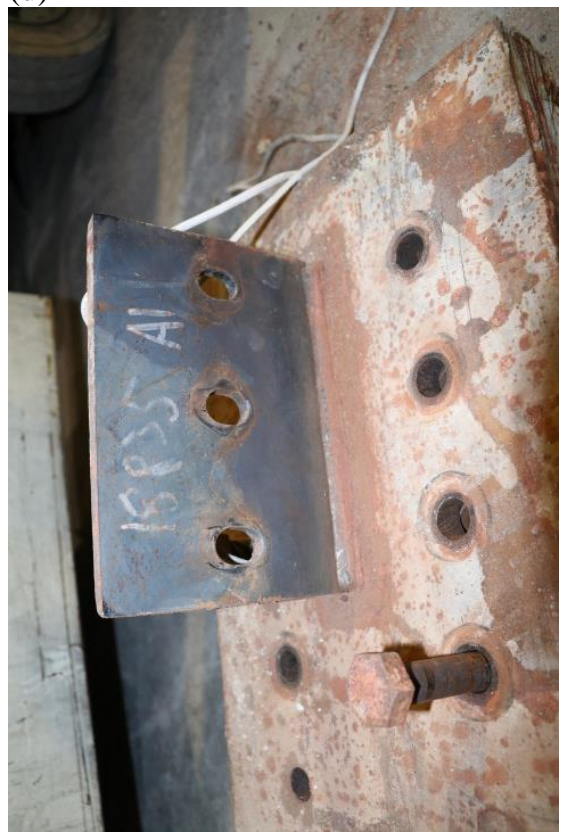

(e)

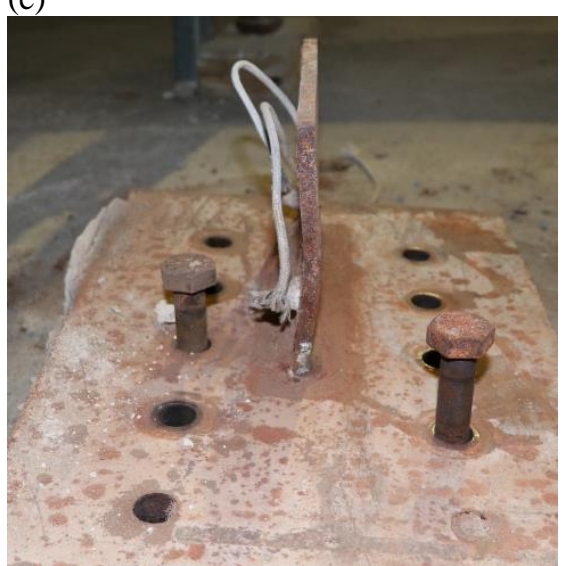

(f)

Fig. B-26. Beam-end connections of north primary beam; (a, b, c) east end and (d, e, f) west end. 


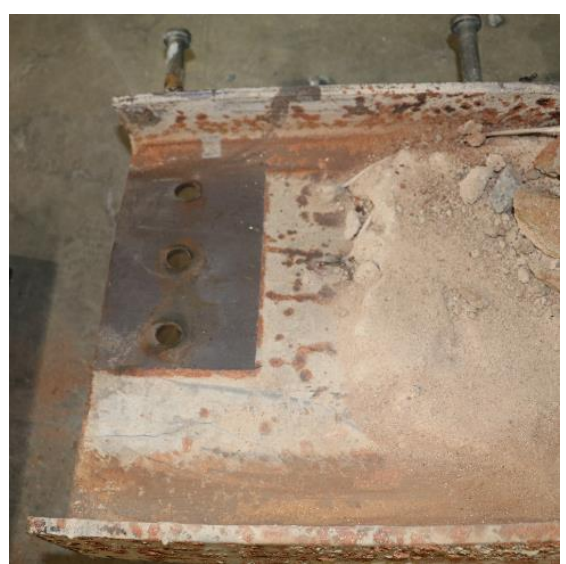

(a)

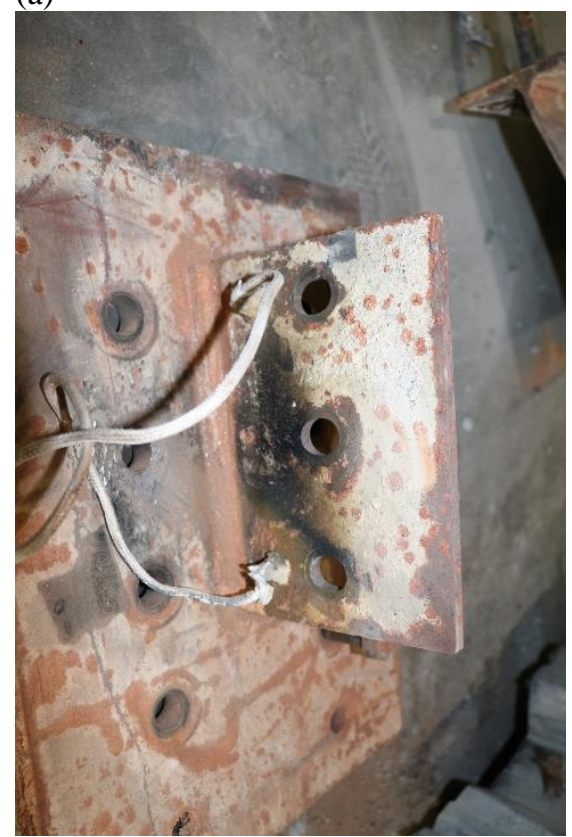

(b)

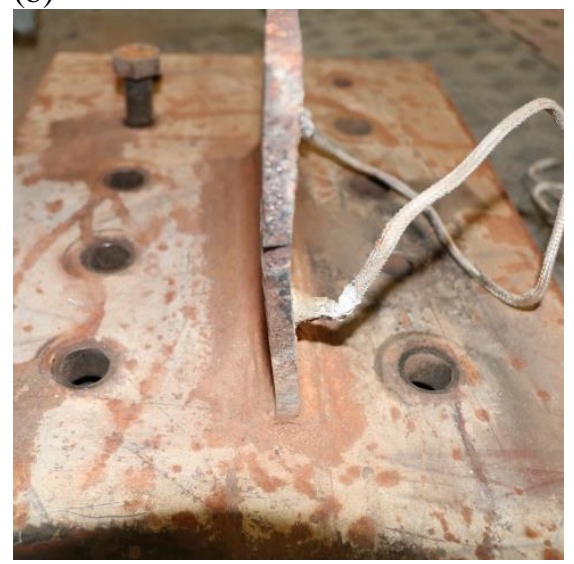

(c)

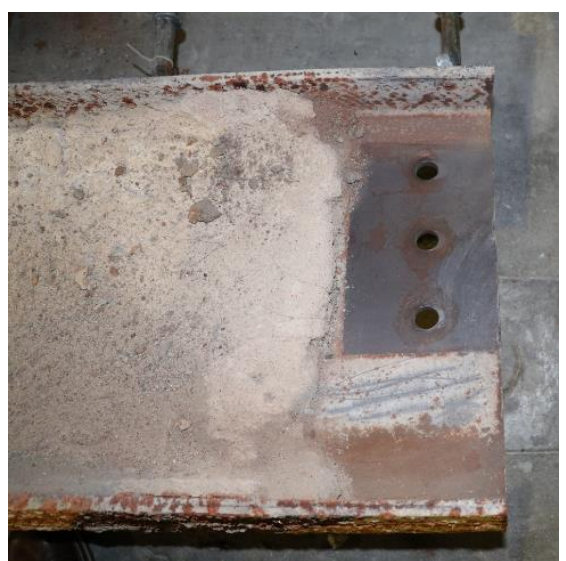

(d)

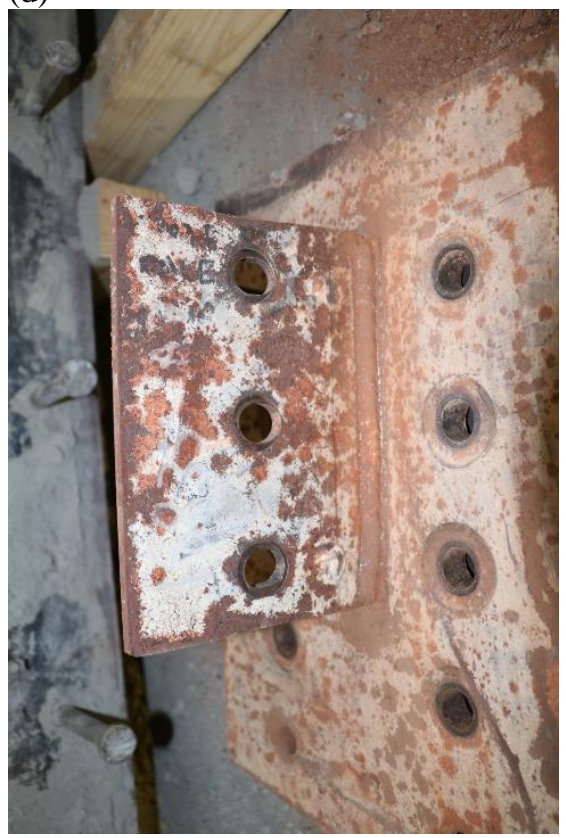

(e)

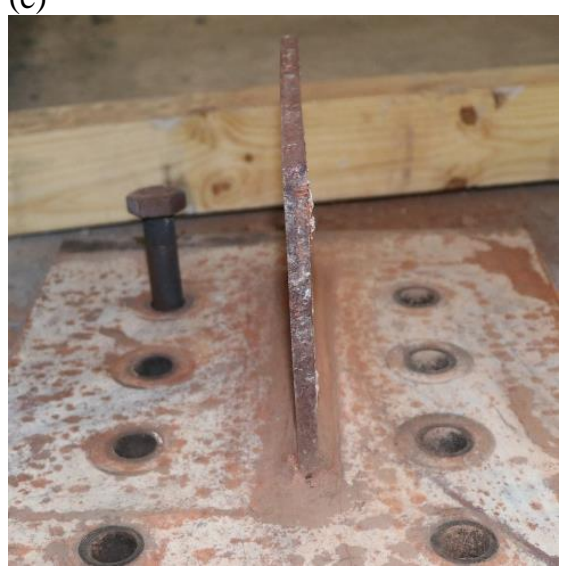

(f)

Fig. B-27. Beam-end connections of south primary beam; (a, b, c) east end and (d, e, f) west end. 


\section{Appendix C Post-Processed Data}

\section{C.1. Heat Flux Calculation}

A total of four $10 \mathrm{~cm}$ by $10 \mathrm{~cm}$ plate thermometers were mounted around the $9.1 \mathrm{~m}$ long beams within the test bay as shown in Fig. C-1.
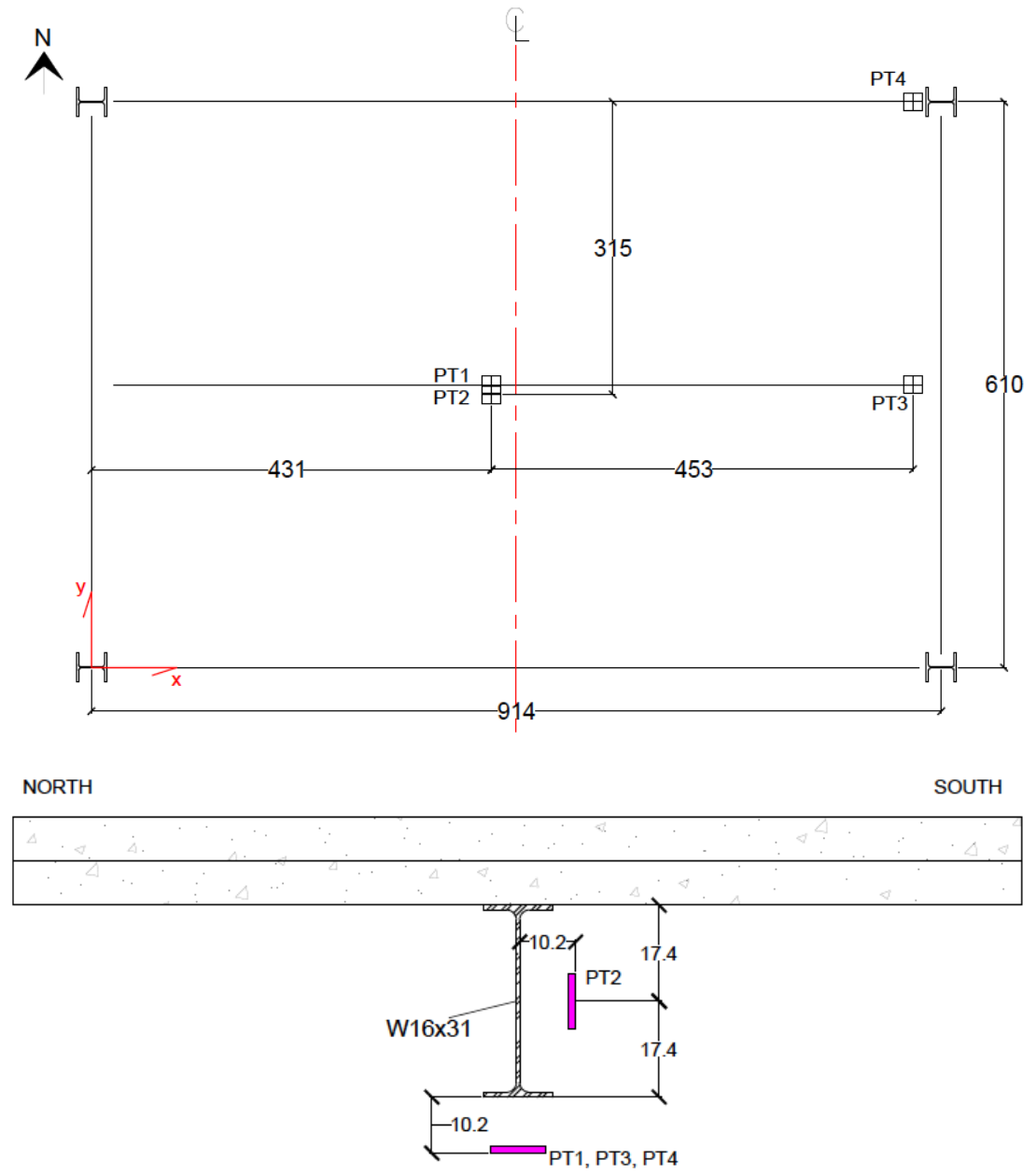

Fig. C-1. Locations of plate thermometers.

The temperature data measured using plate thermometers and bare-bead thermocouples are presented in Fig. C-2, with a 60 s moving average. To calculate the incident radiant heat flux using the plate thermometers, the surrounding gas temperature of each plate thermometer was measured using bare-bead thermocouples (Model GG-K-24). As shown, the peak mean value of the temperature measured using plate thermometers was approximately $1040{ }^{\circ} \mathrm{C}$ and the maximum standard deviation was $68^{\circ} \mathrm{C}$. The gas temperatures measured using bear-bead thermocouples were slightly higher. 
The measured temperature of the plate thermometer $\left(T_{\mathrm{PT}}\right.$, in $\left.\mathrm{K}\right)$ and the gas temperature near the plate thermometer ( $T_{\text {gas }}$, in $\mathrm{K}$ ) are used to compute the incident radiant heat flux at the plate thermocouples at step $i\left(\left[\dot{\mathrm{q}}_{i n c}{ }^{\prime \prime}\right]^{\mathrm{i}}\right.$, in W/m$\left.{ }^{2}\right)$ as follows (Häggkvist et al. 2013):

$$
\left[\dot{q}_{i n c}^{\prime \prime}\right]^{i}=\sigma\left[T_{P T}^{4}\right]^{i}+\frac{\left(h+K_{P T}\right)\left(\left[T_{P T}\right]^{i}-\left[T_{g a s}\right]^{i}\right)}{\varepsilon_{P T}}+\frac{C_{P T} \frac{\left[T_{P T}\right]^{i+1}-\left[T_{P T}\right]^{i-1}}{[t]^{i+1}-[t]^{i-1}}}{\varepsilon_{P T}}
$$

where the time $(t)$ is in seconds, the Stefan Boltzmann constant $(\sigma)$ is $5.6704 \mathrm{E}-8 \mathrm{~W} / \mathrm{m}^{2} / \mathrm{K}^{4}$, the convection coefficient $\left(h_{\mathrm{c}}\right)$ is taken to be $10 \mathrm{~W} / \mathrm{m}^{2} / \mathrm{K}$, the heat transfer coefficient due to heat losses of the plate thermocouples $\left(K_{\mathrm{PT}}\right)$ is taken to be $8 \mathrm{~W} / \mathrm{m}^{2} / \mathrm{K}$ (Häggkvist et al. 2013), the lumped heat capacity of the plate thermocouples $\left(C_{\mathrm{PT}}\right)$ is taken to be $4200 \mathrm{~J} / \mathrm{m}^{2} / \mathrm{K}$ (Häggkvist et al. 2013), and the emissivity of the plate thermocouple ( $\varepsilon$ PT) is taken to be 0.9 .

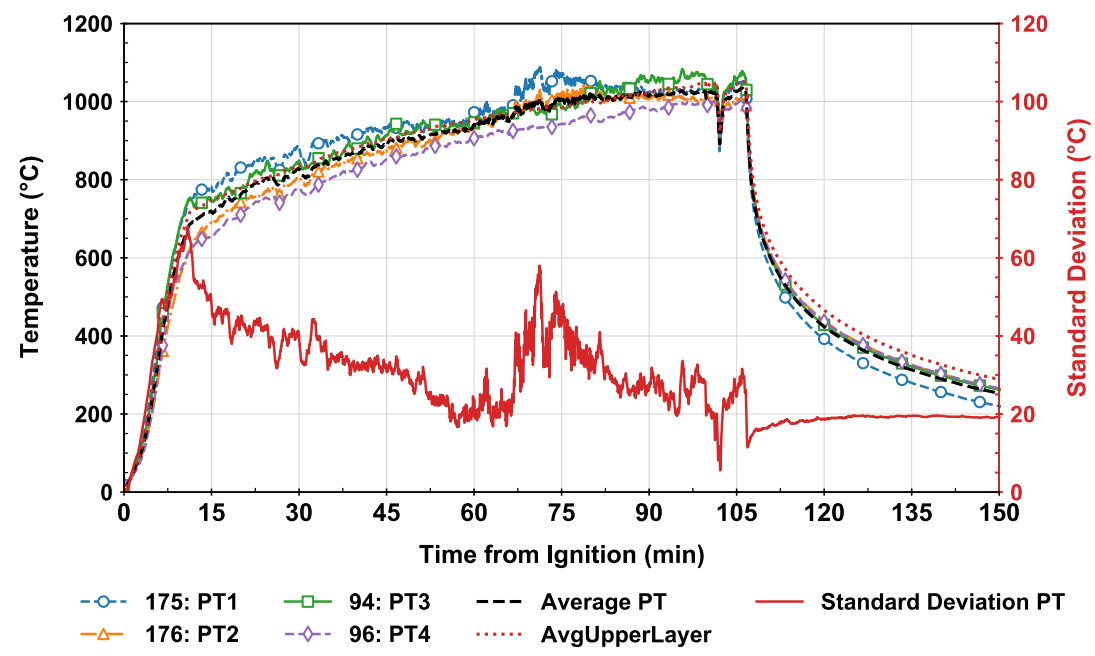

(a)

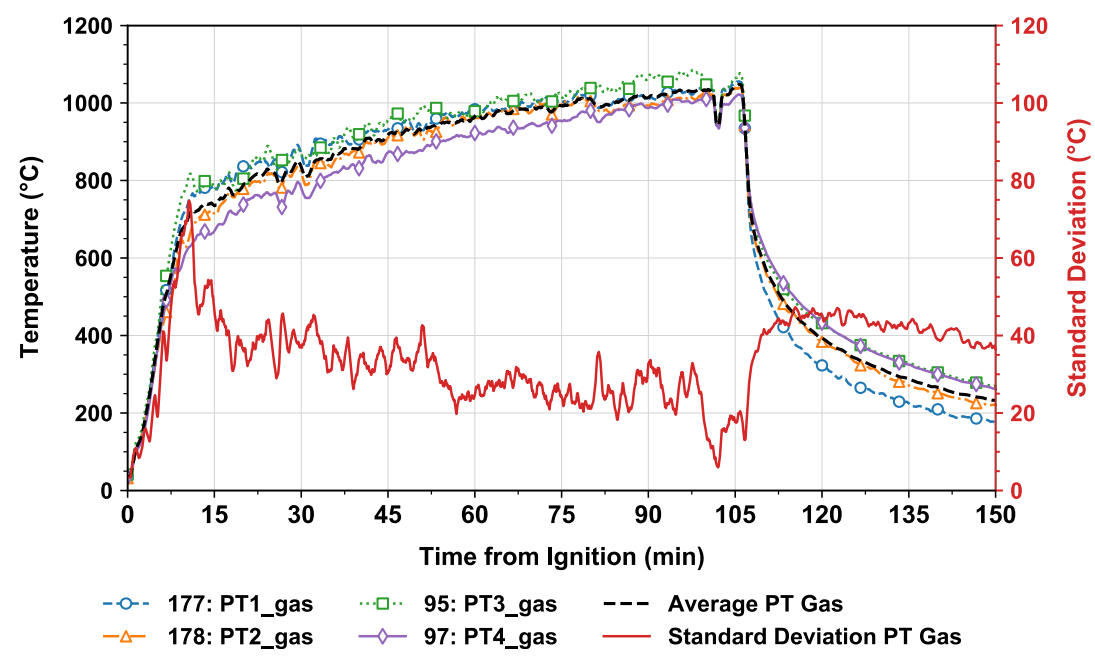

(b)

Fig. C-2. Temperatures measured using (a) plater thermometers (PT) and (b) bare-bead thermocouples close to the plate thermometers (PT_gas). 
It is worth noting that $h_{\mathrm{c}}$ and $C_{\mathrm{PT}} / \varepsilon_{\mathrm{PT}}$ are values subjected to change case by case, hence parameter calibration and sensitivity study are needed to quantify this uncertainty. Since the convection and conduction term tends to be zero in this test case, the determination of $h_{\mathrm{c}}$ becomes less important. The impact of parameters $C_{\mathrm{PT}}, \varepsilon_{\mathrm{PT}}$ for calculating heat stored term in PT shows that, $\varepsilon_{\text {PT }}$ between 0.8 and $0.9, C_{\text {PT }}$ between $2610 \mathrm{~J} / \mathrm{m}^{2} / \mathrm{K}$ and $4200 \mathrm{~J} / \mathrm{m}^{2} / \mathrm{K}$ (range suggested by Häggkvist et al. 2013), would generate $2.2 \%$ and $7.2 \%$ difference respectively on the resultant incidental radiant heat flux for PT1.

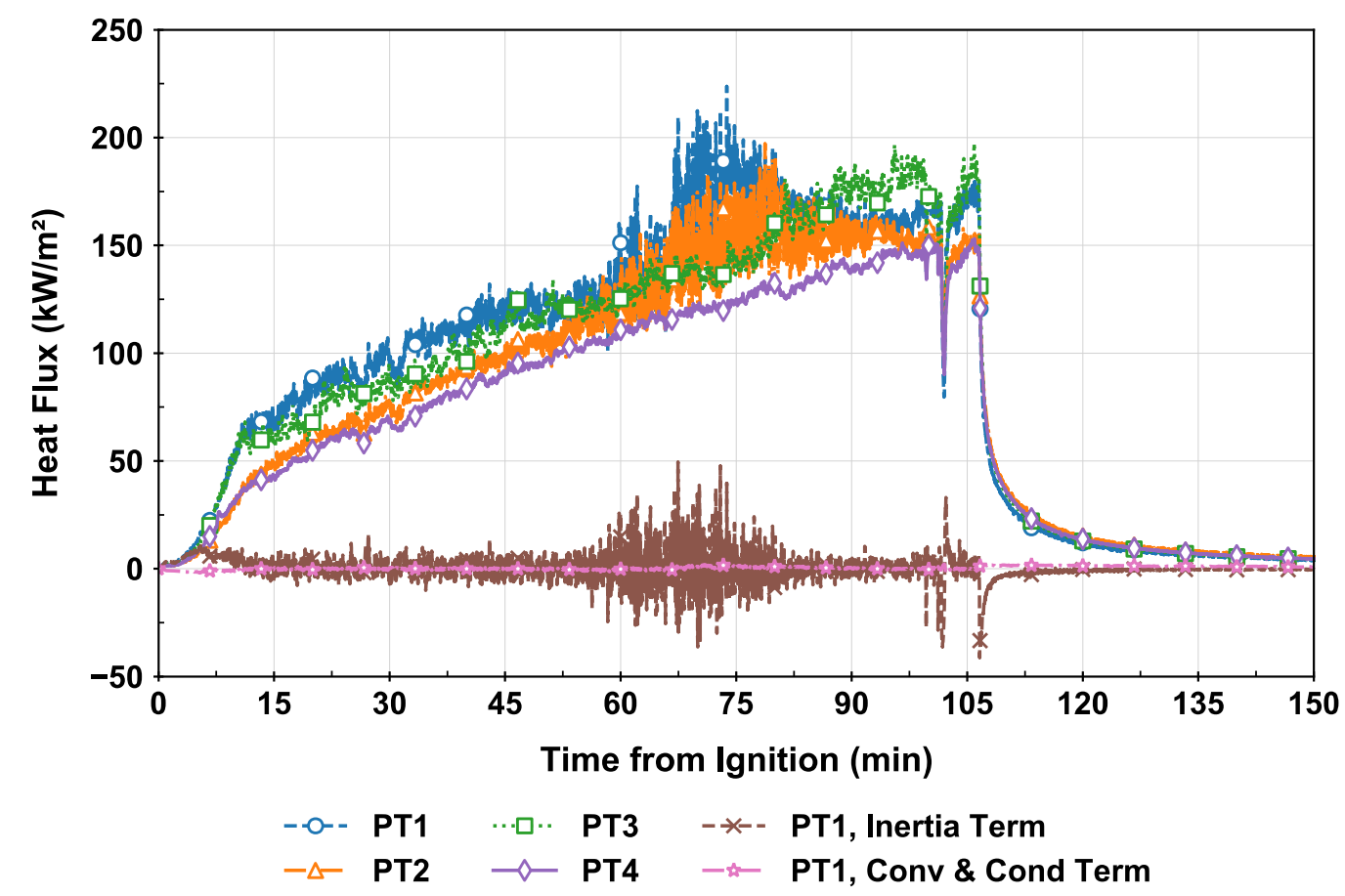

Fig. C-3. Incident radiant fluxes estimated using the plate thermometer data 